\title{
Mammalian distal humerus fossils from eastern Montana, USA with implications for the Cretaceous-Paleogene mass extinction and the adaptive radiation of placentals
}

\author{
Lauren B. DeBey and Gregory P. Wilson
}

\begin{abstract}
Postcrania of Cretaceous-Paleogene (K-Pg) mammals offer insights into richness, body size, and locomotor ecology that supplement patterns from well-sampled dental assemblages. Here, we describe and morphotype 50 distal humeri from Lancian-Puercan assemblages of eastern Montana. Using geometric morphometric analysis of a taxonomically broad sample of humeri from extant small-bodied therians of diverse locomotor modes, we constrain locomotor inferences of some morphotypes. We use this database to preliminarily assess body-size and locomotor diversity across the KPg boundary.

The seven Lancian humerus morphotypes include the multituberculates ?Mesodma sp., ?Cimolodon nitidus, and ?Meniscoessus robustus and the metatherian ?Didelphodon vorax. Morphotype richness decreased to four or five across the K-Pg boundary and rebounded in the late Puercan to six, mostly eutherian, morphotypes. Puercan morphotypes include the multituberculate ?Stygimys kuszmauli, the "plesiadapiform" primate ?Purgatorius, small and large archaic ungulates, a possible palaeoryctid, and a very large eutherian. Humerus size data imply a decrease in body size across the K-Pg boundary, followed by an increase by the late Puercan, a trend consistent with the dental fossil record. Geometric morphometrics analysis and functional morphology imply greater locomotor diversity among K-Pg mammals than previously recognized: we infer that most Lancian and Puercan multituberculates were arboreal; the Lancian eutherian was arboreal or semifossorial; the early Puercan palaeoryctid was semifossorial and the small archaic ungulate was terrestrial; and the late Puercan "plesiadapiform" primate was arboreal and the large archaic ungulate was scansorial. Taken together, these preliminary results expand our understanding of K-Pg mammals and our basis for testing ecological hypotheses of the K-Pg mass extinction and recovery.
\end{abstract}

\footnotetext{
DeBey Lauren B. and Wilson, Gregory P. 2017. Mammalian distal humerus fossils from eastern Montana, USA with implications for the Cretaceous-Paleogene mass extinction and the adaptive radiation of placentals. Palaeontologia Electronica 20.3.49A: 1-92 palaeo-electronica.org/content/2017/1983-mammal-humeri-across-the-k-pg

Copyright: October 2017 Paleontology Society. This is an open access article distributed under the terms of AttributionNonCommercial-ShareAlike 4.0 International (CC BY-NC-SA 4.0), which permits users to copy and redistribute the material in any medium or format, provided it is not used for commercial purposes and the original author and source are credited, with indications if any changes are made.

creativecommons.org/licenses/by-nc-sa/4.0/
} 
Lauren B. DeBey. Department of Biology, University of Washington, Box 351800, Seattle, WA 98195-1800, USA. Burke Museum of Natural History and Culture, Box 353010, Seattle, WA 98195-0001, USA. Ibdebey@uw.edu Gregory P. Wilson. Department of Biology, University of Washington, Box 351800, Seattle, WA 981951800, USA. Burke Museum of Natural History and Culture, Box 353010, Seattle, WA 98195-0001, USA. gpwilson@uw.edu

Keywords: Mammalia; postcrania; humerus; mass extinction; Cretaceous-Paleogene; geometric morphometrics

Submission: 24 June 2016 Acceptance: 21 August 2017

\section{INTRODUCTION}

The Cretaceous-Paleogene (K-Pg) mass extinction was a watershed event in mammalian evolutionary history. Research on $\mathrm{K}-\mathrm{Pg}$ mammals has yielded important insights regarding changes in taxonomic and morphological diversity, diet, and body size across mass extinction events; however, the majority of these patterns are based on dental fossils (e.g., Alroy, 1999; Smith et al., 2010; Wilson et al., 2012; Wilson, 2013, 2014; O'Leary et al., 2013; Raia et al., 2013). With few exceptions (Borths and Hunter, 2008; DeBey and Wilson, 2014), postcranial-based patterns of extinction and recovery and hypotheses for locomotor-related extinction selectivity (e.g., the Sheltering Hypothesis; Robertson et al., 2004) remain largely unexplored. Here, we use fossils of distal humeri from well-sampled and well-studied localities in eastern Montana to document richness, body size, and locomotor patterns among latest Cretaceous and earliest Paleogene mammals.

Research to date on K-Pg mammalian postcrania has mostly focused on a narrow taxonomic scope (i.e., multituberculates, plesiadapiform primates; Deischl, 1964; Krause and Jenkins, 1983; Szalay, 1994; Borths and Hunter, 2008; Chester et al., 2015) or on a single assemblage (e.g., the Bug Creek Anthills; Deischl, 1964; Sloan and Van Valen, 1965; Szalay and Decker, 1975). More temporally and taxonomically comprehensive research has been limited by low sample sizes of postcranial fossils, which is likely a function of the rarity of these elements (and extreme rarity of skeletons) relative to the thousands of mammalian teeth known from these deposits (e.g., Sloan and Van Valen, 1965; Archibald, 1982; Lofgren, 1995; Clemens, 2002; DeBey and Wilson, 2014; Wilson, 2014). Despite small sample sizes, our recent study of fossil femora from eastern Montana
(DeBey and Wilson, 2014) shows that isolated postcranial elements provide patterns of change in taxonomic richness, body size, and locomotor ecology across the K-Pg boundary that supplement patterns from dental data (Wilson, 2013, 2014).

The humerus plays a key role in locomotion and is a relatively common element in fossil assemblages of mammalian postcrania. Morphology of the humerus is strongly correlated to locomotor and substrate preference in a wide range of mammals (e.g., Smith and Savage, 1956; Brown and Yalden, 1973; Hildebrand, 1985; Van Valkenburgh, 1987; Janis and Figueirido, 2014; Chen and Wilson, 2015; Fabre et al., 2015). Functional morphological analyses of the humerus have been performed in the context of the appendicular skeleton or forelimb (e.g., Iwaniuk et al., 1999; Argot, 2001; Janis and Figueirido, 2014; Chen and Wilson, 2015; Fabre et al., 2015), and as an isolated element (e.g., Milne et al., 2009; Steiner-Souza et al., 2010; Morgan and Alvarez, 2013). These studies varied in their approach, from more traditional, comparative anatomical methods (e.g., Szalay and Dagosto, 1980; Argot, 2001) to linear measurements and indices (e.g., Van Valkenburgh, 1987; Argot, 2001; Samuels and Van Valkenburgh, 2008; Janis and Figueirido, 2014; Chen and Wilson, 2015), and two- and three-dimensional geometric morphometrics (e.g., Schutz and Guranlick, 2007; Milne et al., 2009; Steiner-Souza et al., 2010; Morgan and Alvarez, 2013; Fabre et al., 2015). Here, we constrain locomotor inferences and quantify morphospace occupation of fossil taxa using twodimensional geometric morphometrics (2D GM) because it confers several benefits over traditional morphometric analysis. First, geometric morphometrics enables a quantitative comparison of shape across fossil and modern specimens independent of size (e.g., Polly, 2008). Second, it allows a more comprehensive investigation and 
visualization of the particular areas of the distal humerus that are hypothesized as driving the variation in the sample (e.g., Zelditch et al., 2004).

Previous research on fossil humeri from our study area is largely limited to more qualitative assessments of morphological variation of material from the Bug Creek Anthills localities (e.g., Deischl, 1964; Krause and Jenkins, 1983; Szalay and Dagosto, 1980), which unfortunately preserve a time-averaged assemblage of latest Cretaceous and earliest Paleogene material (Lofgren, 1995; Clemens, 2002). We expand upon these studies to include fossils of distal humeri from well-sampled and stratigraphically well-constrained localities in the Hell Creek and the Tullock formations (e.g., Archibald, 1982; Lofgren, 1995; Wilson, 2005), in addition to the Bug Creek Anthills material. Our study represents the first quantitative assessment of postcrania for a taxonomically diverse, succession of mammalian assemblages across the K-Pg boundary.

Specifically, we describe and morphotype 50 mammalian distal humeri from 25 localities in the Hell Creek and Tullock formations of eastern Montana. We then (1) assess humeral morphotype richness through the latest Cretaceous and earliest Paleogene of our study area; (2) quantitatively and qualitatively constrain taxonomic affinities of humeral morphotypes on the basis of size and abundance; (3) infer body size changes across and following the K-Pg boundary; and (4) constrain morphofunctional affinities of select, well-preserved latest Cretaceous and earliest Paleogene distal humeri on the basis of a geometric morphometric analysis of a broad sample of extant, smallbodied mammals of diverse locomotor function.

\section{Institutional Abbreviations}

AMNH, American Museum of Natural History, New York, New York, USA; FMNH, Field Museum of Natural History, Chicago, Illinois, USA; GISPS, Geological Institute, Section of Palaeontology and Stratigraphy the Academy of Sciences of the Mongolian People's Republic, Ulanbaataar, Mongolia; IVPP, Institute of Vertebrate Paleontology and Paleoanthropology, Beijing, China; LSUMG, Louisiana State University Museum of Geoscience (now the LSU Museum of Natural History), Baton Rouge, Louisiana, USA; MCZ, Museum of Comparative Zoology, Harvard University, Cambridge, Massachusetts, USA; MHNC, Museo de Historia Natural de Cochabamba, Cochabamba, Bolivia; MNHN, Musée National d'Histoire Naturelle, Paris, France; NMMNH, New Mexico Museum of Natural
History and Science, Albuquerque, New Mexico, USA; PM, Paleontological Center of the Mongolian Academy of Sciences, Ulaanbaatar, Mongolia; PSS-MAE, Paleontology Section, Mongolian Academy of Sciences, Ulaanbaatar, Mongolia; PU, Princeton University, Princeton, New Jersey, USA; TMM, Texas Memorial Museum, Austin, Texas, USA; UA, University of Alberta, Edmonton, Alberta, Canada; UALVP, University of Alberta, Edmonton, Alberta, Canada; UCMP, University of California Museum of Paleontology, Berkeley, California, USA; UMVP, University of Minnesota, Minneapolis, Minnesota, USA; UM, University of Michigan Museum of Paleontology, Ann Arbor, Michigan, USA; UNM, Department of Geology, University of New Mexico, Albuquerque, New Mexico, USA; URBAC, Uzbek-Russian-British-American-Canadian Joint Paleontological Expedition (specimens currently housed at San Diego State University, San Diego, California, USA); USGS, U.S. Geological Survey, Denver, Colorado, USA; USNM, United States National Museum, Washington, D.C., USA; UWBM, University of Washington Burke Museum of Natural History and Culture, Seattle, Washington, USA; YPM, Yale Peabody Museum of Natural History, Yale University, New Haven, Connecticut, USA; YPFB, Yacimentos Petroliferos Fiscales Bolivianos, Santa Cruz, Bolivia.

\section{Other Abbreviations}

Eu, Eutherian; Me, Metatherian; Mu, Multituberculate; NALMA, North American Land Mammal "age"; La, Lancian NALMA; Pu1, early Puercan NALMA; Pu3, late Puercan NALMA; SD, standard deviation.

\section{MATERIALS}

\section{Study Area and Specimens}

Fossil specimens used in this study are from Cretaceous- and Paleogene-age deposits mainly in the Williston Basin. We include material from eastern Montana, specifically in Carter, Fallon, Garfield, and McCone counties (Figure 1), as well as from one locality in Niobrara County, Wyoming (see Appendix 1 for locality information). Our eastern Montana study area is tied into a high-resolution chronostratigraphic framework that spans ca. 3.2 Ma across the K-Pg boundary (Archibald, 1982; Swisher et al., 1993; Lofgren, 1995; Clemens, 2002; Renne et al., 2013; Wilson, 2005, 2014; LeCain et al., 2014; Moore et al., 2014; Sprain et al., 2015). In the Western Interior of North America, the K-Pg boundary is approximately coincident with 


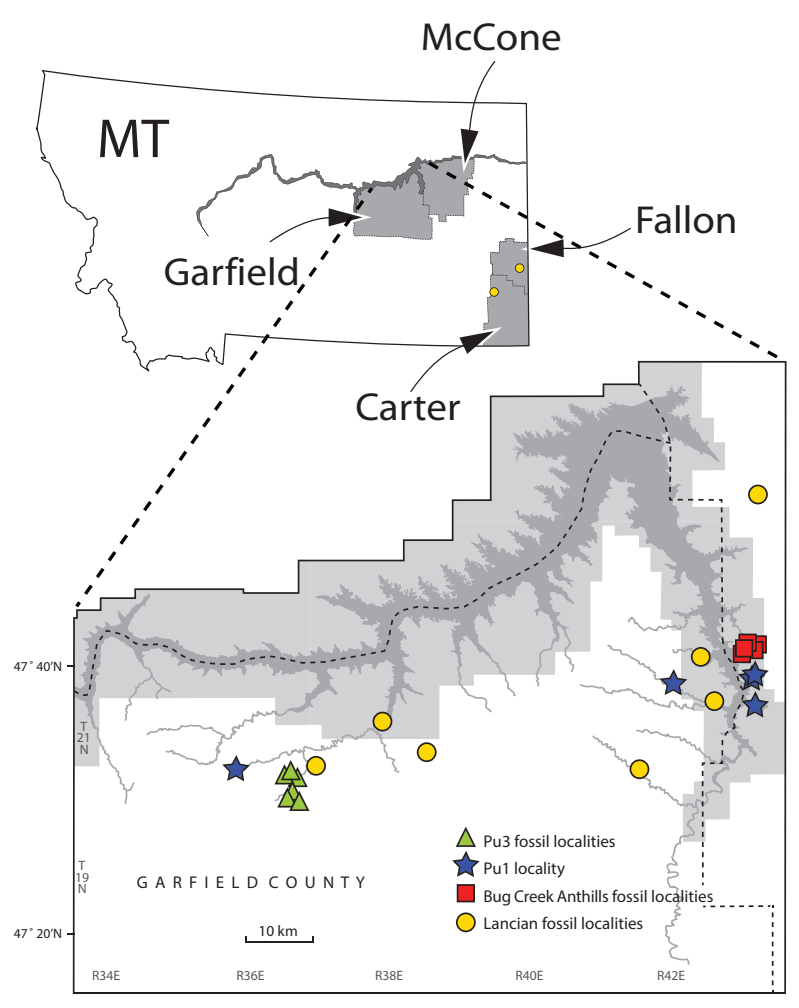

FIGURE 1. Map of humerus-bearing fossil localities from this study. Localities span the Lancian biozone (yellow circles), and early and late Puercan biozones (Pu1 and Pu3, in blue stars and green triangles, respectively), as well as the temporally mixed Lancian-Pu1 localities of the Bug Creek Anthills (red squares). Most localities are in Garfield and McCone counties; Fallon and Carter counties in Montana and Niobrara County in eastern Wyoming (not pictured) each have one locality. Locality names and details are given in Appendix 1. Modified from Wilson et al. 2014.

the boundary between the Lancian and Puercan North American Land Mammal "ages" (NALMAs; Cifelli et al., 2004; Lofgren et al., 2004; Sprain et al., 2015; but see Fox, 1989 and Kelly, 2014). Our specimens are from the Hell Creek and Tullock formations, except for three specimens that are from the Lance Formation of Wyoming (UCMP locality V5620). Hell Creek specimens are largely Lancian in age (ca. 68-66.04 Ma; Swisher et al., 1993; Renne et al., 2011, 2013; Wilson, 2014; Sprain et al., 2015); all Lance Formation specimens are Lancian in age. In eastern Garfield County and western McCone County, some localities from the uppermost Hell Creek Formation are earliest Paleogene (early Puercan, Pu1) in age; we include two specimens from two of these localities (UCMP localities V84162 in Garfield County and V84193 in McCone County; Lofgren, 1995; Sprain et al.,
2015). Specimens from the lowermost Tullock Formation are early Puercan (Pu1 interval zone, ca. 66.04-65.97 Ma), whereas those from the middle part of the Tullock Formation are late Puercan (Pu3 interval zone, ca. 65.74-65.12 Ma; Swisher et al., 1993; Renne et al., 2011, 2013; Wilson, 2014; Sprain et al., 2015). We also greatly increased our sample sizes by including specimens from the prolific Bug Creek Anthills localities, but we note that these localities yield both Lancian and earliest Puercan specimens (Lancian-Pu1 mixed; Lofgren, 1995). Local faunas in our study area referable to the Pu2 interval zone (65.97-65.74 Ma; Sprain et al., 2015) have yet to be found or described (e.g., Clemens, 2015).

Fifty distal humeri from 25 fossil localities preserve sufficient morphology to be assessed in a comparative context. Of these, 14 specimens are from 10 Lancian localities, six specimens are from four Pu1 localities, seven specimens are from five Pu3 localities, and an additional 23 are from six Lancian-Pu1 mixed-age localities (e.g., Bug Creek Anthills; Appendices 1-2).

\section{METHODS}

\section{Taxonomic Scope}

The large, well-studied Lancian and Puercan mammalian dental assemblages from this study area comprise multituberculates, metatherians, and eutherians (e.g., Archibald, 1982; Lofgren, 1995; Clemens, 2002; Wilson, 2014). Thus, we use those taxa as starting points for our comparative morphological and taxonomic analyses of the humeri fossils studied here.

\section{Osteological Terminology}

Proposed differences in forelimb posture of multituberculates and therians (e.g., Kielan-Jaworowska and Hurum, 2006) dictates that we use different anatomical directional terms for humeri of these taxa. Following Krause and Jenkins (1983) and Kielan-Jaworowska and Gambaryan (1994), the dorsal and ventral aspects of the multituberculate humerus correspond to the posterior and anterior aspects of the therian humerus. Osteological terminology follows Krause and Jenkins (1983) for multituberculates, Szalay and Sargis (2001) for metatherians, and Szalay and Dagosto (1980) and Boyer and colleagues (2010) for eutherians.

\section{Morphotype Assignment}

We assign our specimens to 15 morphotypes on the basis of morphology and size, comparisons 
with published specimens of similar age and/or related taxa, and guidelines from other studies that employ morphotype 'parataxonomy' for analysis of isolated proximal limb elements (e.g., Deischl, 1964; Chester et al., 2010, 2012; DeBey and Wilson, 2014; Szalay and Sargis, 2001). We assign an alphabetical code (e.g., EuA) to each morphotype to designate higher-level taxonomic assignment (i.e., eutherian) and size rank among all morphotypes in that higher-level taxon (ranked smallest to largest, on the basis of measured or inferred mean Total Distal Width, TDW; Figure 2; Tables 1-3).

Following the methodology of DeBey and Wilson (2014), we constrain the possible taxonomic assignments of our 15 humerus morphotypes by first using published morphological descriptions, photographs, and figures of Late Cretaceous and Paleogene multituberculate and therian humeri from North America and Asia, including material found in our study area; all comparative fossil taxa examined are listed in the Supplementary Information (Appendices 3-4). Because most of these comparative humeri were also found as isolated elements unassociated with diagnostic dental fossils, their taxonomic assignments should be considered tentative; we follow Krause and Jenkins (1983) in using a query ('?') to indicate the uncertain taxonomic status of previously published postcranial elements that were not found in direct association with dental material or as part of an articulated skeleton. Second, we examined comparative material of extant therians, including specimens, descriptions, photographs, and figures (e.g., Caluromys, Didelphis, Oryzorictes, Rhyncholestes, Tenrec; Szalay and Sargis, 2001; Argot, 2001; Sargis, 2002; Salton and Sargis, 2008; Flores, 2009). Third, we compared sizes among our humeri to taxa known from the same time and area (based on dental material), and used relative size to distinguish amongst candidate taxa (Wilson et al., 2012; Wilson, 2013, 2014).

\section{Linear Measurements}

Contingent upon completeness, we took 10 measurements on each specimen (see Figure 2, Tables 1-3). Measurements are identical to or slightly modified from those in previous studies, and have been correlated with body size or locomotor function (Deischl, 1964; Szalay and Dagosto, 1980; Argot, 2001; Szalay and Sargis, 2001; Boyer et al., 2010). All measurements were taken using a Leica MZ9.5 binocular dissecting microscope with a custom measuring stage that has an accuracy of $0.001 \mathrm{~mm}$.
Because of the variable completeness of specimens in our sample, we were unable to collect all of the measurements on all of our specimens; thus, we opted to explore differences among morphotypes and across biozones using univariate rather than multivariate analyses of the data. Our univariate analyses include comparisons of all measurements (excluding minimum values; Tables 1-3), which are largely informative of specimen size. We explored size differences across morphotypes using one-way ANOVAs. For ANOVAs with significant differences among morphotypes, we conducted Tukey honest significant difference (HSD) post-hoc tests to determine which specific variables (i.e., particular morphotypes) were significantly different from one another. To increase sample sizes, we included the mixed-age assemblages of the Bug Creek Anthills (BCA) in these calculations; however, we omitted any specimens only tentatively attributed to morphotype. Because we only used qualitative features to morphotype our material and we did not use geologic age information (i.e., biozones) to separate morphotypes, inclusion of BCA specimens should not affect a quantitative assessment of differences across morphotypes. Additionally, to compare with dental- and femur-based body-size patterns (Archibald, 1982; Maas and Krause, 1994; Clemens, 2002; Wilson, 2005, 2013; DeBey and Wilson, 2014), we tested for significant changes in body size through our study section, using humeri measurements. Specifically, we conducted one-way ANOVAs of these measurements grouped by biozones, followed by Tukey HSD post-hoc tests to identify which biozones were significantly different from one another. As with our ANOVAs on morphotype size, we include BCA material in all calculations, but assign the BCA assemblages to "Lancian-Pu1 mixed" rather than to either Lancian or Pu1 biozones. Including this material in our analyses does not affect the pattern or interpretation of Lancian and Pu1 sizes; however, the "Lancian-Pu1 mixed" size likely averages the Lancian and Pu1 signals.

Multituberculate humeri are the most abundant and best-preserved specimens in our assemblage. To graphically represent the shape of these humeri in multivariate space, we conducted principal components analyses (PCA) of their measurement data. To control for size, all measurements were standardized to radial condyle width (RCW); as a result, the dataset was reduced to specimens in which the RCW could be measured. We acknowledge problems with using RCW, a potentially functionally informative measurement, to 


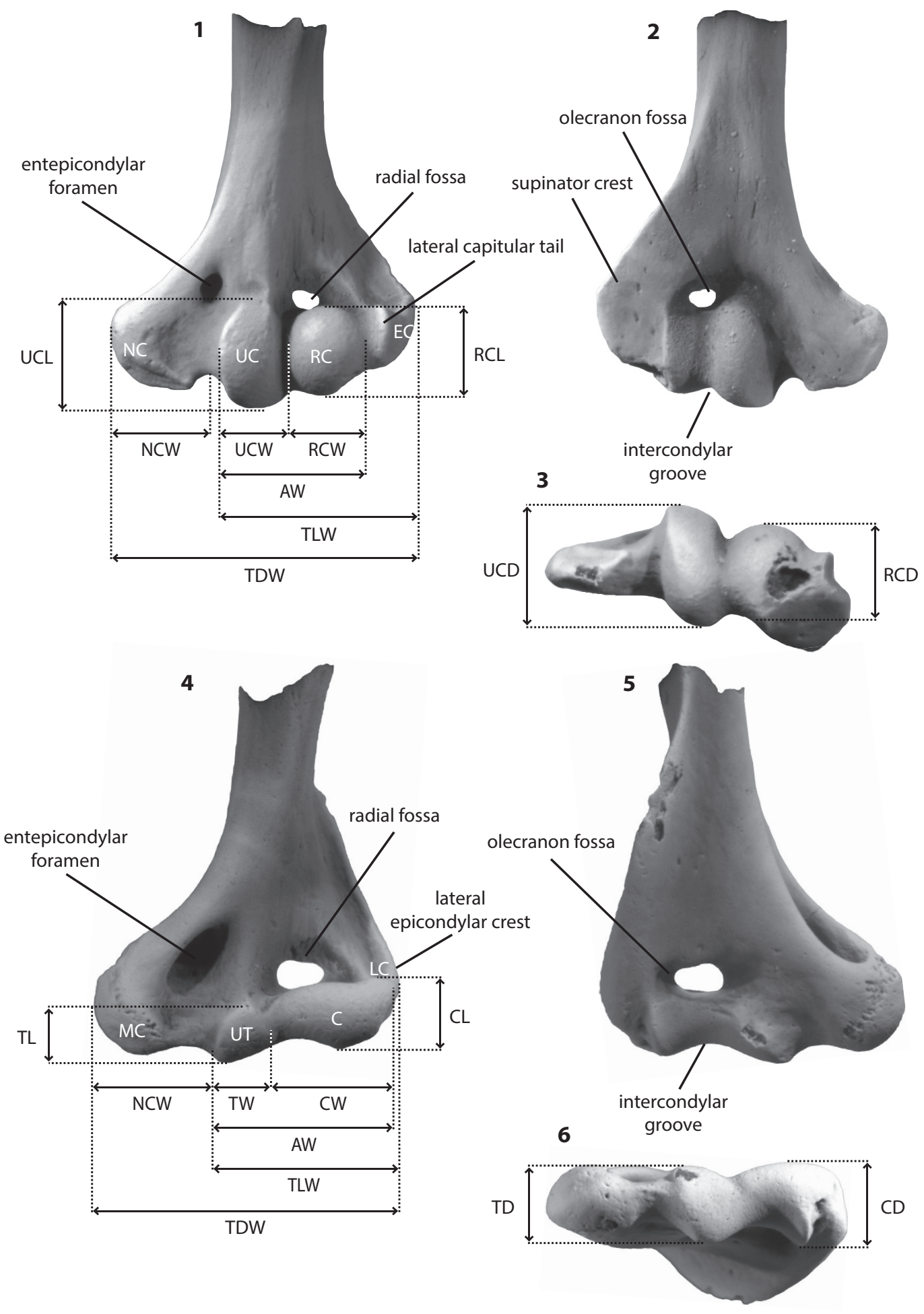

FIGURE 2. Schematic of humerus measurements used in this study. Multituberculate specimen (UCMP 153039; left) in ventral (1), dorsal (2), and distal (3) views; eutherian specimen (UCMP 151964; right, reversed to appear as left) in anterior (4), posterior (5), and distal (6) views. See Table 1 for measurement descriptions. Abbreviations: AW, articular width; C, capitulum; CL, capitulum length; $C D$, capitulum depth; CW, capitulum width; EC, ectepicondyle; LC, lateral epicondyle (ectepicondyle); MC, medial epicondyle (entepicondyle); NC, entepicondyle; NCW, entepicondylar width; RC, radial condyle; RCL, radial condyle length; RCD, radial condyle depth; RCW, radial condyle width; TDW, total distal width; TL, trochlear length; TD, trochlear depth; TLW, total lateral width; TW; trochlear width; UC, ulnar condyle; UCL, ulnar condyle length; UCD, ulnar condyle depth; UCW, ulnar condyle width; UT, ulnar trochlea. 
TABLE 1. Measurements taken on distal humeri in this study. Columns (from left to right) are: measurements (abbreviation and name); measurement description; taxon of study; and source reference for each measurement. We took the following measurements (Figure 2) on all multituberculate and therian specimens, contingent upon specimen completeness (see Table 2). The anatomical view from which the measurement was taken is indicated in parentheses in the description, as it relates to either multituberculate (Mu) or therian (Th) humeri, see text for more details. Measurements are identical to those in the indicated sources, with the following exceptions: our measurement TDW is 'BW' of Szalay and Dagosto (1980) and measurement 5 of Argot (2001); NCW is measurement 6 of Argot (2001) and 'EEC' of Boyer et al. (2010); TLW is 'TLE' of Szalay and Dagosto (1980); measurements TD and CD are modified from Szalay and Dagosto (1980) and Boyer et al. (2010). Multituberculate measurements lacking references are based on the structurally (but not necessarily functional) analogous measurement for therian humeri (see Figure 2).

\begin{tabular}{|c|c|c|c|c|}
\hline \multicolumn{2}{|c|}{ Measurements } & \multirow{2}{*}{$\begin{array}{l}\text { Description } \\
\text { Medial edge of specimen to lateral edge, measured at the } \\
\text { maximum extensions of the entepicondyle and } \\
\text { ectepicondyle; parallel to other distal width measures } \\
\text { (anterior view in therians; ventral view in multituberculates) }\end{array}$} & \multirow{2}{*}{$\begin{array}{l}\text { Taxon } \\
\text { Th, Mu }\end{array}$} & \multirow{2}{*}{$\begin{array}{c}\text { Source } \\
\text { Deischl 1964; Szalay and } \\
\text { Dagosto 1980; Argot } 2001\end{array}$} \\
\hline TDW & $\begin{array}{l}\text { Total Distal } \\
\text { Width }\end{array}$ & & & \\
\hline AW & $\begin{array}{l}\text { Articular } \\
\text { Surface Width }\end{array}$ & $\begin{array}{l}\text { Eu: Lateral edge of capitulum to medial edge of trochlea } \\
\text { (anterior) } \\
\text { Mu: Lateral edge of radial condyle to medial edge of ulnar } \\
\text { condyle (ventral) }\end{array}$ & $\mathrm{Th}, \mathrm{Mu}$ & $\begin{array}{l}\text { Szalay and Dagosto } \\
1980 ; \text { Szalay and Sargis } \\
2001\end{array}$ \\
\hline TLW & $\begin{array}{l}\text { Total Lateral } \\
\text { Width }\end{array}$ & $\begin{array}{l}\text { Eu: Medial edge of trochlea to lateral edge of ectepicondyle } \\
\text { (anterior) } \\
\text { Mu: Medial edge of ulnar condyle to lateral edge of } \\
\text { ectepicondyle (ventral) }\end{array}$ & $\mathrm{Th}, \mathrm{Mu}$ & Szalay and Dagosto 1980 \\
\hline NCW & $\begin{array}{l}\text { Entepicondylar } \\
\text { Width }\end{array}$ & $\begin{array}{l}\text { Eu: Medial edge of trochlear lip to medial edge of } \\
\text { entepicondyle (anterior) } \\
\text { Mu: From midpoint of groove between entepicondyle and } \\
\text { ulnar condyle to medial edge of entepicondyle (ventral) }\end{array}$ & $\mathrm{Th}, \mathrm{Mu}$ & $\begin{array}{l}\text { Argot 2001; Boyer et al. } \\
2010\end{array}$ \\
\hline TW & Trochlear Width & $\begin{array}{l}\text { Medial edge of trochlea (trochlear lip) to lateral edge of } \\
\text { trochlea (medial edge of intercondylar groove) (anterior) }\end{array}$ & Th & $\begin{array}{l}\text { Szalay and Dagosto } \\
\text { 1980; Boyer et al. } 2010\end{array}$ \\
\hline CW & $\begin{array}{l}\text { Capitulum } \\
\text { Width }\end{array}$ & $\begin{array}{l}\text { Lateral edge of capitulum to medial edge of intercondylar } \\
\text { groove (anterior) }\end{array}$ & Th & $\begin{array}{l}\text { Szalay and Dagosto } \\
\text { 1980; Boyer et al. } 2010\end{array}$ \\
\hline TL & $\begin{array}{l}\text { Trochlear } \\
\text { Length }\end{array}$ & $\begin{array}{l}\text { Length from proximal margin to distal margin of trochlear lip } \\
\text { (anterior) }\end{array}$ & Th & $\begin{array}{l}\text { Szalay and Dagosto } \\
\text { 1980; Boyer et al. } 2010\end{array}$ \\
\hline $\mathrm{CL}$ & $\begin{array}{l}\text { Capitulum } \\
\text { Length }\end{array}$ & $\begin{array}{l}\text { Length from proximal margin to distal margin of capitulum } \\
\text { (anterior) }\end{array}$ & Th & this study \\
\hline TD & Trochlear Depth & $\begin{array}{l}\text { Maximum length from anterior surface to posterior surface } \\
\text { of trochlea, parallel to } C D \text { (distal) }\end{array}$ & Th & $\begin{array}{l}\text { Szalay and Dagosto } \\
\text { 1980; Boyer et al. } 2010\end{array}$ \\
\hline CD & $\begin{array}{l}\text { Capitulum } \\
\text { Depth }\end{array}$ & $\begin{array}{l}\text { Length of capitulum articular surface, from anterior to } \\
\text { posterior extent, parallel to TD (distal) }\end{array}$ & Th & $\begin{array}{l}\text { Szalay and Dagosto } \\
\text { 1980; Boyer et al. } 2010\end{array}$ \\
\hline UCW & $\begin{array}{l}\text { Ulnar Condyle } \\
\text { Width }\end{array}$ & $\begin{array}{l}\text { Medial edge of ulnar condyle to lateral edge of ulnar } \\
\text { condyle (ventral) }\end{array}$ & $\mathrm{Mu}$ & this study \\
\hline RCW & $\begin{array}{l}\text { Radial Condyle } \\
\text { Width }\end{array}$ & $\begin{array}{l}\text { Medial edge of radial condyle to lateral edge of radial } \\
\text { condyle (ventral) }\end{array}$ & $\mathrm{Mu}$ & this study \\
\hline UCL & $\begin{array}{l}\text { Ulnar Condyle } \\
\text { Length }\end{array}$ & $\begin{array}{l}\text { Length from proximal margin to distal margin of ulnar } \\
\text { condyle (ventral) }\end{array}$ & $\mathrm{Mu}$ & this study \\
\hline $\mathrm{RCL}$ & $\begin{array}{l}\text { Radial Condyle } \\
\text { Length }\end{array}$ & $\begin{array}{l}\text { Length from proximal margin to distal margin of radial } \\
\text { condyle (ventral) }\end{array}$ & $\mathrm{Mu}$ & this study \\
\hline UCD & $\begin{array}{l}\text { Ulnar Condyle } \\
\text { Depth }\end{array}$ & $\begin{array}{l}\text { Maximum length from ventral surface to dorsal surface } \\
\text { ulnar condyle, parallel to } R C D \text { (distal) }\end{array}$ & $\mathrm{Mu}$ & this study \\
\hline RCD & $\begin{array}{l}\text { Radial Condyle } \\
\text { Depth }\end{array}$ & $\begin{array}{l}\text { Maximum length from ventral surface to dorsal surface } \\
\text { radial condyle, parallel to UCD (distal) }\end{array}$ & $\mathrm{Mu}$ & this study \\
\hline
\end{tabular}


TABLE 2. Linear measurements of multituberculate distal humeri specimens. See Table 1 for measurement descriptions; all measurements on multituberculate humeri are taken in ventral view except for RCD and UCD, which are taken in distal view. All measurements are in millimeters. Abbreviations: Fm, Formation; HC, Hell Creek Formation; La, Lancian Biozone; Lan, Lance Formation; Morph., Morphotype; Pu1, Puercan 1 Biozone; Pu3, Puercan 3 Biozone; Tu, Tullock Formation. Asterisks indicate minimum size values, where preserved morphology was measured but the full measurement was not possible, due to specimen breakage; "-" indicates specimen was too broken for measurement; "?" indicates more tentative assignment to morphotype, due to specimen breakage. Locality numbers follow the system of each institution; those beginning with "V" are UCMP localities; those beginning with "C" are UWBM localities (see Appendix 1 for additional locality details).

\begin{tabular}{|c|c|c|c|c|c|c|c|c|c|c|c|c|c|c|}
\hline Specimen & Locality & $\mathrm{Fm}$ & Biozone & Morph. & TDW & AW & TDW & NCW & UCW & RCW & UCL & RCL & UCD & RCD \\
\hline 195999 & V5620 & Lan & $\mathrm{La}$ & MuA & 3.695 & 2.060 & 2.550 & 1.045 & 0.950 & 1.115 & 1.365 & 1.195 & 1.625 & 1.525 \\
\hline 195974 & V65127 & $\mathrm{Tu}$ & BCA & MuA & 3.995 & 2.005 & 2.455 & 1.255 & 0.765 & 1.000 & 1.305 & 1.140 & 1.530 & 1.510 \\
\hline 195982 & V65127 & $\mathrm{Tu}$ & $\mathrm{BCA}$ & MuA & - & 2.040 & 2.210 & - & 0.865 & 1.170 & 1.405 & 1.055 & 1.445 & - \\
\hline 122045 & V70201 & $\mathrm{Tu}$ & $\mathrm{BCA}$ & MuA & 4.120 & 2.105 & 2.565 & 1.375 & 0.875 & 1.235 & 1.315 & 1.165 & 1.650 & 1.580 \\
\hline 196956 & V70201 & $\mathrm{Tu}$ & $\mathrm{BCA}$ & MuA & - & $1.960^{*}$ & - & - & 0.780 & $1.120^{*}$ & 1.225 & 1.005 & 1.275 & - \\
\hline 196957 & V70201 & $\mathrm{Tu}$ & $\mathrm{BCA}$ & MuA & 3.915 & 2.090 & 2.615 & 1.175 & 0.840 & 1.160 & 1.465 & 1.240 & 1.460 & 1.455 \\
\hline 70976 & C0338 & $\mathrm{Tu}$ & $\mathrm{BCA}$ & MuA & - & 1.850 & 2.420 & - & 0.855 & 1.070 & 1.345 & 1.150 & 1.440 & 1.400 \\
\hline 70977 & C0338 & $\mathrm{Tu}$ & $\mathrm{BCA}$ & MuA & 3.695 & - & 2.580 & 1.075 & 1.065 & - & 1.480 & - & 1.415 & - \\
\hline 195998 & V5620 & Lan & $\mathrm{La}$ & ?MuA & - & - & - & - & 0.690 & - & 0.805 & - & 1.805 & - \\
\hline 153016 & V74111 & $\mathrm{Tu}$ & Pu1 & ?MuA & - & $2.165^{\star}$ & - & - & - & 1.240 & $1.475^{\star}$ & $1.240^{*}$ & 1.585 & $1.475^{*}$ \\
\hline 195933 & V99438 & $\mathrm{Tu}$ & Pu3 & MuB & - & - & - & 1.240 & 1.080 & - & 1.465 & - & 1.670 & - \\
\hline 174490 & V73087 & $\mathrm{HC}$ & $\mathrm{La}$ & MuC & - & $3.555^{\star}$ & - & - & 1.690 & 2.055 & 2.440 & 1.980 & 2.845 & 2.445 \\
\hline 195997 & V5620 & Lan & $\mathrm{La}$ & MuC & - & 2.525 & 3.150 & - & 0.985 & 1.360 & 1.925 & 1.600 & 2.145 & 2.000 \\
\hline 174420 & V70209 & $\mathrm{Tu}$ & $\mathrm{BCA}$ & MuC & 5.290 & 2.975 & 3.595 & 1.480 & 1.295 & 1.630 & 1.975 & $2.030^{*}$ & 2.130 & 1.975 \\
\hline 153039 & V84193 & $\mathrm{HC}$ & Pu1 & MuC & 6.460 & 3.090 & 4.250 & 1.960 & 1.570 & 1.700 & 2.185 & 1.830 & 2.555 & 2.335 \\
\hline 197687 & V74111 & $\mathrm{Tu}$ & Pu1 & MuC & - & $3.565^{\star}$ & - & - & $1.480^{*}$ & $2.050^{*}$ & 2.240 & 1.885 & 2.330 & - \\
\hline 195932 & V99438 & $\mathrm{Tu}$ & Pu3 & MuC & $5.350^{*}$ & 3.035 & 3.820 & $1.460^{*}$ & 1.505 & 1.640 & 2.180 & 1.765 & 2.515 & 2.295 \\
\hline 195945 & V74122 & $\mathrm{Tu}$ & Pu3 & MuC & $5.590^{*}$ & 3.040 & 3.815 & 1.480 & 1.270 & 1.420 & 2.455 & 1.755 & 2.345 & 2.305 \\
\hline 195990 & V5620 & Lan & $\mathrm{La}$ & MuD & $7.310^{*}$ & $4.230^{*}$ & $5.470^{*}$ & $1.835^{\star}$ & - & 2.160 & - & 2.135 & - & 2.350 \\
\hline 174439 & V70209 & $\mathrm{Tu}$ & $\mathrm{BCA}$ & MuE & - & - & - & 2.385 & 1.855 & - & 3.265 & - & 3.200 & - \\
\hline 174442 & V70209 & $\mathrm{Tu}$ & $\mathrm{BCA}$ & MuE & - & - & - & - & 1.965 & - & $2.730^{\star}$ & - & $2.600^{*}$ & 2.680 \\
\hline 195973 & V65127 & $\mathrm{Tu}$ & $\mathrm{BCA}$ & MuE & 8.130 & 4.025 & 5.080 & 2.445 & 1.485 & 2.410 & 2.810 & 2.265 & 3.200 & 3.145 \\
\hline 97031 & C1845 & $\mathrm{Tu}$ & $\mathrm{BCA}$ & MuE & 8.420 & 4.400 & 5.230 & 2.595 & 2.000 & 2.565 & 2.695 & 2.485 & 3.355 & 3.335 \\
\hline 174412 & V84162 & $\mathrm{HC}$ & Pu1 & MuE & - & - & - & - & 2.360 & - & 3.535 & - & 3.910 & - \\
\hline 127384 & V87001 & $\mathrm{HC}$ & $\mathrm{La}$ & MuF & 14.025 & 7.730 & 9.990 & 3.970 & 3.865 & 4.435 & 5.440 & 5.095 & 6.420 & 5.580 \\
\hline 174400 & V85092 & $\mathrm{HC}$ & $\mathrm{La}$ & MuF & - & 6.900 & - & - & 3.135 & 3.945 & 4.985 & 4.260 & 5.180 & 4.530 \\
\hline 174232 & V72207 & $\mathrm{HC}$ & La & MuF & - & - & - & - & - & 5.050 & - & 5.655 & - & 6.365 \\
\hline 174225 & V72207 & $\mathrm{HC}$ & $\mathrm{La}$ & MuF & - & $6.815^{*}$ & - & 3.255 & 3.435 & $4.215^{\star}$ & 5.045 & 4.900 & 5.835 & - \\
\hline 174218 & V73097 & $\mathrm{HC}$ & $\mathrm{La}$ & MuF & - & $7.820^{*}$ & - & - & 2.450 & 4.325 & 5.605 & 5.145 & 6.420 & - \\
\hline 101970 & C1521 & $\mathrm{HC}$ & $\mathrm{La}$ & MuF & 13.705 & 6.945 & 9.105 & 3.995 & 2.985 & 3.915 & 5.030 & 3.900 & 5.030 & 4.405 \\
\hline
\end{tabular}

standardize for size; however, this measurement was the best preserved among our material, and were we to use more conventional measurements for standardization (e.g., total distal width) we would have unduly decreased our sample size further.

We performed three PCAs, each of which used different permutations of the dataset. The first PCA used nearly the full set of variables (i.e., measurements), excluding AW, TLW, and TDW, which are not independent of the other measurements (six variables; Figure 2; Tables 1-2). Because some measurements could not be taken on some specimens (incomplete preservation), those specimens were excluded from this PCA $(n=10)$. The second PCA used a reduced set of variables (five measurements) that enabled us to increase the number of specimens included $(n=11)$. The third PCA used a further reduced set of variables (four measurements) and included additional specimens 
TABLE 3. Linear measurements of therian distal humeri specimens. See Table 1 for measurement descriptions; all measurements on therian humeri are taken in anterior view except for CD and TD, which are taken in distal view. All measurements are in millimeters. Abbreviations: Fm, Formation; HC, Hell Creek Formation; La, Lancian Biozone; Morph., Morphotype; Pu1, Puercan 1 Biozone; Pu3, Puercan 3 Biozone; Tu, Tullock Formation. Asterisks indicate minimum size values, where preserved morphology was measured but the full measurement was not possible, due to specimen breakage; "-" indicates specimen was broken; "?" indicates more tentative assignment to morphotype; " $\ddagger$ " indicates specimen was used in 2D GM locomotor analyses. Locality numbers follow the system of each institution: those beginning with "V" are UCMP localities; those beginning with "C" are UWBM localities (see Appendix 1 for additional locality details). Five additional specimens from the BCA biozone (UCMP 151945, 151965, 151983, and 151984 from loc. V65127, and UCMP 174429 from loc. V70209) are tentatively attributed to EuD but are not listed below as they lack preservation sufficient for measurement, see text for more details.

\begin{tabular}{|c|c|c|c|c|c|c|c|c|c|c|c|c|c|c|}
\hline Specime & Locality & $\mathrm{Fm}$ & Biozone & Morph. & TDW & AW & TLW & NCW & TW & CW & TL & CL & TD & CD \\
\hline 127391 & V88007 & $\mathrm{HC}$ & La & ThA & $4.900^{*}$ & - & - & 2.380 & 1.210 & - & 1.340 & - & 1.380 & - \\
\hline 152394 & V93169 & $\mathrm{HC}$ & La & $\mathrm{MeA}$ & $18.235^{\star}$ & - & - & - & - & - & - & - & - & - \\
\hline 153100 & V99438 & $\mathrm{Tu}$ & Pu3 & EuA & $6.400^{*}$ & 3.850 & 3.850 & $2.900 *$ & 1.330 & 2.406 & 1.630 & 1.579 & 1.756 & 1.920 \\
\hline $97114 \ddagger$ & C1115 & $\mathrm{HC}$ & La & EuB & $8.53^{*}$ & 4.765 & 5.120 & $3.400^{*}$ & 1.705 & 2.895 & 1.960 & 1.945 & 2.355 & $2.335^{\star}$ \\
\hline 151991‡ & V71203 & $\mathrm{HC}$ & BCA & EuC & 9.520 & 5.635 & 5.735 & 3.820 & 1.670 & 3.945 & 2.680 & 2.515 & 3.030 & 3.310 \\
\hline 153023 & V74111 & $\mathrm{Tu}$ & Pu1 & EuC & - & - & - & 4.015 & $1.510^{*}$ & - & $2.500^{*}$ & - & 3.160 & - \\
\hline 151985 & V70201 & $\mathrm{Tu}$ & BCA & EuD & $7.810^{*}$ & 5.295 & 5.285 & - & 1.890 & 3.255 & 2.175 & 1.720 & 2.235 & 2.495 \\
\hline 151944 & V65127 & $\mathrm{Tu}$ & $\mathrm{BCA}$ & EuD & $8.845^{\star}$ & 5.735 & 6.005 & $2.190^{\star}$ & 2.185 & 3.655 & 1.940 & 2.320 & $2.230^{*}$ & $2.575^{\star}$ \\
\hline 151946 & V65127 & $\mathrm{Tu}$ & $\mathrm{BCA}$ & EuD & $8.800^{*}$ & 5.270 & 6.060 & - & 1.970 & 3.255 & 1.665 & 2.080 & 2.185 & $2.510^{*}$ \\
\hline $151964 \ddagger$ & V65127 & $\mathrm{Tu}$ & BCA & EuD & 9.225 & 5.340 & 5.700 & 3.550 & 1.750 & 3.585 & 1.645 & 2.005 & 2.225 & 2.380 \\
\hline $153036 \ddagger$ & V65127 & $\mathrm{Tu}$ & BCA & EuD & 9.935 & 5.675 & 5.850 & 4.210 & 1.820 & 3.800 & 1.775 & 2.155 & 2.470 & 2.710 \\
\hline 218901 & V91065 & $\mathrm{Tu}$ & Pu1 & EuE & $17.925^{\star}$ & 10.685 & 10.850 & $7.175^{\star}$ & 2.950 & 7.620 & 4.575 & 5.110 & 6.280 & 7.525 \\
\hline 92928 & C1163 & $\mathrm{Tu}$ & Pu3 & EuE & $15.030^{*}$ & 9.550 & 9.700 & - & 2.640 & 6.960 & 4.330 & 4.580 & $5.120^{*}$ & 5.320 \\
\hline 153089 & V72129 & $\mathrm{Tu}$ & Pu3 & EuF & $19.415^{\star}$ & 17.280 & 17.395 & - & 5.480 & 11.820 & 6.945 & 7.280 & $8.735^{\star}$ & 9.670 \\
\hline 192678 & V72124 & $\mathrm{Tu}$ & Pu3 & EuG & - & - & - & 10.300 & 5.095 & - & 7.435 & - & $9.425^{*}$ & - \\
\hline
\end{tabular}

that were measured from published figures $(n=9$ specimens from our sample, and $n=7$ specimens from the published literature; see Appendix 3 for specimens). We added these published specimens to increase the sample size and to examine where our specimens plotted in the PCA morphospace relative to specimens that have previously been described and attributed to taxon.

\section{Geometric Morphometrics}

To quantitatively compare morphology and to infer locomotion, we applied geometric morphometrics to select, well-preserved therian distal humeri from our K-Pg samples and to humeri of extant, small-bodied mammals of known locomotor mode. Our sample of extant mammals includes (1) a subset of those used in Chen and Wilson (2015), which broadly sampled taxonomic and locomotormode diversity of small-bodied mammals (Table 4); (2) five UWBM specimens that further expand our sampling of taxa and locomotor modes; and (3) photographs of 15 species of didelphids and tenrecs that were figured in distal view in Argot (2001) and Salton and Sargis (2008), respectively (Table 4). Our extant mammal dataset samples a total of
109 individuals and 71 species from nearly half of all mammalian orders.

Each extant species was assigned to one of eight locomotor modes [arboreal $(A)$, fossorial $(F)$, gliding $(\mathrm{G})$, saltatorial $(\mathrm{S})$, semi-aquatic $(\mathrm{Sa})$, scansorial (Sc), semi-fossorial (Sf), or terrestrial (T)] on the basis of natural history compendia and the primary literature (Nowak, 1999; Argot, 2001; Salton and Sargis, 2008; as used by Chen and Wilson, 2015; Table 4). Due to specimen availability, our database is predominantly composed of carnivorans, rodents, primates, and afrosoricids. We photographed and digitized one adult male and female of each species, unless otherwise indicated (Table 4). Some major taxa in our dataset (e.g., primates) only sample one locomotor mode (e.g., arboreal), possibly confounding functional morphology with phylogenetic relatedness; this issue was also discussed in Chen and Wilson (2015).

All specimens were photographed using a Nikon D80 Digital SLR camera with an interchangeable Quantaray AF LD 70-300 mm 1:4-5.6 Tele-macro lens. Rather than choose between the anterior or posterior view for our geometric morphometrics analyses, we chose to photograph 
TABLE 4. Modern mammalian specimens used in geometric morphometrics analyses. Species list and locomotor references are modified from Chen and Wilson 2015; see text for more details. All specimens are from the UWBM except for those with specimen numbers A2001 and S2008, which are taken from images of specimens in distal view in Argot (2001, figure 8) and Salton and Sargis (2008, figure 4.10), respectively. Code number assigned (and table sorted) as follows: clade, order, family, and locomotor mode. Locomotor mode abbreviations are as follows: A, arboreal; F, fossorial; G, gliding; S, saltatorial; Sa, semiaquatic; Sc, scansorial; Sf, semifossorial; T, terrestrial. Other abbreviations: F, female; LM, locomotor mode; M, male; Spec., specimen number; U, sex unknown.

\begin{tabular}{|c|c|c|c|c|c|c|c|c|c|}
\hline Clade & Order & Code & LM & Genus & Species & Family & Spec. & Sex & Locomotor Reference \\
\hline \multicolumn{10}{|c|}{ Metatheria } \\
\hline & \multicolumn{9}{|c|}{ Dasyuromorphia } \\
\hline & & 1 & $\mathrm{~T}$ & Antechinus & swainsonii & Dasyuridae & 68900 & M & Nowak 1999 \\
\hline & & 2 & $\mathrm{~T}$ & Sarcophilus & harrisii & Dasyuridae & 20671 & M & Van Valkenburgh 1987 \\
\hline & \multicolumn{9}{|c|}{ Didelphimorphia } \\
\hline & & 3 & A & Caluromys & philander & Didelphidae & A2001 & $U$ & $\begin{array}{l}\text { Argot 2001; Nowak } \\
1999\end{array}$ \\
\hline & & 4 & $A$ & Caluromys & derbianus & Didelphidae & 32255 & $\mathrm{U}$ & Argot 2001 \\
\hline & & 5 & A & Micoureus & demerarae & Didelphidae & A2001 & $\mathrm{U}$ & Argot 2001 \\
\hline & & 6 & $\mathrm{Sc}$ & Didelphis & virginiana & Didelphidae & 35525 & $\mathrm{~F}$ & Argot 2001 \\
\hline & & 7 & Sc & Didelphis & virginiana & Didelphidae & 74661 & M & Argot 2001 \\
\hline & & 8 & Sc & Didelphis & marsupialis & Didelphidae & A2001 & $U$ & $\begin{array}{l}\text { Argot 2001; Nowak } \\
1999\end{array}$ \\
\hline & & 9 & Sc & Marmosa & murina & Didelphidae & A2001 & $U$ & $\begin{array}{l}\text { Argot 2001; Nowak } \\
1999\end{array}$ \\
\hline & & 10 & $\mathrm{~T}$ & Metachirus & nudicaudatus & Didelphidae & 35438 & $\mathrm{~F}$ & $\begin{array}{l}\text { Argot 2001; Delciellos } \\
\text { and Vieira } 2006\end{array}$ \\
\hline & & 11 & $\mathrm{~T}$ & Monodelphis & brevicaudata & Didelphidae & A2001 & $U$ & $\begin{array}{l}\text { Argot 2001; Nowak } \\
1999\end{array}$ \\
\hline & \multicolumn{9}{|c|}{ Diprotodontia } \\
\hline & & 12 & G & Petaurus & breviceps & Petauridae & 34181 & M & $\begin{array}{l}\text { Smith 1973; Nowak } \\
\text { 1999; Körtner and } \\
\text { Geiser } 2000\end{array}$ \\
\hline & & 13 & G & Petaurus & breviceps & Petauridae & 72928 & $\mathrm{U}$ & $\begin{array}{l}\text { Smith 1973; Nowak } \\
\text { 1999; Körtner and } \\
\text { Geiser } 2000\end{array}$ \\
\hline & & 14 & $A$ & Trichosurus & vulpecula & Phalangeridae & 68913 & M & Nowak 1999 \\
\hline & & 15 & $S$ & Potorous & tridactylus & Potoroidae & 41025 & $\mathrm{~F}$ & Bassarova et al. 2009 \\
\hline & & 16 & $S$ & Potorous & tridactylus & Potoroidae & 34200 & M & Bassarova et al. 2009 \\
\hline & & 17 & $S$ & Aepyprymnus & rufescens & Potoroidae & 68898 & $\mathrm{~F}$ & Bassarova et al. 2009 \\
\hline & & 18 & A & Pseudocheirus & peregrinus & Pseudocheiridae & 68924 & $\mathrm{~F}$ & Bassarova et al. 2009 \\
\hline & & 19 & A & Pseudocheirus & peregrinus & Pseudocheiridae & 68908 & M & Bassarova et al. 2009 \\
\hline & \multicolumn{9}{|c|}{ Peramelemorphia } \\
\hline & & 20 & $\mathrm{~T}$ & Perameles & nasuta & Peramelidae & 68919 & $\mathrm{~F}$ & Nowak 1999 \\
\hline \multicolumn{10}{|c|}{ Eutheria } \\
\hline & \multicolumn{9}{|c|}{ Afrosoricida } \\
\hline & & 21 & $\mathrm{Sa}$ & Potamogale & velox & Potamogalidae & S2008 & $U$ & $\begin{array}{l}\text { Nowak 1999; Salton } \\
\text { and Sargis } 2008\end{array}$ \\
\hline & & 22 & A & Dendrohyrax & arboreus & Procaviidae & 39039 & $\mathrm{~F}$ & Nowak 1999 \\
\hline & & 23 & $A$ & Dendrohyrax & arboreus & Procaviidae & 39038 & M & Nowak 1999 \\
\hline & & 24 & $\mathrm{Sa}$ & Limnogale & mergulus & Tenrecidae & S2008 & $\mathrm{U}$ & $\begin{array}{l}\text { Nowak 1999; Salton } \\
\text { and Sargis } 2008\end{array}$ \\
\hline
\end{tabular}


TABLE 4 (continued).

\begin{tabular}{|c|c|c|c|c|c|c|c|c|c|}
\hline Clade & Order & Code & LM & Genus & Species & Family & Spec. & Sex & Locomotor Reference \\
\hline & & 25 & $\mathrm{Sc}$ & Echinops & telfairi & Tenrecidae & 34168 & $\mathrm{~F}$ & $\begin{array}{l}\text { Endo et al. 2006; Salton } \\
\text { and Sargis } 2008\end{array}$ \\
\hline & & 26 & $\mathrm{Sc}$ & Echinops & telfairi & Tenrecidae & S2008 & $U$ & $\begin{array}{l}\text { Endo et al. 2006; Salton } \\
\text { and Sargis } 2008\end{array}$ \\
\hline & & 27 & Sf & Hemicentetes & semispinosus & Tenrecidae & S2008 & $U$ & $\begin{array}{l}\text { Nowak 1999; Salton } \\
\text { and Sargis } 2008\end{array}$ \\
\hline & & 28 & Sf & Oryzorictes & $s p$. & Tenrecidae & S2008 & $U$ & $\begin{array}{l}\text { Nowak 1999; Salton } \\
\text { and Sargis } 2008\end{array}$ \\
\hline & & 29 & $\mathrm{~T}$ & Setifer & setosus & Tenrecidae & S2008 & $U$ & Salton and Sargis 2008 \\
\hline & & 30 & $\mathrm{~T}$ & Tenrec & ecaudatus & Tenrecidae & S2008 & $U$ & Salton and Sargis 2008 \\
\hline & & 31 & $\mathrm{~T}$ & Microgale & cowani & Tenrecidae & S2008 & $U$ & $\begin{array}{l}\text { Nowak 1999; Salton } \\
\text { and Sargis } 2008\end{array}$ \\
\hline & & 32 & $\mathrm{~T}$ & Microgale & dobsoni & Tenrecidae & S2008 & $U$ & $\begin{array}{l}\text { Nowak 1999; Salton } \\
\text { and Sargis } 2008\end{array}$ \\
\hline & & 33 & $\mathrm{~T}$ & Microgale & talazaci & Tenrecidae & S2008 & U & $\begin{array}{l}\text { Nowak 1999; Salton } \\
\text { and Sargis } 2008\end{array}$ \\
\hline \multicolumn{10}{|c|}{ Carnivora } \\
\hline & & 34 & $\mathrm{~T}$ & Vulpes & vulpes & Canidae & 39490 & $\mathrm{~F}$ & $\begin{array}{l}\text { Lariviére and } \\
\text { Pasitschniak-Arts 1996; } \\
\text { Meachen-Samuels } \\
2010\end{array}$ \\
\hline & & 35 & $\mathrm{~T}$ & Vulpes & vulpes & Canidae & 39489 & $\mathrm{M}$ & $\begin{array}{l}\text { Lariviére and } \\
\text { Pasitschniak-Arts 1996; } \\
\text { Meachen-Samuels } \\
2010\end{array}$ \\
\hline & & 36 & $\mathrm{Sc}$ & Urocyon & $\begin{array}{l}\text { cinereoargente } \\
\text { us }\end{array}$ & Felidae & 77676 & $\mathrm{~F}$ & $\begin{array}{l}\text { Van Valkenburgh 1987; } \\
\text { Meachen-Samuels } \\
2010\end{array}$ \\
\hline & & 37 & $\mathrm{Sc}$ & Urocyon & $\begin{array}{l}\text { cinereoargente } \\
\text { us }\end{array}$ & Felidae & 35221 & M & $\begin{array}{l}\text { Van Valkenburgh 1987; } \\
\text { Meachen-Samuels } \\
2010\end{array}$ \\
\hline & & 38 & $\mathrm{Sc}$ & Suricata & suricatta & Herpestidae & 35470 & $\mathrm{~F}$ & $\begin{array}{l}\text { van Staaden 1994; } \\
\text { Iwaniuk et al. } 1999\end{array}$ \\
\hline & & 39 & $\mathrm{Sc}$ & Suricata & suricatta & Herpestidae & 35469 & M & $\begin{array}{l}\text { van Staaden 1994; } \\
\text { Iwaniuk et al. } 1999\end{array}$ \\
\hline & & 40 & Sf & Mephitis & mephitis & Mephitidae & 35951 & $\mathrm{~F}$ & $\begin{array}{l}\text { Wade-Smith and Verts } \\
\text { 1982; Van Valkenburgh } \\
\text { 1987; Samuels and Van } \\
\text { Valkenburgh } 2008\end{array}$ \\
\hline & & 41 & $\mathrm{Sf}$ & Mephitis & mephitis & Mephitidae & 39321 & M & $\begin{array}{l}\text { Wade-Smith and Verts } \\
\text { 1982; Van Valkenburgh } \\
\text { 1987; Samuels and Van } \\
\text { Valkenburgh } 2008\end{array}$ \\
\hline & & 42 & $\mathrm{Sa}$ & Lontra & canadensis & Mustelidae & 32226 & $\mathrm{~F}$ & Gingerich 2003 \\
\hline & & 43 & $\mathrm{Sa}$ & Lontra & canadensis & Mustelidae & 32230 & $M$ & Gingerich 2003 \\
\hline & & 44 & $\mathrm{Sa}$ & Mustela & vison & Mustelidae & 41780 & $\mathrm{~F}$ & $\begin{array}{l}\text { Howell 1930; Lariviére } \\
\text { 1999; Gingerich } 2003\end{array}$ \\
\hline & & 45 & $\mathrm{Sa}$ & Mustela & vison & Mustelidae & 35223 & M & $\begin{array}{l}\text { Howell 1930; Lariviére } \\
\text { 1999; Gingerich } 2003\end{array}$ \\
\hline & & 46 & $\mathrm{Sc}$ & Gulo & gulo & Mustelidae & 14200 & $F$ & $\begin{array}{l}\text { Van Valkenburgh 1987; } \\
\text { Pasitschniak-Arts and } \\
\text { Lariviére } 1995\end{array}$ \\
\hline
\end{tabular}


DEBEy \& WILSON: MAMmAL HUMERI ACROSS THE K/PG

TABLE 4 (continued).

\begin{tabular}{|c|c|c|c|c|c|c|c|c|c|}
\hline Clade & Order & Code & LM & Genus & Species & Family & Spec. & Sex & Locomotor Reference \\
\hline & & 47 & $\mathrm{Sc}$ & Gulo & gulo & Mustelidae & 34417 & M & $\begin{array}{l}\text { Van Valkenburgh 1987; } \\
\text { Pasitschniak-Arts and } \\
\text { Lariviére } 1995\end{array}$ \\
\hline & & 48 & Sf & Spilogale & putorius & Mustelidae & 39331 & $\mathrm{~F}$ & $\begin{array}{l}\text { Heinrich and Houde } \\
2006\end{array}$ \\
\hline & & 49 & Sf & Spilogale & putorius & Mustelidae & 39155 & M & $\begin{array}{l}\text { Heinrich and Houde } \\
2006\end{array}$ \\
\hline & & 50 & $\mathrm{~T}$ & Mustela & erminea & Mustelidae & 39366 & $\mathrm{~F}$ & Nowak 1999 \\
\hline & & 51 & $\mathrm{~T}$ & Mustela & erminea & Mustelidae & 72863 & M & Nowak 1999 \\
\hline & & 52 & $\mathrm{~T}$ & Mustela & putorius & Mustelidae & 32599 & $\mathrm{~F}$ & Nowak 1999 \\
\hline & & 53 & $\mathrm{~T}$ & Mustela & putorius & Mustelidae & 58727 & M & Nowak 1999 \\
\hline & & 54 & A & Paguma & larvata & Viverridae & 73281 & $U$ & Nowak 1999 \\
\hline \multicolumn{10}{|c|}{ Cingulata } \\
\hline & & 55 & $\mathrm{~F}$ & Cabassous & centralis & Dasypodidae & 34167 & $\mathrm{~F}$ & Nowak 1999 \\
\hline & & 56 & $\mathrm{~F}$ & Dasypus & novemcinctus & Dasypodidae & 20735 & $\mathrm{~F}$ & $\begin{array}{l}\text { Samuels and Van } \\
\text { Valkenburgh } 2008\end{array}$ \\
\hline & & 57 & $\mathrm{~F}$ & Dasypus & novemcinctus & Dasypodidae & 22458 & M & $\begin{array}{l}\text { Samuels and Van } \\
\text { Valkenburgh } 2008\end{array}$ \\
\hline & & 58 & $\mathrm{~F}$ & Euphractus & sexcinctus & Dasypodidae & 35468 & M & $\begin{array}{l}\text { Redford and Wetzel } \\
\text { 1985; Nowak } 1999\end{array}$ \\
\hline & \multicolumn{9}{|c|}{ Eulipotyphla } \\
\hline & & 59 & $\mathrm{~T}$ & Echinosorex & gymnurus & Erinaceidae & S2008 & $U$ & $\begin{array}{l}\text { Nowak 1999; Salton } \\
\text { and Sargis } 2008\end{array}$ \\
\hline & & 60 & Sf & Solenodon & paradoxus & Solenodontidae & S2008 & $U$ & $\begin{array}{l}\text { Nowak 1999; Salton } \\
\text { and Sargis } 2008\end{array}$ \\
\hline & \multicolumn{9}{|c|}{ Lagomorpha } \\
\hline & & 61 & $S$ & Brachylagus & idahoensis & Leporidae & 38628 & $\mathrm{~F}$ & Nowak 1999 \\
\hline & & 62 & $S$ & Brachylagus & idahoensis & Leporidae & 38631 & M & Nowak 1999 \\
\hline & & 63 & $S$ & Lepus & americanus & Leporidae & 21111 & $\mathrm{~F}$ & Nowak 1999 \\
\hline & & 64 & $S$ & Lepus & americanus & Leporidae & 33263 & M & Nowak 1999 \\
\hline & & 65 & Sf & Ochotona & princeps & Ochtonidae & 18435 & $\mathrm{~F}$ & Nowak 1999 \\
\hline & & 66 & Sf & Ochotona & princeps & Ochtonidae & 60068 & M & Nowak 1999 \\
\hline & \multicolumn{9}{|c|}{ Macroscelidea } \\
\hline & & 67 & $S$ & Petrodromus & tetradactylus & Macroscelididae & S2008 & $U$ & Salton and Sargis 2008 \\
\hline & & 68 & $\mathrm{~T}$ & Elephantulus & rufescens & Macroscelididae & 35475 & $\mathrm{~F}$ & Nowak 1999 \\
\hline & & 69 & $\mathrm{~T}$ & Elephantulus & rufescens & Macroscelididae & 34189 & M & Nowak 1999 \\
\hline \multicolumn{10}{|c|}{ Primates } \\
\hline & & 70 & A & Callithrix & pygmaea & Cebidae & 39003 & $\mathrm{~F}$ & Nowak 1999 \\
\hline & & 71 & $A$ & Callithrix & pygmaea & Cebidae & 39005 & M & Nowak 1999 \\
\hline & & 72 & A & Leontopithecus & rosalia & Cebidae & 75541 & $\mathrm{~F}$ & Nowak 1999 \\
\hline & & 73 & A & Saguinus & oedipus & Cebidae & 35406 & $\mathrm{~F}$ & Nyakatura et al. 2008 \\
\hline & & 74 & $A$ & Saguinus & oedipus & Cebidae & 35405 & M & Nyakatura et al. 2008 \\
\hline & & 75 & $A$ & Saimiri & sciureus & Cebidae & 82302 & $\mathrm{~F}$ & Nowak 1999 \\
\hline & & 76 & $A$ & Saimiri & sciureus & Cebidae & 39014 & M & Nowak 1999 \\
\hline
\end{tabular}


TABLE 4 (continued).

\begin{tabular}{|c|c|c|c|c|c|c|c|c|c|}
\hline Clade & Order & Code & LM & Genus & Species & Family & Spec. & Sex & Locomotor Reference \\
\hline & \multicolumn{9}{|c|}{ Rodentia } \\
\hline & & 77 & $\mathrm{~F}$ & Aplodontia & rufa & Aplodontiidae & 34071 & $\mathrm{~F}$ & $\begin{array}{l}\text { Samuels and Van } \\
\text { Valkenburgh } 2008\end{array}$ \\
\hline & & 78 & $\mathrm{~F}$ & Aplodontia & rufa & Aplodontiidae & 34058 & M & $\begin{array}{l}\text { Samuels and Van } \\
\text { Valkenburgh } 2008\end{array}$ \\
\hline & & 79 & $\mathrm{Sa}$ & Castor & canadensis & Castoridae & 34116 & $\mathrm{~F}$ & Nowak 1999 \\
\hline & & 80 & $\mathrm{Sa}$ & Castor & canadensis & Castoridae & 34588 & $\mathrm{M}$ & Nowak 1999 \\
\hline & & 81 & $\mathrm{~T}$ & Cavia & porcellus & Caviidae & 72830 & $\mathrm{~F}$ & Nowak 1999 \\
\hline & & 82 & $\mathrm{~T}$ & Cavia & porcellus & Caviidae & 72831 & M & Nowak 1999 \\
\hline & & 83 & $\mathrm{~F}$ & Microtus & $\begin{array}{l}\text { pennsylvanicu } \\
s\end{array}$ & Cricetidae & 76622 & $\mathrm{~F}$ & Nowak 1999 \\
\hline & & 84 & $\mathrm{~F}$ & Microtus & $\begin{array}{l}\text { pennsylvanicu } \\
s\end{array}$ & Cricetidae & 34326 & M & Nowak 1999 \\
\hline & & 85 & $\mathrm{Sa}$ & Ondatra & zibethicus & Cricetidae & 34324 & $\mathrm{~F}$ & $\begin{array}{l}\text { Howell 1930; Gingerich } \\
2003\end{array}$ \\
\hline & & 86 & $\mathrm{Sa}$ & Ondatra & zibethicus & Cricetidae & 72879 & M & $\begin{array}{l}\text { Howell 1930; Gingerich } \\
2003\end{array}$ \\
\hline & & 87 & $\mathrm{Sf}$ & Synaptomys & borealis & Cricetidae & 66559 & $\mathrm{~F}$ & Nowak 1999 \\
\hline & & 88 & $\mathrm{Sf}$ & Synaptomys & borealis & Cricetidae & 66561 & $\mathrm{M}$ & Nowak 1999 \\
\hline & & 89 & $S$ & Zapus & princeps & Dipodidae & 76721 & $\mathrm{~F}$ & Nowak 1999 \\
\hline & & 90 & $S$ & Zapus & princeps & Dipodidae & 75136 & M & Nowak 1999 \\
\hline & & 91 & Sc & Coendou & prehensilis & Erethizontidae & 34176 & $\mathrm{~F}$ & Nowak 1999 \\
\hline & & 92 & $\mathrm{~F}$ & Thomomys & bottae & Geomyidae & 44624 & $\mathrm{~F}$ & Nowak 1999 \\
\hline & & 93 & $\mathrm{~F}$ & Thomomys & bottae & Geomyidae & 38261 & $\mathrm{M}$ & Nowak 1999 \\
\hline & & 94 & $\mathrm{~F}$ & Chaetodipus & fallax & Heteromyidae & 47378 & $\mathrm{~F}$ & Lackey 1996 \\
\hline & & 95 & $\mathrm{~F}$ & Chaetodipus & fallax & Heteromyidae & 47379 & $\mathrm{M}$ & Lackey 1996 \\
\hline & & 96 & $S$ & Dipodomys & deserti & Heteromyidae & 78740 & $\mathrm{~F}$ & $\begin{array}{l}\text { Samuels and Van } \\
\text { Valkenburgh } 2008\end{array}$ \\
\hline & & 97 & $\mathrm{Sf}$ & Octodon & degus & Octodontidae & 48984 & $\mathrm{~F}$ & Nowak 1999 \\
\hline & & 98 & $\mathrm{Sf}$ & Octodon & degus & Octodontidae & 39501 & $\mathrm{M}$ & Nowak 1999 \\
\hline & & 99 & $A$ & Sciurus & aberti & Sciuridae & 35278 & $\mathrm{~F}$ & Nowak 1999 \\
\hline & & 100 & $A$ & Sciurus & aberti & Sciuridae & 82349 & M & Nowak 1999 \\
\hline & & 101 & $A$ & Sciurus & carolinensis & Sciuridae & 20646 & $F$ & Nowak 1999 \\
\hline & & 102 & A & Sciurus & carolinensis & Sciuridae & 30010 & M & Nowak 1999 \\
\hline & & 103 & G & Glaucomys & sabrinus & Sciuridae & 36334 & $\mathrm{~F}$ & $\begin{array}{l}\text { Samuels and Van } \\
\text { Valkenburgh } 2008\end{array}$ \\
\hline & & 104 & G & Glaucomys & sabrinus & Sciuridae & 35129 & M & $\begin{array}{l}\text { Samuels and Van } \\
\text { Valkenburgh } 2008\end{array}$ \\
\hline & & 105 & $\mathrm{G}$ & Glaucomys & volans & Sciuridae & 43897 & $\mathrm{~F}$ & Nowak 1999 \\
\hline & & 106 & G & Glaucomys & volans & Sciuridae & 32254 & M & Nowak 1999 \\
\hline & & 107 & $\mathrm{Sf}$ & Cynomys & ludovicianus & Sciuridae & 75774 & $\mathrm{M}$ & Nowak 1999 \\
\hline \multicolumn{10}{|c|}{ Scandentia } \\
\hline & & 108 & Sc & Tupaia & glis & Tupaiidae & 34227 & $\mathrm{~F}$ & Van Valkenburgh 1987 \\
\hline & & 109 & Sc & Tupaia & glis & Tupaiidae & 34225 & M & Van Valkenburgh 1987 \\
\hline
\end{tabular}


specimens in distal view, which captures gross articular shape about the axis of the elbow joint. Specimens were consistently oriented in three dimensions: the medial to lateral axis was aligned along a horizontal line in the camera view and a plane horizontal with the stage, and the proximalto-distal axis was aligned perpendicular to the stage. A millimeter scale bar was included in all images to enable rescaling in the geometric morphometric analyses. We reflected all right humeri about a vertical axis to appear as left humeri during post-processing of photographs.

We chose morphologically and functionally informative landmarks (LMs) that define articular surfaces and muscle attachment sites in distal view (Zelditch et al., 2004). Most of our LMs were Type II (i.e., tip of structure, local maxima or minima of a curve); a few were Type III (e.g., furthest extent measurement; Bookstein, 1991; Zelditch et al., 2004). All of our LMs are based on LMs in comparable studies (Table 5; Schutz and Guralnick, 2007; Milne et al., 2009; Steiner-Souza et al., 2010). We digitized six LMs (Figure 3.1; Table 5) on each specimen image using tpsDig version 2.17 (Rohlf, 2013a). We acknowledge that plotting landmarks on a two-dimensional (2D) picture of a threedimensional structure may result in a loss of information and a degree of inaccuracy (Cardini, 2014); however, 2D approximation should be sufficient to capture morphological variation because the landmarks are approximately coplanar (Cardini et al., 2015). All of the digitizing was done by one of us (L.B.D.).

We also used semilandmarks (SLMs), evenly spaced along a curve or surface, to characterize aspects of shape not readily captured by LMs (Zelditch et al., 2004). Although an individual SLM might not be homologous across taxa, the curve or surface as a whole may be (Gunz and Mitteroecker, 2013; Wilson, 2013). We traced three curves on the distal humerus (Figure 3.2) using the pencil tool in tpsDig; the resultant curve was resampled for a specific number of points that were equally distributed by length (Figure 3.3). Points along the curve were initially converted to LMs in tpsUtil version 1.58 (Rohlf, 2013b), but were later designated as SLMs (see below).

We performed Procrustes generalized least squares (GLS) superimpositions (Rohlf and Slice, 1990; Zelditch et al., 2004) on our combined dataset of digitized extant and fossil specimens to remove any differences in size, translation, and rotation so that only shape differences remained (Kendall, 1977). To avoid excessive weighting of curves in the analyses, every other point along a curve was designated as a helper point and was used only for superimposition (Figure 3.3; Wilson, 2013). Remaining points along the curve were designated as sliders (Figure 3.3), which minimize Procrustes distances during superimposition by allowing some SLMs (i.e., sliders) of one specimen to slide between helper points, initially with respect to those of another (arbitrary) specimen (Gunz and Mitteroecker, 2013). Procrustes superimposition from these slide coordinates results in a mean shape, and subsequently all SLMs are allowed to slide with respect to the mean Procrustes shape (Gunz and Mitteroecker, 2013). After superimposition, we deleted curve helper points, and designated SLMs (i.e., curve slider points) as separate from LMs (Figure 3.4). The resultant dataset contained six LMs and 14 SLMs (Figure 3.4). We then converted LMs and SLMs to partial warp scores for use in subsequent analyses.

We used principal components analysis (PCA) to visualize the morphospace occupancy of the extant mammalian taxa and where our morphotypes plot within that morphospace. Specifically, we calculated a mean (or consensus) shape for all specimens, and subtracted this from the Procrustes superimposed dataset to produce Procrustes residuals (Polly and MacLeod, 2008; Wilson, 2013). We conducted PCAs on the covariance matrix of the residuals of the extant specimens only, and used singular value decomposition to calculate the eigenvectors for the extant dataset (Polly and MacLeod, 2008). We determined the PCA scores for fossil specimens by calculating the dot product of the eigenvectors and the Procrustes residuals of the fossil specimens. We plotted the PC1-3 scores for fossil specimens to interpret their placement within the morphospace defined by the extant specimens (Wilson, 2013). We also used linear discriminant analysis (LDA) to maximize differences among a priori groups and predict locomotor groups based on distal humerus shape (Mitteroecker and Bookstein, 2011). LDA is an ordination method that uses principal components and an external variable (i.e., locomotor function), predicts a locomotor mode for each specimen, and measures the percentage of specimens correctly assigned in our extant mammal dataset. We then used this LDA to rank predicted locomotor modes for $\mathrm{K}-\mathrm{Pg}$ fossil specimens used in the 2D GM analysis.

To assess intraobserver error, one of us (L.B.D.) digitized LMs on a set of 25 images that consisted of five randomly arranged copies of five 
TABLE 5. Landmark number, location, type, and source reference for two-dimensional geometric morphometrics (2D GM) points on therian distal humeri. All points were digitized on distal images of specimens; see Figure 3 for more details. Numbers in parentheses are the landmark number for the point within the referenced source. Abbreviations: LM, landmark; Type, landmark type according to Zelditch et al. 2004.

\begin{tabular}{clcl}
\hline LM & \multicolumn{1}{c}{ Location } & Type & \multicolumn{1}{c}{ Source Reference } \\
\hline 1 & Lateral point on the posterior trochlea & II & Steiner-Souza et al. 2010 \\
2 & Medial point on the posterior trochlea & II & Steiner-Souza et al. 2010 \\
3 & Medial point on the anterior trochlea & II & Steiner-Souza et al. 2010 \\
4 & Lateral point on the anterior capitulum & II & Steiner-Souza et al. 2010 \\
5 & Most lateral point on the ectepicondyle & III & Schutz and Guralnick 2007 (5); Steiner-Souza et al. 2010 \\
6 & Most medial point on the entepicondyle & III & Milne et al. 2009 (12); Steiner-Souza et al. 2010 \\
\hline
\end{tabular}

specimen images. The five specimens sample the taxonomic range (e.g., one each of Metatheria, Lagomorpha, Carnivora, and two within Rodentia) and the morphologic variation in the dataset (i.e., at the maxima and minima of our PC1 and PC2; Boyer and Seiffert, 2013). For each LM on each specimen, we calculated the digitizing variance across all trials by calculating the mean of the Euclidean distance between each digitized point and the centroid for that LM (Appendix 5). Digitizing error, or variance across trials, was extremely low for each LM, and low for mean variances across LMs and across specimens (Appendix 5). We also conducted F-tests, which compare equivalences among variances, to examine whether digitizing some LMs resulted in different variances than for other LMs (i.e., digitizing had variable precision across LMs; Appendix 6). Some LMs had significantly greater variance than others (e.g., LM6 for Lepus americanus and Dipodomys deserti; Appendix 6); however, this was not consistent for any LM across all specimens. Thus, there was not strong justification for excluding any of the LMs from our analyses.

All analyses were performed in RStudio version 0.98.1062 (RStudio, 2012) in $R$ version 3.1.2 (R Core Team, 2014). Specifically, Procrustes superimpositions (including designation of helper and slider points, and LMs and SLMs), intraobserver error assessments, and all PCA analyses were performed using the 'geomorph' package in $R$ (Adams and Otarola-Castillo, 2013). LDA analyses were performed using the 'Ida' function from the 'MASS' package in R (Venables and Ripley, 2002).

\section{DESCRIPTIONS OF FOSSIL DISTAL HUMERI}

\section{Multituberculate Distal Humeri}

In our sample of Cretaceous and Paleogene distal humeri, multituberculates are the most abundant higher-level taxon (60\% of total specimens), and are recognized in every time interval of this study. Here, we describe 10 Lancian, four Pu1, and three Pu3 multituberculate specimens, as well as 12 specimens of Lancian-Pu1 mixed age (Bug Creek Anthills assemblages; Table 2).

Multituberculate humeri are readily distinguished from those of therians by their stout shaft, proximal and distal ends that are twisted relative to one another (Jenkins, 1973; Szalay and Dagosto, 1980; Kielan-Jaworowska and Qi, 1990), a mediolaterally wide distal end, and a distal articular surface that is much narrower mediolaterally (Krause and Jenkins, 1983; Szalay and Dagosto, 1980; Kielan-Jaworowska et al., 2004). More specifically, the distal end of their humeri differs from that of therians in the following ways: (i) the ulnar condyle is more bulbous, proximodistally elongate and mediolaterally compressed, with a sharp medial keel (Figure 2; Kielan-Jaworowska and Dashzeveg, 1978; Clemens and Kielan-Jaworowska, 1979; Szalay and Dagosto, 1980; Weil and Krause, 2008); (ii) the radial condyle is very large and spherical, rather than slight and only somewhat rounded as in most therian mammals, and has a lateral capitular tail (Deischl, 1964; Szalay and Dagosto, 1980; Weil and Krause, 2008); (iii) the intercondylar groove (trochlea) separating the ulnar and radial condyles is a wide, deep, and sharply concave notch (Deischl, 1964; KielanJaworowska and Dashzeveg, 1978; Kielan-Jaworowska, 1990); (iv) the entepicondyle, much larger than the ectepicondyle, is a broad, dorsoventrally compressed flange that is pierced by the entepicondylar foramen (Jenkins, 1973; Krause and Jenkins, 1983; Weil and Krause, 2004); (v) the ectepicondyle is more pronounced than that of generalized therian mammals (Deischl, 1964; Krause and Jenkins, 1983); and (vi) both the radial and ulnar condyles extend from the ventral to the dorsal surface of the distal surface (Gambaryan and Kielan-Jaworowska, 1997). The distal humeri 


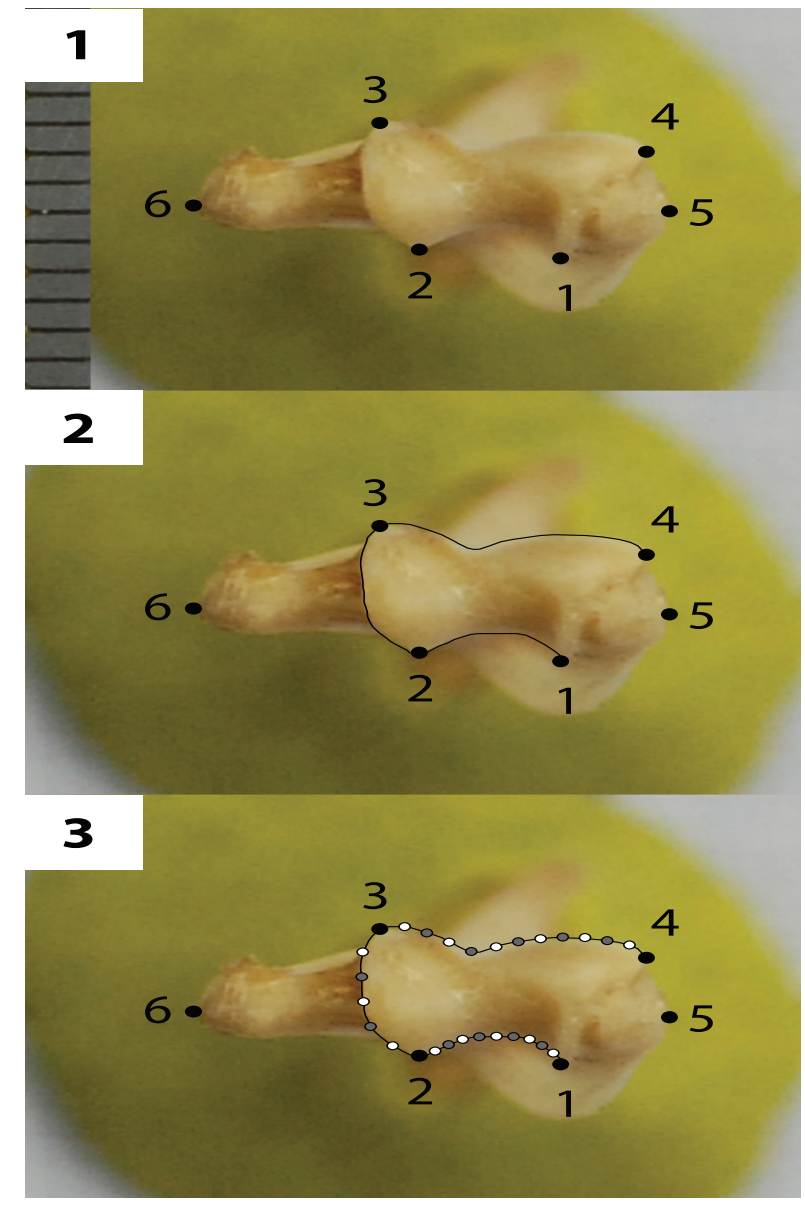

4

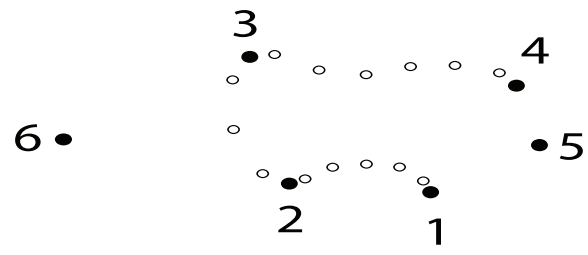

FIGURE 3. Geometric morphometric scheme and method for placement of landmarks (LMs), curves, and semilandmarks (SLMs) on therian left distal humerus (UWBM 20646, Sciurus carolinensis). All specimens were oriented with anterior up and medial to the left; right specimens were reflected to appear as lefts. (1) LMs 1-6 were plotted (see Table 5 for landmark descriptions). (2) Curves were traced along the anterior, posterior, and medial borders of the articular surface. (3) Curves were re-sampled for equivalent lengths between points, with 11 , nine, and five points describing the anterior, posterior, and medial borders of the articular surface, respectively. All resampled points and LMs were used for Procrustes superimposition, with sliders (gray) allowed to slide between helper points (white; see Methods). (4) Helpers were deleted, and all remaining LMs (black) and SLMs (white) were used in PCA analyses. described here all have expanded distal ends, as in North American ptilodontoid and taeniolabidoid multituberculates (Krause and Jenkins, 1983; Kielan-Jaworowska and Gambaryan, 1994).

Distal humerus morphotype MuA (Figure 4). The eight humeri assigned to this morphotype are among the smallest in our sample (TDW mean = $3.9 \mathrm{~mm}, \mathrm{SD}=0.19 \mathrm{~mm}$ ). Diagnostic features of this morphotype include: (i) a transverse depression at the blunt proximal termination of the ventral surface of the ulnar condyle; (ii) a broad, shallow separation dorsally between the entepicondyle and ulnar condyle; and (iii) an inflated appearance, especially on the condyles and entepicondyle, but otherwise with proportions and morphology that generally resemble larger multituberculate morphotypes MuE and MuC. We note one additional specimen attributed to this morphotype despite a much smaller size (UCMP 195998 from locality V5620, preserved TDW $=2.2 \mathrm{~mm}, 80 \%$ complete); this specimen was excluded from calculations of average measurements of the MuA morphotype, and we discuss this further below.

This morphotype greatly resembles Bug Creek Anthills material previously attributed to ?Mesodma sp., ?M. thompsoni, and ?M. formosa (Deischl, 1964; Krause and Jenkins, 1983). Because most of our MuA specimens are from Bug Creek Anthills localities and they do not resemble any other comparative material (Appendix 4), it is likely that they are from the same or closely related taxa. We advocate a more conservative attribution of MuA to ?Mesodma sp.

Among the two humeri tentatively attributed to this morphotype, one is missing the area proximal to the ulnar condyle and portions of the entepi- and ectepicondyles, key features for diagnosing this morphotype. The other (UCMP 195998 from Lancian locality V5620) greatly resembles the other MuA specimens in morphology but is much smaller. Perhaps this specimen is attributable to the smallest of the Lancian species of Mesodma, $M$. hensleighi, a taxon that is known to occur at this locality on the basis of dental specimens (Clemens, 1964).

Distal humerus morphotype MuB (Figure 5). The humerus specimen (UCMP 195933) assigned to this morphotype is among the smallest in our sample. Diagnostic features of this morphotype include: (i) an entepicondyle, ulnar condyle, and radial and olecranon fossae that are small relative to specimen size; (ii) a relatively large supinator crest lateral to the radial and olecranon fossae; (iii) a mediolaterally wide ulnar condyle with a shallow 


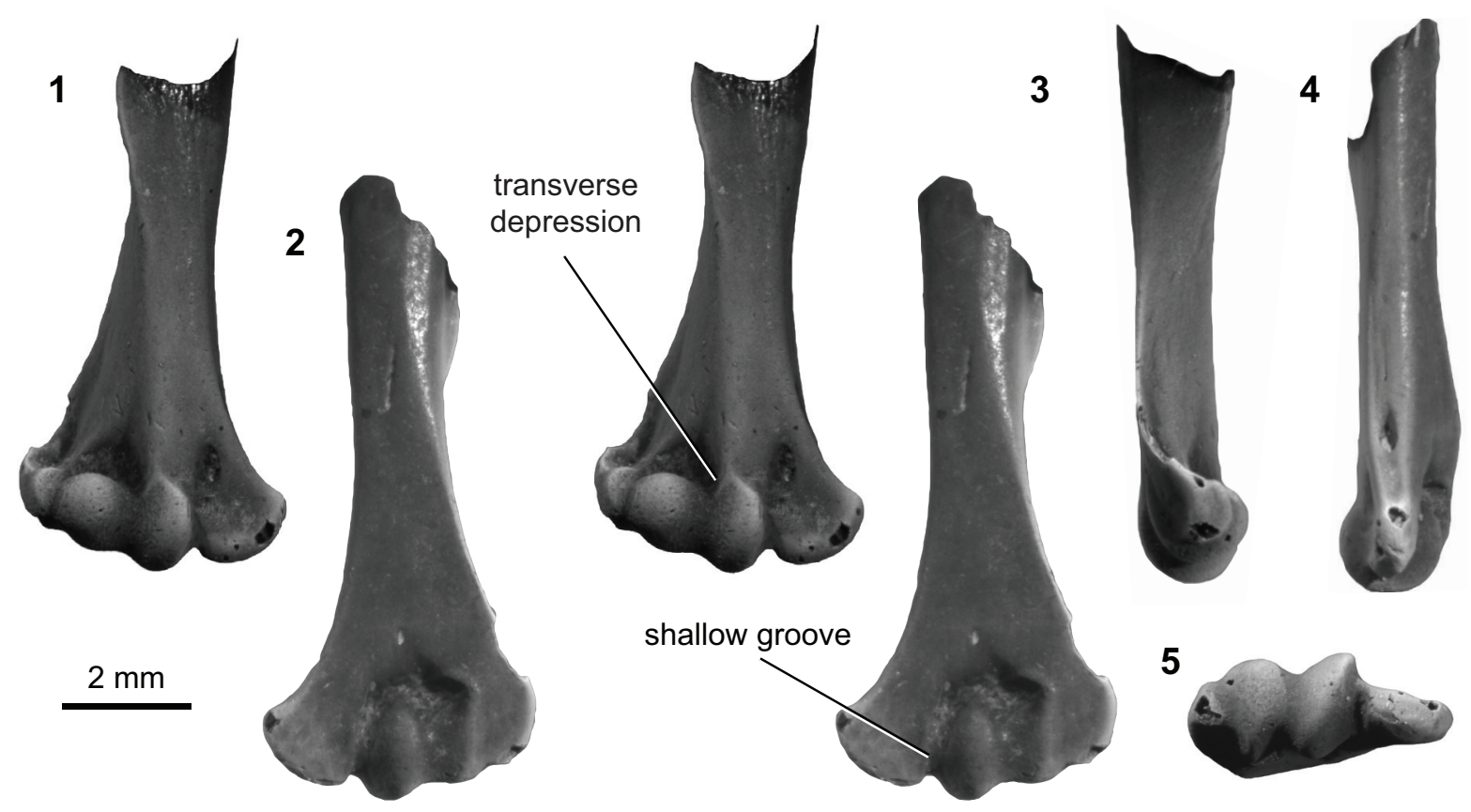

FIGURE 4. Multituberculate morphotype MuA (UCMP specimen 122045, from locality V70201; right), in ventral (1) and dorsal (2) stereopair views, and in lateral (3), medial (4), and distal (5) views.

dimple proximally on the ventral surface; and (iv) an even more inflated appearance than in MuA.

UCMP 195933 is quite small, but is comparable in size to some MuA specimens. Despite its poor preservation (i.e., missing the radial condyle and ectepicondyle), diagnostic features separate it from all comparative material that we studied (e.g., ?Mesodma sp., ?Meniscoessus sp., Microcosomodon conus, ?Ptilodus montanus, ?Stygimys kuszmauli; Cope, 1884; Marsh, 1889; Gidley, 1909; Deischl, 1964; Sahni, 1972; Krause and Jenkins, 1983; Fox, 2005). We suggest that this morphotype represents one of the many small multituberculates from the Pu3 in our study area (e.g., ?Xyronomys, Microcosmodon harleyi, M. arcuatus, Mesodma garfieldensis, in increasing size order; Clemens, 2002; Wilson et al., 2012; Wilson, 2014); however, it does not share the distal, especially articular, morphology of similarly sized humeri attributed to the late Paleocene Microcosmodon conus (Fox, 2005). Thus, until we have more comparative material representing small multituberculates, we do not attribute MuB to lower-level taxon. Distal humerus morphotype MuC (Figure 6). The seven specimens in this morphotype are larger (TDW > $6.5 \mathrm{~mm}$ ) than MuA and MuB mor- photypes and smaller than MuE and MuF. Diagnostic features of this morphotype include: (i) a deeper separation between the ulnar condyle and entepicondyle dorsally; (ii) a larger ectepicondyle lateral to the capitular tail; and (iii) a shallow, transverse dimple proximal to the ulnar condyle on the ventral surface.

This morphotype is morphologically very similar to the MuE morphotype and to specimens attributed to ?Stygimys kuszmauli, differing only in the dorsal morphology between the entepicondyle and ulnar condyle and in size (MuC is approximately $0.8 \mathrm{x}$ the size of MuE and ?Stygimys kuszmauli; Deischl, 1964; Krause and Jenkins, 1983). Similarly, MuC is morphologically similar to, but approximately $1.5-1.6 x$ the size of the smallest morphotypes (e.g., MuA) and specimens attributed to ?Mesodma sp. and ?M. thompsoni (Deischl, 1964; Krause and Jenkins, 1983); among the 87 distal humeri from the mixed-age Bug Creek Anthills that were examined by Deischl (1964), none are in the size range occupied by our MuC specimens. MuC differs from smaller, late Paleocene specimens attributed to ?Microcosmodon conus (Fox, 2005) in having a much more laterally projecting ectepicondyle, and from select Asian multi- 


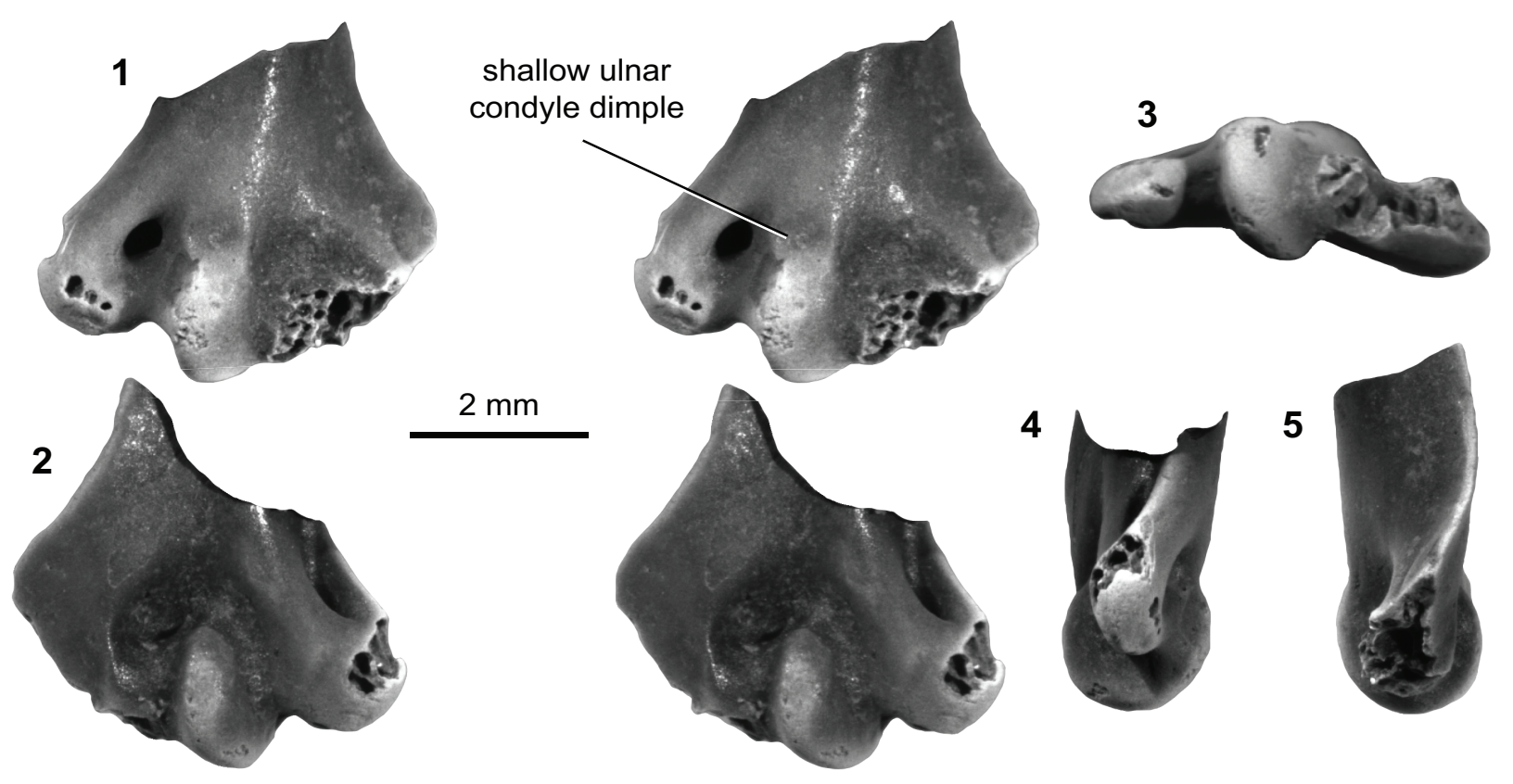

FIGURE 5. Multituberculate morphotype MuB (UCMP specimen 195933, from locality V99438; left), in ventral (1) and dorsal (2) stereopair views, and in distal (3), medial (4), and lateral (5) views.

tuberculates in having a larger and more bulbous radial condyle than the slightly smaller Late Cretaceous Kryptobaatar (formerly Tugrigbaatar; KielanJaworowska and Dashzeveg, 1978). MuC differs from larger humeri attributed to the late Paleocene ?Lambdopsalis bulla in having a mediolaterally larger, but dorsoventrally less robust entepicondyle (Kielan-Jaworowska and Qi, 1990). The specimens in MuC represent Lancian, Pu1, and Pu3 taxa that are likely larger than Microcosmodon conus and smaller than Stygimys kuszmauli and Cimolodon nitidus. We do not attribute this morphotype to taxon, but note that candidate taxa known from our study area in this size range include the Lancian Parectypodus foxi and Pu1-Pu3 Cimexomys gratus (Clemens, 2002; Wilson et al., 2012; Wilson, 2014).

Distal humerus morphotype MuD (Figure 7). The humerus assigned to this morphotype (UCMP 195990) greatly resembles the slightly larger MuE in morphology (MuD TDW $=7.3 \mathrm{~mm}$ ). Diagnostic features of this morphotype, particularly those that differ from MuE, include: (i) a radial condyle dorsally that is reduced; (ii) a more bulbous ulnar condyle dorsally; and (iii) a relatively small radial fossa, both mediolaterally and proximodistally. This specimen lacks a dimple proximal to the ulnar condyle. UCMP 195990 is a Lancian specimen that in many ways resembles the MuE morphotype and specimens that others attributed to Stygimys kuszmauli
(Deischl, 1964; Krause and Jenkins, 1983). However, the eucosmodontid Stygimys has not been reported from the Late Cretaceous of the Western Interior (but see Lillegraven, 1972 for a possible Campanian occurrence in Baja California); in our study area, the earliest occurrence of Stygimys is Pu1 (Clemens, 2002; Wilson, 2014). Along with this temporal incongruity, slight differences in size and morphology suggest that MuD represents a different taxon. If we assume that the body size of individuals in MuD is slightly smaller than that of Stygimys $(\sim 210 \mathrm{~g})$, MuD might be attributable to the cimolodontid Cimolodon nitidus $(\sim 180 \mathrm{~g}$; Wilson et al., 2012), a taxon that is known from the Lance formation and from this locality specifically (UCMP locality V5620; Clemens, 1964).

Distal humerus morphotype MuE (Figure 8). The five specimens assigned to this morphotype are medium-sized humeri in our sample (TDW mean $=8.31 \mathrm{~mm}, \mathrm{SD}=0.25 \mathrm{~mm}$ ). Diagnostic features of this morphotype include: (i) an ulnar condyle that tapers proximally on the ventral surface (i.e., mediolaterally narrows at the proximal ulnar condyle extent); (ii) an ulnar condyle that terminates in a small pit or dimple; (iii) a stout distal shaft; and (iv) a deep olecranon fossa.

These humeri are nearly identical to specimens from the Bug Creek Anthills attributed to ?Stygimys kuzsmauli (mean TDW $=8.18 \mathrm{~mm}$, SD $=0.64 \mathrm{~mm}$; Deischl, 1964; Krause and Jenkins, 

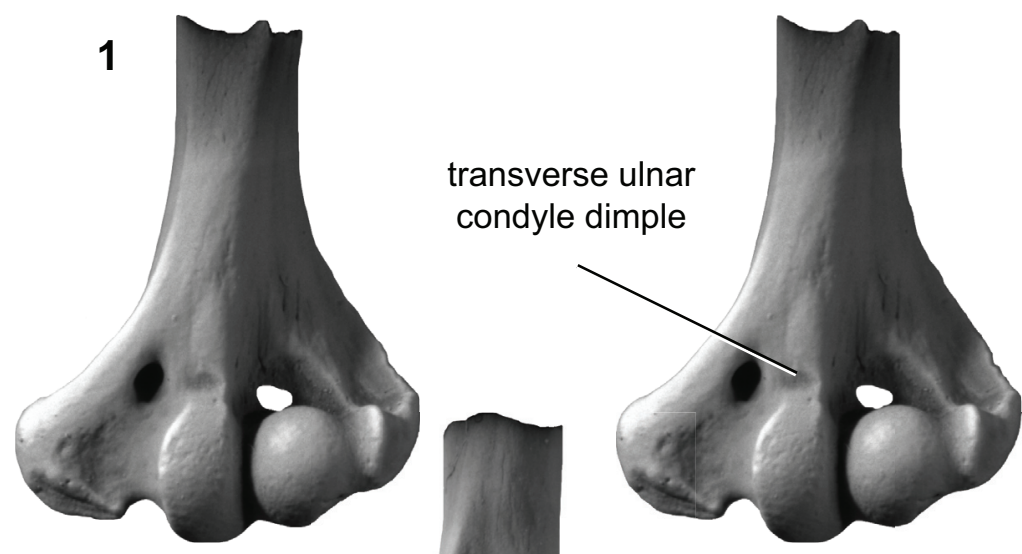

3
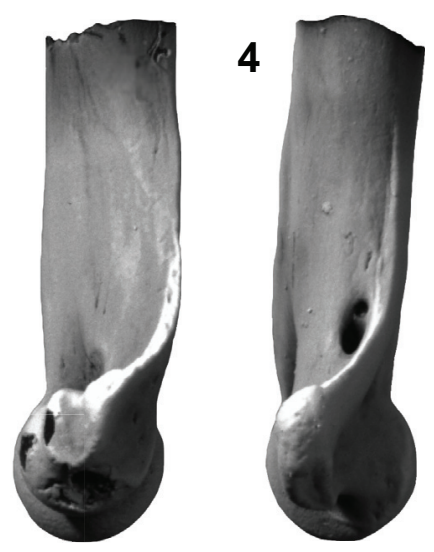

5

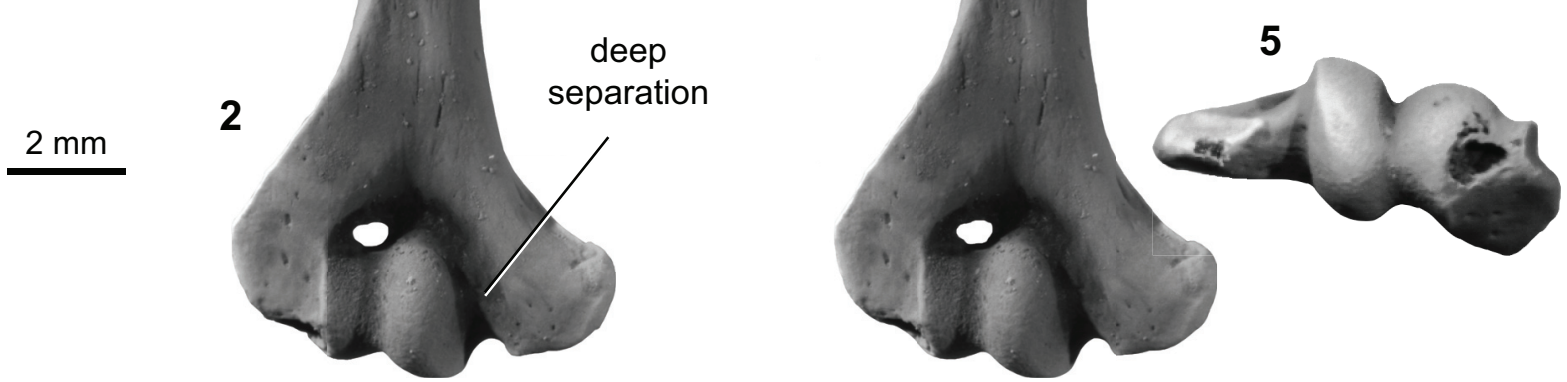

FIGURE 6. Multituberculate morphotype MuC (UCMP specimen 153039, from locality V84193; left), in ventral (1) and dorsal (2) stereopair views, and in lateral (3), medial (4), and distal (5) views.

1983). The Bug Creek Anthills localities are mixed Lancian and Pu1 assemblages (Lofgren, 1995; Clemens, 2002). Stygimys kuszmauli is the only Pu1 taxon in this size range (body mass estimate = $210 \mathrm{~g}$ ), with the next closest candidate in size being the smaller Cimexomys gratus (body mass estimate $=110 \mathrm{~g}$ ); the only Lancian taxa in this size range is the slightly smaller Cimolodon nitidus (180 g; Wilson et al., 2012). Thus, we attribute these Pu1 and mixed-age MuE specimens to Stygimys kuszmauli (Deischl, 1964; Krause and Jenkins, 1983).

Distal humerus morphotype MuF (Figure 9). The six specimens in this morphotype are among the largest in our sample of K-Pg multituberculate humeri (mean TDW $=13.9 \mathrm{~mm}, \mathrm{SD}=0.23 \mathrm{~mm}$ ). Diagnostic features of this morphotype include: (i) a large, spherical radial condyle with a prominent, ventrolaterally flaring capitular tail that extends to nearly the lateral edge of the specimen; (ii) a small entepicondylar foramen relative to specimen size that is more distally displaced relative to the proximal extent of the ulnar condyle; (iii) a rugosity on the dorsomedial surface of the entepicondyle; and (iv) a pronounced, sharp medial margin of the ulnar condyle dorsally. Larger specimens in this morphotype (e.g., UCMP 174232) generally appear more robust, and specifically have a more rugose proximal surface of the olecranon fossa, which we attribute to differences in size. One specimen (UCMP 127384; Figure 9) has a pronounced distolaterally facing notch with a sharp proximal border proximal to the ulnar condyle on the ventral surface of the specimen (i.e., the location of the ulnar condyle dimple in MuB, MuC, MuE, and transverse depression in MuA). Because another specimen (UCMP 174400 ) has a slight depression in this same area, we suggest that this represents morphological variation of this feature within MuF.

These specimens are morphologically generalized and closely resemble humeri attributed to ?Stygimys kuszmauli from the Bug Creek Anthills, but are twice as large (Deischl, 1964; Krause and Jenkins, 1983). They also closely resemble the more fragmentary Lancian specimens attributed to ?Meniscoessus conquistus (Cope, 1884; Deischl, 1964) and ?Meniscoessus robustus (formerly ?Dipriodon lunatus; Marsh, 1889). The cimolomyid Meniscoessus robustus and ?cimolomyid Essonodon browni are the two largest multituberculate taxa present in Lancian deposits in our study area (Clemens, 2002; Wilson et al., 2014). We tentatively attribute these MuF specimens to the most abundant of these large Lancian multituberculates, 


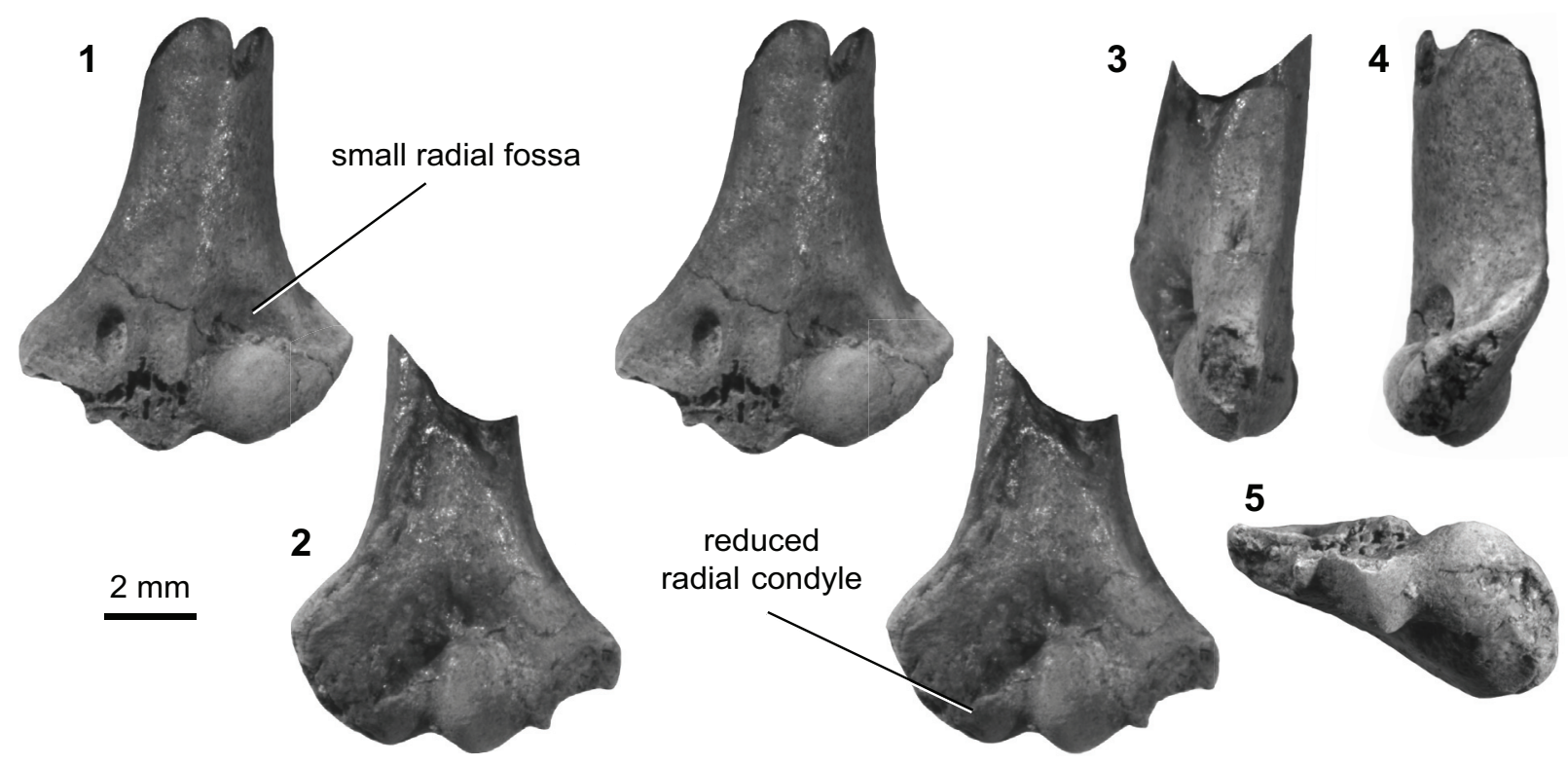

FIGURE 7. Multituberculate morphotype MuD (UCMP specimen 195990, from locality V5620; left), in ventral (1) and dorsal (2) stereopair views, and in medial (3), lateral (4), and distal (5) views.

Meniscoessus robustus (e.g., Wilson, 2005, 2014). A femur from eastern Montana (Museum of the

was previously attributed to this species (Hunter et al., 1997; DeBey and Wilson, 2014).

Rockies specimen MOR882, locality unknown), which is comparable in size to these MuF humeri,
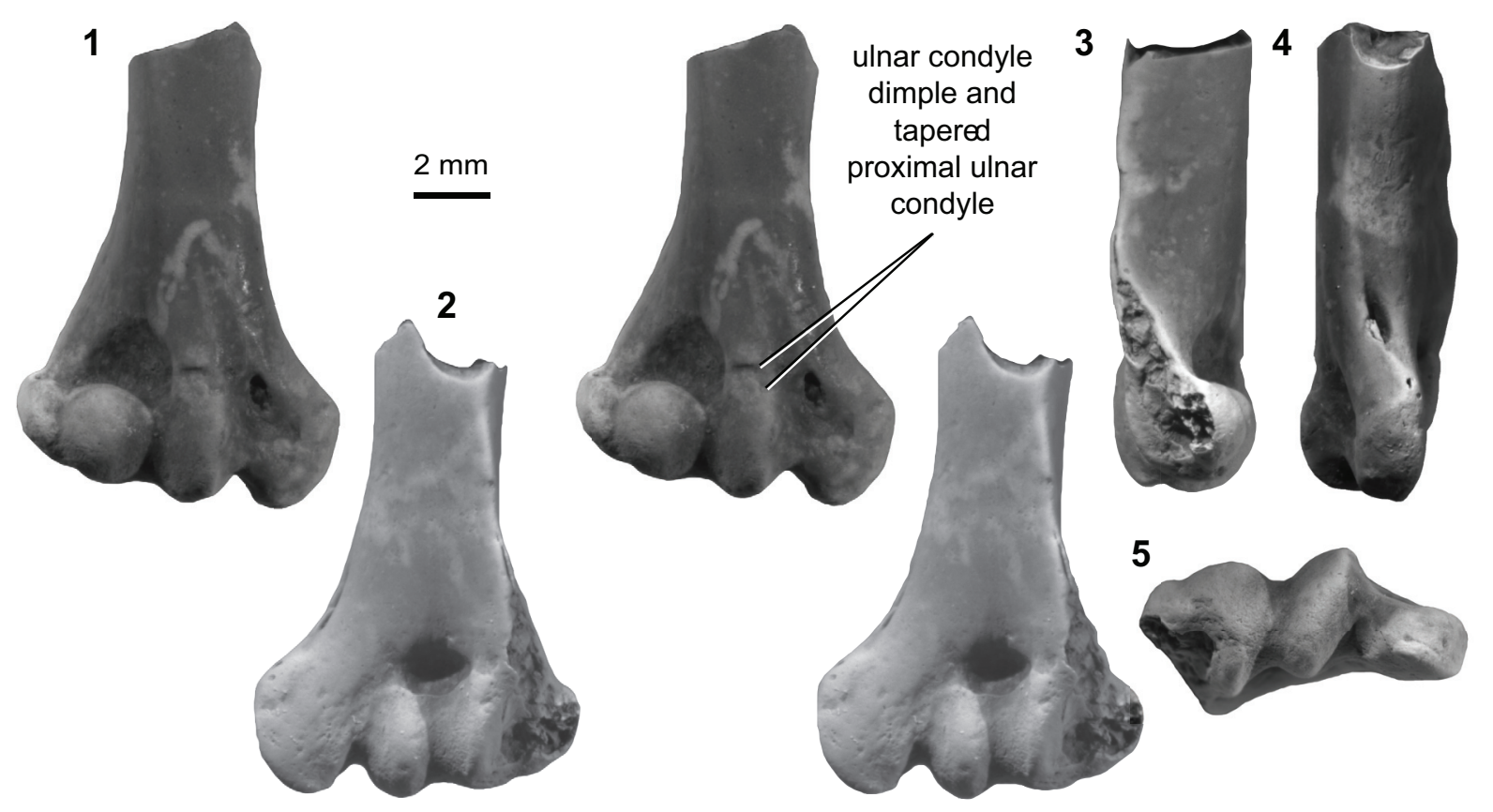

FIGURE 8. Multituberculate morphotype MuE (UWBM specimen 97031, from locality C1845; right), in ventral (1) and dorsal (2) stereopair views, and in lateral (3), medial (4), and distal (5) views. 

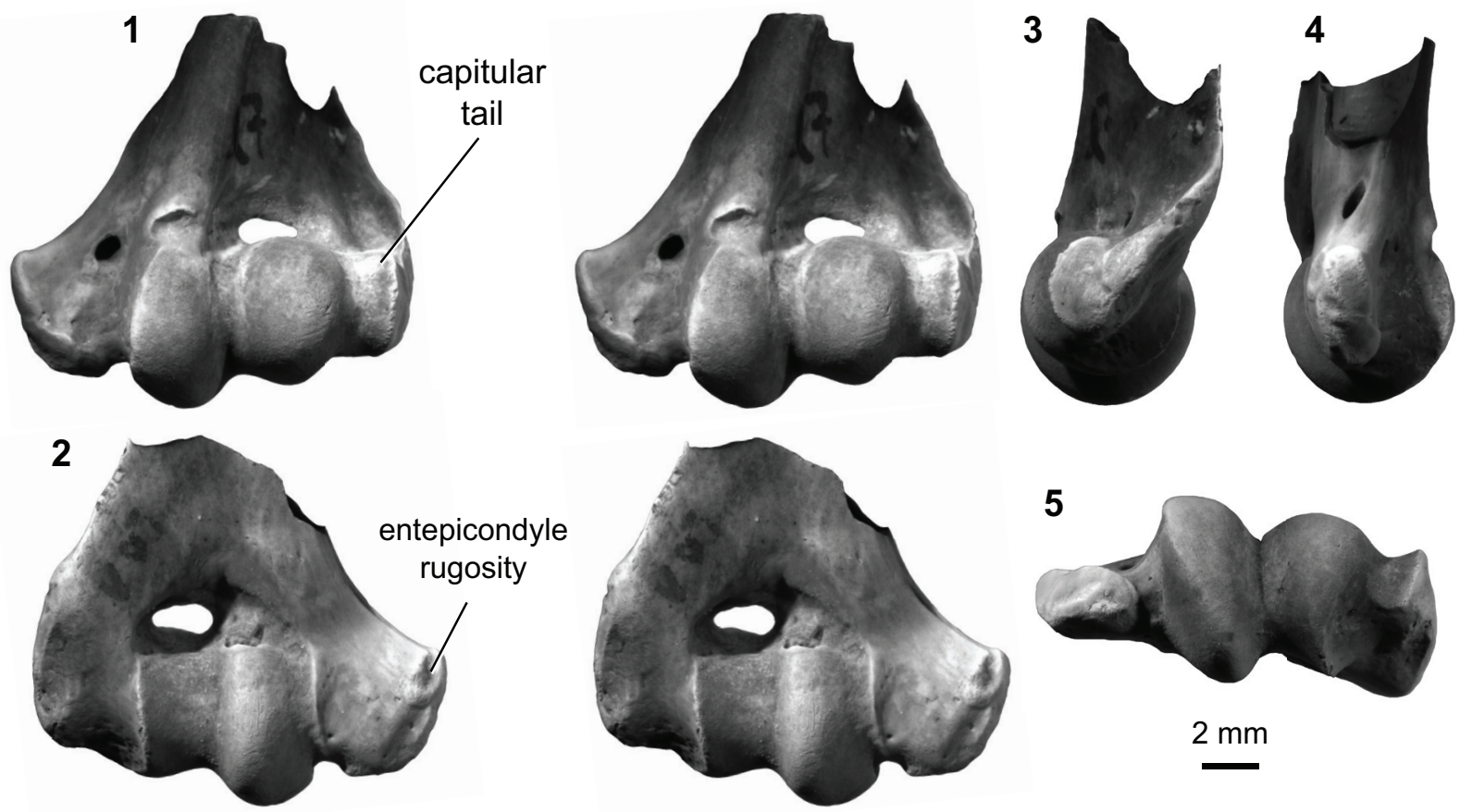

$2 \mathrm{~mm}$

FIGURE 9. Multituberculate morphotype MuF (UCMP specimen 127384, from locality V87001; left), in ventral (1) and dorsal (2) stereopair views, and in lateral (3), medial (4), and distal (5) views.

\section{Therian Distal Humeri}

Therian distal humeri are characterized by a trochlear articular surface, as opposed to the bulbous, condylar articular surface morphology of multituberculate humeri. Although in some more derived therians the entepi- and ectepicondyles are reduced and the entepicondylar foramen is lost (e.g., Rowe, 1988; Ji et al., 2002), our latest Cretaceous and earliest Paleogene therian specimens retain substantial entepi- and ectepicondyles and an entepicondylar foramen. Here, we attribute one Lancian fragmentary distal humerus to Theria; all other specimens are attributed to Metatheria or Eutheria.

Distal humerus morphotype ThA (Figure 10). This morphotype contains one fragmentary specimen, a very small left humerus that preserves only the entepicondyle and entepicondylar foramen, trochlea, and partial radial and olecranon fossae (minimum TDW $=4.9 \mathrm{~mm}$ ). Diagnostic features of this morphotype include: (i) a relatively large entepicondyle with a large elliptical entepicondylar foramen; (ii) a posterior surface between the entepicondyle and trochlea that is flat and lacks a dorsoepitrochlear fossa; and (iii) olecranon and radial fossae that are inferred to be shallow.
This very small Lancian specimen, although fragmentary, is morphologically unique among our specimens. The preserved entepicondylar and trochlear morphology indicate that it is not a multituberculate. The absence of a proposed metatherian synapomorphy (presence of a capitular tail; O'Leary et al., 2013), and other features common among Cretaceous and Paleogene metatherian humeri (e.g., spherical capitulum, zona conoidea articulation with the ulna, well-developed ectepicondylar crest; Szalay and Dagosto, 1980; Szalay and Trofimov, 1996; Szalay and Sargis, 2001; Argot, 2001; Chester et al., 2010) are missing in this specimen due to breakage and cannot be evaluated. Until more data are available, we provisionally refer it to Theria indet.

\section{Metatherian Distal Humeri}

Although metatherian distal humeri share some features with eutherian distal humeri, they are generally characterized by a relatively large, spherical capitulum with a capitular tail, a trochlea that is separated from the capitulum, and a relatively large and well-developed supinator crest with a sigmoid profile (Szalay and Dagosto, 1980; Szalay and Trofimov, 1996; Argot, 2001; Szalay and Sargis, 2001; Luo et al., 2003; Chester et al., 2010; O'Leary et al., 2013; Williamson et al., 2014). Here, 


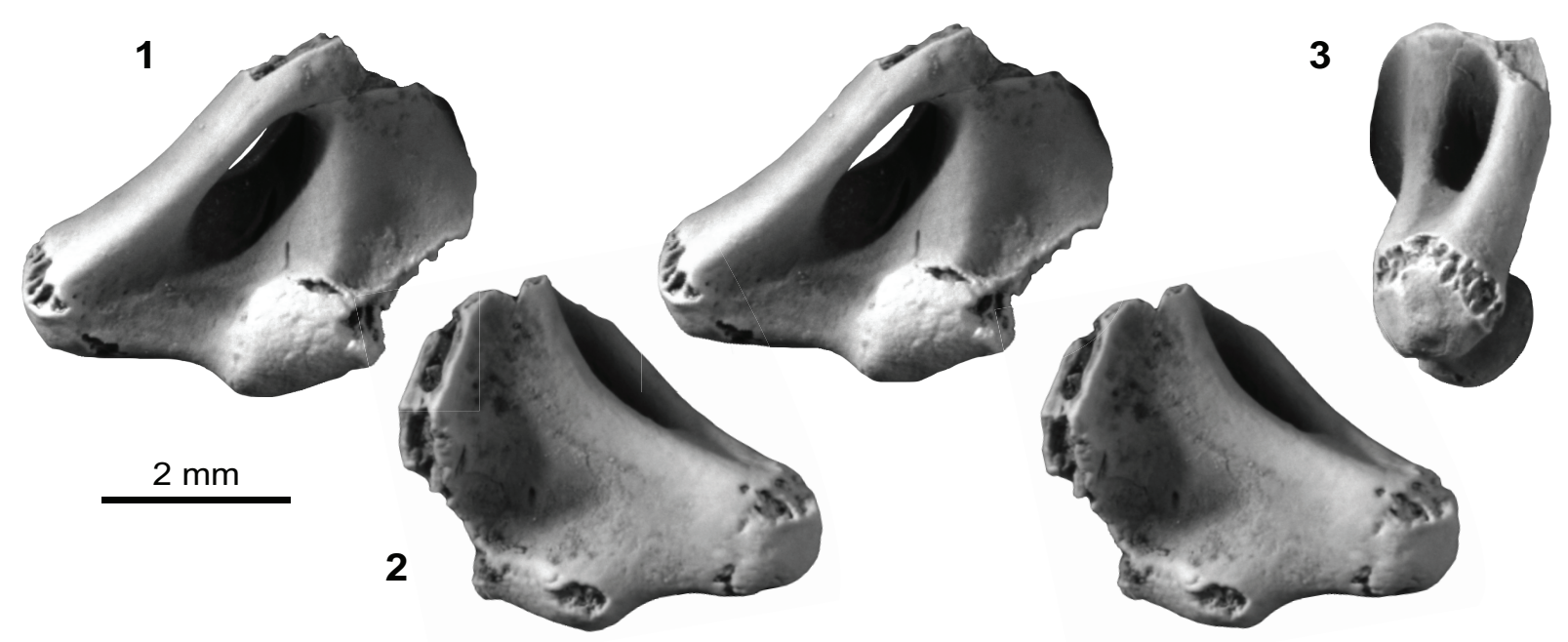

FIGURE 10. Therian morphotype ThA (UCMP specimen 127391, from locality V88007; left) in anterior (1) and posterior (2) stereopair views, and in medial (3) view.

we attribute one Lancian distal humerus to Metatheria.

Distal humerus morphotype MeA (Figure 11). The left humerus (UCMP 152394) attributed to this morphotype is relatively large (minimum TDW = $18.2 \mathrm{~mm}$ ). Proximally, it preserves the narrowest portion of the mid-shaft and the distal extent of the deltopectoral shelf; distally this specimen preserves $80-90 \%$ of the supinator crest, the proximal portion of the entepicondylar foramen, and the proximal extent of the olecranon fossa; this specimen lacks the distal epiphysis, entepicondyle, and the lateral, natural edge of the supinator crest. The diagnostic feature for this morphotype is a very pronounced, laterally extensive supinator crest that is sigmoid in profile and that contains a hypertrophied process on the proximal margin.

Relative to extant material, this specimen broadly resembles humeri of Didelphis spp. in morphology and size. It differs from Didelphis in being more squat (proximodistally compressed), and from Didelphis and other extant marsupial taxa in having a larger, more robust, and more medially extensive supinator crest (e.g., Argot, 2001; Szalay and Sargis, 2001; Flores, 2009). The proximal process of the supinator crest of this specimen is much more developed than it is in Didelphis, more closely resembling other didelphids, such as Monodelphis and Caluromys (Figure 11; Argot, 2001; Szalay and Sargis, 2001; Flores, 2009). This specimen is the largest Lancian humerus in our sample; it has a TDW more than $1.5 x$ that of the largest Lancian multituberculate. The only mammal in this size range is Didelphodon vorax, the largest Cretaceous therian (Clemens, 2002; Wilson, 2013, 2014; Wilson et al., 2016). Marsh (1889, plate V, figures 5-6) reported a distal humerus from the latest Cretaceous of Wyoming (Lance Formation) that he tentatively attributed to Didelphodon vorax (Appendix 4). However, our specimen greatly differs from the published image in the shape of the supinator crest proximally, as well as in overall size; the TDW ( 8-10 $\mathrm{mm})$ that we estimated from the figure is half the size of our specimen, but we are not confident that the listed scaling factor is correct (x2, Marsh, 1889). If the specimen figured by Marsh (1889) in fact belongs to Didelphodon vorax, then it might differ from MeA because it is from an immature individual, it is broken at the proximal supinator crest, and/or the species is sexually dimorphic in size and shape (personal observation, Wilson, 2015). Regardless of Marsh's attribution, the large size of UCMP 152394 warrants an attribution of the MeA morphotype to ?Didelphodon.

\section{Eutherian Distal Humeri}

We compared our fossils with a broad sample of extant eutherians and with Cretaceous, Paleocene, and Eocene fossil taxa. Postcranial synapomorphies for eutherians are not well defined; however, there are some features that are generally shared among eutherians, including a single, continuous articular surface (in contrast to the separated trochlea and capitulum in metatherians) and the presence of a dorsoepitrochlear pit or fossa 

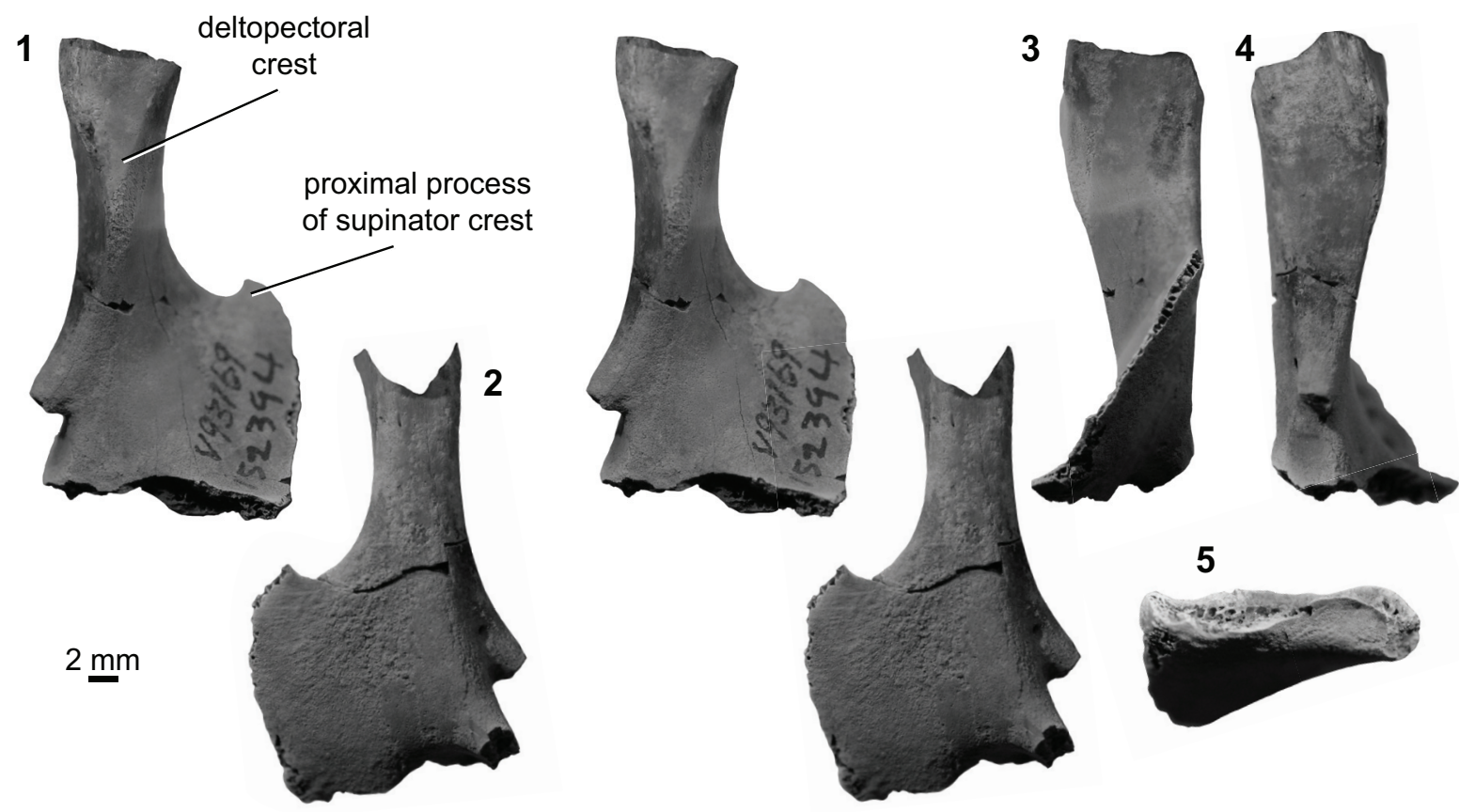

FIGURE 11. Metatherian morphotype MeA (UCMP specimen 152394, from locality V93169; left) in anterior (1) and posterior (2) stereopair views, and in lateral (3), medial (4), and distal (5) views.

(i.e., in some archaic ungulates and early primates; Szalay et al., 1975; Szalay and Dagosto, 1980; Horovitz, 2003; Luo et al., 2003; Boyer et al., 2010; Chester et al., 2010; Hooker et al., 2014). Here, we describe and attribute to Eutheria one Lancian, one Pu1, and four Pu3 specimens, as well as 11 specimens of Lancian-Pu1 mixed-age (Bug Creek Anthills assemblages; Table 3 ).

Distal humerus morphotype EuA (Figure 12). The specimen in this morphotype (UCMP 153100) is among the smaller eutherian specimens in our sample (minimum TDW $=\sim 6.4 \mathrm{~mm}$ ); it preserves the complete distal surface (except for the medial extent of the entepicondyle) and a substantial portion of the shaft. Diagnostic features of this morphotype include: (i) the presence of a small and relatively shallow dorsoepitrochlear fossa (especially compared to e.g., EuC); (ii) a trochlea and capitulum that are separated by a deep zona conoidea, and that are approximately equal in the mediolateral width (trochlea slightly narrower); (iii) a subspherical capitulum with a capitular tail; (iv) a large, circular entepicondylar foramen (mediolaterally wider than in EuB); (v) a shallow border separating the radial fossa from the entepicondyle (proximal to the trochlea); (vi) a large and posteriorly projecting supinator crest; (vii) a trochlea that is proximodistally short and mediolaterally narrow posteriorly; and (viii) a proximodistally tall, shallow olecranon fossa.

UCMP 153100 resembles plesiadapiform and early euprimate distal humeri more closely than it does any published archaic ungulate, "insectivoran," or larger mammalian humeri from the Paleocene of North America (Matthew, 1937; Szalay and Dagosto, 1980; Rigby, 1981; Schoch, 1986; Boyer et al., 2010; Kondrashov and Lucas, 2012; Argot, 2013; Appendix 4). Specifically, in anterior view, the dorsal trochlea morphology, subspherical capitulum, relative proportions of the trochlea and capitulum, and extended entepicondyle all resemble Paleocene plesiadapiforms more than larger specimens from our study area attributed to ?Protungulatum and ?Procerberus (Simpson, 1935; Szalay et al., 1975; Szalay and Dagosto, 1980; Bloch et al., 2007; Boyer et al., 2010; Appendix 4). In posterior view, the short and narrow trochlea, dorsoepitrochlear foramen, and olecranon fossa also more closely resemble Paleocene plesiadapiforms than specimens attributed to ?Protungulatum and ?Procerberus (Simpson, 1935; Szalay et al., 1975; Szalay and Dagosto, 1980; Bloch et al., 2007; Boyer et al., 2010; Appendix 4). Three plesiadapiform taxa (Purgatorius unio, Purgatorius janisae, and Pandemonium dis) have been described from the Pu3 in our study area. We hypothesize that EuA rep- 


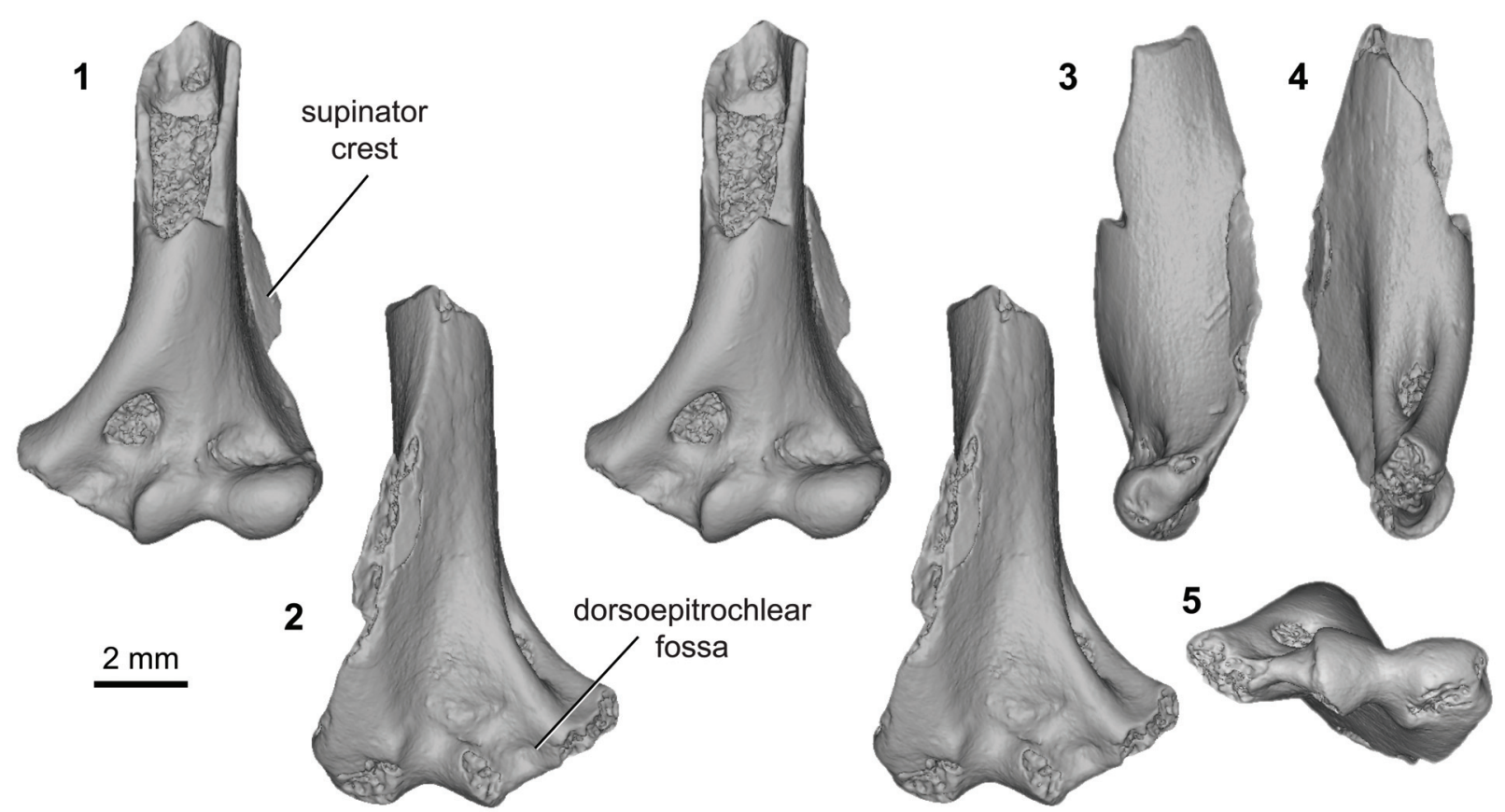

FIGURE 12. Eutherian morphotype EuA (UCMP specimen 153100, from locality V99438; left) in anterior (1) and posterior (2) stereopair views, and in lateral (3), medial (4), and distal (5) views. Specimen images are CT scan views, not photographs; see Methods for details. Rough patches inside the shaft and within the entepicondylar foramen are the result of sediment infilling, whereas other rough areas (i.e., supinator crest, medial entepicondyle, posterior articular surfaces) indicate specimen breakage.

resents a plesiadapiform primate, and specifically, refer it to Purgatorius sp. because this genus is the most abundant plesiadapiform in our Pu3 assemblages (Clemens, 2002, 2004; Wilson, 2014). This is consistent with the presence of teeth and isolated tarsals that have been found at this locality and attributed to Purgatorius (Clemens, 2002, 2004; Wilson, 2014; Chester et al., 2015).

Distal humerus morphotype EuB (Figure 13). This morphotype is represented by one small distal humerus specimen (UWBM 97114) that is $\sim 80-$ $90 \%$ complete, missing only the terminal ends of the entepicondyle and ectepicondyle (minimum TDW = $8.53 \mathrm{~mm}$; Figure 13). The diagnostic features of this morphotype are (i) a rugosity medial to the trochlea on the anterior surface, which has three ridges that extend from the medial edge of the trochlea on to the entepicondyle, each ridge with a pock-like, indented texture; (ii) a very large entepicondyle, with a more exaggerated medial extent than in other eutherian specimens (apparent even in this broken state); (iii) a distal concavity on the posterior surface, that extends medially from the entepicondyle and that becomes less pronounced and ultimately disappears laterally; (iv) a bulbous trochlea (anteriorly) that is $\sim 50-60 \%$ of the capitulum width, and is therefore larger (mediolat- erally and proximodistally) than in other eutherians in our sample (e.g., EuA and EuD); (v) a trochlea (posteriorly) that is mediolaterally narrow relative to specimen distal width; and (vi) a shallow, proximodistally short olecranon fossa that is not perforated. This specimen lacks a dorsoepitrochlear fossa. The medial extent of the entepicondylar rugosity cannot be determined due to specimen breakage.

The Lancian morphotype EuB differs greatly from published humeri material, especially in the expanded entepicondyle and morphology of the olecranon fossa, from our study area (e.g., Bug Creek Anthills material attributed to ?Protungulatum donnae and ?Procerberus formicarum; Szalay and Dagosto, 1980; Boyer et al., 2010; Appendix 4), younger "insectivoran" material (e.g., leptictid cf. Prodiacodon tauricinerei; Rose, 1999; Appendix 4), and older eutherian material (e.g., Barunlestes, Ukhaatherium; Horovitz, 2003; Kielan-Jaworowska, 2009; Chester et al., 2010). Unfortunately, there are no other latest Cretaceous eutherian humeri for comparisons. UWBM 97114 does not possess a capitular tail, a feature that independently arose multiple times, for example, in Metatheria, Afroinsectivora, and Euarchonta (Sargis, 2002; O'Leary et al., 2013; Williamson et al., 


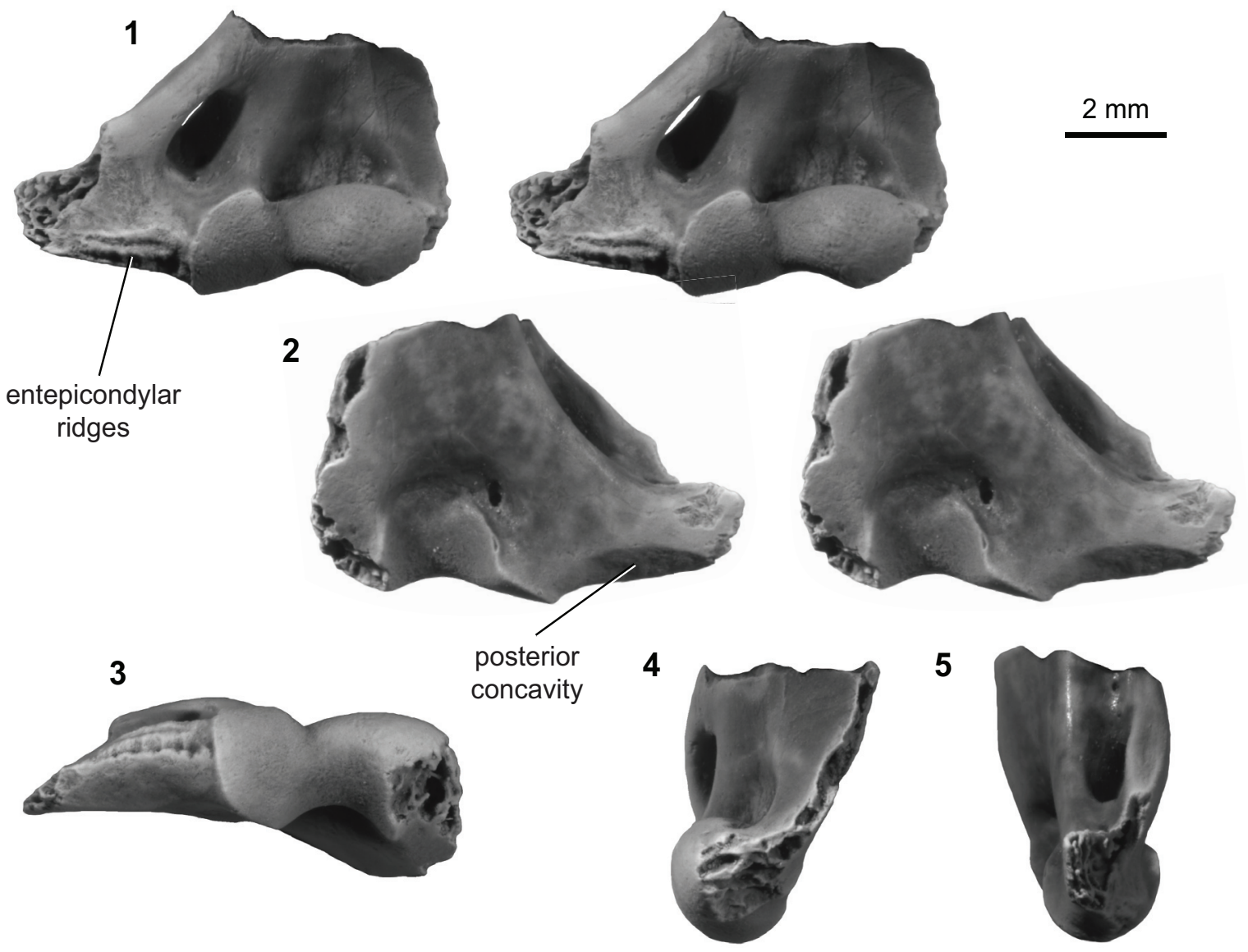

FIGURE 13. Eutherian morphotype EuB (UWBM specimen 97114, from locality C1115; left) in anterior (1) and posterior (2) stereopair views, and in distal (3), lateral (4), and medial (5) views.

2014); the morphology of its entepicondyle, trochlea, and capitulum also differs greatly from the Paleocene Mayulestes and Pucadelphys as well as some extant marsupials, including didelphids (Caluromys, Chironectes, Didelphis, Metachirus), the microbiotherian Dromiciops, and the caenolestid Rhyncholestes (Marshall et al., 1995; Muizon, 1998; Argot, 2001; Szalay and Sargis, 2001; Flores, 2009; Chester et al., 2010). Superficially, EuB most closely resembles extant semi-fossorial tenrecs Oryzorictes sp. in the extreme medial extension of the entepicondyle; however, breakage in EuB prevents comparison with the bulbous nature of the entepicondyle medial extent in Oryzorictes sp. (Salton and Sargis, 2008). Among small eutherian taxa present in the Lancian of our study area, two species of Gypsonictops, and five species of cimolestid Cimolestes are plausible candidate taxa; the small palaeoryctid Batodon tenuis is too small to be a candidate taxon for this morphotype (Clemens, 2002; Wilson, 2014).
Distal humerus morphotype EuC (Figure 14). Specimens in this morphotype (TDW $=9.52 \mathrm{~mm}$ ) have a large and robust entepicondyle, a deep olecranon fossa, proximodistally tall articular surface (in posterior view), and a spindle-shaped capitulum that is approximately three times wider than the mediolaterally narrow trochlea. Diagnostic features of this morphotype include: (i) a pronounced, deep, and round dorsoepitrochlear fossa on the posterior surface; (ii) a prominent medial trochlear keel and proximomedial trochlear lip on the anterior surface; (iii) a sharp and prominent crest extending proximally from the medial edge of the trochlea, delineating the boundary between the radial fossa medially and the entepicondylar foramen laterally; (iv) an entepicondylar foramen that does not extend distally beyond the proximal extent of the capitulum; $(v)$ an entepicondyle that is larger anteroposteriorly in distal view than in morphotype EuD; and (vi) a humerus shaft that has a supinator crest that displays undulation of the lat- 
eral margin (preserved in specimen UCMP 151991; Figure 14).

Of all comparative material we examined, the specimens in this morphotype exactly match those attributed to ?Protungulatum donnae (Szalay and Dagosto, 1980; Boyer et al., 2010; Appendix 4). However, dental specimens of four other archaic ungulates that are similar in size and dental morphology to Protungulatum donnae are known from similarly aged deposits in this area: Protungulatum gorgun, two species of the periptychid Mimatuta (M. morgoth and M. minuial), and the arctocyonid Oxyprimus erikseni (Luo, 1991; Wilson, 2004, 2013, 2014). In fact, Protungulatum and Mimatuta are both known from the mixed and early Puercan localities where these humeri were found (from UCMP locs. V71203 and V74111, respectively; Archibald, 1982; Wilson, 2004, 2014). As such, the rationale is unclear for why so many specimens that resemble EuC were attributed to ?Protungulatum rather than some combination of these five archaic ungulate species (Rigby, 1981). It might point to identification bias that stemmed from one or more factors: (1) Protungulatum was the first genus of archaic ungulate named from the early Puercan (Sloan and Van Valen, 1965), whereas Mimatuta and Oxyprimus were named over a decade later (Van Valen, 1978); (2) many institutions contain older collections from Pu1 assemblages in which specimens were attributed to Protungulatum, and (3) Protungulatum, on the basis of dental material, was the most abundant of these three taxa (Wilson, 2004). Until a humerus is found in association with dental specimens of one of these five taxa, we recommend that isolated humeri referable to the EuC morphotype be attributed to archaic ungulate indet. rather than to a lower taxon. This logic also applies to other isolated postcranial elements previously attributed to Protungulatum.

Distal humerus morphotype EuD (Figure 15). This morphotype is represented by five specimens (plus an additional five specimens tentatively attributed to EuD) from two to three Bug Creek localities with temporally mixed ages (see note below on tentative assignments). Specimens in this morphotype are approximately the same size as those in EuC (EuD TDW mean $=9.58 \mathrm{~mm}, \mathrm{SD}=$ $0.50 \mathrm{~mm}, \mathrm{n}=2$; Figure 15). Diagnostic features of this morphotype include: (i) a large and mediolaterally wide entepicondyle that is less robust than in other morphotypes of similar size (i.e., EuC); (ii) a relatively large entepicondylar foramen that is ovoid (rather than long and thin, as in EuC); (iii) a pronounced and rounded supinator crest that is curved posterolaterally and that greatly expands the anteroposterior width of the specimen compared to other morphotypes (e.g., EuC); (iv) a mediolaterally wide but proximodistally short olecranon fossa, resulting in a squat appearance; and (v) an articular surface that is mediolaterally wider and proximodistally shorter than in EuC, and that contains a lateral flange of the capitulum (Boyer et al., 2010). Additionally, the more completely preserved shaft of UCMP 151946 (Figure 15) has two ridges: one dorsal to and continuous with the entepicondyle and a second on the anterior shaft (i.e., the distal extent of the pectoral crest).

Some specimens have all the diagnostic features of the shaft listed above and include the proximal portions of the entepicondylar foramen and olecranon fossa; however, they are missing articular surfaces (and in some cases, the entire distal epiphysis). We therefore tentatively assign these to morphotype EuD (Table 3).

EuD morphology resembles that of similarly sized humeri attributed to ?Protungulatum donnae and ?Procerberus formicarum in having a trochlea and capitulum that are continuous and are separated by a wide and shallow margin (Szalay and Dagosto, 1980; Boyer et al., 2010; Appendix 4). EuD is more similar to specimens of ?Procerberus than to those of ?Protungulatum in having a proximodistally short trochlea and in lacking a dorsoepitrochlear pit (Szalay and Dagosto, 1980; Boyer et al., 2010; Appendix 4). EuD specimens bear little resemblance to humeri of much larger Paleocene taxa from the San Juan Basin (e.g., taeniodonts, tillodonts, periptychids, or arctocyonids, or the larger pantodont Pantolambda; Matthew, 1937; Schoch, 1986; Kondrashov and Lucas, 2012; Appendix 4). The EuD specimens generally resemble those of the Eocene leptictid Prodiacodon (Rose, 1999; Appendix 4), but most closely resemble those attributed to the Pu1 cimolestid Procerberus formicarum (Szalay and Dagosto, 1980; Boyer et al., 2010; Wilson, 2014).

As with morphotype EuC, we caution against attributing this morphotype to the cimolestid Procerberus formicarum because of the presence of other similarly-sized taxa at the same time and in the same place (Archibald, 1982; Lofgren, 1995; Wilson, 2004, 2013, 2014). This issue is further complicated by the fact that all of our EuD specimens, and all morphologically similar specimens from the literature (Szalay and Dagosto, 1980; Boyer et al., 2010; Appendix 4), are from the temporally mixed assemblages of the Bug Creek Ant- 


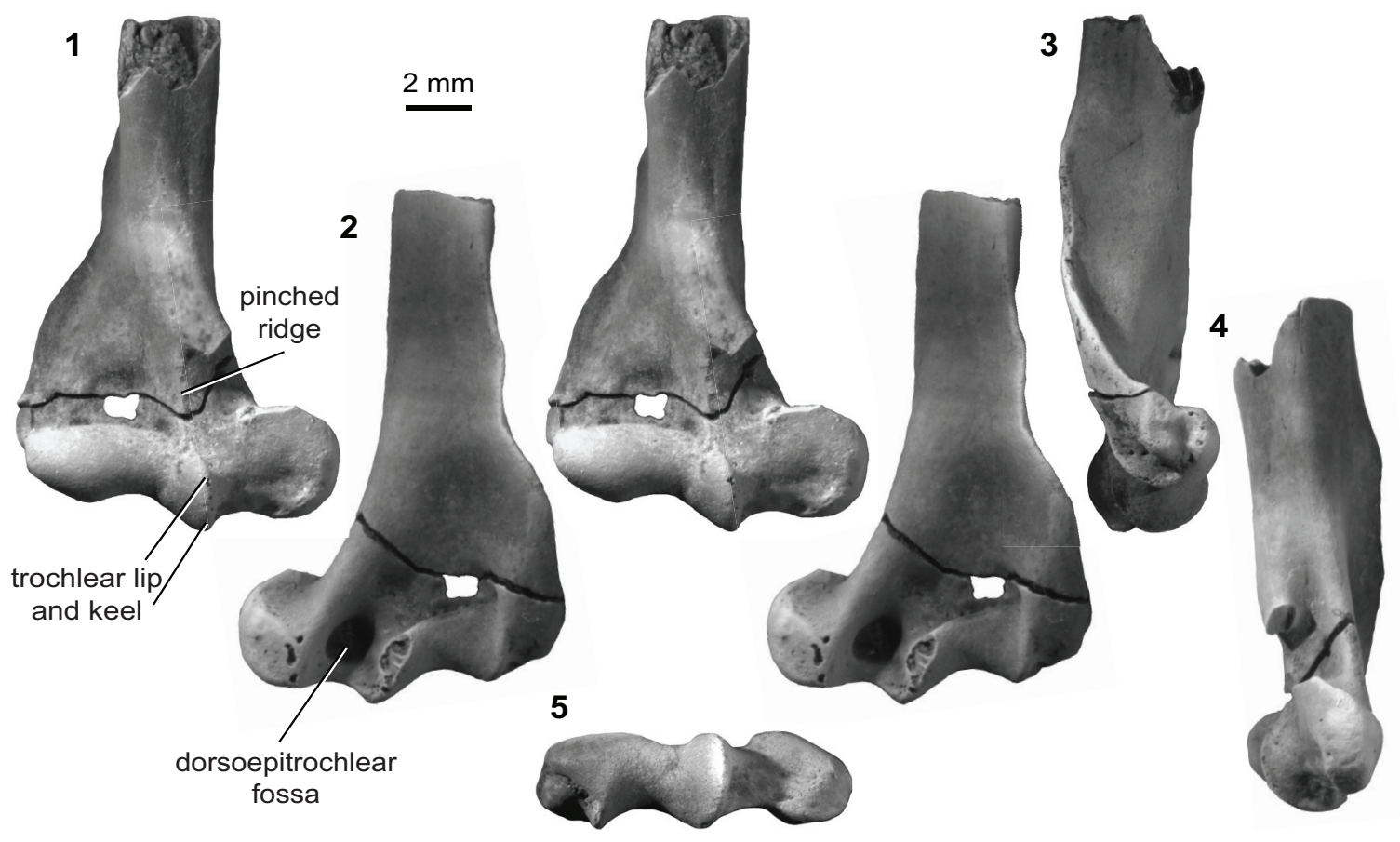

FIGURE 14. Eutherian morphotype EuC (UCMP specimen 151991, from locality V71203; right) in anterior (1) and posterior (2) stereopair views, and in lateral (3), medial (4), and distal (5) views.

hills; thus, they could be Lancian or Pu1 in age. Eutherian candidate taxa present in our study area include the leptictidans Gypsonictops sp. (Lancian) and Prodiacodon sp. A (Pu1), and cimolestids Cimolestes (Lancian and Pu1) and Procerberus sp. (Pu1; Archibald, 1982; Lofgren, 1995; Wilson, 2004, 2014; Clemens, 2015). In fact, Gypsonictops, Cimolestes, and Procerberus have been found at the Bug Creek Anthills (Archibald and Clemens, 1984). Others have commonly referred specimens matching this morphotype to Procerberus, perhaps because (i) Procerberus sp. was the first "insectivoran" named from the study area (Sloan and Van Valen, 1965); (ii) humeri specimens were attributed to this taxon in museum collections and the attributions were propagated by subsequent researchers; and (iii) Procerberus, on the basis of dental evidence, was the most abundant mammal in Pu1 assemblages (Wilson, 2014). Nevertheless, given the multiple candidate taxa for this morphotype and the lack of associated skeletal and dental material of Procerberus (Rigby, 1981), we do not assign EuD to a particular taxon.

Distal humerus morphotype EuE (Figure 16). This morphotype is represented by two right humeri that preserve nearly the complete distal surface, missing only the medial extent of the entepicondyle (minimum mean TDW $=16.48 \mathrm{~mm}$, $\mathrm{SD}=2.05 \mathrm{~mm}, \mathrm{n}=2$ ). Diagnostic features of this morphotype include: (i) a large, deep, and circular dorsoepitrochlear fossa; (ii) a large, spindleshaped capitulum that is $\sim 3 x$ the size of the trochlea; (iii) a large, ellipsoidal entepicondylar foramen with a slightly bulbous appearance at the proximal portion of the thin entepicondylar bridge; (iv) a pronounced proximal border of the trochlea on the posterior surface of the specimen, similar to that in EuF; (v) a mediolaterally and proximodistally large albeit shallow radial fossa, also similar to that of EuF; (vi) a pronounced supinator crest that is reflected more posteriorly than in EuF; and (vii) a moderately deep olecranon fossa that is not perforated. This morphotype is very similar to morphotype EuF; however, because EuE is about half the size of EuF, and many features are differentially preserved, we treat these morphotypes as separate at this time.

Relative to comparative taxa, EuE is morphologically similar to humeri attributed to ?Protungulatum donnae, despite the difference in size (i.e., 


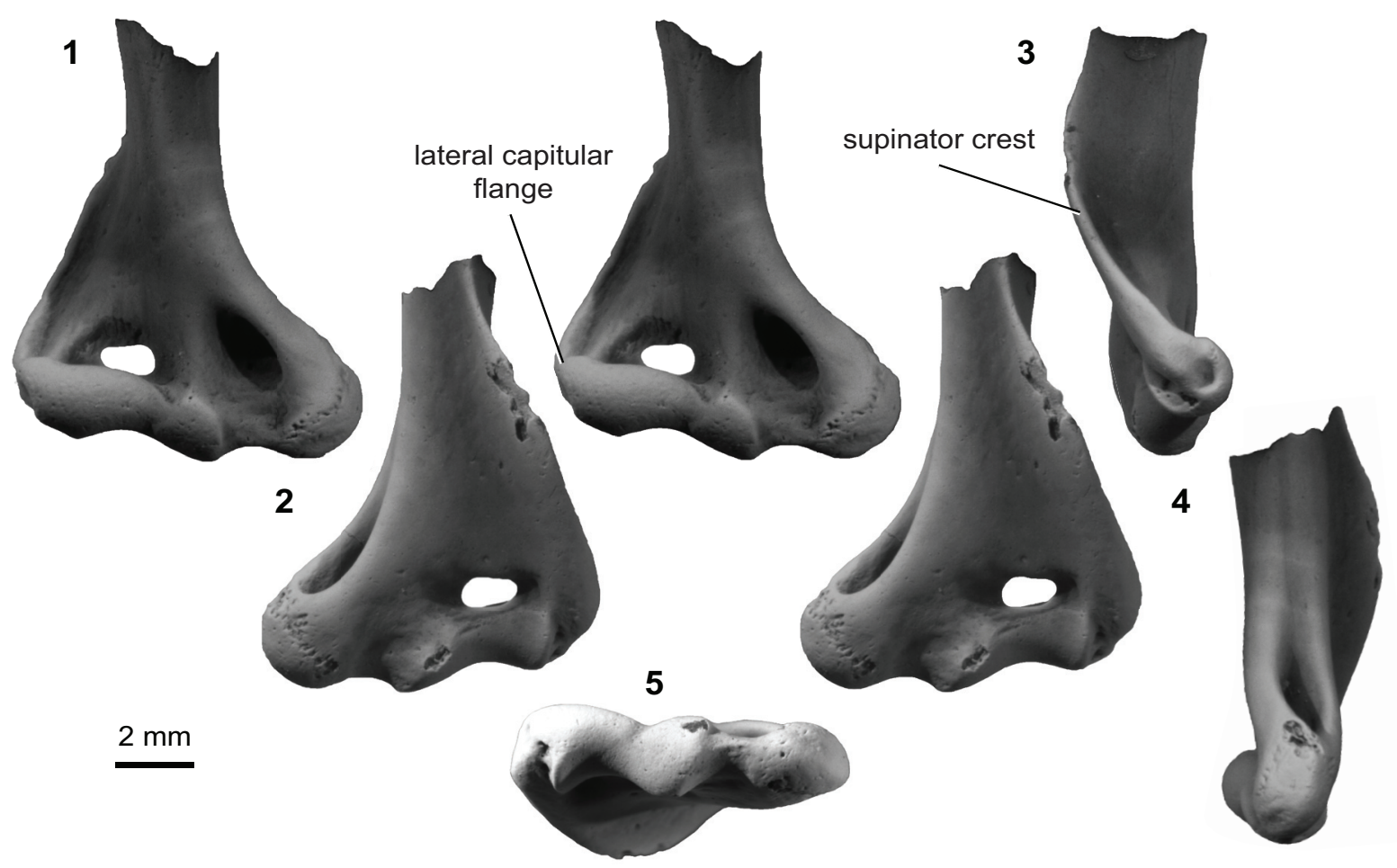

FIGURE 15. Eutherian morphotype EuD (UCMP specimen 151964, from locality V65127; right) in anterior (1) and posterior (2) stereopair views, and in lateral (3), medial (4), and distal (5) views.

EuE is $\sim 1.5 x$ larger than ?Protungulatum specimens; Szalay and Dagosto, 1980; Boyer et al., 2010; Appendix 4). Among the diagnostic features of EuE, the very deep dorsoepitrochlear foramen has so far only been observed in specimens attributed to ?Protungulatum and early primates (Szalay and Dagosto, 1980; Boyer et al., 2010; Appendix 4). Also, the morphology of the olecranon and radial fossae, articular surface, entepicondyle and ectepicondyle, and entepicondylar foramen closely match specimens attributed to ?Protungulatum (Szalay and Dagosto, 1980; Boyer et al., 2010; Appendix 4). However, EuE differs from those specimens in having a larger entepicondylar foramen with a narrower entepicondylar bridge, a wider proximal surface of the trochlea, a larger olecranon fossa posteriorly, and a larger and more pronounced fossa laterally on the ectepicondyle surface (Szalay and Dagosto, 1980; Boyer et al., 2010). EuE and Paleocene archaic ungulates (e.g., Arctocyon, Periptychus) share a few general features, including a wide distal end, a proximally extensive anterior trochlear surface, a lateral capitular flange, and a distal notch between the capitulum posterior articular surface and the ectepicondyle (Matthew, 1937; Argot, 2013; Appendix 4). Yet, some features distinguish EuE from these comparative taxa. For example, the large, ovoid entepicondylar foramen, larger and more laterally extensive and posteriorly reflected supinator crest, and proximodistally shorter and shallower olecranon fossa of EuE differ from those of many comparative archaic ungulate taxa (e.g., Loxolophus, Arctocyon, Periptychus, and Ectoconus; Matthew, 1937; Russell, 1964; Argot, 2013; Appendix 4). Compared to other large therian candidate taxa, we find EuE bears little resemblance to humeri of younger Paleocene tillodont (Deltatherium; Matthew, 1937; Kondrashov and Lucas, 2012), pantodont (Pantolambda; Matthew, 1937), and taeniodont taxa (e.g., Onychodectes, Ectoganus, Lampadophorous, Psittacotherium, Stylinodon; Matthew, 1937; Schoch, 1986; Appendix 4). On the basis of similarities with archaic ungulate taxa that we examined, we suggest that EuE represents an archaic ungulate taxon; given the large size of this specimen and its unique morphology, we suggest that it is attributable to a large archaic ungulate whose humeri are currently unknown. The only candidate taxon present in both Pu1 and 


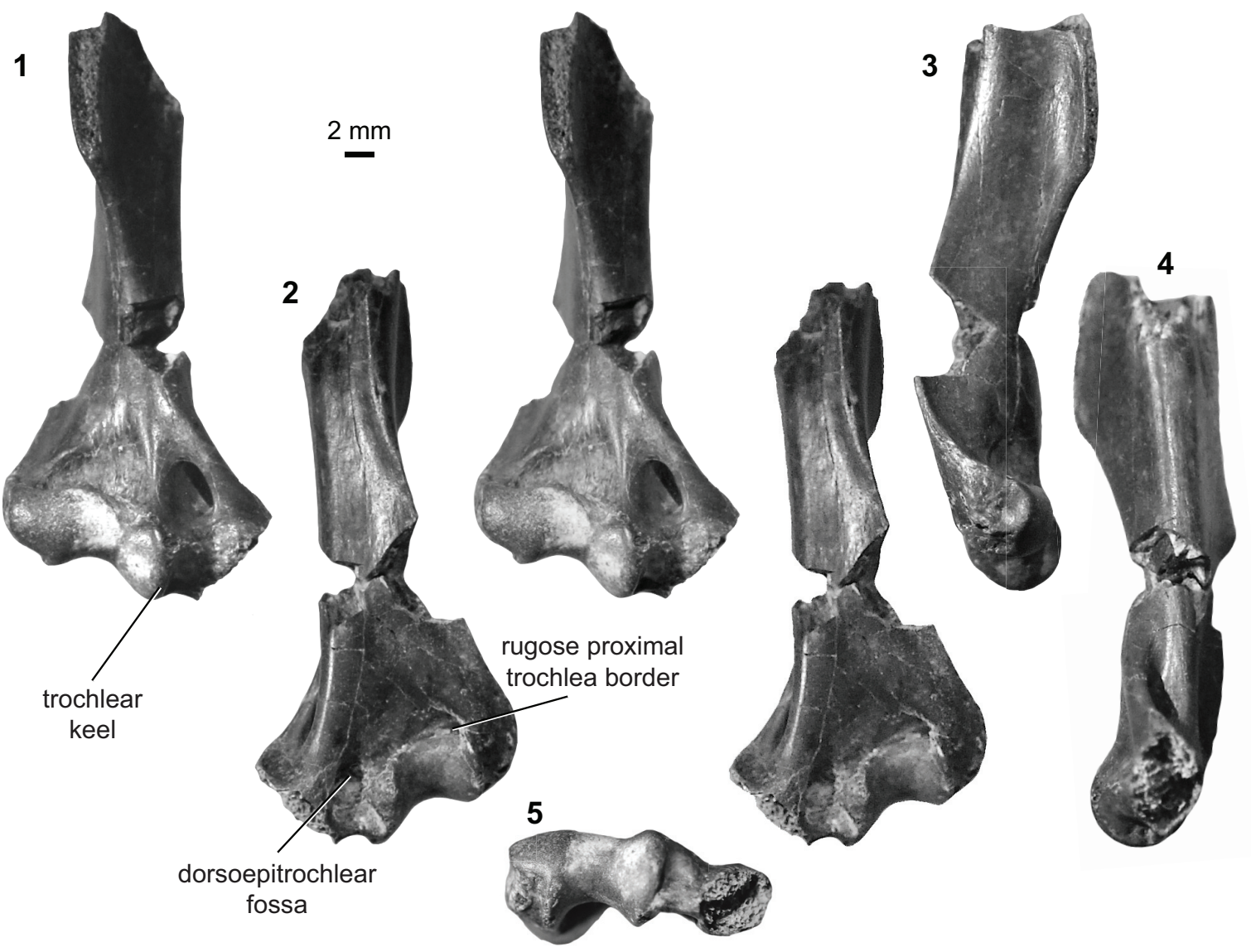

FIGURE 16. Eutherian morphotype EuE (UCMP specimen 218901, from locality V91065; right) in anterior (1) and posterior (2) stereopair views, and in lateral (3), medial (4), and distal (5) views.

Pu3, and in this size category, is Baioconodon sp. (Clemens, 2002; Wilson, 2014); thus we tentatively assign this morphotype to Baioconodon. Indeed, a lower third molar (m3) of Baioconodon (Clemens, personal communication) is known from the locality where an EuE specimen (UCMP 218901) was recovered.

Distal humerus morphotype EuF (Figure 17). This specimen (UCMP 153089), a partial right humerus, is the most complete among the larger eutherian distal humeri in our sample (minimum TDW = $19.4 \mathrm{~mm}$; Figure 17). Diagnostic features of this specimen include: (i) a trochlea that is proximodistally tall, distally extensive, with a fairly flat (not especially convex) lateral distal surface; (ii) a very large trochlear keel, with a smooth and concave facet on the medial surface; (iii) a spindleshaped capitulum that is proximolaterally bulbous, mediolaterally wide ( $\sim 3 x$ the width of the trochlea), and has a slight capitular tail; (iv) a very large, deep, and rugose fossa on the posterior aspect of the ectepicondyle; ( $v$ ) a pronounced, raised, and rugose margin on the proximal trochlea in posterior view, as in EuE; and (vi) a mediolaterally wide olecranon fossa composed of very thin bone that is perforated in the center.

Among the diagnostic features of EuF, the semilunar-shaped radial fossa is found in smaller humeri specimens that have been attributed to ?Protungulatum (Szalay and Dagosto, 1980; Boyer et al., 2010); whereas the proximodistally tall olecranon fossa and the small fossa on the medial surface of the trochlea are not found in any of the comparative material that we examined. That said, EuF has a number of features on the distal humerus in common with humeri of younger taxa. Specifically, it resembles humeri of larger arctocyonids Arctocyon primaevus and A. corrugatus (formerly Claenodon corrugatus) in capitulum and trochlear morphology and in the presence of a capitular flange; however, EuF has a relatively wider capitulum, with a more shallowly sloping distolateral trochlear margin (Matthew, 1937; Russell, 1964; Argot, 2013; Appendix 4). EuF also shares 


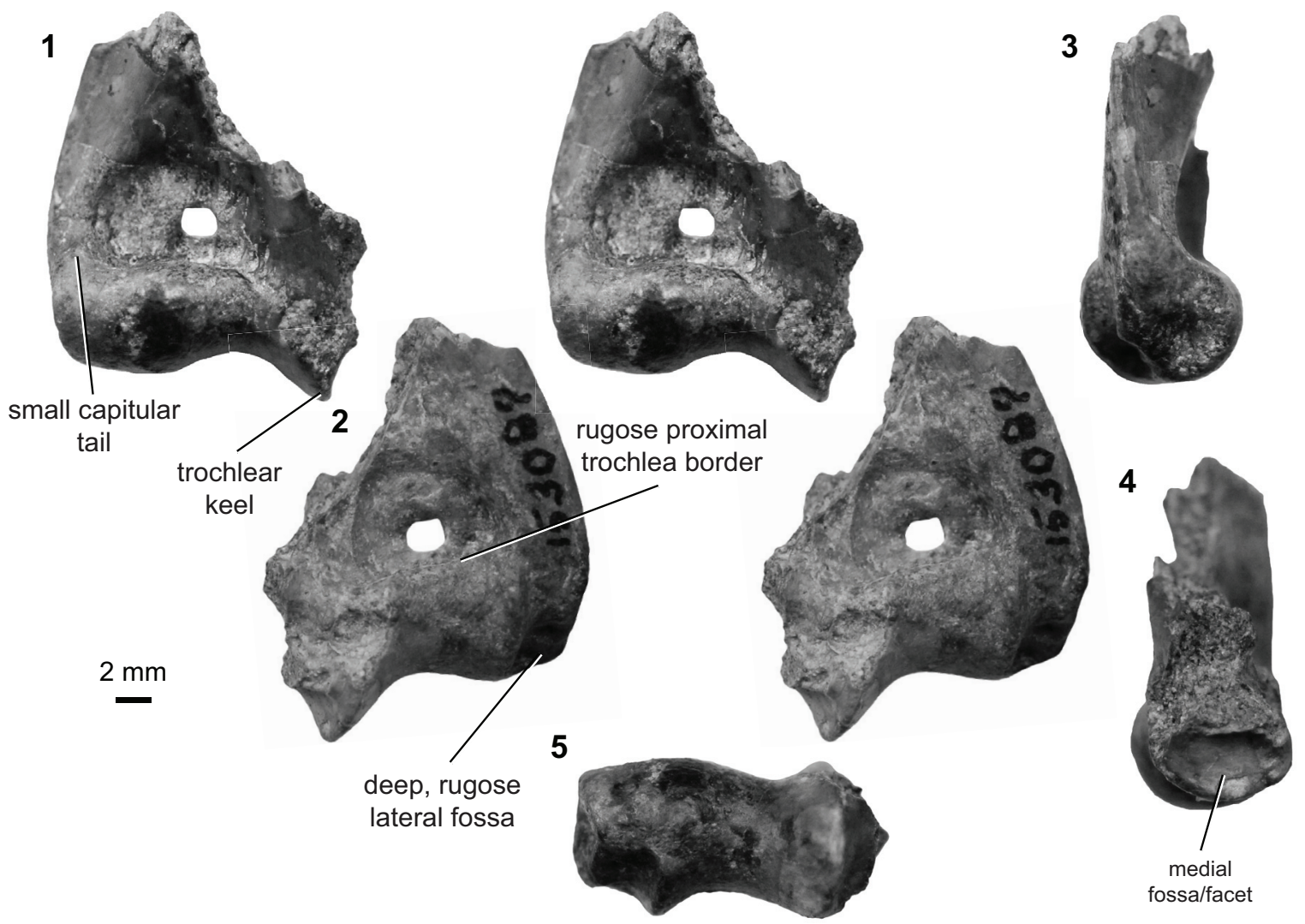

FIGURE 17. Eutherian morphotype EuF (UCMP specimen 92928, from locality V72129; right) in anterior (1) and posterior (2) stereopair views, and in lateral (3), medial (4), and distal (5) views.

the relative proportions of capitulum and trochlea in common with some larger archaic ungulate taxa, including the Paleocene periptychids Periptychus carinidens and Ectoconus majusculus, as well as the smaller Paleocene periptychid Mithrandir gillianus and arctocyonid Chriacus (Matthew, 1937; Rigby, 1981; Appendix 4). Although more similar in size, this specimen is less similar in morphology to the Paleocene archaic ungulates Loxolophus, Tetraclaenodon, and Protoselene (Matthew, 1937; Kondrashov and Lucas, 2012; Appendix 4). Among comparative taeniodonts, EuF differs in morphology from the much larger Paleocene pantodont Pantolambda, tillodont Deltatherium, and stylinodont taeniodonts, including Ectoganus sp., Stylinodon mirus, and Psittacotherium multifragum (Matthew, 1937; Schoch, 1986; Kondrashov and Lucas, 2012; Appendix 4); we therefore exclude the Pu3 taeniodont cf. Wortmania as a candidate taxon. UCMP 153089 might instead represent a medium- to large-sized Pu3 taxon whose humeri have not yet been published, possibly the triisodontid Eoconodon nidhoggi or E. hutchisoni. An unnamed pantodont and an unnamed oxyaenid creodont (Clemens, 2002, unpublished results;
Wilson, 2014) could also be candidate taxa for EuF.

Distal humerus morphotype EuG (Figure 18). This specimen (UCMP 192678) preserves only the medial aspect of the left distal humerus, including the distal entepicondyle and trochlea and a channel just proximal to these that represents the distal portion of the entepicondylar foramen (Figure 18). Despite its fragmentary state, it is one of the largest distal humeri in our study (e.g., approximately the same size as EuF, and $\sim 3.5 x$ the size of EuC; $\mathrm{NCW}=10.3 \mathrm{~mm}$ ), and is sufficiently unique to describe a new morphotype. Diagnostic features of this specimen include: (i) a shallow but pronounced dorsoepitrochlear fossa on the posterior surface, with an especially rugose mediodistal border; (ii) a shallow notch separating the entepicondyle and trochlea distally; (iii) a distal surface of the trochlea that, in anterior view, has a slope similar to that in $\mathrm{EuD}$, and which is intermediate to the shallow slope in EuB and the steep slope in EuF; (iv) a pinched margin, separating the entepicondylar foramen and the radial fossa, that is not seen in the other large eutherian morohotype (EuF); and (v) a 


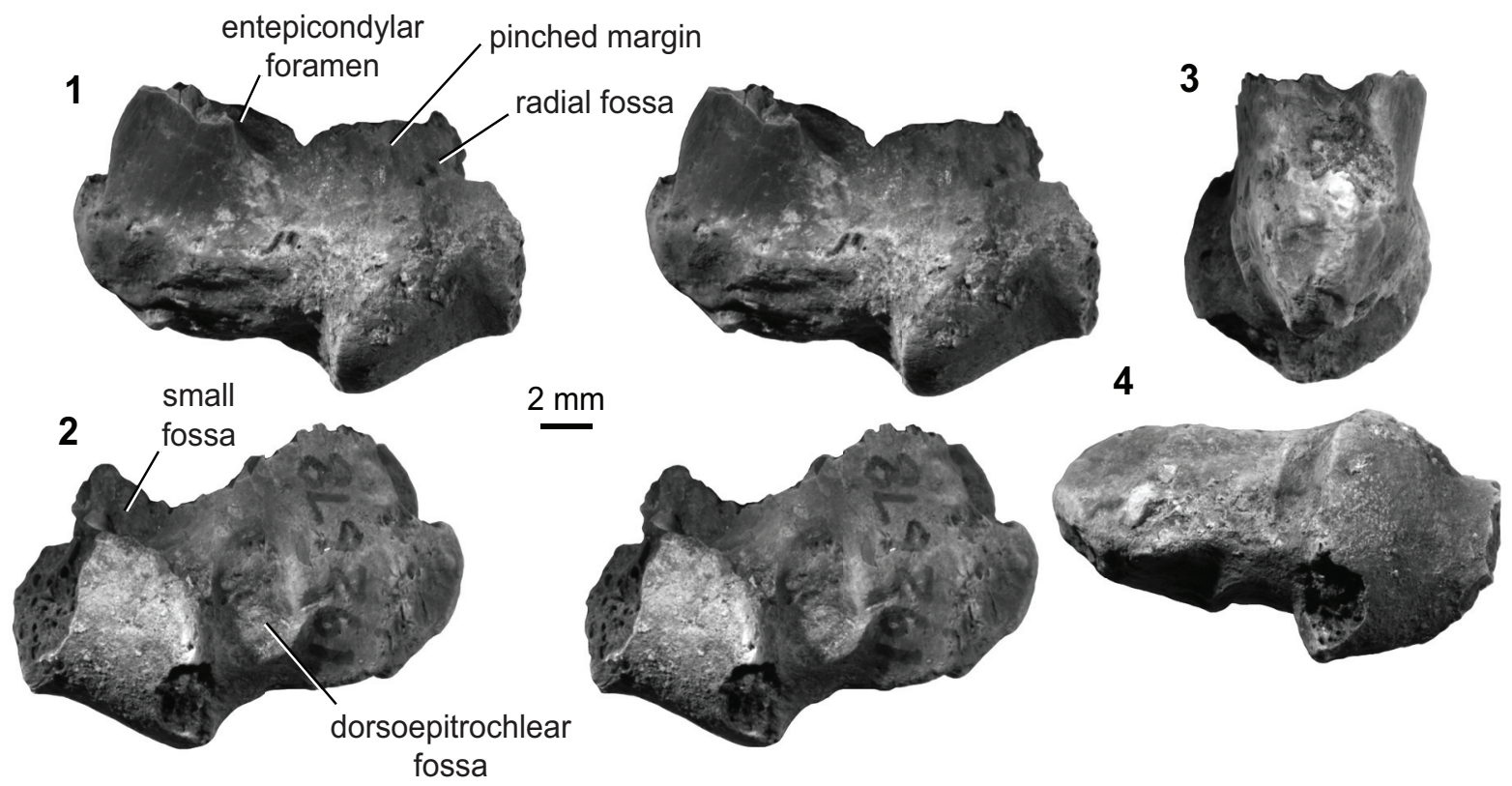

FIGURE 18. Eutherian morphotype EuG (UCMP specimen 192678, from locality V74124; left) in anterior (1) and posterior (2) stereopair views, and in medial (3) and distal (4) views.

small, medially-facing fossa proximal to the trochlea (posteriorly).

Among the larger-bodied Paleocene comparative taxa, UCMP 192678 most strongly resembles the humerus of the Torrejonian pantodont Pantolambda bathmodon (AMNH 16663; Matthew, 1937; Appendix 4). This taxonomic attribution would correspond well with a recently named pantodont from our study area, Crustulus fontanus (Clemens, 2017). This taxon is about half the size of $P$. bathmodon in molar dimensions, but likely had a humerus that was morphologically similar to $P$. bathmodon. Similarly, our humerus specimen is $60-70 \%$ of the size of the distal humerus of Torrejonian P. bathmodon (Matthew, 1937), but the morphological similarities are striking. They include the flat, robust distal surface of the entepicondyle, placement of the entepicondylar foramen, and the modest trochlear flange (Osborn and Earle, 1895; Matthew, 1937). In these features, EuG strongly differs from published specimens of Paleocene Theria indet. (Jenkins, 1973; Standhardt, 1986) and from Paleocene and Eocene archaic ungulates (e.g., Matthew, 1937; Russell, 1964; Rigby, 1981; Rose, 1987; Kondrashov and Lucas, 2012; Argot, 2013; Appendix 4). Moreover, it is unlikely that any of the Pu3 archaic ungulates from our study area would have had a humerus as large as EuG (Clemens, 2002; Wilson, 2014). The taeniodont cf. Wortmania is yet another large-bodied taxon known from our study area (Clemens, 2013). Although humeri of Wortmania are unknown, EuG strongly differs in trochlea and entepicondyle shape with the humeri of other taeniodont taxa, including the much larger stylinodontid taeniodonts Psittacotherium, Lampadophorus, Ectoganus, or Stylinodon, and the similarly sized Onychodectes tisonensis (Schoch, 1986). It is thus unlikely that EuG represents a taeniodont (Matthew, 1937; Schoch, 1986; Clemens, 2013). EuG also bears little resemblance to the humerus of the Paleocene tillodont Deltatherium (Matthew, 1937; Kondrashov and Lucas, 2012; Appendix 4). For other candidate taxa from this study area and geologic interval (the triisodontids Eoconodon hutchisoni and E. nidhoggi and a possible, as yet unnamed oxyaenid creodont), humeri material are currently unknown (Clemens, unpublished results; Clemens, 2011; Wilson, 2014). Thus, we tentatively attribute EuG to Crustulus fontanus (Clemens, 2017), although we recognize we cannot rule out attribution to Eoconodon spp. or the oxyaenid credont. This specimen is too small to be attributed to the same taxon as the largest femur published from this area (morphotype Eu4 of DeBey and Wilson, 2014).

\section{RESULTS AND DISCUSSION}

\section{Quantitative Validation of Humerus Morphotypes}

We classified our sample of 50 distal humeri from Lancian and Puercan of eastern Montana into 
six multituberculate and nine therian morphotypes (Tables 2-3; Figure 19; Appendices 7-8). These morphotypes were based on qualitative characters, but we tested for quantitative differences among morphotypes using univariate (e.g., ANOVAs) and multivariate statistics (e.g., PCAs).

Multituberculate humerus size varies significantly across morphotypes (Appendices 7, 9). Tukey honest significant difference (HSD) post hoc tests indicate all morphotypes vary significantly from all others for measurements TDW, AW, and TLW ( $p<0.01$; Appendix 10). Most morphotypes vary significantly from one or more morphotypes for the other measurements, a pattern that is especially common among larger morphotypes, MuE and MuF (Appendix 10). As is expected, larger morphotypes have a greater variance across measurements than is seen among the smaller morphotypes (Appendices 11-12), so we corrected for size by calculating a coefficient of variation (CV). MuF has the largest CV for RCL, UCD, and RCD; MuE has the largest CV for UCL; and MuC has the largest CV for all other measurements (Appendix 7).

PCA plots of the size-standardized, measurement data show that the multituberculate specimens did not cluster according to morphotype in any permutation of the dataset (Appendices 1318). Also, previously published specimens, both in total and for multiple specimens from the same species, occupy a greater amount of the morphospace than our specimens or morphotypes (Appendix 17). Most of our measurements of condyle shape consistently load positively on PC1, whereas relative entepicondyle width (relNCW) consistently loads most strongly on PC2 (Appendices 13-18). Relative ulnar condyle width (relUCW) is the only variable that strongly loads on both PC1 and PC2, and it varies by dataset whether it is loading with or against relNCW; relUCW also loads most strongly on PC3 (Appendices 14, 16, 18). No quantitative characters (i.e., standardized measurements) discriminate among the multituberculate morphotypes (Appendices 13-18). Possibly our measurements do not capture nuanced differences in multituberculate distal humeri shape, and/ or our small sample sizes fail to represent the patterns of variation across morphotypes. That relUCW has a different pattern depending on the size and composition of the dataset implies small sample sizes affect our results. Nevertheless, the observed qualitative differences among our morphotypes imply that a multivariate analysis of shape that included these qualitative characters would better discriminate among our morphotypes.

Therian morphotypes are significantly different from one another with respect to size. We excluded the metatherian morphotype MeA from these calculations because of poor preservation (see Table 3). All other morphotypes vary significantly across all measurements except for TDW (Appendix 19). Tukey HSD tests indicate larger morphotypes EuE, EuF, and EuG differ the most from all other morphotypes (Appendices 20-22). These results are considered preliminary in light of the very small sample sizes for each morphotype (i.e., six morphotypes have $\mathrm{n}=1$; Appendix 8).

\section{Richness and Taxonomic Composition Across and Following the K-Pg Boundary}

The Lancian humerus morphotype richness $\left(M_{h-L a}=7\right)$ is greater than in any other time bin in our study, perhaps due to its large sample size $(n=$ 14 humeri). It also has the greatest $M_{h}$ of multituberculates $\left(M_{h \text {-La-multis }}=4\right.$; Figure 19$)$, although it is only half the femur morphotype richness of multituberculates from this bin $\left(\mathrm{M}_{\mathrm{f} \text {-La-multis }}=8\right.$; DeBey and Wilson, 2014). This discrepancy might be explained by a similar trend in some small-bodied extant mammals to have generalized forelimbs primarily for habitat construction, prey capture, and manipulation and hind limbs that are specialized for diverse locomotor modes (e.g., Szalay and Dagosto, 1980; Polly, 2007). In contrast to the femur sample, several therians are present in our Lancian humerus sample: MeA, which we attribute to one of the largest Late Cretaceous mammals, the stagodontid metatherian Didelphodon vorax (2.4-5.2 kg; Wilson et al., 2016), and two small humeri attributed to Theria (ThA) and Eutheria (EuB); these three morphotypes are restricted to the Lancian. The relative abundance of metatherians in our Lancian humerus sample is much lower than that of metatherians in the dental sample from this study area ( $14 \%$ vs. $45 \%$, respectively; Wilson, 2014); this discrepancy may be due to small humerus sample sizes or to an undetermined taphonomic filter. The relative abundances of eutherian humeri and teeth, in contrast, are similar to one another ( $7 \%$ vs. $14 \%$, respectively; Wilson, 2014). Among the Lancian multituberculates, MuF is the largest and most abundant morphotype (43\% of specimens) and is attributed to ?Meniscoessus robustus; MuD is known from only a single specimen from the Lance Formation of Wyoming and is attributed to ?Cimolodon nitidus. The Lancian sample also includes a very small morphotype, MuA, 


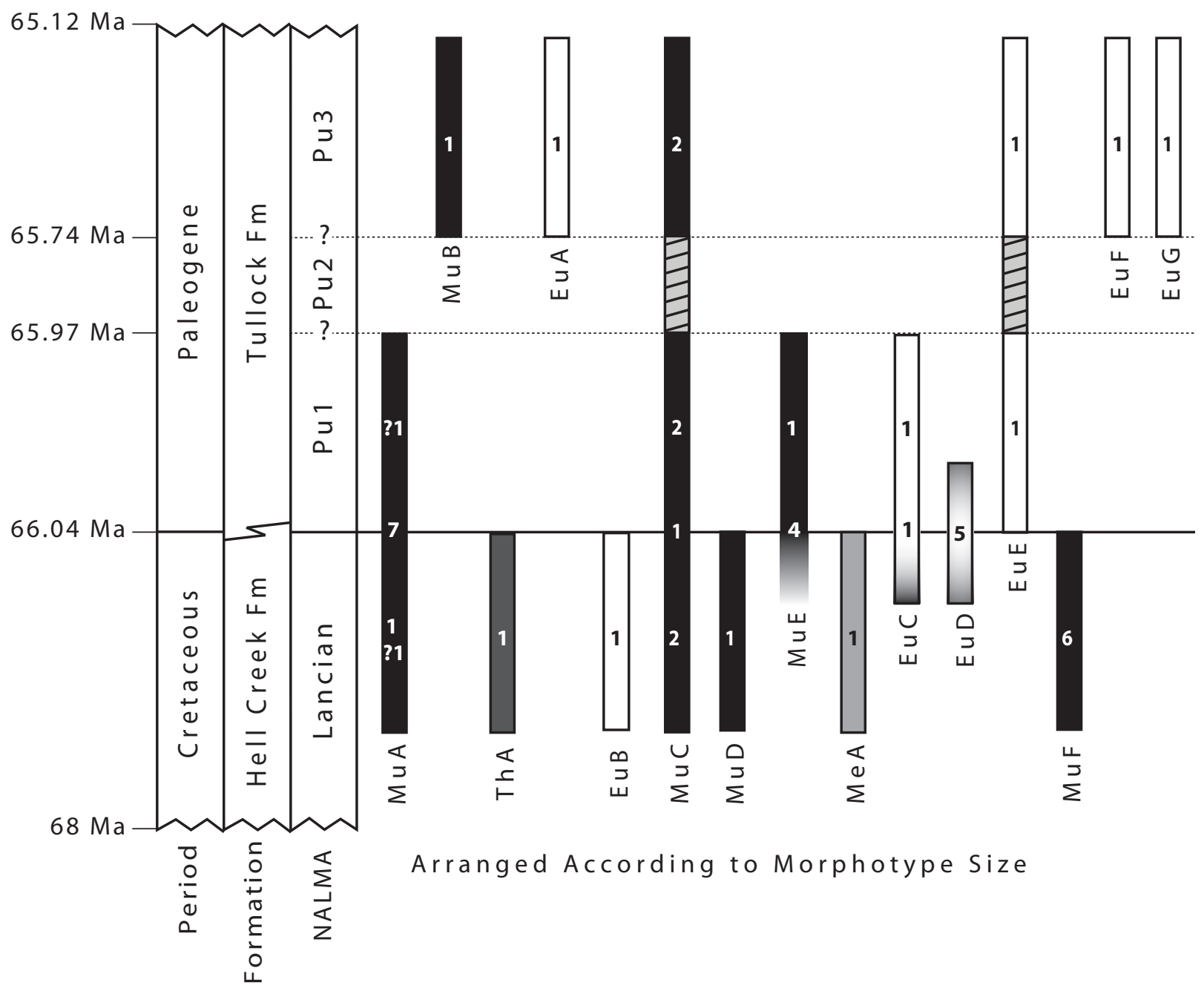

FIGURE 19. Summary of humerus morphotypes and relative sizes in our study area in the Hell Creek and Tullock formations of eastern Montana. Multituberculate morphotypes are shown as black bars, metatherians as gray bars, and eutherians as white bars. Numbers within the bars indicate the sample size for each temporal bin. Morphotypes are arranged left to right according to increasing size (see text for specimen numbers, localities, and details; Appendices 7-8 for morphotype mean sizes). Gradients for MuF, EuC, and EuD indicate morphotypes were present in the timeaveraged Bug Creek Anthills assemblages, and the morphotype range may extend into the Pu1 and/or the Lancian. Pu2 assemblages are not known from our study area (hashmarks indicate resultant uncertainty of range-through morphotypes; Clemens 2015). The age model is based on previous geochronological work in this study area (Swisher et al., 1993; Renne et al., 2011, 2013; Wilson, 2014; Sprain et al. 2014); note the temporal axis is not to scale. Modified from Sprain et al. (2014). Abbreviations: Fm, Formation; NALMA, North American Land Mammal "age"; Pu1, early Puercan; Pu3, middle/late Puercan; queries (?) indicate specimens that are only tentatively attributed to that morphotype, see Methods.

which is attributed to ?Mesodma sp., and the medium-sized MuC (not attributed to taxon); both of these morphotypes are also found in our Pu1 and Pu3 samples. ?Meniscoessus robustus, ?Mesodma sp., and ?Cimolodon nitidus have previously been identified in femur samples from our study area (Hunter et al., 1997; DeBey and Wilson, 2014).
Despite having the largest sample size $(n=$ 23), the Bug Creek Anthills (BCA) mixed-age assemblage records only five morphotypes ( $\mathrm{M}_{\mathrm{h}-\mathrm{BCA}}$ = 5; Figure 19), consisting of multituberculates and eutherians. This is in contrast with the BCA femur sample, which contains only multituberculates (DeBey and Wilson, 2014). Most of the BCA humerus morphotypes are also known from other time bins: MuA (Lancian), MuC (Lancian and Pu1), 
MuE (Pu1), and EuC (Pu1). However, EuD, which is the most abundant morphotype in the sample ( $43 \%$ of specimens), is only recorded in the BCA.

Humerus morphotype richness is lowest in the early Puercan, both overall $\left(\mathrm{M}_{\mathrm{h}-\mathrm{Pu} 1}=4\right.$ or 5$)$ and for multituberculates specifically $\left(\mathrm{M}_{\mathrm{h} \text {-Pu1-multis }}=2\right.$ or 3 ; Figure 19). Although this depressed diversity may be due in part to the small sample size for this bin $(n=6)$, the same pattern occurs in the femur (DeBey and Wilson, 2014) and dental samples (Wilson, 2014) from this study area, and likely reflects a biologically meaningful pattern of K-Pg extinctions. Among the early Puercan humerus morphotypes, MuA is attributed to the small-bodied multituberculate ?Mesodma sp.; MuE to the medium-sized multituberculate ?Stygimys kuszmauli; and EuC to the medium-sized eutherian ?Protungulatum; all but ?Protungulatum have been identified among the femur samples from this study area (DeBey and Wilson, 2014).

In the Pu3, humerus morphotype richness rebounds $\left(M_{h-P u 3}=6\right)$, and is the highest relative to sample size $(n=7$; Figure 19). Again, the sample size is small, but the pattern does mirror the diversity increase found in the femur (DeBey and Wilson, 2014) and dental samples (Wilson, 2014). Among the Pu3 humerus sample, there are five eutherian morphotypes and two multituberculate morphotypes, all restricted to the Pu3 except MuC (Lancian-Pu3) and EuE (Pu1-Pu3). This eutherian:multituberculate ratio $(2.5: 1)$ is the reverse of that seen in the femur sample from this study area (1:2; DeBey and Wilson, 2014); whereas, in the dental sample, the ratio is nearly 1:1 (Wilson, 2014). Like the femur sample, the Pu3 humerus sample includes small- and medium-sized multituberculates, large eutherians, and a possible plesiadapiform (DeBey and Wilson, 2014); however, it has more large eutherian morphotypes and lacks a large multituberculate morphotype (DeBey and Wilson, 2014).

Overall, the patterns of humerus morphotype richness across and following the K-Pg are consistent with those from dental and femoral data from this study area: high richness of mostly multituberculates in the Lancian, a depauperate Pu1 fauna largely composed of small-bodied multituberculates and eutherians, and recovering diversity of mostly eutherians in the Pu3 (i.e., Archibald, 1982, 1983; Lofgren, 1995; Clemens, 2002; Wilson, 2004, 2005, 2013, 2014; DeBey and Wilson, 2014).

\section{Body-size Changes Across and Following the K-Pg Boundary}

Our sample shows a five-fold difference between the smallest and largest specimens of multituberculates and therians (Appendices 7-8). Results of one-way ANOVAs (Appendices 23-24) indicate significant differences through time (Lancian, BCA, Pu1, Pu3) for multituberculate measurements RCW, UCL, RCL, and UCD (all $p<$ 0.05; Appendix 25). These measurements describe the shape and size of the distal humerus articular surfaces, of which the latter is predictive of body mass (e.g., Egi, 2001). Post-hoc Tukey HSD test indicates that for all measurements Lancian multituberculate specimens are significantly larger than only BCA multituberculates (Appendices 2627).

For therians, the small sample sizes across time bins limit the number of measurements that can be compared with ANOVAs (which require at least three time bins). Results from ANOVAs of these measurements indicate a significant difference across time bins for only entepicondylar width $(\mathrm{NCW})$ and trochlear length (TL) $(p<0.01$ and $p<$ 0.05 , respectively; Appendix 28). Tukey post-hoc results indicate Pu3 therian specimens are significantly larger than Lancian, BCA, and Pu1 specimens (for NCW; Appendices 29-30). Entepicondylar width is a functionally significant measurement and is therefore potentially suboptimal for comparison of size through time (e.g., Argot, 2001; Milne et al., 2009; Warburton et al., 2011; Janis and Figueirido, 2014); however, in some groups, e.g., fossorial taxa, entepicondyle size is actually more strongly correlated with body mass than are other humerus measures (Elissamburu and Vizcano, 2004). Although no other measurements yielded significant ANOVA results across time bins, nearly all measurements exhibited the same pattern of Pu3 specimens being larger than those in the Lancian or BCA bins (Appendices 24, 30); this pattern might become significant for these measurements with larger sample sizes.

Humerus size, a proxy for body size, shows changes across and following the $\mathrm{K}-\mathrm{Pg}$ that are consistent with those from femoral (DeBey and Wilson, 2014) and dental data in our study area (e.g., Archibald, 1983; Maas and Krause, 1994; Clemens, 2002; Wilson, 2004, 2005, 2013, 2014). Specifically, (1) multituberculate body size significantly decreased across the K-Pg boundary, and (2) eutherian body size increased through the Puercan. This post-K-Pg increase in eutherian 
body size is also consistent with results from synoptic studies using larger temporal bins (i.e., $1 \mathrm{Ma}$, $2.5 \mathrm{Ma}$ ) and at continental and global scales (e.g., Stucky, 1990; Alroy, 1999; Smith et al., 2010). Additionally, using our taxonomic attributions and previous designations of Pu1 taxa as either "residents" or "immigrants" (Clemens, 2002; Wilson, 2014), we find that Pu1 residents (MuC, and possibly MuA) are smaller than Pu1 immigrants (MuC, EuC, EuE, and possibly EuD) and most Lancian K$\mathrm{Pg}$ victims (MuD, MuF, MeA). This pattern is consistent with the pattern from dental data that indicates that, at least locally, larger-bodied mammals were selected against in the $\mathrm{K}-\mathrm{Pg}$ mass extinction (Wilson, 2013). Similarly, Pu3 resident taxa are smaller than Pu3 immigrants to the study area. These patterns were also seen among femora from the study area (DeBey and Wilson, 2014).

\section{Predictions of Locomotor Mode in Extant and Fossil Therians}

PCA results of full dataset. The results of our 2D GM analysis of extant mammalian humeri are shown in plots of the first three principal components (PCs) of the PCA in Figure 20. We limited our descriptions and interpretations of the morphospace to these PCs because together they comprise a substantial amount of the variance in the dataset $(46 \%, 13 \%$, and $11 \%$, respectively; Figure 20; Appendices 31-33). Humeri with high scores on PC1 have a distal end that is mediolaterally wide, anteroposteriorly narrow, and that has a large, medially projecting entepicondyle (Figure 20; reversed from Appendix 32). Low scores on PC1 correspond to a distal end that is mediolaterally narrow and anteroposteriorly wide, with small entepi- and ectepicondyles, an anteriorly projecting medial trochlear keel, and a posteriorly projecting lateral trochlear margin (Figure 20; reversed from Appendix 32). Humeri with high scores on PC2 have a distal end that has a wider trochlea posteriorly, whereas those with low scores on PC2 have more bulbous articular surfaces and a narrow trochlea posteriorly (Figure 20).

Segregation of extant mammals in the morphospace according to locomotor mode is weak. PC2 generally discriminates between fossorial taxa (high scores on PC2) and arboreal and scansorial taxa (lower scores on PC2; Figure 20.3-4). Semiaquatic and gliding taxa plot in the middle of PC1, and gliding taxa plot in the middle of PC2 (Figure 20.3-4). The distribution of humeri in the morphospace is also influenced by phylogeny (Figure 20.1-2), as shown in other studies (e.g., Morgan and Álvarez, 2013; Fabre et al., 2015). For example, metatherians (circle markers) tend to have higher scores on PC1 and lower scores on PC2 and $\mathrm{PC} 3$ relative to eutherians (square markers) (Appendices 32-33), and they are more restricted in their morphospace occupation (Appendices 3233), although there are far fewer specimens of metatherians than eutherians (Table 4). Among eutherians, there is also some clustering according to higher-level taxa. For example, specimens of afroscoricids have mostly low scores on PC2 and high scores on PC3. This phylogenetic signal in our analysis, in particular, is not surprising given the highly diverse taxonomic sampling (13 mammalian orders across metatherians and eutherians).

In this morphospace, the four fossil specimens (Lancian small eutherian EuB; BCA-Pu1 small archaic ungulate EuC; and two specimens of the BCA small "insectivoran" EuD) have high scores on PC1 and mid-range scores on PC2 (Figure 20.1). They have a wider distal humerus than most of our extant specimens, with a moderately bulbous articular surface, resembling didelphimorph and diprotodont metatherians and afrosoricid and cingulatan eutherians in our dataset (Figure 20.1). On the PC2 vs. PC3 plot, these fossils are nearest to afrosoricids, some rodents, scandentians, and one eulipotyphylan (Figure 20.2).

PCA results of pruned dataset. To reduce the phylogenetic signal, enhance discrimination among pertinent locomotor groups, and better predict locomotor mode in our fossil specimens, we pruned our dataset in subsequent analyses. We removed all metatherians because of their large phylogenetic distance from eutherians (including the fossil morphotypes) and some extant eutherians that we deemed poor functional analogs for our fossils (i.e., taxa and locomotor groups that plotted very far from our fossils). The latter were taxa with extreme cursorial and saltatorial morphological adaptations (i.e., carnivorans and lagomorphs, respectively). Although Mesozoic mammals were diverse with respect to locomotor function (e.g., Luo, 2007; Chen and Wilson, 2015), taxa at the extremes of cursorial and saltatorial locomotion, similar to extant carnivorans and lagomorphs, are as yet unknown (Luo, 2007; Chen and Wilson, 2015). In the PCA of this pruned dataset, PC1, PC2, and PC3 explain $37 \%, 19 \%$, and $13 \%$ of the total variance, respectively (Figure 21; Appendix 31).

As in the first analysis, the specimens distribute along PC1 in this second analysis on the basis of mediolateral width (e.g., entepicondylar and 


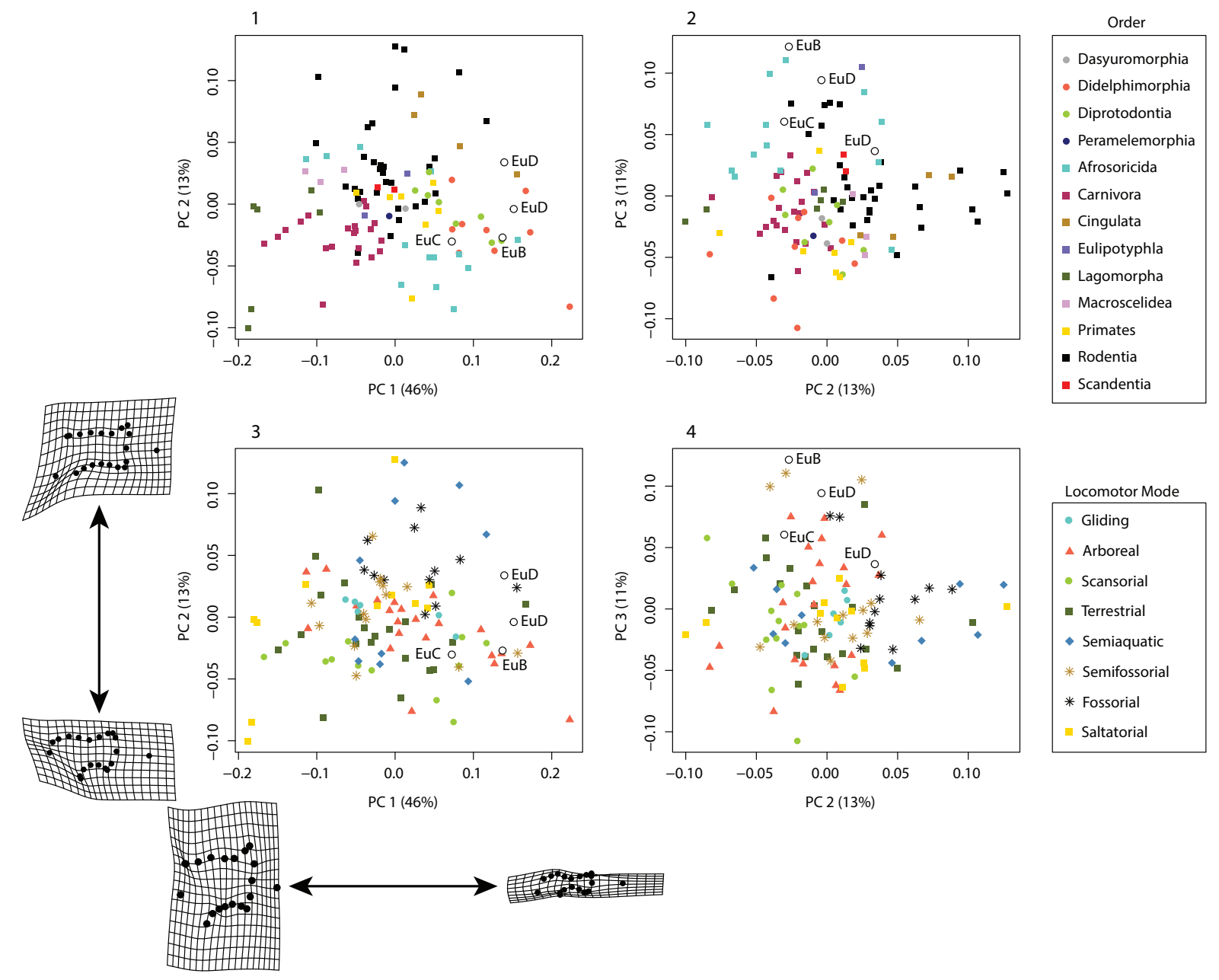

FIGURE 20. Plots of Principal Component Analysis (PCA) of full dataset, color-coded for taxon (top) and locomotor group (bottom), with fossils (open circles) projected into the morphospace. (1) PC1 vs. PC2 and (2) PC2 vs. PC3 for all taxa (legend top right), and the same data for locomotor group (3-4; legend bottom right). Also included are the deformation grids for the extreme ends of PC1 and PC2 on right humerus in distal view (identical to Appendices 3233).

ectepicondylar width) and anteroposterior trochlea height (Figure 21). Humeri with high scores on PC1 have distal ends that are mediolaterally narrow and anteroposteriorly tall and have a large entepicondyle (Figure 21); however, these patterns are less pronounced relative to those in the first analysis (Figure 20). Low scores on PC1 correspond to humeri with distal ends that are mediolaterally wide and anteroposteriorly short (Figure 21), although not as anteroposteriorly constricted at the trochlea as in the first analysis (Figure 20). Variation along PC2 in the analysis of the reduced dataset is also similar to that in the first analysis (Figures 20-21); humeri with low scores on PC2 also have a lateral extension of the articular surface beyond the capitulum (Figure 21).
Relative to the first analysis, locomotor discrimination is improved and the phylogenetic signal is reduced in the analysis of the pruned dataset (Figure 20 vs. Figure 21). PC2 discriminates arboreal, terrestrial, and scansorial taxa (high scores) from fossorial, semifossorial, and semiaquatic taxa (low scores; Figure 21.3-4). On PC1, saltatorial and gliding taxa generally have high scores (Figure 21.3). The discrimination of locomotor groups, especially on PC2, is consistent with the morphofunctional continuum found in Chen and Wilson (2015). In this morphospace, all fossil specimens generally plot low on PC1, with mediolaterally wide distal humeri and anteroposteriorly short articular surfaces; the Lancian EuB and BCA "insectivorans" (EuD) have the lowest PC1 scores among our fossil taxa (Figure 21.1, 21.3). Lancian EuB 


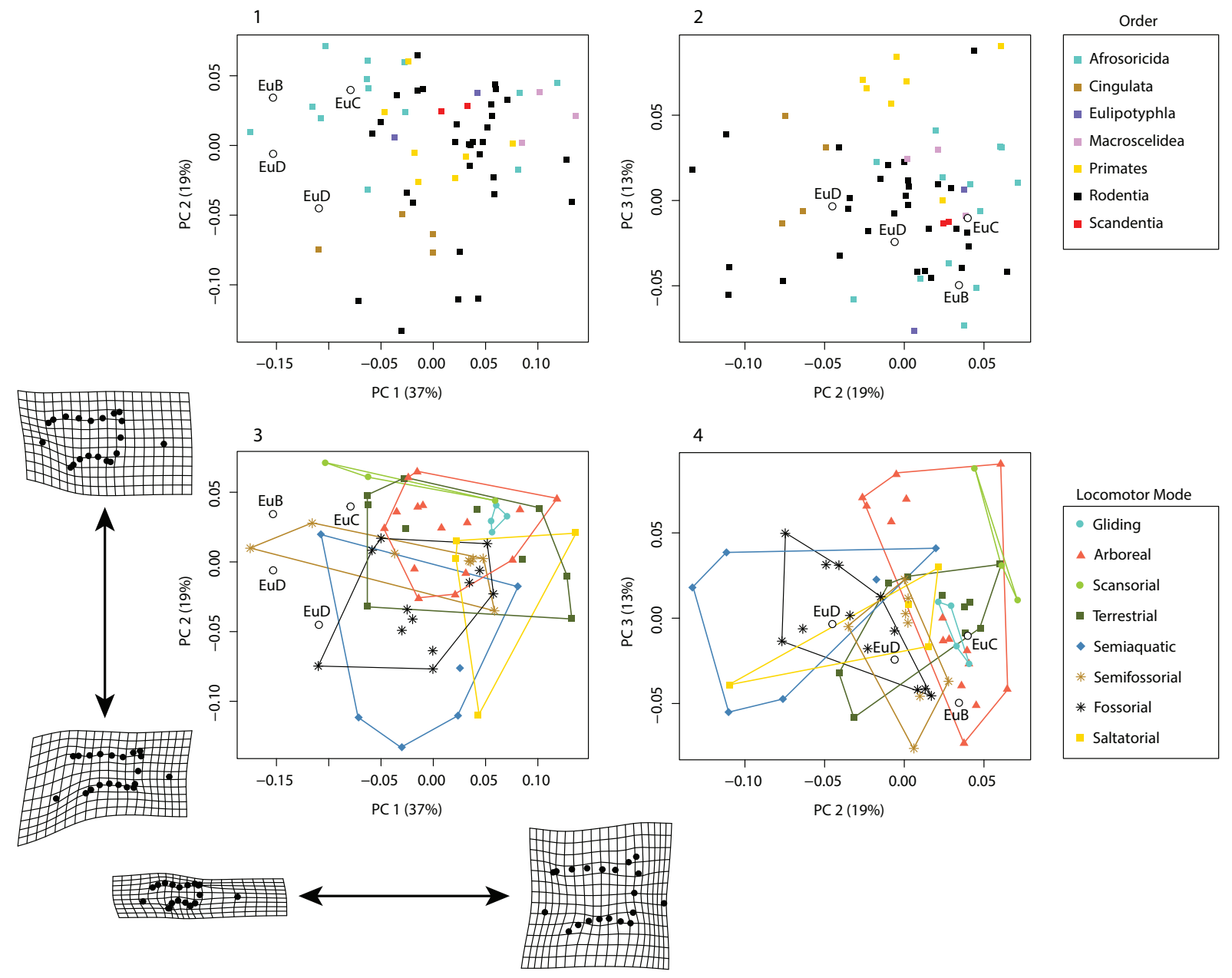

FIGURE 21. Plots of PCA of pruned dataset, color-coded for taxon (top) and locomotor group (bottom), with fossils (open circles) projected into the morphospace. (1) PC1 vs. PC2 and (2) PC2 vs. PC3 for all taxa (legend top right), and the same data for locomotor group (3-4; legend bottom right). Also included are the deformation grids for the extreme ends of PC1 and PC2.

and archaic ungulate EuC have the highest PC2 scores, having the most bulbous articular surfaces among our four fossil specimens (Figure 21).

We plotted PC1 vs. PC2 (Figure 22) and PC2 vs. PC3 (Figure 23) separately for each locomotor group to more clearly assess how our fossil specimens compare to those groups. Our fossil specimens plot lower on PC1 than all arboreal, gliding, saltatorial, and terrestrial taxa (Figure 22.1, 22.3-4, 22.8) because of a mediolaterally wider distal humerus than in those locomotor groups. The only locomotor groups with PC1 and PC2 scores similar to all our fossils are the semifossorial, fossorial, and semiaquatic groups (Figure 22.2, 22.5, 22.7). Specifically, the Lancian EuB specimen and one BCA "insectivoran" EuD specimen each have a mediolaterally wide distal humerus with a large entepicondyle, and plot within the semifossorial locomotor group on PC1, PC2, and PC3 (i.e., nearest tenrecs Hemicentetes and Oryzorictes; Figures 22-23). The other EuD specimen plots nearest the fossorial dasypodid Cabassous and close to the terrestrial tenrec Microgale on the PC1 vs. PC2 plot (Figure 22). The BCA archaic ungulate EuC plots nearest members of fossorial, semiaquatic, scansorial, and terrestrial locomotor groups (i.e., fossorial rodent Aplodontia, scansorial and semiaquatic tenrecs Limnogale and Tupaia, respectively, and terrestrial tenrecs Setifer, Tenrec, and Microgale; Figure 22). Although our fossils specimens plot nearest to a number of afrosoricids (i.e., tenrecs) and rodents, they do not plot near the arboreal representatives of these two groups, Dendrohyrax (22-23) and Sciurus spp. (99-102), or 

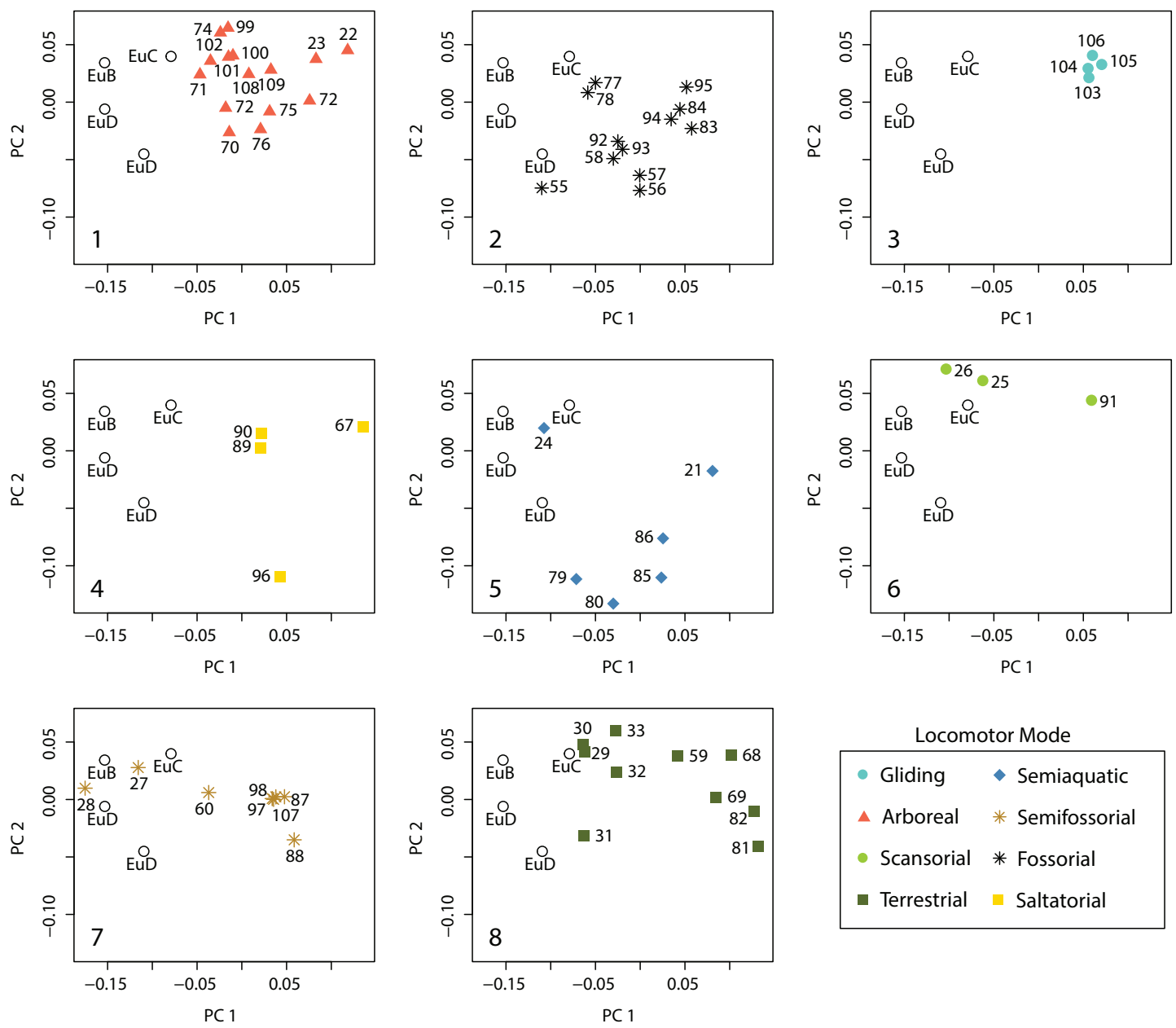

FIGURE 22. Plot of PC1 vs. PC2 for the pruned dataset with (1-8) each locomotor group plotted separately (data, legend, and fossil placement identical to Figure 21.3).

the gliding rodent Glaucomys spp. (103-106; Figure 22).

LDA results of pruned dataset. To emphasize morphological differences among our locomotor groups and to quantitatively predict locomotor mode among our fossil morphotypes, we conducted a linear discriminant analysis (LDA) of the pruned dataset on the PCs that explained $>1 \%$ of the total variance. The LDA morphospace (i.e., LDs 1-3) shows good discrimination among locomotor groups (Figure 24). Arboreal and scansorial taxa have high scores on LD1, whereas semiaquatic and saltatorial taxa have low scores (Figure 24). Fossorial taxa have low scores on LD2, and terrestrial taxa high scores on LD2; semifossorial taxa fall between and overlap these two groups (Figure 24). Scansorial and gliding taxa plot between arboreal and terrestrial taxa on LD1 (Figure 24). The extant specimens were assigned to locomotor cat- egory with $74 \%$ accuracy ( $100 \%$ of gliding taxa; $93 \%$ of arboreal taxa; $90 \%$ of terrestrial taxa; $67 \%$ of semiaquatic and scansorial taxa; $63 \%$ of semifossorial taxa; $58 \%$ of fossorial taxa; and $33 \%$ of saltatorial taxa; Appendices 34-35). In total, 16 of 62 specimens were misclassified (Appendix 35) and the majority of misclassified taxa were classified as terrestrial, semifossorial, and fossorial.

Notably, the locomotor groups vary in how much morphospace they occupy; this reflects sampling as well as some biologically meaningful patterns. For example, gliding taxa have low morphological variance in our dataset. Granted the pruned dataset includes only two species of the sciurid rodent Glaucomys (Table 4), but the original dataset that included the metatherian sugar glider Petaurus breviceps also shows similarly low levels of morphological variance. This is likely due to the strict functional constraints on the morphology of 

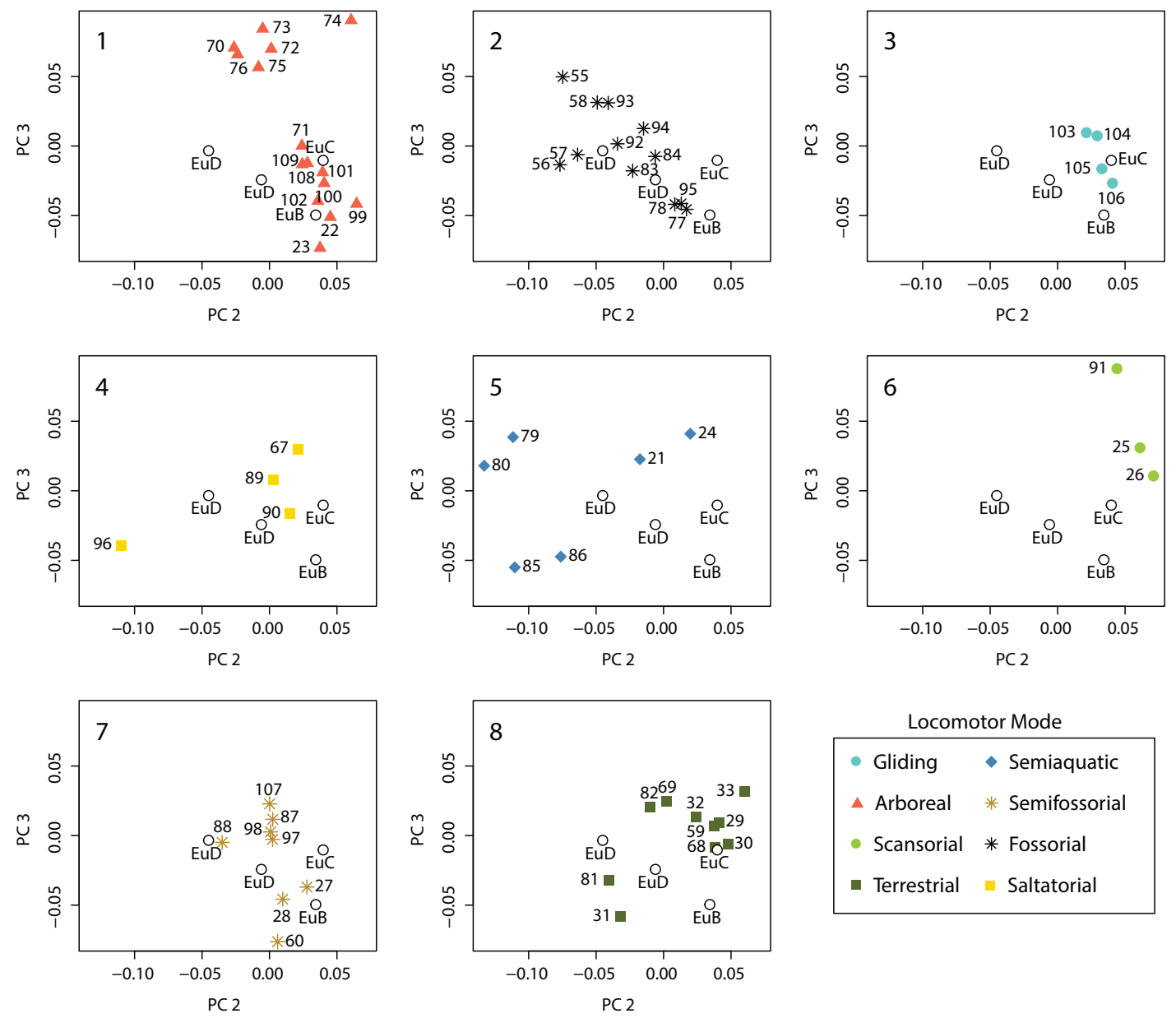

FIGURE 23. Plot of PC2 vs. PC3 for the pruned dataset with (1-8) each locomotor group plotted separately (data, legend, and fossil placement identical to Figure 21.4).

gliders (Chen and Wilson, 2015). In contrast, saltatorial taxa occupy a greater amount of morphospace in our analyses, perhaps due to greater functional diversity in this category. Some saltatorial species are more bipedal (e.g., kangaroo rat, jerboas; Nowak, 1999), whereas others use their forelimbs during locomotion (e.g., lagomorphs; Nowak, 1999); the latter submode is perhaps more similar to cursorial locomotion than to bipedal saltatorial locomotion (Hildebrand, 1988; Polly, 2007). Some saltatorial taxa have also freed their forelimbs for greater use in other activities, such as food manipulation and digging (Hildebrand et al., 1985; Chen and Wilson, 2015). Semiaquatic taxa also show a substantial amount of morphological variation in our analyses. For example, the semiaquatic rodents and afrosoricids plot separately from each other on PC2, reflecting their phylogenetic differences; and on PC 1, the semiaquatic afrosoricids (Limnogale mergulus, Potamogale velox) plot separately from each other, reflecting their functional differences (Figures 20-21). The web-footed tenrec Limnogale mergulus and the giant otter shrew Potamogale velox differ from one another in body size (accounted for in our PCA), body dimensions, and habits (Nowak, 1999). They also swim differently (i.e., Potamogale via tail propulsion, and Limnogale via tail plus hind limb propulsion), and use their forelimbs for other functions (i.e., burrowing in Limnogale; Nowak, 1999). Although this substantial functional diversity within locomotor groups can reduce the signal-to-noise ratio, we agree with Chen and Wilson (2015) that it better accounts for potential functional diversity in fossil taxa.

Our analyses also show the converse pattern in which taxa of divergent locomotor modes exhibit similar humerus morphologies. Arboreal taxa, semifossorial, and fossorial taxa possess a humerus with a large entepicondyle indicative of 

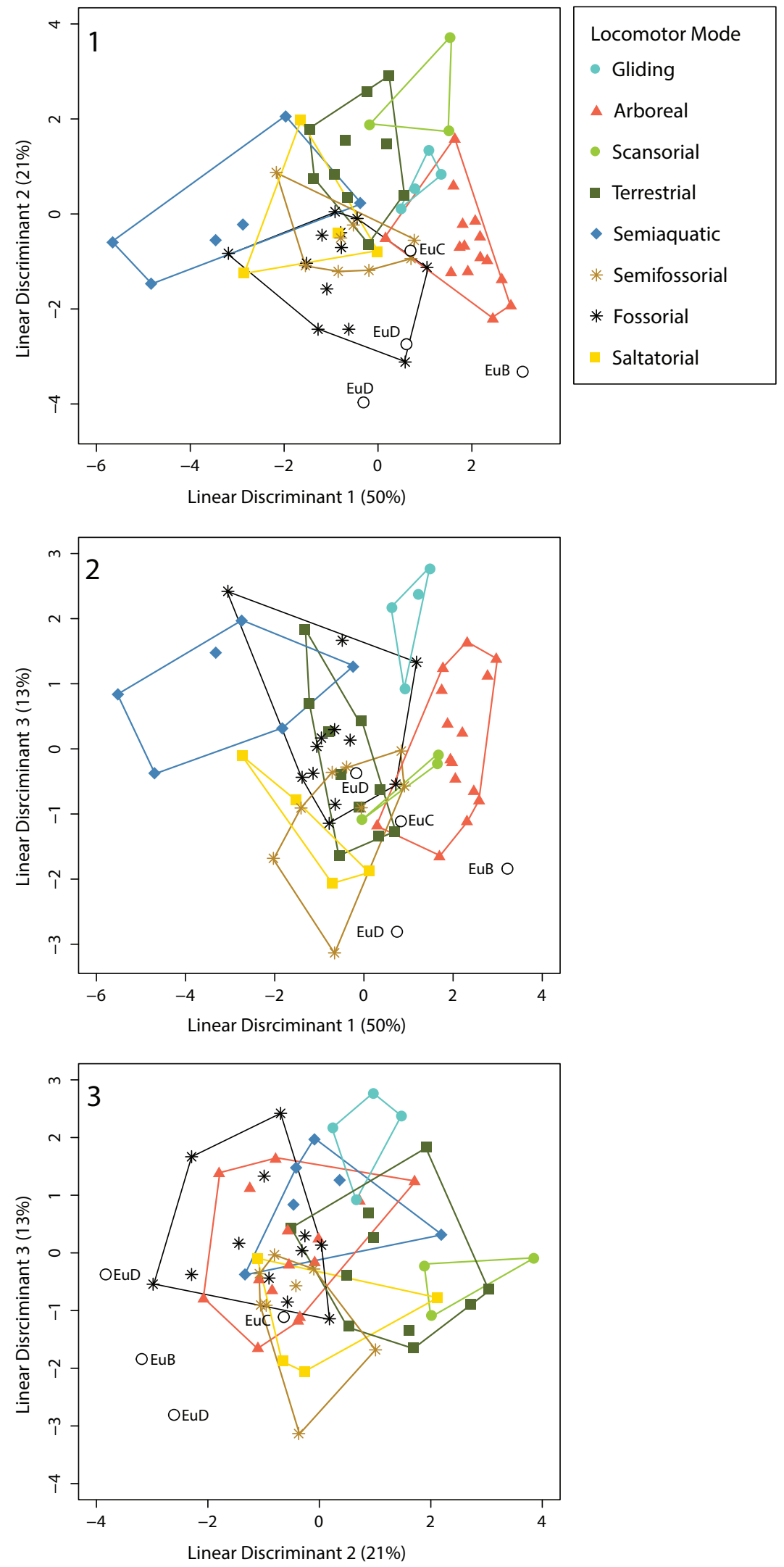

FIGURE 24. Plots of Linear Discriminant Analysis of the pruned dataset according to locomotor group. (1) LD1 vs. LD2; (2) LD1 vs. LD3; and (3) LD2 vs. LD3. 
strong wrist and digital flexors (e.g., Taylor, 1974; Szalay and Sargis, 2001; Salton and Sargis, 2008; Flores, 2009). Indeed in our PCA (Figure 21), arboreal, semifossorial, and fossorial taxa, all having mediolaterally wide distal humeri with large entepicondyles, plot together near the extreme of PC1. Nevertheless, we suggest that arboreal and fossorial taxa could be morphologically and functionally distinguished on the basis of the humerus, if other functionally informative areas were examined, e.g., muscle attachments sites on the proximal shaft (e.g., Hildebrand, 1988; Polly, 2007; Salton and Sargis, 2008; Samuels and Van Valkenburgh, 2008; Chen and Wilson, 2015).

Locomotor mode of fossil therians. In the LDA morphospace, the small Lancian eutherian (EuB) plotted outside the area occupied by extant taxa, but closest to fossorial and arboreal taxa, respectively (Figure 24.1). The LDA gives a 99\% prediction probability that EuB was arboreal, with only a $0.4 \%$ probability of a semifossorial locomotor mode. Indeed, the large, medially extensive entepicondyle of this morphotype is associated with welldeveloped wrist- and digit flexors in extant taxa and implies powerful grasping typical of climbers and diggers (Taylor, 1974; Hildebrand, 1985; Szalay and Sargis, 2001; Sargis, 2002; Salton and Sargis, 2008; Flores, 2009). The bulbous articular surfaces and subspherical capitulum of EuB imply that it was capable of more flexible, multi-axial movement at the elbow joint (Argot, 2001; Szalay and Sargis, 2001; Sargis, 2002; Salton and Sargis, 2008; Fabre et al., 2015). The shallow olecranon fossa of EuB indicates habitual, but less extreme extension (Penkrot et al., 2008; Salton and Sargis, 2008; Flores, 2009). These features would have conferred EuB with rotational and grasping abilities consistent with arboreality or fossoriality; however, we note that relative to the arboreal Ptilocercus (Sargis, 2002), EuB has a less spherical capitulum and a less distinct separation between the trochlea and capitulum.

The BCA archaic ungulate (EuC) plotted among arboreal and semifossorial taxa and also near fossorial and saltatorial specimens in the LDA morphospace (Figure 24.1). This ambiguity is reflected in a $61 \%$ prediction probability of a semifossorial mode and $27 \%$ prediction probability of an arboreal mode (Appendix 36). EuC has a very deep dorsoepitrochlear fossa, which is possibly the site of attachment for a ligament binding the humerus with the ulna (cf. medial ligament of Szalay et al., 1975; Szalay and Dagosto, 1980) and which might imply that EuC had a well-developed flexor carpi ulnaris that acted in flexion/adduction of the hand (Argot, 2013). The deep and perforated olecranon fossa, much deeper than in EuB, enables major extension of the forearm and indicates a more upright forelimb posture (Penkrot et al., 2008; Flores, 2009). The large entepicondyle is more robust and proximally extensive than in EuB or EuD, reflecting greater area for muscle attachment, namely for wrist and digit flexors (Taylor, 1974; Hildebrand, 1985; Szalay and Sargis, 2001; Sargis, 2002; Salton and Sargis, 2008; Flores, 2009). Combining these data, we interpret the BCA archaic ungulate (EuC) as having engaged in generalized locomotor activities that involved strong grasping muscles (i.e., digging and climbing) and an upright posture. Like many small-bodied extant mammals (e.g., squirrels; Jenkins, 1974; Jenkins and Parrington, 1976), this taxon probably exploited an array of niches in its environment.

Of the BCA "insectivoran" (EuD) specimens, one plots among the fossorial taxa in LDA morphospace and the other falls outside the area occupied by extant taxa but closest to fossorial and arboreal taxa. Locomotor predictions for these specimens vary from fossorial (93\% for UCMP 151964) to semifossorial (51\% for UCMP 153036; Appendix 36). The large entepicondyle of this morphotype, although not as medially extensive as in EuB or as robust as in EuC, implies that this taxon had powerful grasping muscles (Taylor, 1974; Szalay and Dagosto, 1980; Hildebrand, 1985; Szalay and Sargis, 2001; Salton and Sargis, 2008; Flores, 2009). The deep radial and olecranon fossae of EuD would have enabled substantial flexion and extension of its forelimbs (Penkrot et al., 2008; Flores, 2009). The lateral extension of the capitulum, where the supinator brevis muscle originates, implies habitual supination of the manus (the supinator brevis inserts on the proximal anterior radius; Flores, 2009). The morphology of EuD most closely resembles that of semifossorial afrosoricids and fossorial cingulatans, and fossorial, semifossorial, and saltatorial rodents (Figure 20.3-4). These data imply that EuD had a mobile elbow joint, capable of frequent supination and/or powerful grasping of the hand, typical of fossorial and semifossorial taxa.

We also provide functional comment on several other morphotypes that were not sufficiently preserved for inclusion in our quantitative analyses. Although the six multituberculate humerus morphotypes are distinct from one another, they all possess morphologies consistent with arboreality: they were capable of substantial pronation-supina- 
tion at the radial condyle and had large areas of attachment on the entepicondyle for muscles used in grasping (Krause and Jenkins, 1983). Likewise, the late Puercan ?plesiadapiform primate (EuA) has many humerus features in common with primates and Ptilocercus that imply an arboreal mode of locomotion; e.g., a wide entepicondyle for attachment of strong grasping muscles, a nearly spherical capitulum and separation of the capitulum and trochlea, both allowing forearm rotation, and weight-bearing humeroulnar joint (e.g., Szalay et al., 1975; Szalay and Dagosto, 1980; Szalay and Lucas, 1996; Sargis, 2002; Bloch et al., 2007; Boyer et al., 2010). This interpretation is consistent with recent analysis of tarsal fossils from the same assemblage that were attributed to the plesiadapiform Purgatorius (Chester et al., 2015). The large archaic ungulate (EuE) has broad epicondyles, unlike those found in cursorial mammals (e.g., Rose, 1987; Polly, 2007; Argot, 2010), and an elbow joint that does not restrict rotational movement on the posterior trochlea. This distal humerus morphology is similar to that of Arctocyon primaevus, which we take to mean that EuE was a late Puercan archaic ungulate with arboreal/scansorial capabilities (Argot, 2013).

\section{Evolutionary Implications of Locomotor Inferences}

Depressed latest Cretaceous locomotor diversity? Because mammals had diversified into semiaquatic, terrestrial, scansorial, arboreal, fossorial, semifossorial, and gliding forms by the Late Jurassic (Luo, 2007; Chen and Wilson, 2015), we might expect younger, Late Cretaceous faunas to have equal or greater locomotor diversity. However, our latest Cretaceous (Lancian) assemblage contains forms that we infer were only arboreal and semifossorial, and, more tentatively, saltatorial and semiaquatic. It lacks terrestrial and scansorial forms, as well as the more extreme forms of earlier Mesozoic mammals, such as the fossorial Fruitafossor (Luo and Wible, 2005), semiaquatic Castorocauda (Ji et al., 2006), and the gliding Volaticotherium (Meng et al., 2006). Several possible biases might contribute to this pattern: (i) the sample size of our Lancian assemblage is small; metatherians and eutherians are each represented by only a single humerus morphotype; (ii) greater locomotor diversity in the Lancian assemblage is masked by the incomplete nature of the specimens; and (iii) our Lancian assemblage represents the locomotor diversity from only a small geographic area (eastern Montana), a coastal lowland paleoenvironment, and a short temporal interval (ca. 69-66 Ma), compared to the locomotor diversity aggregated globally, across a diversity of paleohabitats and over tens of millions of years (Luo, 2007). Alternatively, this pattern could be biologically and evolutionarily meaningful. Our latest Cretaceous (Lancian) assemblage lacks many non-therian taxa (docodontans, eutriconodontans, and symmetrodontans) of the more ecomorphologically diverse Jurassic and Early Cretaceous mammalian faunas. The lower locomotor diversity of the latest Cretaceous assemblage could thus reflect the emerging picture that non-therian mammals, for unknown reasons, were able to ecologically diversify in the Mesozoic, whereas therians were more ecologically constrained until after the K-Pg mass extinction event (Wilson et al., 2012; Grossnickle and Polly, 2013; Wilson, 2013, 2014; but see Grossnickle and Newham, 2016; Wilson et al., 2016 for pre-K-Pg ecological diversification among therians).

Selectivity of diggers across the K-Pg mass extinction event? The Robertson et al. (2004) "Sheltering Hypothesis" implies that because certain behaviors (e.g., swimming and burrowing) would have protected animals from a global heat pulse of infrared radiation from ejecta re-entering the atmosphere in a K-Pg impact scenario, they would have been selected for in the mass extinction. Thus, we would predict a relative increase in fossorial, semifossorial, and/or semiaquatic forms from Lancian to earliest Paleocene (Pu1) mammalian assemblages. That said, none of our Puercan specimens show semiaquatic adaptations (DeBey and Wilson, 2014; this study), although one Lancian taxon, Didelphodon vorax, has been proposed as semiaquatic (Szalay, 1994; Longrich, 2005; Borths and Hunter, 2008; but see Fox and Naylor, 2006). We did, however, identify semifossorial forms in the Pu1 sample, specifically specimens attributed to the eutherians ?Protungulatum and ?Procerberus. The late Puercan (Pu3) sample, in contrast, lacks semifossorial forms and instead has arboreal and scansorial forms attributed to ?Purgatorius and a large archaic ungulate, respectively. One possible interpretation is that this pattern represents preferential survival of semifossorial forms across the K-Pg boundary; however, larger samples are needed to more robustly test this hypothesis.

Alternatively, differences in paleoenvironments might also affect the locomotor diversity across the K-Pg boundary. The shift from Hell Creek to Tullock deposition, which is locally nearly coincident with the K-Pg boundary, has been inter- 
preted as a broad-scale shift from open and broad, alluvial plains with meandering rivers to closed forests with more standing water and larger stream channels (Fastovsky,1987; Clemens, 2002; Johnson, 2002; Nichols and Johnson, 2008). However, our inferences of locomotor diversity in the Lancian and early Puercan assemblages in part run counter to changes predicted by this paleoenvironmental shift: we find no semiaquatic taxa and more semifossorial taxa in the wetter, more closed paleoenvironment of the Tullock Formation. Moreover, if solely paleoenvironment were driving these patterns, we would expect to see more consistent representation of locomotor modes across the Pu1 and Pu3 assemblages from the Tullock Formation, but we do not.

Decoupled diversification in the early Paleogene mammalian recovery. The dental fossil record indicates that the transition from "disaster" to "recovery" mammalian faunas occurred within 925,000 years of the K-Pg mass extinction event, from the Pu1 to Pu3 (Wilson, 2014; Sprain et al., 2015). In this episode, mammalian species richness more than doubled, from 18 to at least 40 species (Wilson, 2014). Because these mammalian species are based on dental morphology, this increase in species richness implies a concomitant and possibly equivalent expansion of dental and dietary diversity (Wilson, 2013). Body size also increased over this interval, by nearly two orders of magnitude as approximated by the dental and postcranial record (Wilson, 2013; DeBey and Wilson, 2014; this study). In contrast, gains in locomotor diversity per our current dataset appear to be more modest: there was the addition of scansorial and arboreal morphologies among eutherians, and the appearance of fossorial forms among multituberculates. This pattern could in part reflect poor sampling of the postcranial record, but it might also imply that taxonomic, dietary, and body-size diversification were decoupled from locomotor diversification. One possible explanation is that $\mathrm{K}-\mathrm{Pg}$ mass extinction removed some evolutionary constraints (e.g., competition from and predation by non-avian dinosaurs) but others remained or newly arose that differentially dampened locomotor diversification, at least locally. As stated above, sedimentological and paleobotanical data (e.g., Fastovsky, 1987; Johnson, 2002; Nichols and Johnson, 2008) indicate that habitat structure in our study area shifted near the K-Pg boundary. This shift from a more open paleoenvironment during the Lancian to a more heavily forested and closed habitat in the Puercan (Johnson, 2002; Nichols and Johnson,
2008) might have favored certain locomotor types, namely terrestrial, scansorial, and arboreal forms, whereas other locomotor types evolved or were favored as other habitats became more prevalent later. Additional postcranial and paleovegetational data are needed to more fully test this hypothesis.

\section{CONCLUSIONS}

Our research on postcranial fossils of K-Pg mammals (DeBey and Wilson, 2014; DeBey, 2015; this paper) is a preliminary step toward tracking the taxonomic, morphological, and ecological changes associated with the mass extinction event and the early Paleogene rise of placental mammals. We aim to use this record to test the ecological components of mass extinction and recovery dynamics beyond the traditional focus on dental fossils. We acknowledge the challenges of using isolated and fragmentary postcranial elements for this purpose: (i) taxonomic attributions are inherently tentative; (ii) locomotor inferences are blind to conflicting functional signals across elements (e.g., Chen and Wilson, 2015; Fabre et al., 2015); and (iii) the ability to discriminate among functionally similar locomotor modes (e.g., fossorial vs. semi-aquatic modes) let alone locomotor sub-modes (e.g., different methods of burrowing; Hopkins and Davis, 2009; Chen and Wilson, 2015; Fabre et al., 2015) is weaker than in analyses of more complete skeletons. However, the postcranial record of Late Cretaceous and early Paleogene mammals mostly consists of isolated and fragmentary elements (e.g., Deischl, 1964; Sloan and Van Valen, 1965; Szalay and Decker, 1974; Clemens, 2002; DeBey and Wilson, 2014); thus, we emphasize that the discussion points presented above, which follow from the results of our analyses of the limited postcranial fossil data (DeBey and Wilson, 2014; this study), should be considered working hypotheses to be more robustly tested in future studies with better samples. To this end, we urge researchers to redouble their efforts to amass larger samples of K$\mathrm{Pg}$ postcranial fossils by revisiting existing museum collections and investing in more intensive field efforts, particularly in undersampled depositional environments that might preserve more complete, associated postcranial remains of mammals (Wilson and Varricchio, 2014).

\section{ACKNOWLEDGMENTS}

We thank the individuals whose fieldwork and curation efforts have made this study possible, especially J.D. Archibald, W.A. Clemens, D. Lof- 
gren, the UCMP field crews who collected most of these specimens, and the students and volunteers, S. Zack and T. Stidham in particular, who sorted, identified, and curated them. For the recently collected material, we thank D. DeMar, Jr., S. Smith, S. Wang, M. Washington, and UW field crews. We thank P. Holroyd and W.A. Clemens (UCMP), J. Bradley, R. Eng, S. Santana, and C. Sidor (UWBM) for access to collections; the United States Bureau of Land Management (U.S. BLM), the Charles M. Russell National Wildlife Refuge, the Montana Department of Natural Resources and Conservation, the Hell Creek State Park, and the Engdahl, McKeever, Twitchell, Olsen and Strohs families for access to land; L. Heilicher for specimen photography, S. Chester for CT scans of UCMP 153100, O. Campos for 3D printing, and A. Brannick, J. Calede, M. Chen, S. Chester, W.A. Clemens, D. DeBey, D. DeMar, Jr., E. Nesbitt, C. Sidor, S. Smith, and C. Strömberg for suggestions, discussion, and comments on earlier drafts of this manuscript. We thank C. Huang and two anonymous reviewers for their thoughtful reviews of the manuscript. Funding was provided by the National Science Foundation Gradate Research Fellowship, Charlotte Cornell Crary Distinguished Teaching Fellowship, Henry and Frances Decker Fellowship, Evolving Earth Foundation, UCMP Doris O. and Samuel P. Welles Fund, U.S. BLM, and the UW Graduate and Professional Student Senate (all to LBD) and by the UW Department of Biology and N. Myhrvold support of the Hell Creek Project III (to LBD and GPW).

\section{REFERENCES}

Adams, D.C. and Otarola-Castillo, E. 2013. Geomorph: an $\mathrm{R}$ package for the collection and analysis of geometric morphometric shape data. Methods in Ecology and Evolution, 4:393-399.

Alroy, J. 1999. The fossil record of North American mammals: evidence for a Paleocene evolutionary radiation. Systematic Biology, 48:107-118.

Archibald, J.D. 1982. A study of Mammalia and geology across the Cretaceous-Tertiary boundary in Garfield County, Montana. University of California Publications in Geological Sciences, 122:1-286.

Archibald, J.D. 1983. Structure of the K-T mammal radiation in North America: speculations on turnover rates and trophic structure. Acta Palaeontologica Polonica, 28:7-17.

Archibald, J.D. and Clemens, W.A. 1984. Mammal evolution near the Cretaceous-Tertiary boundary, p. 339371. In Berggren, W.A. and Van Couvering, J.A. (eds.), Catastrophes in Earth History: the New Uni- formitarianism. Princeton University Press, Princeton.

Argot, C. 2001. Functional-adaptive anatomy of the forelimb in the Didelphidae, and the paleobiology of the Paleocene marsupials Mayulestes ferox and Pucadelphys andinus. Journal of Morphology, 247:51-79.

Argot, C. 2010. Morphofunctional analysis of the postcranium of Amphicyon major (Mammalia, Carnivora, Amphicyonidae) from the Miocene of Sansan (Gers, France) compared to three extant carnivores: Ursus arctos, Panthera leo, and Canis lupus. Geodiversitas, 32:65-106.

Argot, C. 2013. Postcranial analysis of a Carnivoran-like archaic ungulate: the case of Arctocyon primaevus (Arctocyonidae, Mammalia) from the Late Paleocene of France. Journal of Mammalian Evolution, 20:83114.

Bassarova, M., Janis, C.M., and Archer, M. 2009. The calcaneum-on the heels of marsupial locomotion. Journal of Mammalian Evolution, 16:1-23.

Bloch, J.I., Silcox, M.T., Boyer, D.M., and Sargis, E.J. 2007. New Paleocene skeletons and the relationship of plesiadapiforms to crown-clade primates. Proceedings of the National Academy of Sciences, 104:1159-1164.

Bookstein, F.L. 1991. Morphometric Tools for Landmark Data: Geometry and Biology. Cambridge University Press, Cambridge.

Borths, M. and Hunter, J. 2008. Gimme shelter? Locomotor trends and mammalian survivorship at the KPg boundary. Journal of Vertebrate Paleontology, 28:3A.

Boyer, D.M., Prasad, G.V.R., Krause, D.W., Godinot, M., Goswami, A., Verma, O., and Flynn, J.J. 2010. New postcrania of Deccanolestes from the Late Cretaceous of India and their bearing on the evolutionary and biogeographic history of euarchontan mammals. Naturwissenschaften, 97:365-377.

Boyer, D.M. and Seiffert, E.R. 2013. Patterns of astragalar fibular facet orientation in extant and fossil primates and their evolutionary implications. American Journal of Physical Anthropology, 151:420-447.

Brown, J.C. and Yalden, D.W. 1973. Limbs and locomotion of terrestrial mammals. Mammal Review, 3:107134.

Cardini, A. 2014. Missing the third dimension in geometric morphometrics: How to assess if $2 \mathrm{D}$ images really are a good proxy for 3D Structures? Hystrix, the Italian Journal of Mammalogy, 25:73-81.

Cardini, A., Seetah, K., and Barker, G. 2015. How many specimens do I need? Sampling error in geometric morphometrics: testing the sensitivity of means and variances in simple randomized selection experiments. Zoomorphology, 134:149-163.

Chen, M. and Wilson, G.P. 2015. A multivariate approach to infer locomotor modes in Mesozoic mammals. Paleobiology, 41:280-312.

Chester, S.G.B., Bloch, J.I., Boyer, D.M., and Clemens, W.A. 2015. Oldest known euarchontan tarsals and 
affinities of Paleocene Purgatorius to primates. Proceedings of the National Academy of Sciences, 112:1487-1492.

Chester, S.G.B., Sargis, E.J., Szalay, F.S., Archibald, J.D., and Averianov, A.O. 2010. Mammalian distal humeri from the Late Cretaceous of Uzbekistan. Acta Palaeontologica Polonica, 55:199-211.

Chester, S.G.B., Sargis, E.J., Szalay, F.S., Archibald, J.D., and Averianov, A.O. 2012. Therian femora from the Late Cretaceous of Uzbekistan. Acta Palaeontologica Polonica, 57:53-64.

Cifelli, R.L., Eberle, J.J., Lofgren, D.L., Lillegraven, J.A., and Clemens, W.A. 2004. Mammalian biochronology of the latest Cretaceous, p. 21-42. In Woodburne, M.O. (ed.), Late Cretaceous and Cenozoic Mammals of North America: Biostratigraphy and Geochronology. Columbia University Press, New York.

Clemens, W.A. 1963. Fossil mammals of the type Lance formation Wyoming; Part I, introduction and Multituberculata. University of California Publications in Geological Sciences, 48:1-105.

Clemens, W.A. 1964. Fossil mammals of the type Lance Formation, Wyoming, Part I. Introduction and Multituberculata. University of California Publications in Geological Sciences, 48:1-105.

Clemens, W.A. 2002. Evolution of the mammalian fauna across the Cretaceous-Tertiary boundary in northeastern Montana and other areas of the Western Interior, p. 217-245. In Hartman, J.H., Johnson, K.R., and Nichols, D.J. (eds.), The Hell Creek Formation and the Cretaceous-Tertiary Boundary in the Northern Great Plains: An Integrated Continental Record of the End of the Cretaceous. Geological Society of America Special Paper 361, Boulder, Colorado.

Clemens, W.A. 2004. Purgatorius (Plesiadapiformes, Primates?, Mammalia), a Paleocene immigrant into northeastern Montana: stratigraphic occurrences and incisor proportions. Bulletin of Carnegie Museum of Natural History, 36:3-13.

Clemens, W.A. 2011. Eoconodon ("Triisodontidae," Mammalia) From the Early Paleocene (Puercan) of Northeastern Montana, USA. Palaeontologia Electronica, 14.3.22A:22 pp, 2.9MB; http://palaeo-electronica.org/2011_3/3clemens/index.html

Clemens, W.A. 2015. Prodiacodon crustulum (Leptictidae, Mammalia) from the Tullock Member of the Fort Union Formation, Garfield and McCone counties, Montana, USA. PaleoBios, 32:1-17.

Clemens, W.A. 2017. A pantodont (Mammalia) from the latest Puercan North American Land Mammal Age (earliest Paleocene) of the Western Interior, USA. Historical Biology: 1-6, doi.org/10.1080/08912963.2016.1276178.

Clemens, W.A. and Kielan-Jaworowska, Z. 1979. Multituberculata, p. 99-149. In Lillegraven, J.A., KielanJaworowska, Z., and Clemens, W.A. (eds.), Mesozoic Mammals: the First Two-Thirds of Mammalian History, University of California Press, Berkeley.
Cope, E.D. 1884. The Tertiary Marsupialia. American Naturalist, 18:686-697.

DeBey, L.B. 2015. Digging up the Past: Postcranial Perspectives on Mammals Across the CretaceousPaleogene Boundary. Unpublished Ph.D. Dissertation. University of Washington, Seattle, Washington, USA.

DeBey, L.B. and Wilson, G.P. 2014. Mammalian femora across the Cretaceous-Paleogene boundary in eastern Montana. Cretaceous Research, 51:361-385.

Deischl, D.G. 1964. The Postcranial Anatomy of Cretaceous Multituberculate Mammals. Unpublished M.Sc. Thesis, University of Minnesota, Minneapolis, Minnesota, USA.

Delciellos, A.C. and Vieira, M.V. 2006. Arboreal walking performance in seven didelphid marsupials as an aspect of their fundamental niche. Austral Ecology, 31:449-457.

Egi, N. 2001. Body mass estimates in extinct mammals from limb bone dimensions: the case of North American Hyaenodontids. Palaeontology, 44:497-528.

Elissamburu, A. and Vizcano, S.F. 2004. Limb proportions and adaptations in caviomorph rodents (Rodentia: Caviomorpha). Journal of Zoology, 262:145-159.

Endo, H., Yonezawa, T., Rakotondraparany, F., Sasaki, M., and Hasegawa, M. 2006. The adaptational strategies of the hindlimb muscles in the Tenrecidae species including the aquatic web-footed tenrec (Limnogale mergulus). Annals of Anatomy, 188:383390.

Fabre, A.-C., Salesa, M.J., Cornette, R., Antón, M., Morales, J., and Peigné, S. 2015. Quantitative inferences on the locomotor behaviour of extinct species applied to Simocyon batalleri (Ailuridae, Late Miocene, Spain). The Science of Nature, 102:30.

Fastovsky, D.E. 1987. Paleoenvironments of vertebratebearing strata during the Cretaceous-Paleogene transition, eastern Montana and western North Dakota. PALAIOS, 2:282-295.

Flores, D.A. 2009. Phylogenetic analyses of postcranial skeletal morphology in didelphid marsupials. Bulletin of the American Museum of Natural History, 320:181.

Fox, R.C. 1989. The Wounded Knee local fauna and mammalian evolution near the Cretaceous-Tertiary boundary, Saskatchewan, Canada. Palaeontographica, Abteilung A, 208:11-59.

Fox, R.C. 2005. Microcosmodontid multituberculates (Allotheria, Mammalia) from the Paleocene and Late Cretaceous of western Canada. Palaeontographica Canadiana, 23:1-109.

Fox, R.C. and B.G. Naylor. 2006. Stagodontid marsupials from the Late Cretaceous of Canada and their systematic and functional implications. Acta Palaeontologica Polonica 51:13-36.

Gambaryan, P.P. and Kielan-Jaworowska, Z. 1997. Sprawling versus parasagittal stance in multituberculate mammals. Acta Palaeontologica Polonica, 42:12-44. 
Gidley, J.W. 1909. Notes on the fossil mammalian genus Ptilodus, with descriptions of new species. Proceedings of the United States National Museum, 36:611627.

Gingerich, P.D. 2003. Land-to-sea transition in early whales: evolution of Eocene Archaeoceti (Cetacea) in relation to skeletal proportions and locomotion of living semiaquatic mammals. Paleobiology, 29:429454.

Grossnickle, D.M. and Polly. P.D. 2013. Mammal disparity decreases during the Cretaceous angiosperm radiation. Proceedings of the Royal Society of London B: Biological Sciences 280:20132110.

Grossnickle, D.M. and Newham, E. 2016. Therian mammals experience an ecomorphological radiation during the Late Cretaceous and selective extinction at the K-Pg boundary. Proceedings of the Royal Society of London B: Biological Sciences 283:20160256.

Gunz, P. and Mitteroecker, P. 2013. Semilandmarks: a method for quantifying curves and surfaces. Hystrix, the Italian Journal of Mammalogy, 24:103-109.

Heinrich, R. and Houde, P. 2006. Postcranial anatomy of Viverravus (Mammalia, Carnivora) and implications for substrate use in basal Carnivora. Journal of Vertebrate Paleontology, 26:422-435

Hildebrand, M. 1985. Digging in quadrupeds, p. 89-109. In Hildebrand, M., Bramble, D.M., Liem, K.F., and Wake, D.B. (eds.), Functional Vertebrate Morphology. Harvard University Press, Cambridge.

Hildebrand, M. 1988. Analysis of Vertebrate Structure. Wiley, New York.

Hildebrand, M., Bramble, D.M., Liem, K.F., and Wake, D.B. 1985. Functional Vertebrate Morphology. Harvard University Press, Cambridge.

Hooker, J.J. 2014. New postcranial bones of the extinct mammalian family Nyctitheriidae (Paleogene, UK): primitive euarchontans with scansorial locomotion. Palaeontologia Electronica, 17.3.47A:82pp, 16.7MB; http://palaeo-electronica.org/content/2014/974-nyctithere-postcrania

Horovitz, I. 2003. Postcranial skeleton of Ukhaatherium nessovi (Eutheria, Mammalia) from the Late Cretaceous of Mongolia. Journal of Vertebrate Paleontology, 23:857-68.

Howell, A.B. 1930. Aquatic Mammals. Charles C. Thomas, Springfield, Illinois.

Hunter, J.P., Hartman, J.H., and Krause, D.W. 1997. Mammals and mollusks across the Cretaceous-Tertiary boundary from Makoshika State Park and vicinity (Williston Basin), Montana. University of Wyoming Contributions to Geology, 32:61-114.

Iwaniuk, A.N., Pellis, S.M., and Whishaw, I.Q. 1999. The relationship between forelimb morphology and behavior in North American carnivores (Carnivora). Canadian Journal of Zoology, 77:1064-1074.

Janis, C.M. and Figueirido, B. 2014. Forelimb anatomy and the discrimination of the predatory behavior of carnivorous mammals: the thylacine as a case study. Journal of Morphology, 275:1321-1338.

Jenkins, F.A., Jr. 1973. The functional anatomy and evolution of the mammalian humero-ulnar articulation. American Journal of Anatomy, 137:281-298.

Ji, Q., Luo, Z.-X., Yuan, C.-Z., Wible, J.R., Zhang, J.-P., and Georgi, J.A. 2002. The earliest known eutherian mammal. Nature, 416:816-822.

Johnson, K.R. 2002. Megaflora of the Hell Creek and lower Fort Union Formations in the western Dakotas: Vegetational response to climate change, the Cretaceous-Tertiary boundary event, and rapid marine transgression, p. 329-391. In Hartman, J.H., Johnson, K.R., and Nichols, D.J. (eds.), The Hell Creek Formation and the Cretaceous-Tertiary Boundary in the Northern Great Plains: An Integrated Continental Record of the End of the Cretaceous. Geological Society of America Special Paper 361, Boulder, Colorado.

Kelly, T.S. 2014. Preliminary report on the mammals from Lane's Little Jaw Site Quarry: a Latest Cretaceous (earliest Puercan?) Local Fauna, Hell Creek Formation, southeastern Montana. Paludicola, 10:50-91.

Kendall, D.G. 1977. The diffusion of shape. Advances in Applied Probability, 9:428-430.

Kielan-Jaworowska, Z. and Dashzeveg, D. 1978. New Late Cretaceous mammal locality in Mongolia and a description of a new multituberculate. Acta Paleontologica Polonica, 23:115-130.

Kielan-Jaworowska, Z. and Gambaryan, P.P. 1994. Postcranial anatomy and habits of Asian multituberculate mammals. Fossils and Strata, 36:1-92.

Kielan-Jaworowska, Z. and Hurum, J.H. 2006. Limb posture in early mammals: sprawling or parasagittal. Acta Palaeontologica Polonica, 51:393-406.

Kielan-Jaworowska, Z. and Qi, T. 1990. Fossorial adaptations of a taeniolabidoid multituberculate mammal from the Eocene of China. Vertebrata PalAsiatica, 28:81-94.

Kondrashov, P.E. and Lucas, S.G. 2012. Nearly complete skeleton of Tetraclaenodon (Mammalia, Phenacodontidae) from the Early Paleocene of New Mexico: morpho-functional analysis. Journal of Paleontology, 86:25-43.

Körtner, G. and Geiser, F. 2000. Torpor and activity patterns in free-ranging sugar gliders Petaurus breviceps (Marsupialia). Oecologia, 123:350-357.

Krause, D.W. and Jenkins, Jr., F.A. 1983. The postcranial skeleton of North American multituberculates. Bulletin of the Museum of Comparative Zoology, 150:199-246.

Lackey, J.A. 1996. Chaetodipus fallax. Mammalian Species, 517:1-6.

Lariviére, S. 1999. Mustela vison. Mammalian Species, 608:1-9.

Lariviére, S. and Pasitschniak-Arts, M. 1996. Vulpes vulpes. Mammalian Species, 537:1-11. 
LeCain, R., Clyde, W.C., Wilson, G.P., and Riedel, J. 2014. Magnetostratigraphy of the Hell Creek and lower Fort Union Formations in northeastern Montana, p. 137-147. In Wilson, G.P., Clemens, W.A., Horner, J.R., and Hartman, J.H. (eds.), Through the End of the Cretaceous in the Type Locality of the Hell Creek Formation in Montana and Adjacent Areas. Geological Society of America Special Paper 503, Boulder, Colorado.

Lillegraven, J.A. 1972. Preliminary report on Late Cretaceous mammals from the El Gallo Formation, Baja de California, Mexico. In Clemens, W.A., Fox, R.C., and Whistler, D.P. (eds.), Contributions in Science, 1-11. Los Angeles County Natural History Museum, Los Angeles.

Lofgren, D.L. 1995. The Bug Creek problem and the Cretaceous-Tertiary transition at McGuire Creek, Montana. University of California Publications in Geological Sciences, 140:1-185.

Lofgren, D.L., Lillegraven, J.A., Clemens, W.A., Gingerich, P.D., and Williamson, T.E. 2004. Paleocene biochronology: The Puercan through Clarkforkian land mammal ages, p. 43-105. In Woodburne, M.O. (ed.), Late Cretaceous and Cenozoic Mammals of North America: Biostratigraphy and Geochronology. Columbia University Press, New York.

Longrich, N. 2005. Aquatic specialization in marsupials from the Late Cretaceous of North America. Cranbrook Institiute of Science Miscellaneous Publications (Evolution of Aquatic Tetrapods Convention Abstracts) $V, 1: 53$.

Luo, Z.-X. 1991. Variability of dental morphology and the relationships of the earliest arctocyonid species. Journal of Vertebrate Paleontology, 11:452-471.

Luo, Z.-X. 2007. Transformation and diversification in early mammal evolution. Nature, 450:1011-1019.

Luo, Z.-X., Ji, Q., Wible, J.R., and Yuan, C.-X. 2003. An Early Cretaceous tribosphenic mammal and metatherian evolution. Science, 302:1934-1940.

Maas, M.C. and Krause, D.W. 1994. Mammalian turnover and community structure of the Paleocene of North America. Historical Biology, 8:91-128.

Marsh, O.C. 1889. Discovery of Cretaceous Mammalia. American Journal of Science, 38:81-92.

Marshall, L.G., de Muizon, C., and Sigogneau-Russell, D. 1995. Pucadelphys andinus (Marsupialia, Mammalia) from the Early Paleocene of Bolivia. Mémoires du Muséum National D'Histoire Naturelle, 165:91164.

Matthew, W.D. 1937. Paleocene faunas of the San Juan Basin, New Mexico. Transactions of the American Philosophical Society, 30:1-523.

Meachen-Samuels, J. 2010. Comparative scaling of humeral cross-sections of felids and canids using radiographic images. Journal of Mammalian Evolution, 17:193-209.

Milne, N., Vizcaíno, S.F., and Fernicola, J.C. 2009. A 3D geometric morphometric analysis of digging ability in the extant and fossil cingulate humerus. Journal of Zoology, 278:48-56.

Mitteroecker, P. and Bookstein, F. 2011. Linear discrimination, ordination, and the visualization of selection gradients in modern morphometrics. Evolutionary Biology, 38:100-114.

Moore, J.R., Wilson, G.P., Sharma, M., Hallock, H.R., Braman, D.R., and Renne, P. 2014. Assessing the relationships of the Hell Creek-Fort Union contact, Cretaceous-Paleogene boundary, and Chicxulub impact ejecta horizon at the Hell Creek Formation lectostratotype, Montana, USA, p. 123-136. In Wilson, G.P., Clemens, W.A., Horner, J.R., and Hartman, J.H. (eds.), Through the End of the Cretaceous in the Type Locality of the Hell Creek Formation in Montana and Adjacent Areas. Geological Society of America Special Paper 503, Boulder, Colorado.

Morgan, C.C. and Álvarez, A. 2013. The humerus of South American caviomorph rodents: shape, function and size in a phylogenetic context. Journal of Zoology, 290:107-116.

Muizon, C. 1998. Mayulestes ferox, a bohyaenoid (Metatheria, Mammalia) from the early Palaeocene of Bolivia. Phylogenetic and palaeobiologic implications. Geodiversitas, 20:19-142.

Nichols, D.J. and Johnson, K.R. 2008. Plants and the K$T$ Boundary. Cambridge University Press, Cambridge.

Nowak, R.M. 1999. Walker's Mammals of the World. Johns Hopkins University Press, Baltimore, Maryland.

Nyakatura, J.A., Fischer, M.S., and Schmidt, M. 2008. Gait parameter adjustments of cotton-top tamarins (Saguinus oedipus, Callitrichidae) to locomotion on inclined arboreal substrates. American Journal of Physical Anthropology, 135:13-26.

O'Leary, M.A., Bloch, J.I., Flynn, J.J., Gaudin, T.J., Giallombardo, A., Giannini, N.P., Goldberg, S.L., Kraatz, B.P., Luo, Z.-X., Meng, J., Ni, X., Novacek, M.J., Perini, F.A., Randall, Z.S., Rougier, G.W., Sargis, E.J., Silcox, M.T., Simmons, N.B., Spaulding, M., Velazco, P.M., Weksler, M., Wible, J.R., and Cirranello, A.L. 2013. The placental mammal ancestor and the postK-Pg radiation of placentals. Science, 339:662-667.

Osborn, H.F. and Earle, C. 1895. Fossil mammals of the Puerco beds. Collection of 1892. Bulletin of the American Museum of Natural History, 7:1-70.

Pasitschniak-Arts, M. and Lariviére, S. 1995. Gulo gulo. Mammalian Species, 499:1-10.

Penkrot, T.A., Zack, S.P., Rose, K.D., and Bloch, J.I. 2008. Postcranial morphology of Apheliscus and Haplomylus (Condylarthra, Apheliscidae): evidence for a Paleocene Holarctic origin of Macroscelidea, $p$. 73-106. In Sargis, E.J. and Dagosto, M. (eds.), Mammalian Evolutionary Morphology: A Tribute to Frederick S. Szalay. Springer, Dordrecht.

Polly, P.D. 2007. Limbs in mammalian evolution, p. 1-24. In Hall, B.K. (ed.) Fins into Limbs: Evolution, Devel- 
opment, and Transformation. University of Chicago Press, Chicago.

Polly, P.D. 2008. Adaptive zones and the pinniped ankle: a 3D quantitative analysis of carnivoran tarsal evolution, p. 167-196. In Sargis, E. and Dagosto, M. (eds.), Mammalian Evolutionary Morphology: A Tribute to Frederick S. Szalay. Springer, Dordrecht.

Polly, P.D. and MacLeod, N. 2008. Locomotion in fossil Carnivora: an application of eigensurface analysis for morphometric comparison of 3D surfaces. Palaeontologia Electronica, 11.2.10A:13pp, 0.8MB; http:// palaeo-electronica.org/2008_2/135/index.html

R Core Team. 2014. R: A language and environment for statistical computing (Version 3.1.2). R Foundation for Statistical Computing, Vienna, Austria. URL http:// www.R-project.org/.

RStudio. 2012. RStudio: Integrated development environment for $\mathrm{R}$ (Version 0.98.1062). Boston, MA. URL http://www.rstudio.com/.

Raia, P., Carotenuto, F., Passaro, F., Piras, P., Fulgione, D., Werdelin, L., Saarinen, J., and Fortelius, M. 2012. Rapid action in the Palaeogene, the relationship between phenotypic and taxonomic diversification in Coenozoic mammals. Proceedings of the Royal Society B: Biological Sciences, 280:20122244.

Redford, K.H. and Wetzel, R.M. 1985. Euphractus sexcinctus. Mammalian Species, 252:1-4.

Renne, P.R., Balco, G., Ludwig, K.R., Mundil, R., and Min, K. 2011. Response to the comment by W.H. Schwartz et al. on "Joint determination of $40 \mathrm{~K}$ decay constants and $40 \mathrm{Ar}^{*} / 40 \mathrm{~K}$ for the Fish Canyon sanidine standard, and improved accuracy for the 40Ar/ 39Ar geochronology" by P.R. Renne et al. (2010). Geochimica et Cosmochimica Acta, 75:5097-5100.

Renne, P.R., Deino, A.L., Hilgen, F.J., Kuiper, K.F., Mark, D.F., Mitchell III, W.S., Morgan, L.E., Mundil, R., and Smit, J. 2013. Time scales of critical events around the Cretaceous-Paleogene boundary. Science, 339:684-687.

Rigby, J.K. Jr., 1981. A skeleton of Gillisonchus gillianus (Mammalia; Condylarthra) from the Early Paleocene (Puercan) Ojo Alamo Sandstone, San Juan Basin, New Mexico, with comments on the local stratigraphy of Betonnie Tsosie Wash, p. 89-126. In Lucas, S.G., Rigby Jr., J.K., and Kues, B.S. (eds.), Advances in San Juan Basin Paleontology. University of New Mexico Press, Albuquerque.

Robertson, D.S., McKenna, M.C., Toon, O.B., Hope, S., and Lillegraven, J.A. 2004. Survival in the first hours of the Cenozoic. Geological Society of America Bulletin, 116:760-768.

Rohlf, F.J. 2013a. tpsDIG Version 2.17. Department of Ecology and Evolution, State University of New York at Stony Brook, New York.

Rohlf, F.J. 2013b. tpsUtil Version 1.58. Department of Ecology and Evolution, State University of New York at Stony Brook, New York.
Rohlf, F.J. and Slice, D. 1990. Extensions of the Procrustes method for the optimal superimposition of landmarks. Systematic Zoology, 39:40-59.

Rose, K.D. 1987. Climbing adaptations in the early Eocene mammal Chriacus and the origin of Artiodactyla. Science, 236:314-316.

Rose, K. 1999. Postcranial skeleton of Eocene Leptictidae (Mammalia), and its implications for behavior and relationships. Journal of Vertebrate Paleontology, 19:355-372.

Rowe, T. 1988. Definition, diagnosis, and origin of Mammalia. Journal of Vertebrate Paleontology, 8:241264.

Russell, D.E. 1964. Les mammifères paléocènes d'Europe. Mémoires du Muséum National D'Histoire Naturelle, Série C. Sciences de la Terre, 13:1-324.

Sahni, A. 1972. The vertebrate fauna of the Judith River Formation, Montana. Bulletin of the American Museum of Natural History, 147:323-412.

Salton, J.A. and Sargis, E.J. 2008. Evolutionary morphology of the Tenrecoidea (Mammalia) forelimb skeleton, p. 51-71. In Sargis, E.J. and Dagosto, M. (eds.), Mammalian Evolutionary Morphology: A Tribute to Frederick S. Szalay. Springer, Dordrecht.

Samuels, J.X. and Van Valkenburgh, B. 2008. Skeletal indicators of locomotor adaptations in living and extinct rodents. Journal of Morphology, 269:13871411.

Sargis, E.J. 2002. Functional morphology of the forelimb of tupaiids (Mammalia, Scandentia) and its phylogenetic implications. Journal of Morphology, 253:10-42.

Schoch, R.M. 1986. Systematics, functional morphology and macroevolution of the extinct mammalian order Taeniodonta. Peabody Museum of Natural History, Yale University Bulletin, 42:1-307.

Schutz, H. and Guralnick, R.P. 2007. Postcranial element shape and function: assessing locomotor mode in extant and extinct mustelid carnivorans. Zoological Journal of the Linnean Society, 150:895-914.

Simpson, G.G. 1935. The Tiffany Fauna, Upper Paleocene II.-Structure and relationships of Plesiadapis. American Museum Novitates, 816:1-30.

Sloan, R.E. and Van Valen, L. 1965. Cretaceous mammals from Montana. Science, 148:220-227.

Smith, F.A., Boyer, A.G., Brown, J.H., Costa, D.P., Dayan, T., Ernest, S.K.M., Evans, A.R., Fortelius, M., Gittleman, J.L., Hamilton, M.J., Harding, L.E., Lintulaakso, K., Lyons, S.K., McCain, C., Okie, J.G., Saarinen, J.J., Sibly, R.M., Stephens, P.R., Theodor, J., and Uhen, M.D. 2010. The evolution of maximum body size of terrestrial mammals. Science, 330:1216-1219.

Smith, J.M. and Savage, R.J.G. 1956. Locomotor adaptations in mammals. Zoological Journal of the Linnean Society, 42:603-622.

Smith, M.J. 1973. Petaurus breviceps. Mammalian Species, 30:1-5.

Sprain, C.J., Renne, P.R., Wilson, G.P., and Clemens, W.A. 2014. High-resolution chronostratigraphy of the 
terrestrial Cretaceous-Paleogene transition and recovery interval in the Hell Creek region, Montana. Geological Society of America Bulletin, 127:393-409.

Standhardt, B.R. 1986. Vertebrate Paleontology of the Cretaceous/Tertiary Transition of Big Bend National Park, Texas. Ph.D. Dissertation. Louisiana State University and Agricultural and Mechanical College, Baton Rouge, Louisiana, USA.

Steiner-Souza, F., De Freitas, T.R.O., and CordeiroEstrela, P. 2010. Inferring adaptation within shape diversity of the humerus of subterranean rodent Ctenomys. Biological Journal of the Linnean Society, 100:353-367.

Stucky, R.K. 1990. Evolution of land mammal diversity in North America during the Cenozoic. Current Mammalogy, 2:375-432.

Swisher III, C.C., Dingus, L., and Butler, R.F. 1993. 40Ar/ 39Ar dating and magnetostratigraphic correlation of the terrestrial Cretaceous-Paleogene boundary and Puercan mammal age, Hell Creek-Tullock formations, eastern Montana. Canadian Journal of Earth Sciences, 30:1981-1996.

Szalay, F.S. 1994. Evolutionary History of the Marsupials and an Analysis of Osteological Characters. Cambridge University Press, New York.

Szalay, F.S. and Dagosto, M. 1980. Locomotor adaptations as reflected on the humerus of Paleogene primates. Folia Primatologica, 34:1-45.

Szalay, F.S. and Decker, R.L. 1974. Origins, evolution, and function of the tarsus in Late Cretaceous Eutheria and Paleocene primates, p. 223-259. In Jenkins Jr., F.A. (ed.), Primate Locomotion. Academic Press, Inc., New York.

Szalay, F.S. and Lucas, S.G. 1996. The postcranial morphology of Paleocene Chriacus and Mixodectes and the phylogenetic relationships of archontan mammals. New Mexico Museum of Natural History and Science Bulletin, 7:1-47.

Szalay, F.S. and Sargis, E.J. 2001. Model-based analysis of postcranial osteology of marsupials from the Palaeocene of Itaborai (Brazil) and the phylogenetics and biogeography of Metatheria. Geodiversitas, 23:139-302.

Szalay, F.S., Tattersall, I., and Decker, R.L. 1975. Phylogenetic relationships of Plesiadapis-postcranial evidence. Contributions to Primatology, 5:136-166.

Szalay, F.S. and Trofimov, B.A. 1996. The Mongolian Late Cretaceous Asiatherium, and the early phylogeny and paleobiogeography of Metatheria. Journal of Vertebrate Paleontology, 16:474-509.

Taylor, M.E. 1974. The functional anatomy of the forelimb of some African Viverridae (Carnivora). Journal of Morphology, 143:307-336.

van Staaden, M.J. 1994. Suricata suricatta. Mammalian Species, 483:1-8.

Van Valen, L.M. 1978. The beginning of the Age of Mammals. Evolutionary Theory, 4:45-80.
Van Valkenburgh, B. 1987. Skeletal indicators of locomotor behavior in living and extinct carnivores. Journal of Vertebrate Paleontology, 7:162-182.

Venables, W.N. and Ripley, B.D. 2002. Modern Applied Statistics with S. Fourth Edition. Springer, New York.

Wade-Smith, J. and Verts, B.J. 1982. Mephitis mephitis. Mammalian Species, 173:1-7.

Warburton, N.M., Harvey, K.J., Prideaux, G.J., and O'Shea, J.E. 2011. Functional morphology of the forelimb of living and extinct tree-kangaroos (Marsupialia: Macropodidae). Journal of Morphology, 272:1230-1244.

Weil, A. and Krause, D.W. 2008. Multituberculata, p. 1938. In Janis, C.M., Gunnell, G.F., and Uhen, M.D. (eds.), Evolution of Tertiary Mammals of North America Vol. 2. Cambridge University Press, Cambridge.

Wilf, P., Johnson, K.R., and Huber, B.T. 2003. Correlated terrestrial and marine evidence for global climate changes before mass extinction at the CretaceousPaleogene boundary. Proceedings of the National Academy of Sciences, 100:599-604.

Wilson, G.P. 2004. A Quantitative Assessment of Evolutionary and Ecological Change in Mammalian Faunas Leading up to and across the CretaceousTertiary Boundary in Northeastern Montana. Unpublished Ph.D. Dissertation, University of California Berkeley, Berkeley, California, USA.

Wilson, G.P. 2005. Mammalian faunal dynamics during the last 1.8 million years of the Cretaceous in Garfield County, Montana. Journal of Mammalian Evolution, 12:53-75.

Wilson, G.P. 2013. Mammals across the K/Pg boundary in northeastern Montana, U.S.A.: dental morphology and body-size patterns reveal extinction selectivity and immigrant fueled ecospace filling. Paleobiology, 39:429-469.

Wilson, G.P. 2014. Mammalian extinction, survival, and recovery dynamics across the Cretaceous-Paleogene boundary in northeastern Montana, p. 365392. In Wilson, G.P., Clemens, W.A., Horner, J.R., and Hartman, J.H. (eds.), Through the End of the Cretaceous in the Type Locality of the Hell Creek Formation in Montana and Adjacent Areas. Geological Society of America Special Paper 503, Boulder, Colorado.

Wilson, G.P., Evans, A.R., Corfe, I.J., Smits, P.D., Fortelius, M., and Jernvall, J. 2012. Adaptive radiation of multituberculate mammals before the extinction of dinosaurs. Nature, 483:457-460.

Wilson, G.P., DeMar Jr., D.G., and Carter, G. 2014. Extinction and survival of salamander and salamander-like amphibians across the Cretaceous-Paleogene boundary in northeastern Montana, p. 271297. In Wilson, G.P., Clemens, W.A., Horner, J.R., and Hartman, J.H. (eds.), Through the End of the Cretaceous in the Type Locality of the Hell Creek Formation in Montana and Adjacent Areas. Geological Society of America Special Paper 503, Boulder, Colorado. 
Wilson, G.P., Ekdale, E.G., Hoganson, J.W., Calede, J.J., and Vander Linden, A. 2016. A large carnivorous mammal from the Late Cretaceous and the North American origin of marsupials. Nature Communications, 10 pages, doi:10.1038/ncomms13734.
Williamson, T.E., Brusatte, S.L., and Wilson, G.P. 2014. The origin and early evolution of Metatherian mammals: The Cretaceous record. ZooKeys, 465:1-76.

Zelditch, M.L., Swiderski, D.L., Sheets, H.D., and Fink, W.L. 2004. Geometric Morphometrics for Biologists: a Primer. Elsevier Academic Press, Amsterdam. 


\section{APPENDIX 1.}

Localities containing specimens used in this study. Locality numbers follow the system of each institution; those beginning with "V" are UCMP localities; those beginning with "C" are UWBM localities. All localities are in Montana except for V5620, which is in Wyoming. Abbreviations: Fm, formation; La, Lancian; n, number of specimens from the locality; Pu1, Puercan 1; Pu3, Puercan 3.

\begin{tabular}{|c|c|c|c|c|c|}
\hline Loc. Number & Locality Name & County & Fm & Biozone & $\mathbf{n}$ \\
\hline $\mathrm{C0338}$ & Bug Creek A & McCone & Hell Creek & mixed & 2 \\
\hline C1115 & Celeste's Magnificent Microsite & Garfield & Hell Creek & Lancian & 1 \\
\hline C1163 & MacDonald & Garfield & Tullock & Pu3 & 1 \\
\hline C1521 & Wake Up & Garfield & Hell Creek & Lancian & 1 \\
\hline C1845 & Bug Creek & McCone & Hell Creek & mixed & 1 \\
\hline V5620 & Lull 2 & Niobrara & Lance & Lancian & 4 \\
\hline V65127 & Bug Creek Anthills General & McCone & Hell Creek & mixed & 11 \\
\hline V70201 & Bug Creek Anthills C & McCone & Hell Creek & mixed & 4 \\
\hline V70209 & Bug Creek W & McCone & Hell Creek & mixed & 4 \\
\hline V71203 & Harbicht Hill 1 & McCone & Hell Creek & mixed & 1 \\
\hline V72129 & Garbani 04-Nw-S Level 1 & Garfield & Tullock & Pu3 & 1 \\
\hline V72207 & Windy Hill & Garfield & Hell Creek & Lancian & 2 \\
\hline V73087 & Flat Creek 5 & Garfield & Hell Creek & Lancian & 1 \\
\hline V73097 & Brownie Butte & Garfield & Hell Creek & Lancian & 1 \\
\hline V74111 & Worm Coulee 1 & Garfield & Tullock & Pu1 & 3 \\
\hline V74122 & Biscuit Springs & Garfield & Tullock & Pu3 & 1 \\
\hline V74124 & Yellow Sand Hill 2 & Garfield & Tullock & Pu3 & 1 \\
\hline V84162 & Sand Cave & Garfield & Hell Creek & Pu1 & 1 \\
\hline V84193 & Z-Line Quarry & McCone & Hell Creek & Pu1 & 1 \\
\hline V85092 & Kmark II & McCone & Hell Creek & Lancian & 1 \\
\hline V87001 & O'Connor Site & Fallon & Hell Creek & Lancian & 1 \\
\hline V88007 & Spigot Bottle & Carter & Hell Creek & Lancian & 1 \\
\hline V91065 & Capping Channel & Garfield & Tullock & Pu1 & 1 \\
\hline V93169 & Anne's Beast & Garfield & Hell Creek & Lancian & 1 \\
\hline V99438 & Garbani Sandy Channel & Garfield & Tullock & Pu3 & 3 \\
\hline
\end{tabular}




\section{APPENDIX 2.}

Histograms illustrating the number of multituberculate (1) and therian (2) specimens in each biozone. Abbreviations: BCA, Bug Creek Anthills mixed-age assemblage; La, Lancian; Pu1, early Puercan; Pu3; middle-late Puercan. See text for morphotype details.
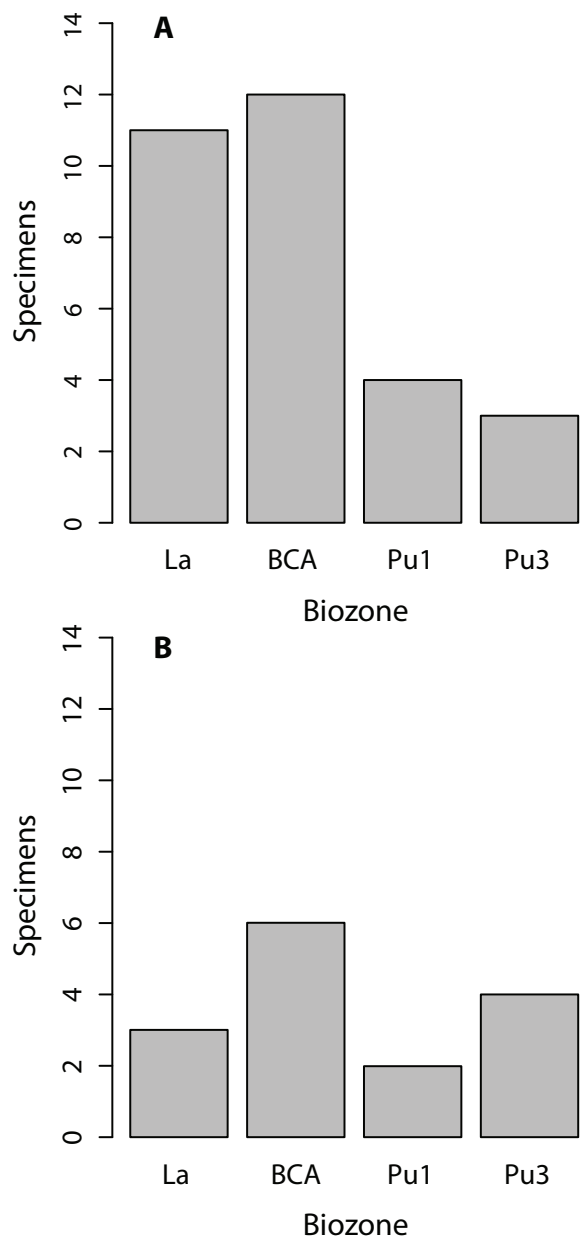


\section{APPENDIX 3.}

Comparative multituberculate distal humeri used in this study. We follow the convention of Krause and Jenkins (1983) with regards to prefacing unassociated attributions with a query (e.g., for isolated material). Age data for Late Cretaceous and Paleogene North American taxa are given as NALMAs, respectively; ages of Asian taxa are given as geologic stages. Specimens from the Bug Creek Anthills localities (e.g., Deischl 1964; Krause and Jenkins 1983) are given a "Lancian-Pu1 mixed" age. All families are in the Infraorder Cimolodonta. See text for museum abbreviations.

\begin{tabular}{|c|c|c|c|c|c|}
\hline $\begin{array}{l}\text { Specimen } \\
\text { Number }\end{array}$ & Taxon Name & Family & Age & Location & Reference \\
\hline AMNH 77175 & ?Mesodma primaeva & Neoplagaiulacidae & Judithian & North America & Sahni, 1972 \\
\hline AMNH 3011a & $\begin{array}{l}\text { ?Meniscoessus } \\
\text { conquistus }\end{array}$ & Cimolomyidae & Lancian & North America & $\begin{array}{l}\text { Cope, 1884; } \\
\text { Krause and } \\
\text { Jenkins, } 1983\end{array}$ \\
\hline YPM 10612a & $\begin{array}{l}\text { ?Meniscoessus } \\
\text { robustus (formerly } \\
\text { Dipriodon lunatus) }\end{array}$ & Cimolomyidae & Lancian & North America & $\begin{array}{l}\text { Marsh, 1889; } \\
\text { Krause and } \\
\text { Jenkins, } 1983\end{array}$ \\
\hline $\begin{array}{l}\text { MCZ 20786- } \\
20789\end{array}$ & ?Mesodma sp. & Neoplagaiulacidae & Lancian-Pu1 mixed & North America & $\begin{array}{l}\text { Krause and } \\
\text { Jenkins, } 1983\end{array}$ \\
\hline UMVP 1405 & ?Mesodma formosa & Neoplagaiulacidae & Lancian-Pu1 mixed & North America & Deischl,1964 \\
\hline $\begin{array}{l}\text { UMVP 1403, } \\
1406\end{array}$ & ?Mesodma thompsoni & Neoplagaiulacidae & Lancian-Pu1 mixed & North America & Deischl,1964 \\
\hline UMVP 1404 & ?Cimexomys minor & Neoplagaiulacidae & Lancian-Pu1 mixed & North America & Deischl,1964 \\
\hline UMVP 1407 & ?Stygimys kuszmauli & Eucosmodontidae & Lancian-Pu1 mixed & North America & $\begin{array}{l}\text { Deischl,1964; } \\
\text { Krause and } \\
\text { Jenkins, } 1983\end{array}$ \\
\hline UA 11994 & ?Stygimys kuszmauli & Eucosmodontidae & Lancian-Pu1 mixed & North America & $\begin{array}{l}\text { Krause and } \\
\text { Jenkins, } 1983\end{array}$ \\
\hline MCZ 19529 & ?Catopsalis & Taeniolabididae & Lancian-Pu1 mixed & North America & Jenkins, 1973 \\
\hline AMNH 3036 & ?Taeniolabis taoensis & Taeniolabididae & Puercan & North America & Sloan, 1981 \\
\hline $\begin{array}{l}\text { Cope 1884: } \\
\text { Figure } 4 b\end{array}$ & $\begin{array}{l}\text { Taeniolabis taoensis } \\
\text { (formerly } \\
\text { Polymastodon } \\
\text { taoensis) }\end{array}$ & Taeniolabididae & Puercan & North America & Cope, 1884 \\
\hline $\begin{array}{l}\text { IVPP V8408, } \\
\text { V9051 }\end{array}$ & ?Lambdopsalis bulla & Taeniolabididae & Late Paleocene & Asia & $\begin{array}{l}\text { Kielan- } \\
\text { Jaworowska and } \\
\text { Qi, } 1990\end{array}$ \\
\hline USNM 9735 & ?Ptilodus montanus & Ptilodontidae & Torrejonian & North America & $\begin{array}{l}\text { Krause and } \\
\text { Jenkins, } 1983\end{array}$ \\
\hline USNM 6076 & Ptilodus montanus & Ptilodontidae & Torrejonian & North America & $\begin{array}{l}\text { Gidley, 1909; } \\
\text { Krause and } \\
\text { Jenkins, } 1983\end{array}$ \\
\hline UA 9001 & Ptilodus kummae & Ptilodontidae & Tiffanian & North America & $\begin{array}{l}\text { Krause and } \\
\text { Jenkins, } 1983\end{array}$ \\
\hline UA 11300 & ?Ptilodus kummae & Ptilodontidae & Tiffanian & North America & $\begin{array}{l}\text { Krause and } \\
\text { Jenkins, } 1983\end{array}$ \\
\hline UALVP 42816 & Microcosmodon conus & Microcosmodontidae & Tiffanian & North America & Fox, 2005 \\
\hline $\begin{array}{l}\text { GISPS 8-2 } \\
\text { PST }\end{array}$ & $\begin{array}{l}\text { Tugrigbaatar } \\
\text { saichanensis }\end{array}$ & Djadochtatheriidae & Campanian & Asia & $\begin{array}{l}\text { Kielan- } \\
\text { Jaworowska and } \\
\text { Dashzeveg, } \\
1978\end{array}$ \\
\hline PSS-MAE 103 & $\begin{array}{l}\text { Kryptobaatar } \\
\text { dashzevegi }\end{array}$ & Djadochtatheriidae & Campanian & Asia & Sereno 2006 \\
\hline
\end{tabular}


DeBey \& WiLson: Mammal humeri ACROSS the K/PG

\begin{tabular}{|c|c|c|c|c|c|}
\hline $\begin{array}{l}\text { Specimen } \\
\text { Number }\end{array}$ & Taxon Name & Family & Age & Location & Reference \\
\hline PM 120/107 & $\begin{array}{l}\text { Catopsbaatar } \\
\text { catopsaloides }\end{array}$ & Djadochtatheriidae & Campanian & Asia & $\begin{array}{l}\text { Hurum and } \\
\text { Kielan- } \\
\text { Jaworowska, } \\
2008\end{array}$ \\
\hline $\begin{array}{l}\text { URBAC 03- } \\
076\end{array}$ & Multituberculata & & Turonian & Asia & $\begin{array}{l}\text { Chester et al., } \\
2010\end{array}$ \\
\hline $\begin{array}{l}\text { AMNH } \\
118267\end{array}$ & Multituberculata & & Lancian-Pu1 mixed & North America & $\begin{array}{l}\text { Kielan- } \\
\text { Jaworowska and } \\
\text { Gambaryan, } \\
1994\end{array}$ \\
\hline
\end{tabular}




\section{APPENDIX 4.}

Comparative therian fossils specimens used in this study. List of fossil specimens used for comparative study. We follow the convention of Krause and Jenkins with regards to prefacing unassociated attributions with a query (e.g., for isolated material). Age data for Late Cretaceous and Paleogene North and South American taxa are given as NALMAs and SALMAs, respectively; ages of European taxa are given as geologic stages. Specimens from the Bug Creek Anthills localities (e.g., Szalay and Dagosto, 1980; Boyer et al., 2010) are given a "Lancian-Pu1 mixed" age. See text for museum abbreviations.

\begin{tabular}{|c|c|c|c|c|c|c|}
\hline $\begin{array}{c}\text { Specimen } \\
\text { Number }\end{array}$ & Taxon Name & Higher Taxon & Family & Age & Location & References \\
\hline $\begin{array}{l}\text { Marsh,1889: } \\
\text { Plate V, figs. 5- } \\
6\end{array}$ & Didelphodon vorax & Didelphimorphia & Stagodontidae & Lancian & $\begin{array}{l}\text { North } \\
\text { America }\end{array}$ & Marsh,1889 \\
\hline MHNC 1249 & Mayulestes ferox & Didelphimorphia & Mayulestidae & Tiupampan & $\begin{array}{l}\text { South } \\
\text { America }\end{array}$ & Muizon, 1998 \\
\hline $\begin{array}{l}\text { YPFB 6105, } \\
6106,6110, \\
6111\end{array}$ & $\begin{array}{l}\text { Pucadelphys } \\
\text { andinus }\end{array}$ & Didelphimorphia & Didelphidae & Tiupampan & $\begin{array}{l}\text { South } \\
\text { America }\end{array}$ & $\begin{array}{l}\text { Marshall et al., } \\
1995\end{array}$ \\
\hline AMNH 118456 & $\begin{array}{l}\text { ?Procerberus } \\
\text { formicarum }\end{array}$ & & Cimolestidae & $\begin{array}{l}\text { Lancian- } \\
\text { Pu1 mixed }\end{array}$ & $\begin{array}{l}\text { North } \\
\text { America }\end{array}$ & $\begin{array}{l}\text { Boyer et al., } \\
2010\end{array}$ \\
\hline UMVP 1837 & $\begin{array}{l}\text { ?Procerberus } \\
\text { formicarum }\end{array}$ & & Cimolestidae & $\begin{array}{l}\text { Lancian- } \\
\text { Pu1 mixed }\end{array}$ & $\begin{array}{l}\text { North } \\
\text { America }\end{array}$ & $\begin{array}{l}\text { Szalay and } \\
\text { Dagosto, } 1980\end{array}$ \\
\hline UM 88105 & $\begin{array}{l}\text { ?Prodiacodon } \\
\text { tauricinerei }\end{array}$ & Leptictida & Leptictidae & Wasatchian & $\begin{array}{l}\text { North } \\
\text { America }\end{array}$ & Rose, 1999 \\
\hline AMNH 16614 & $\begin{array}{l}\text { Protoselene } \\
\text { opisthacus }\end{array}$ & archaic ungulate & Hyopsodontidae & Torrejonian & $\begin{array}{l}\text { North } \\
\text { America }\end{array}$ & Matthew, 1937 \\
\hline $\begin{array}{l}\text { NMMNH P- } \\
20949\end{array}$ & $\begin{array}{l}\text { Tetraclaenodon } \\
\text { puercensis }\end{array}$ & archaic ungulate & Phenacodontidae & Torrejonian & $\begin{array}{l}\text { North } \\
\text { America }\end{array}$ & $\begin{array}{l}\text { Kondrashov } \\
\text { and Lucas, } \\
2012\end{array}$ \\
\hline AMNH 119994 & $\begin{array}{l}\text { ?Protungulatum } \\
\text { donnae }\end{array}$ & archaic ungulate & Arctocyonidae & $\begin{array}{l}\text { Lancian- } \\
\text { Pu1 mixed }\end{array}$ & $\begin{array}{l}\text { North } \\
\text { America }\end{array}$ & $\begin{array}{l}\text { Boyer et al., } \\
2010\end{array}$ \\
\hline UM 1836 & $\begin{array}{l}\text { ?Protungulatum } \\
\text { donnae }\end{array}$ & archaic ungulate & Arctocyonidae & $\begin{array}{l}\text { Lancian- } \\
\text { Pu1 mixed }\end{array}$ & $\begin{array}{l}\text { North } \\
\text { America }\end{array}$ & $\begin{array}{l}\text { Szalay and } \\
\text { Dagosto, } 1980\end{array}$ \\
\hline AMNH 16343 & $\begin{array}{l}\text { Loxolophus } \\
\text { hyattianus }\end{array}$ & archaic ungulate & Artocyonidae & Puercan & $\begin{array}{l}\text { North } \\
\text { America }\end{array}$ & Matthew, 1937 \\
\hline AMNH 16543 & $\begin{array}{l}\text { Arctocyon } \\
\text { corrugatus } \\
\text { (formerly } \\
\text { Claenodon } \\
\text { corrugatus) }\end{array}$ & archaic ungulate & Artocyonidae & Torrejonian & $\begin{array}{l}\text { North } \\
\text { America }\end{array}$ & Matthew, 1937 \\
\hline AMNH 16591 & Chriacus sp. & archaic ungulate & Artocyonidae & Torrejonian & $\begin{array}{l}\text { North } \\
\text { America }\end{array}$ & Matthew, 1937 \\
\hline $\begin{array}{l}\text { MNHN.F.CR17 } \\
\text { MNHN.F.CR16 }\end{array}$ & $\begin{array}{l}\text { Arctocyon } \\
\text { primaevus }\end{array}$ & archaic ungulate & Artocyonidae & Thanetian & Europe & $\begin{array}{l}\text { Russell, 1964; } \\
\text { Argot, } 2013\end{array}$ \\
\hline USGS 2353 & Chriacus sp. & archaic ungulate & Artocyonidae & Wasatchian & $\begin{array}{l}\text { North } \\
\text { America }\end{array}$ & $\begin{array}{l}\text { Rose, 1987; } \\
\text { O'Leary and } \\
\text { Rose, } 1995\end{array}$ \\
\hline AMNH 16500 & $\begin{array}{l}\text { Ectoconus } \\
\text { ditrigonus (formerly } \\
\text { E. majusculus) }\end{array}$ & archaic ungulate & Periptychidae & Puercan & $\begin{array}{l}\text { North } \\
\text { America }\end{array}$ & Matthew, 1937 \\
\hline UNM-B029 & $\begin{array}{l}\text { Mithrandir gillianus } \\
\text { (formerly } \\
\text { Gillisonchus } \\
\text { gillianus) }\end{array}$ & archaic ungulate & Periptychidae & Puercan & $\begin{array}{l}\text { North } \\
\text { America }\end{array}$ & Rigby, 1981 \\
\hline
\end{tabular}


DEBEy \& WILSON: MAMmAL HUMERI ACROSS THE K/PG

\begin{tabular}{|c|c|c|c|c|c|c|}
\hline $\begin{array}{l}\text { Specimen } \\
\text { Number }\end{array}$ & Taxon Name & Higher Taxon & Family & Age & Location & References \\
\hline AMNH 3636 & $\begin{array}{l}\text { ?Periptychus } \\
\text { carinidens } \\
\text { (formerly P. } \\
\text { rhabdodon) }\end{array}$ & archaic ungulate & Periptychidae & Torrejonian & $\begin{array}{l}\text { North } \\
\text { America }\end{array}$ & Matthew, 1937 \\
\hline AMNH 17075 & $\begin{array}{l}\text { ?Periptychus } \\
\text { carinidens } \\
\text { (formerly P. } \\
\text { rhabdodon) }\end{array}$ & archaic ungulate & Periptychidae & Torrejonian & $\begin{array}{l}\text { North } \\
\text { America }\end{array}$ & Matthew, 1937 \\
\hline USGS 2352 & $\begin{array}{l}\text { Diacodexis } \\
\text { metsiacus }\end{array}$ & Artiodactyla & Diacodexeidae & Wasatchian & $\begin{array}{l}\text { North } \\
\text { America }\end{array}$ & Rose, 1982 \\
\hline UALVP 49114 & $\begin{array}{l}\text { Pronothodectes } \\
\text { gaoi }\end{array}$ & "Plesiadapiformes" & Plesiadapidae & Tiffanian & $\begin{array}{l}\text { North } \\
\text { America }\end{array}$ & $\begin{array}{l}\text { Boyer et al., } \\
2010\end{array}$ \\
\hline AMNH 17379 & $\begin{array}{l}\text { ?Nannodectes } \\
\text { gidleyi (formerly } \\
\text { Plesiadapis gidleyi) }\end{array}$ & "Plesiadapiformes" & Plesiadapidae & Tiffanian & $\begin{array}{l}\text { North } \\
\text { America }\end{array}$ & Simpson, 1935 \\
\hline UM 64588 & Plesiadapis rex & "Plesiadapiformes" & Plesiadapidae & Tiffanian & $\begin{array}{l}\text { North } \\
\text { America }\end{array}$ & $\begin{array}{l}\text { Boyer et al., } \\
2010\end{array}$ \\
\hline $\begin{array}{l}\text { MNHN BR 3L } \\
\text { and B4L }\end{array}$ & $\begin{array}{l}\text { Plesiadapis } \\
\text { tricuspidens }\end{array}$ & "Plesiadapiformes" & Plesiadapidae & Thanetian & Europe & $\begin{array}{l}\text { Szalay et al., } \\
1975\end{array}$ \\
\hline UM 87990 & Plesiadapis cookei & "Plesiadapiformes" & Plesiadapidae & Clarkforkian & $\begin{array}{l}\text { North } \\
\text { America }\end{array}$ & $\begin{array}{l}\text { Bloch et al., } \\
2007\end{array}$ \\
\hline $\begin{array}{l}\text { UM } 108210 \\
\text { and } 82606\end{array}$ & $\begin{array}{l}\text { lgnacius } \\
\text { clarkforkensis }\end{array}$ & "Plesiadapiformes" & Paramomyidae & Clarkforkian & $\begin{array}{l}\text { North } \\
\text { America }\end{array}$ & $\begin{array}{l}\text { Bloch et al., } \\
2007\end{array}$ \\
\hline UM 101963 & $\begin{array}{l}\text { Carpolestes } \\
\text { simpsoni }\end{array}$ & "Plesiadapiformes" & Carpolestidae & Clarkforkian & $\begin{array}{l}\text { North } \\
\text { America }\end{array}$ & $\begin{array}{l}\text { Bloch and } \\
\text { Boyer,2002 }\end{array}$ \\
\hline AMNH 2549 & $\begin{array}{l}\text { Pantolambda } \\
\text { bathmodon }\end{array}$ & Pantodonta & & Torrejonian & $\begin{array}{l}\text { North } \\
\text { America }\end{array}$ & Matthew, 1937 \\
\hline AMNH 16663 & $\begin{array}{l}\text { Pantolambda } \\
\text { bathmodon }\end{array}$ & Pantodonta & & Torrejonian & $\begin{array}{l}\text { North } \\
\text { America }\end{array}$ & Matthew, 1937 \\
\hline AMNH 16410 & $\begin{array}{l}\text { Onychodectes } \\
\text { tisonensis }\end{array}$ & Taeniodonta & Conoryctidae & Puercan & $\begin{array}{l}\text { North } \\
\text { America }\end{array}$ & Schoch, 1986 \\
\hline TMM 41364-1 & $\begin{array}{l}\text { Psittacotherium } \\
\text { multifragum }\end{array}$ & Taeniodonta & Stylinodontidae & Torrejonian & $\begin{array}{l}\text { North } \\
\text { America }\end{array}$ & Schoch, 1986 \\
\hline $\begin{array}{l}\text { FMNH P } \\
26090\end{array}$ & $\begin{array}{l}\text { Ectoganus } \\
\text { gliriformis }\end{array}$ & Taeniodonta & Stylinodontidae & $\begin{array}{l}\text { Tiffanian- } \\
\text { Clarkforkian }\end{array}$ & $\begin{array}{l}\text { North } \\
\text { America }\end{array}$ & Schoch, 1986 \\
\hline $\begin{array}{l}\text { FMNH P } \\
26083\end{array}$ & $\begin{array}{l}\text { Ectoganus lobdelli } \\
\text { (formerly } \\
\text { Lampadophorus } \\
\text { expectatus) }\end{array}$ & Taeniodonta & Stylinodontidae & $\begin{array}{l}\text { Tiffanian- } \\
\text { Clarkforkian }\end{array}$ & $\begin{array}{l}\text { North } \\
\text { America }\end{array}$ & Schoch, 1986 \\
\hline YPM 27201 & Ectoganus sp. & Taeniodonta & Stylinodontidae & Wasatchian & $\begin{array}{l}\text { North } \\
\text { America }\end{array}$ & Schoch, 1986 \\
\hline YPM 11096 & Stylinodon mirus & Taeniodonta & Stylinodontidae & Bridgerian & $\begin{array}{l}\text { North } \\
\text { America }\end{array}$ & Schoch, 1986 \\
\hline AMNH 16610 & Deltherium & Tillodontia & Deltatheriidae & Torrejonian & $\begin{array}{l}\text { North } \\
\text { America }\end{array}$ & Matthew, 1937 \\
\hline PU 14389 & Theria indet. & & & $\begin{array}{l}\text { Fort Union } \\
\text { Formation }\end{array}$ & $\begin{array}{l}\text { North } \\
\text { America }\end{array}$ & Jenkins, 1973 \\
\hline LSUMG V-802 & Theria indet. & & & Puercan & $\begin{array}{l}\text { North } \\
\text { America }\end{array}$ & $\begin{array}{l}\text { Standhardt, } \\
1986\end{array}$ \\
\hline
\end{tabular}




\section{APPENDIX 5.}

Intraobserver error results. We performed five trials in which we plotted all six landmarks (LMs) on five specimens for each trial. Specimens were chosen to represent the overall variation in the study (i.e., at the maxima and minima of PC1 and PC2, see Appendix 32). We report the variances for each LM placement for each specimen across the five trials, as well as the mean variance across all LMs for a single specimen, and the mean variance across all specimens for a single LM. See Appendix 6 for $F$ test comparison of differences in variance across all LMs. We report the genus and species, sex (in parentheses), and specimen number for each specimen used in this repeatability study. The specimen for Caluromys philander was taken from Argot (2001, figure 8) and lacks sex information; see Methods. Specimen ID Numbers used in this study are the same throughout; see Table 4 for additional specimen information.

\begin{tabular}{|c|c|c|c|c|c|c|c|c|c|}
\hline & $\begin{array}{l}\text { Specimen } \\
\text { Number }\end{array}$ & $\begin{array}{c}\text { ID } \\
\text { Number }\end{array}$ & LM1 & LM2 & LM3 & LM4 & LM5 & LM6 & $\begin{array}{c}\text { Mean of } \\
\text { Variances } \\
\text { Across } \\
\text { LMs }\end{array}$ \\
\hline $\begin{array}{l}\text { Cavia porcellus } \\
\text { (F) }\end{array}$ & UWBM 72830 & 80 & $5.453 \mathrm{E}-04$ & $1.599 \mathrm{E}-04$ & $1.096 \mathrm{E}-05$ & $6.610 \mathrm{E}-05$ & $1.795 \mathrm{E}-04$ & 4.135E-05 & $1.672 \mathrm{E}-04$ \\
\hline $\begin{array}{l}\text { Caluromys } \\
\text { philander (NA) }\end{array}$ & Argot, 2001, fig. 8 & 3 & $3.751 \mathrm{E}-05$ & 4.613E-05 & 9.017E-05 & 2.406E-05 & $2.586 \mathrm{E}-05$ & $6.837 \mathrm{E}-05$ & $4.868 \mathrm{E}-05$ \\
\hline $\begin{array}{l}\text { Dipodomys } \\
\text { deserti (F) }\end{array}$ & UWBM 78740 & 95 & $7.200 \mathrm{E}-05$ & $1.451 \mathrm{E}-05$ & $3.171 \mathrm{E}-05$ & 8.272E-05 & 1.913E-04 & $6.401 \mathrm{E}-06$ & $6.643 \mathrm{E}-05$ \\
\hline $\begin{array}{l}\text { Lepus } \\
\text { americanus (F) }\end{array}$ & UWBM 21111 & 62 & 8.579E-06 & 4.393E-05 & $2.749 \mathrm{E}-04$ & $1.938 \mathrm{E}-05$ & 4.885E-05 & $5.885 \mathrm{E}-04$ & $1.640 \mathrm{E}-04$ \\
\hline $\begin{array}{l}\text { Mustela erminea } \\
\text { (M) }\end{array}$ & UWBM 72863 & 51 & $9.250 \mathrm{E}-05$ & 1.794E-04 & 3.547E-05 & 1.169E-05 & 7.590E-05 & $6.506 \mathrm{E}-05$ & 7.668E-05 \\
\hline \multicolumn{3}{|c|}{$\begin{array}{l}\text { Mean of Variances Across } \\
\text { Specimens }\end{array}$} & $1.512 \mathrm{E}-04$ & 8.878E-05 & 8.864E-05 & 4.079E-05 & 1.043E-04 & $1.539 \mathrm{E}-04$ & \\
\hline
\end{tabular}




\section{APPENDIX 6.}

Results from $F$ tests of variances pairwise across all landmarks. Specimens are those used in the repeatability study for measurement error (Appendix 5), variances were calculated across Euclidean distances from the centroid for each landmark (LM), and across all five trials for a single specimen. P-values are reported for each pairwise $F$ test, with significance as follows: * for $p$ $<0.05$; ${ }^{* *}$ for $p<0.01$.

\begin{tabular}{|c|c|c|c|c|c|c|}
\hline & LM1 & LM2 & LM3 & LM4 & LM5 & LM6 \\
\hline \multicolumn{7}{|l|}{ Cavia porcellus } \\
\hline LM1 & - & 0.262 & $* *$ & 0.065 & 0.307 & * \\
\hline LM2 & 0.262 & - & * & 0.413 & 0.913 & 0.219 \\
\hline LM3 & ** & * & - & 0.110 & * & 0.227 \\
\hline LM4 & 0.065 & 0.413 & 0.110 & - & 0.357 & 0.661 \\
\hline LM5 & 0.307 & 0.913 & * & 0.357 & - & 0.184 \\
\hline LM6 & * & 0.219 & 0.227 & 0.661 & 0.184 & - \\
\hline \multicolumn{7}{|c|}{ Caluromys philander } \\
\hline LM1 & - & 0.846 & 0.416 & 0.677 & 0.727 & 0.575 \\
\hline LM2 & 0.846 & - & 0.532 & 0.544 & 0.589 & 0.712 \\
\hline LM3 & 0.416 & 0.532 & - & 0.229 & 0.254 & 0.795 \\
\hline LM4 & 0.677 & 0.544 & 0.229 & - & 0.946 & 0.336 \\
\hline LM5 & 0.727 & 0.589 & 0.254 & 0.946 & - & 0.369 \\
\hline LM6 & 0.575 & 0.712 & 0.795 & 0.336 & 0.369 & - \\
\hline \multicolumn{7}{|l|}{ Dipodomys deserti } \\
\hline LM1 & - & 0.150 & 0.447 & 0.896 & 0.367 & * \\
\hline LM2 & 0.150 & - & 0.468 & 0.120 & * & 0.447 \\
\hline LM3 & 0.447 & 0.468 & - & 0.376 & 0.110 & 0.150 \\
\hline LM4 & 0.896 & 0.120 & 0.376 & - & 0.437 & * \\
\hline LM5 & 0.367 & * & 0.110 & 0.437 & - & ** \\
\hline LM6 & * & 0.447 & 0.150 & * & ** & - \\
\hline \multicolumn{7}{|l|}{ Lepus americanus } \\
\hline LM1 & - & 0.143 & ** & 0.449 & 0.121 & $* *$ \\
\hline LM2 & 0.143 & - & 0.103 & 0.447 & 0.921 & * \\
\hline LM3 & ** & 0.103 & - & * & 0.123 & 0.479 \\
\hline LM4 & 0.449 & 0.447 & * & - & 0.392 & ** \\
\hline LM5 & 0.121 & 0.921 & 0.123 & 0.392 & - & * \\
\hline LM6 & $* *$ & * & 0.479 & ** & * & - \\
\hline \multicolumn{7}{|l|}{ Mustela erminea } \\
\hline LM1 & - & 0.537 & 0.376 & 0.070 & 0.853 & 0.741 \\
\hline LM2 & 0.537 & - & 0.145 & * & 0.425 & 0.350 \\
\hline LM3 & 0.376 & 0.145 & - & 0.308 & 0.479 & 0.571 \\
\hline LM4 & 0.070 & * & 0.308 & - & 0.097 & 0.125 \\
\hline LM5 & 0.853 & 0.425 & 0.479 & 0.097 & - & 0.885 \\
\hline LM6 & 0.741 & 0.350 & 0.571 & 0.125 & 0.885 & - \\
\hline
\end{tabular}




\section{APPENDIX 7.}

Means, standard deviations, and percent preservation for multituberculate measurements by morphotype. We include all specimens except for the two specimens tentatively attributed to morphotype MuA (i.e., ?MuA), see text for more details. See Table 1 for measurement descriptions; see Table 2 for data (data excludes minimum values). NA indicates no specimens preserved the measurement (i.e., NA for means) or only one specimen preserved the measurement (i.e., NA for SD). Bold values indicate specimen percent preservation (i.e., the number of specimens that preserve that measurement divided by the total number of specimens in the morphotype) greater than or equal to $80 \%$. We calculate the coefficient of variation (CV) for morphotypes containing more than two specimens. Abbreviations: $\mathrm{CV}$, coefficient of variation; $\mathrm{n}$, number of specimens; SD, standard deviation.

\begin{tabular}{|c|c|c|c|c|c|c|c|c|c|c|}
\hline & TDW & AW & TLW & NCW & UCW & RCW & UCL & RCL & UCD & RCD \\
\hline \multicolumn{11}{|c|}{ Full Dataset $(n=28)$} \\
\hline Mean & 6.86 & 3.55 & 4.09 & 2.05 & 1.68 & 2.27 & 2.65 & 2.48 & 2.92 & 2.80 \\
\hline SD & 3.86 & 1.95 & 2.33 & 1.02 & 0.90 & 1.32 & 1.46 & 1.55 & 1.64 & 1.44 \\
\hline$\%$ Preservation & 39.29 & 57.14 & 57.14 & 53.57 & 89.29 & 71.43 & 89.29 & 78.57 & 89.29 & 67.86 \\
\hline \multicolumn{11}{|l|}{$\operatorname{MuA}(n=8)$} \\
\hline Mean & 3.884 & 2.025 & 2.485 & 1.185 & 0.874 & 1.125 & 1.363 & 1.136 & 1.480 & 1.494 \\
\hline SD & 0.187 & 0.093 & 0.140 & 0.135 & 0.096 & 0.083 & 0.085 & 0.081 & 0.121 & 0.069 \\
\hline$\%$ Preservation & 62.50 & 75.00 & 87.50 & 62.50 & 100.00 & 75.00 & 100.00 & 87.50 & 100.00 & 62.50 \\
\hline CV & 0.048 & 0.046 & 0.056 & 0.114 & 0.110 & 0.073 & 0.063 & 0.071 & 0.082 & 0.046 \\
\hline \multicolumn{11}{|l|}{ MuB $(n=1)$} \\
\hline Mean & NA & NA & NA & 1.240 & 1.080 & NA & 1.465 & NA & 1.670 & NA \\
\hline SD & NA & NA & NA & NA & NA & NA & NA & NA & NA & NA \\
\hline$\%$ Preservation & 0.00 & 0.00 & 0.00 & 100.00 & 100.00 & 0.00 & 100.00 & 0.00 & 100.00 & 0.00 \\
\hline \multicolumn{11}{|l|}{$\operatorname{MuC}(n=7)$} \\
\hline Mean & 5.875 & 2.933 & 3.726 & 1.640 & 1.386 & 1.634 & 2.200 & 1.803 & 2.409 & 2.226 \\
\hline SD & 0.827 & 0.232 & 0.400 & 0.277 & 0.254 & 0.246 & 0.205 & 0.129 & 0.252 & 0.192 \\
\hline$\%$ Preservation & 28.57 & 71.43 & 71.43 & 42.86 & 85.71 & 85.71 & 100.00 & 85.71 & 100.00 & 85.71 \\
\hline CV & 0.141 & 0.079 & 0.107 & 0.169 & 0.183 & 0.151 & 0.093 & 0.072 & 0.105 & 0.086 \\
\hline \multicolumn{11}{|l|}{$\operatorname{MuD}(n=1)$} \\
\hline Mean & NA & NA & NA & NA & NA & 2.160 & NA & 2.135 & NA & 2.350 \\
\hline SD & NA & NA & NA & NA & NA & NA & NA & NA & NA & NA \\
\hline$\%$ Preservation & 0.00 & 0.00 & 0.00 & 0.00 & 0.00 & 100.00 & 0.00 & 100.00 & 0.00 & 100.00 \\
\hline \multicolumn{11}{|l|}{ MuE (n= 5) } \\
\hline Mean & 8.275 & 4.213 & 5.155 & 2.475 & 1.933 & 2.488 & 3.076 & 2.375 & 3.416 & 3.053 \\
\hline SD & 0.205 & 0.265 & 0.106 & 0.108 & 0.314 & 0.110 & 0.393 & 0.156 & 0.337 & 0.337 \\
\hline$\%$ Preservation & 40.00 & 40.00 & 40.00 & 60.00 & 100.00 & 40.00 & 80.00 & 40.00 & 80.00 & 60.00 \\
\hline CV & 0.025 & 0.063 & 0.021 & 0.044 & 0.162 & 0.044 & 0.128 & 0.066 & 0.099 & 0.110 \\
\hline \multicolumn{11}{|l|}{$\operatorname{MuF}(n=6)$} \\
\hline Mean & 13.865 & 7.192 & 9.548 & 3.740 & 3.174 & 4.334 & 5.221 & 4.826 & 5.777 & 5.220 \\
\hline SD & 0.226 & 0.467 & 0.626 & 0.420 & 0.526 & 0.461 & 0.282 & 0.639 & 0.660 & 0.928 \\
\hline$\%$ Preservation & 33.33 & 50.00 & 33.33 & 50.00 & 83.33 & 83.33 & 83.33 & 100.00 & 83.33 & 66.67 \\
\hline $\mathrm{CV}$ & 0.016 & 0.065 & 0.066 & 0.112 & 0.166 & 0.106 & 0.054 & 0.133 & 0.114 & 0.178 \\
\hline
\end{tabular}




\section{APPENDIX 8.}

Means, standard deviations, and percent preservation for therian measurements by morphotype. We include all specimens except for the specimen in morphotype MeA, which lacked any measureable features. See Table 1 for measurement descriptions; see Table 3 for data (data excludes minimum values). NA indicates no specimens preserved the measurement (i.e., NA for means) or only one specimen preserved the measurement (i.e., NA for SD). Bold values indicate specimen percent preservation (i.e., the number of specimens that preserve that measurement divided by the total number of specimens in the morphotype) greater than or equal to $80 \%$. We calculate the coefficient of variation (CV) for morphotypes containing more than two specimens (i.e., only EuD). Abbreviations: CV, coefficient of variation; $n$, number of specimens; SD, standard deviation.

\begin{tabular}{|c|c|c|c|c|c|c|c|c|c|c|}
\hline & TDW & AW & TLW & NCW & TW & CW & TL & CL & TD & CD \\
\hline \multicolumn{11}{|c|}{ Full Dataset $(n=14)$} \\
\hline Mean & 9.560 & 7.189 & 7.414 & 4.713 & 2.438 & 4.836 & 3.084 & 3.026 & 2.708 & 4.416 \\
\hline SD & 0.357 & 3.926 & 3.888 & 2.812 & 1.351 & 2.838 & 2.084 & 1.824 & 1.360 & 2.836 \\
\hline$\%$ Preservation & 21.43 & 78.57 & 78.57 & 42.86 & 92.86 & 78.57 & 92.86 & 78.57 & 71.43 & 57.14 \\
\hline \multicolumn{11}{|l|}{$\operatorname{EuA}(n=1)$} \\
\hline Mean & NA & 3.850 & 3.850 & NA & 1.330 & 2.406 & 1.630 & 1.579 & 1.756 & 1.920 \\
\hline SD & NA & NA & NA & NA & NA & NA & NA & NA & NA & NA \\
\hline$\%$ Preservation & 0.00 & 100.00 & 100.00 & 0.00 & 100.00 & 100.00 & 100.00 & 100.00 & 100.00 & 100.00 \\
\hline \multicolumn{11}{|l|}{$\operatorname{EuB}(n=1)$} \\
\hline Mean & NA & 4.765 & 5.120 & NA & 1.705 & 2.895 & 1.960 & 1.945 & 2.355 & NA \\
\hline SD & NA & NA & NA & NA & NA & NA & NA & NA & NA & NA \\
\hline$\%$ Preservation & 0.00 & 100.00 & 100.00 & 0.00 & 100.00 & 100.00 & 100.00 & 100.00 & 100.00 & 0.00 \\
\hline \multicolumn{11}{|l|}{$\mathrm{EuC}(n=2)$} \\
\hline Mean & 9.520 & 5.635 & 5.735 & 3.918 & 1.670 & 3.945 & 2.680 & 2.515 & 3.095 & 3.310 \\
\hline SD & NA & NA & NA & 0.138 & NA & NA & NA & NA & 0.092 & NA \\
\hline$\%$ Preservation & 50.00 & 50.00 & 50.00 & 100.00 & 50.00 & 50.00 & 50.00 & 50.00 & 100.00 & 50.00 \\
\hline \multicolumn{11}{|l|}{$\operatorname{EuD}(n=5)$} \\
\hline Mean & 9.580 & 5.463 & 5.780 & 3.880 & 1.923 & 3.510 & 1.840 & 2.056 & 2.279 & 2.528 \\
\hline SD & 0.502 & 0.223 & 0.310 & 0.467 & 0.168 & 0.245 & 0.221 & 0.221 & 0.129 & 0.168 \\
\hline$\%$ Preservation & 40.00 & 100.00 & 100.00 & 40.00 & 100.00 & 100.00 & 100.00 & 100.00 & 80.00 & 60.00 \\
\hline $\mathrm{CV}$ & 0.052 & 0.041 & 0.054 & 0.120 & 0.087 & 0.070 & 0.120 & 0.108 & 0.057 & 0.066 \\
\hline \multicolumn{11}{|l|}{$\operatorname{EuE}(n=2)$} \\
\hline Mean & NA & 10.118 & 10.275 & NA & 2.795 & 7.290 & 4.453 & 4.845 & 6.280 & 6.423 \\
\hline SD & NA & 0.803 & 0.813 & NA & 0.219 & 0.467 & 0.173 & 0.375 & NA & 1.559 \\
\hline$\%$ Preservation & 0.00 & 100.00 & 100.00 & 0.00 & 100.00 & 100.00 & 100.00 & 100.00 & 50.00 & 100.00 \\
\hline \multicolumn{11}{|l|}{$\operatorname{EuF}(n=1)$} \\
\hline Mean & NA & 17.280 & 17.395 & NA & 5.480 & 11.820 & 6.945 & 7.280 & NA & 9.670 \\
\hline SD & NA & NA & NA & NA & NA & NA & NA & NA & NA & NA \\
\hline$\%$ Preservation & 0.00 & 100.00 & 100.00 & 0.00 & 100.00 & 100.00 & 100.00 & 100.00 & 0.00 & 100.00 \\
\hline \multicolumn{11}{|l|}{ EuG (n=1) } \\
\hline Mean & NA & NA & NA & 10.300 & 5.095 & NA & 7.435 & NA & NA & NA \\
\hline SD & NA & NA & NA & NA & NA & NA & NA & NA & NA & NA \\
\hline$\%$ Preservation & 0.00 & 0.00 & 0.00 & 100.00 & 100.00 & 0.00 & 100.00 & 0.00 & 0.00 & 0.00 \\
\hline
\end{tabular}


PALAEO-ELECTRONICA.ORG

ThA (n = 1)

Mean

NA NA

NA $\quad 2.380$

1.210

NA $\quad 1.340$

NA

1.380

NA

SD

NA NA

NA NA

NA

NA NA

NA NA

NA

$\%$ Preservation

$0.00 \quad 0.00$

0.00

$100.00 \quad 100.00$

$0.00 \quad 100.00$

0.00

$100.00 \quad 0.00$ 


\section{APPENDIX 9.}

The results of One-Way ANOVAs of difference for all multituberculate measurements across all morphotypes. Asterisks $\left({ }^{* * *}\right)$ indicate significant $p$-values $(<0.0001)$. Both biozone $(b)$ and residuals ( $r$ ) values are given for Sum of Squares, df, and Mean Squares. See Table 1 for measurement details; see Table 3 for data.

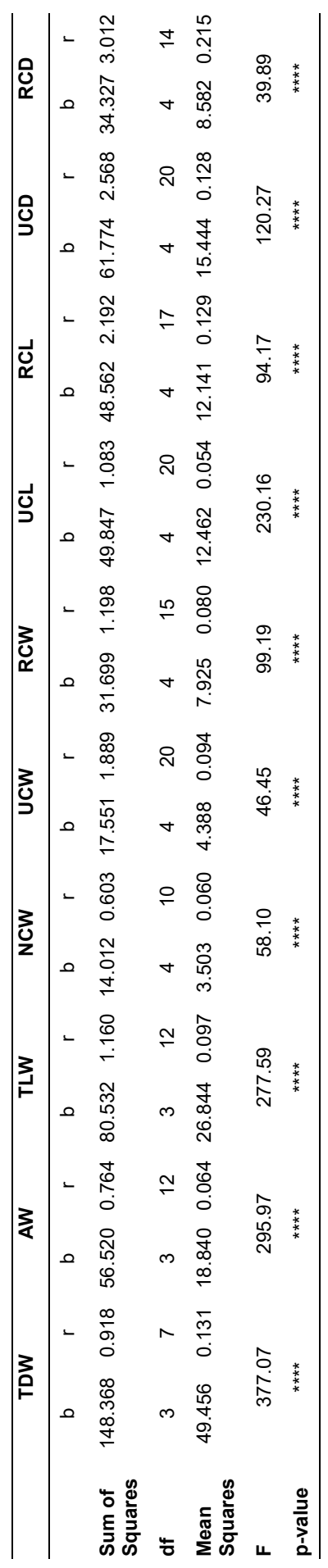




\section{APPENDIX 10.}

Probabilities from Tukey honest significant difference (HSD) post hoc test of multituberculate measurements by morphotype. All measurements had significant ANOVA results, and therefore all measurements were subjected to the Tukey HSD test and have results below. Significance indicated by the following: * for $p<0.05$; ${ }^{* *}$ for $p<0.01$; ${ }^{* * *}$ for $p<0.001$; ${ }^{* * * *}$ for $p<0.0001$. NA indicates the morphotype did not include that particular measurement and therefore could not be subjected to ANOVA or Tukey tests.

\begin{tabular}{|c|c|c|c|c|c|c|c|}
\hline Measurement & & MuA & MuB & MuC & MuD & MuE & MuF \\
\hline \multirow[t]{6}{*}{ TDW } & MuA & - & NA & ** & NA & $\star * \star *$ & $* * * *$ \\
\hline & MuB & NA & - & NA & NA & NA & NA \\
\hline & MuC & $* *$ & NA & - & NA & $* *$ & $* * * *$ \\
\hline & MuD & NA & NA & NA & - & NA & NA \\
\hline & MuE & $* * * *$ & NA & ** & NA & - & $* * * *$ \\
\hline & MuF & $* * * *$ & NA & $* * * *$ & NA & $* * * *$ & - \\
\hline \multirow[t]{6}{*}{ AW } & MuA & - & NA & *** & NA & $* * * *$ & $* * * *$ \\
\hline & MuB & NA & - & NA & NA & NA & NA \\
\hline & MuC & $* \star *$ & NA & - & NA & $* * *$ & $* * * *$ \\
\hline & MuD & NA & NA & NA & - & NA & NA \\
\hline & MuE & $* * * *$ & NA & *** & NA & - & $* * * *$ \\
\hline & MuF & 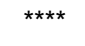 & NA & $* * * *$ & NA & $* * * *$ & - \\
\hline \multirow[t]{6}{*}{ TLW } & MuA & - & NA & *** & NA & $* * * *$ & $* * * *$ \\
\hline & MuB & NA & - & NA & NA & NA & NA \\
\hline & MuC & $* * *$ & NA & - & NA & *** & $* * * *$ \\
\hline & MuD & NA & NA & NA & - & NA & NA \\
\hline & MuE & $* * \star *$ & NA & $* * *$ & NA & - & $\star \star \star * *$ \\
\hline & MuF & $* * * *$ & NA & $* * * *$ & NA & $* * * *$ & - \\
\hline \multirow[t]{6}{*}{ NCW } & MuA & - & 1.000 & 0.158 & NA & $* * *$ & $* * * *$ \\
\hline & MuB & 1.000 & - & 0.635 & NA & $* *$ & $* * * *$ \\
\hline & MuC & 0.158 & 0.635 & - & NA & * & $* * * *$ \\
\hline & MuD & NA & NA & NA & - & NA & NA \\
\hline & MuE & $* * *$ & $* *$ & * & NA & - & $* * *$ \\
\hline & MuF & 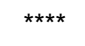 & $\star * \star * *$ & $* * \star *$ & NA & $* * *$ & - \\
\hline \multirow[t]{6}{*}{ UCW } & MuA & - & 0.968 & * & NA & $* * *$ & $\star * \star * *$ \\
\hline & MuB & 0.968 & - & 0.885 & NA & 0.123 & $\star * \star * *$ \\
\hline & MuC & * & 0.885 & - & NA & 0.056 & 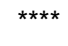 \\
\hline & MuD & NA & NA & NA & - & NA & NA \\
\hline & MuE & $\star \star * *$ & 0.123 & 0.056 & NA & - & $* * * *$ \\
\hline & MuF & $* * * *$ & $* * * *$ & $* * * *$ & NA & $* * * *$ & - \\
\hline \multirow[t]{4}{*}{ RCW } & MuA & - & NA & * & * & $* * *$ & $* * * *$ \\
\hline & MuB & NA & - & NA & NA & NA & NA \\
\hline & MuC & * & NA & - & 0.451 & * & $* * * *$ \\
\hline & MuD & * & NA & 0.451 & - & 0.874 & $\star * \star * *$ \\
\hline
\end{tabular}


DeBey \& WiLson: Mammal humeri ACROSS the K/PG

\begin{tabular}{|c|c|c|c|c|c|c|c|}
\hline Measurement & & MuA & MuB & MuC & MuD & MuE & MuF \\
\hline & MuE & $* * *$ & NA & * & 0.874 & - & $\star * \star * *$ \\
\hline & MuF & $\star * \star *$ & NA & $* * * *$ & $* * \star *$ & $* * * *$ & - \\
\hline \multirow[t]{6}{*}{ UCL } & MuA & - & 0.993 & $* * * *$ & NA & $* * * *$ & $* * * *$ \\
\hline & MuB & 0.993 & - & 0.054 & NA & $* * * *$ & $\star * \star *$ \\
\hline & MuC & $* * * *$ & 0.054 & - & NA & *** & $* * * *$ \\
\hline & MuD & NA & NA & NA & - & NA & NA \\
\hline & MuE & $\star \star \star * *$ & $* * \star *$ & $* * *$ & NA & - & $* * * *$ \\
\hline & MuF & $* * * *$ & $* * * *$ & $* * * *$ & NA & $* * * *$ & - \\
\hline \multirow[t]{6}{*}{$\mathrm{RCL}$} & MuA & - & NA & * & 0.114 & $* *$ & $\star * \star *$ \\
\hline & MuB & NA & - & NA & NA & NA & NA \\
\hline & MuC & * & NA & - & 0.908 & 0.329 & $* * * *$ \\
\hline & MuD & 0.114 & NA & 0.908 & - & 0.981 & $* * * *$ \\
\hline & MuE & $* *$ & NA & 0.329 & 0.981 & - & $* * * *$ \\
\hline & MuF & $* * * *$ & NA & $* * * *$ & $* * \star *$ & $* * * *$ & - \\
\hline \multirow[t]{6}{*}{ UCD } & MuA & - & 0.986 & *** & NA & $* * * *$ & $* * * *$ \\
\hline & MuB & 0.986 & - & 0.335 & NA & $* *$ & $\star * \star *$ \\
\hline & MuC & $* \star *$ & 0.335 & - & NA & $* *$ & $\star \star \star \star *$ \\
\hline & MuD & NA & NA & NA & - & NA & NA \\
\hline & MuE & $* * \star *$ & $* *$ & $* *$ & NA & - & $\star * \star *$ \\
\hline & MuF & $* * * *$ & $\star \star \star \star *$ & $* * \star *$ & NA & $* * \star *$ & - \\
\hline \multirow[t]{6}{*}{ RCD } & MuA & - & NA & 0.123 & 0.473 & $* *$ & $\star * \star *$ \\
\hline & MuB & NA & - & NA & NA & NA & NA \\
\hline & MuC & 0.123 & NA & - & 0.999 & 0.141 & $* * * *$ \\
\hline & MuD & 0.473 & NA & 0.999 & - & 0.688 & $* * *$ \\
\hline & MuE & $* *$ & NA & 0.141 & 0.688 & - & $* * *$ \\
\hline & MuF & $* * * *$ & NA & $* * * *$ & $* * *$ & $* * *$ & - \\
\hline
\end{tabular}




\section{APPENDIX 11.}

Boxplots for all multituberculate measurement with significant ANOVA results according to morphotype. Boxplots include minimum, quartiles, median, and maximum values. See Table 1 for measurements, Table 2 for data, and Appendices 9-10 for ANOVA and Tukey HSD results, respectively. Specimens tentatively attributed to morphotype MuA (i.e., ?MuA), were not included in ANOVA and Tukey tests.
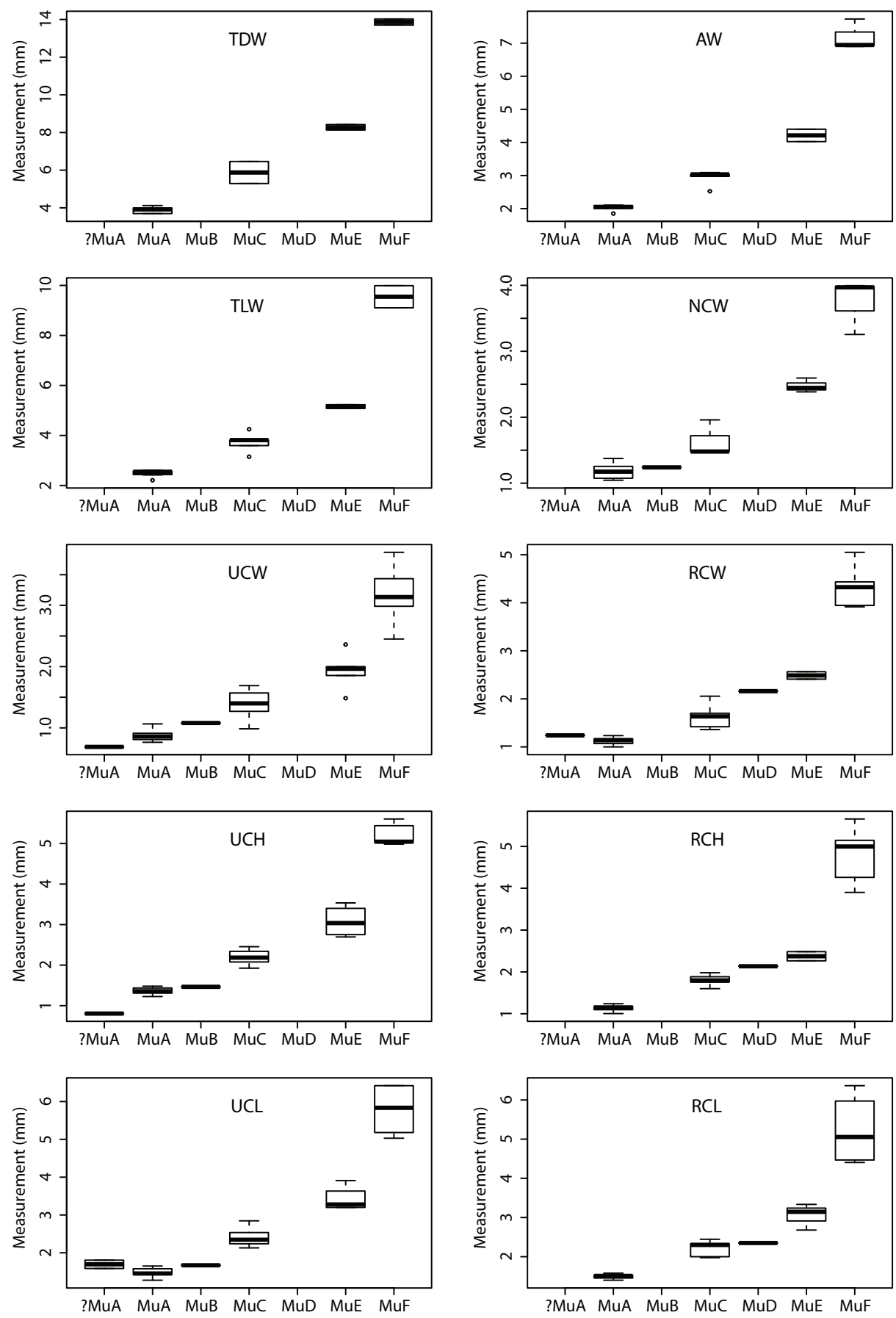
APPENDIX 12.

Variances for all multituberculate measurement with significant ANOVA results according to morphotype. See Appendix 2 for means, maxima, minima, and quartiles. See Table 1 for measurements, Table 2 for data, and Appendices 9-10 for ANOVA and Tukey HSD results, respectively.
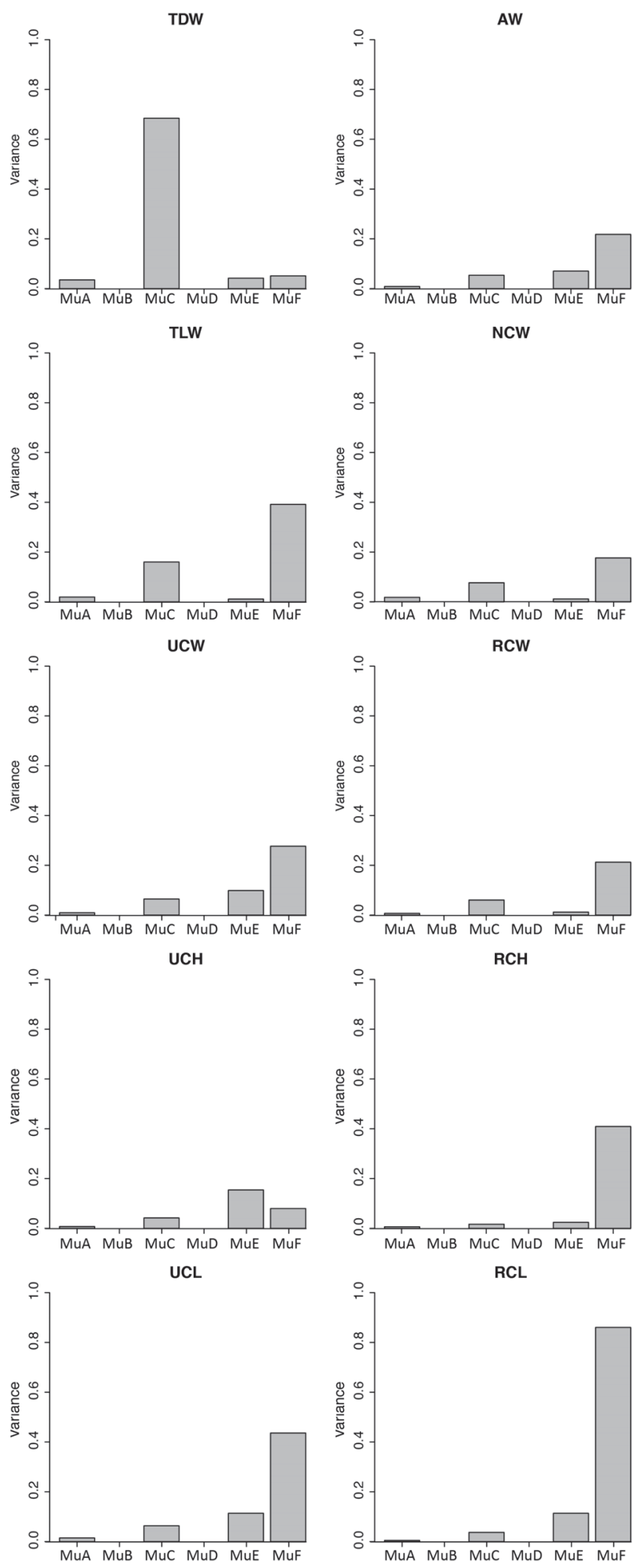


\section{APPENDIX 13.}

Principal Components 1 and 2 on the full set of variables (i.e., measurements; excluding TDW, AW, and TLW; $n=10$ specimens). All measurements are standardized to (i.e., "relative to") RCW. The first and second principal components explain $64 \%$ and $20 \%$ of the variation, respectively. See Appendix 14 for all principal component loadings and variances. Plotted multituberculate morphotypes include: MuA (blue), MuC (red), MuE (orange), and MuF (green). See Table 1 for measurements and Table 2 for data.

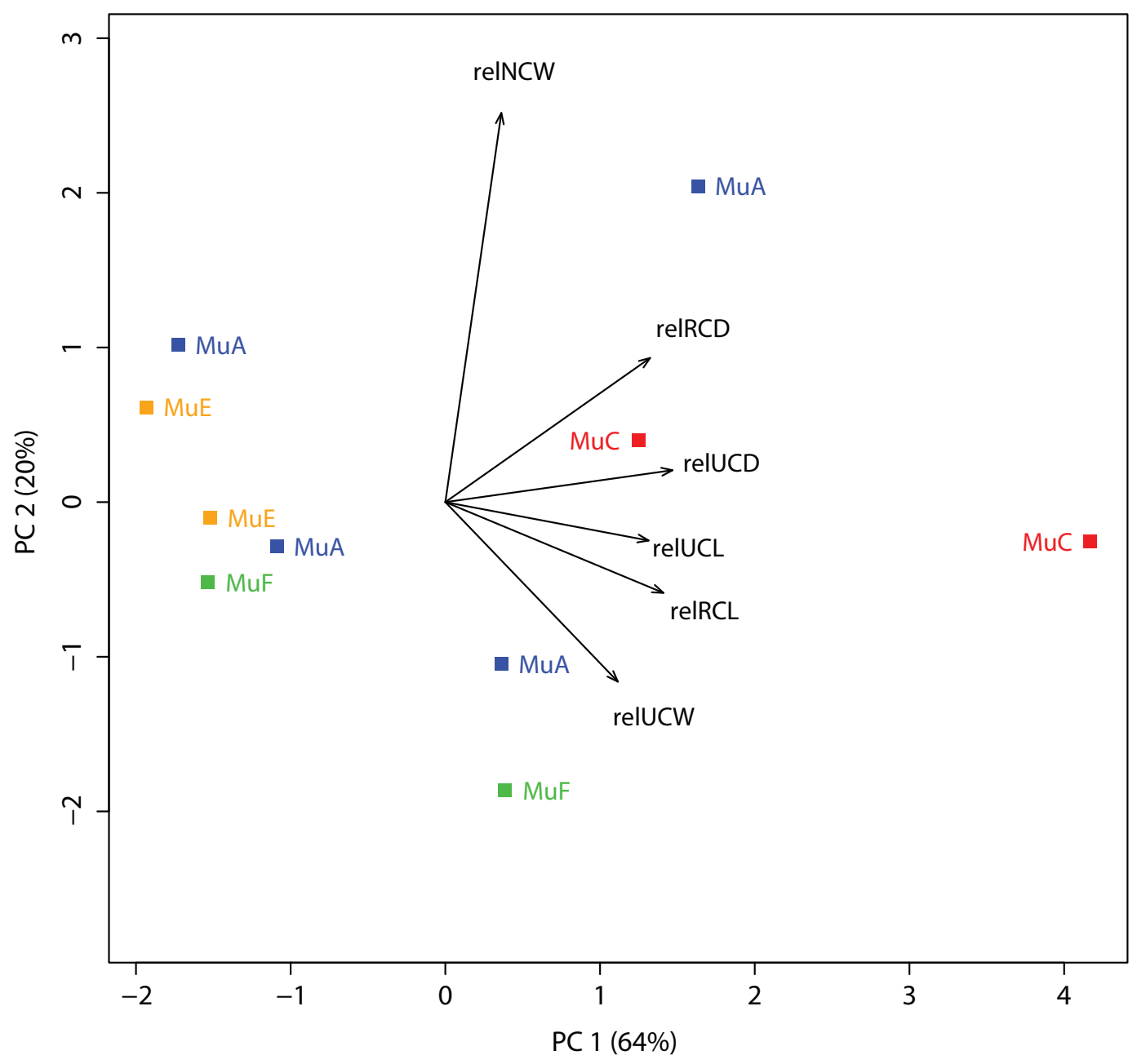




\section{APPENDIX 14.}

Measurement loading and variance results of Principal Components Analysis on linear measurements of multituberculate specimens from our assemblage $(n=10)$. Measurements include NCW, RCL, RCD, UCL, UCD, and UCW, all standardized to RCW (Table 1; Appendix 13). Loadings in bold represent dominant loadings for each principal component (i.e., values greater than $\left(1 /(\text { number of columns })^{2}\right)$.

\begin{tabular}{lcccccc}
\hline & PC1 & PC2 & PC3 & PC4 & PC5 & PC6 \\
\hline $\begin{array}{l}\text { Loadings } \\
\text { relUCD }\end{array}$ & $\mathbf{0 . 4 9 0}$ & 0.069 & 0.120 & 0.354 & -0.130 & $\mathbf{0 . 7 7 4}$ \\
reIRCL & $\mathbf{0 . 4 7 0}$ & -0.196 & -0.096 & -0.236 & $\mathbf{0 . 8 2 2}$ & -0.019 \\
reIRCD & $\mathbf{0 . 4 4 1}$ & 0.311 & -0.206 & $\mathbf{0 . 5 9 7}$ & -0.044 & $\mathbf{- 0 . 5 5 6}$ \\
relUCL & $\mathbf{0 . 4 3 8}$ & -0.083 & $\mathbf{- 0 . 5 3 7}$ & $\mathbf{- 0 . 5 2 7}$ & $\mathbf{- 0 . 4 8 5}$ & -0.027 \\
reINCW & 0.121 & $\mathbf{0 . 8 3 9}$ & 0.329 & $\mathbf{- 0 . 4 1 3}$ & 0.050 & -0.004 \\
relUCW & 0.372 & -0.387 & $\mathbf{0 . 7 3 3}$ & -0.122 & -0.261 & -0.303 \\
Variance & & & & & & \\
Percent Variance & 0.637 & 0.199 & 0.085 & 0.048 & 0.022 & 0.009 \\
Cumulative Variance & 0.637 & 0.836 & 0.921 & 0.969 & 0.991 & 1.000 \\
\hline
\end{tabular}




\section{APPENDIX 15.}

Principal Components 1 and 2 on measurements NCW, RCL, UCL, and UCW, and standardized to (i.e., "relative to") RCW. The first and second principal components explain $61 \%$ and $23 \%$ of the variation, respectively. See Appendix 16 for all principal component loadings and variances. Plotted multituberculate morphotypes include: MuA (blue), MuC (red), MuE (orange), and MuF (green). This dataset is similar to that of Appendix 13, but excludes measurement RCD and includes one additional specimen $(n=11)$. See Table 1 for measurements and Table 2 for data.

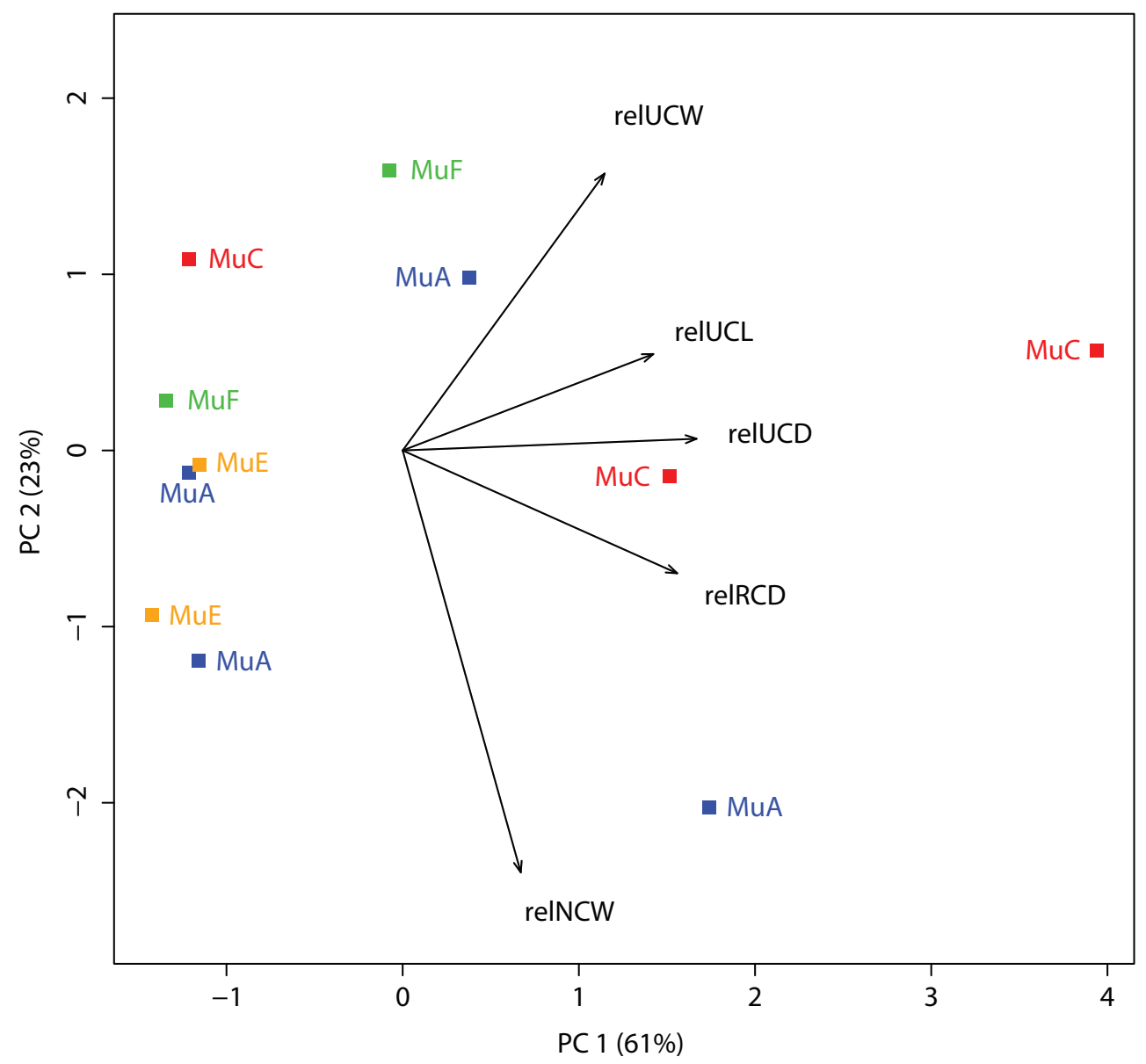




\section{APPENDIX 16.}

Measurement loading and variance results of Principal Components Analysis on linear measurements of multituberculate specimens from our assemblage $(n=11)$. Measurements include NCW, RCD, UCL, UCD, and UCW, all standardized to RCW (Table 1; Appendix 15). Loadings in bold represent dominant loadings for each principal component.

\begin{tabular}{lccccc}
\hline & PC1 & PC2 & PC3 & PC4 & PC5 \\
\hline $\begin{array}{l}\text { Loadings } \\
\text { relUCD }\end{array}$ & $\mathbf{0 . 5 5 6}$ & 0.022 & 0.092 & -0.309 & $\mathbf{- 0 . 7 6 6}$ \\
reIRCD & $\mathbf{0 . 5 1 9}$ & -0.232 & -0.201 & $\mathbf{- 0 . 5 5 7}$ & $\mathbf{0 . 5 7 1}$ \\
relUCL & $\mathbf{0 . 4 7 4}$ & 0.183 & $\mathbf{- 0 . 6 0 2}$ & $\mathbf{0 . 6 1 5}$ & 0.030 \\
relNCW & 0.223 & $\mathbf{- 0 . 7 9 8}$ & 0.366 & 0.423 & 0.012 \\
relUCW & 0.382 & $\mathbf{0 . 5 2 4}$ & $\mathbf{0 . 6 7 4}$ & 0.196 & 0.294 \\
Variance & & & & & \\
Percent Variance & 0.608 & 0.231 & 0.099 & 0.052 & 0.010 \\
Cumulative Variance & 0.608 & 0.839 & 0.938 & 0.990 & 1.000 \\
\hline
\end{tabular}




\section{APPENDIX 17.}

Principal Components 1 and 2 on measurements NCW, RCL, UCL, and UCW, and standardized to ("relative to") RCW, see Table 1 for measurements. The first and second principal components explain $44 \%$ and $24 \%$ of the variation, respectively. See Appendix 18 for all principal component loadings and variances. Plotted multituberculate morphotypes include: MuA (blue), MuC (red), MuE (orange), and MuF (green; Table 2); published specimens include: ?Cimexomys minor, UMVP 1404 (Deischl 1964); Microcosmodon conus, UALVP 42816 (Fox 2005); Mesodma formosa, UMVP 1405 (Deischl 1964); M. thompsoni (A), UMVP 1406 (Deischl 1964); M. thompsoni (B), UMVP 1403 (Deischl 1964); Multituberculata, AMNH 118267 (Kielan-Jaworowska and Gambaryan 1994); Stygimys kuszmauli (C), UA 11994 (Krause and Jenkins 1983); and S. kuszmauli (D), UMVP 1407 (Deischl 1964; Krause and Jenkins 1983); see Appendix 3 for additional details on published material.

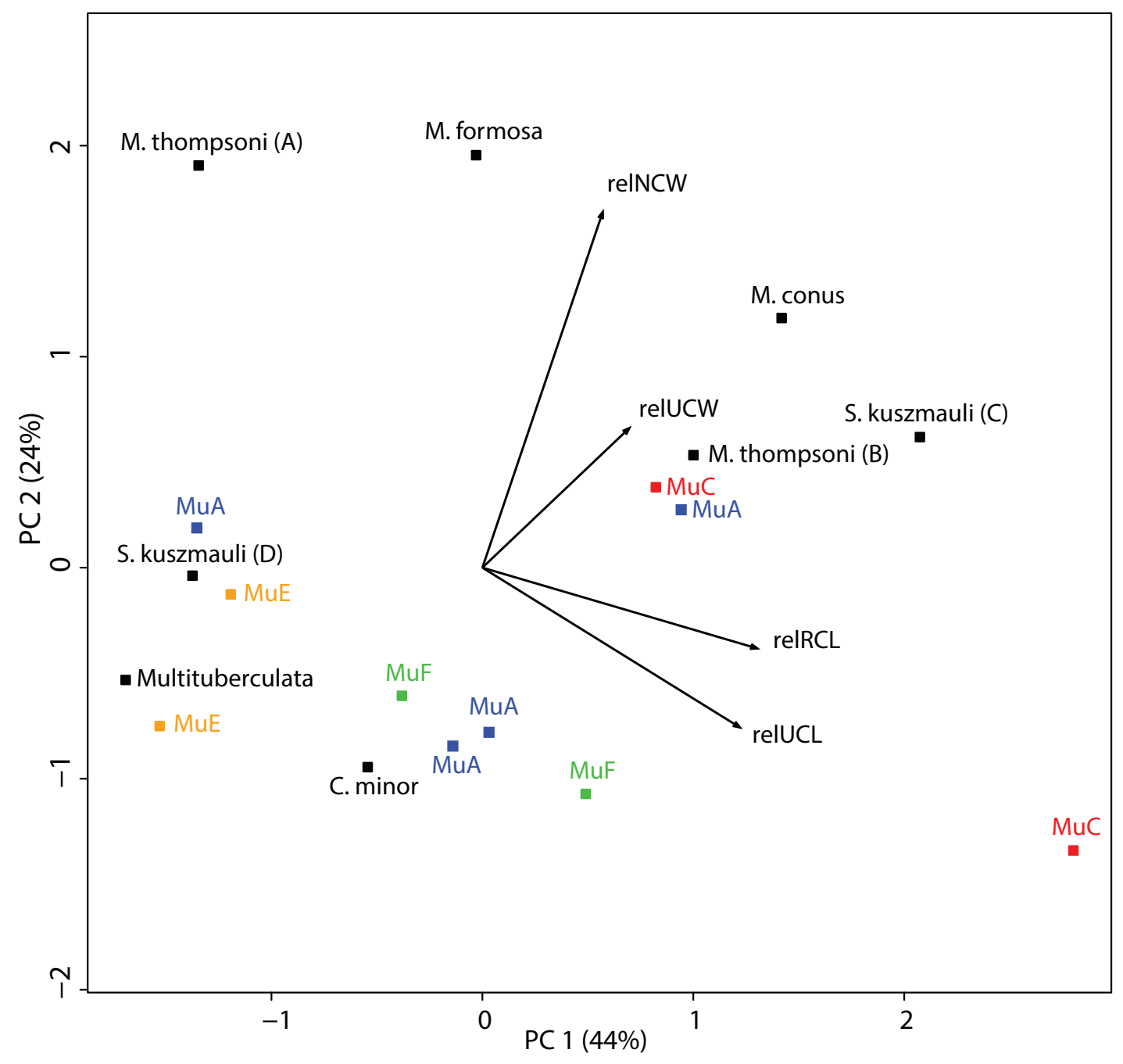




\section{APPENDIX 18}

Measurement loading and variance results of Principal Components Analysis on linear measurements of multituberculate specimens. Measurements include NCW, RCL, UCL, and UCW, all standardized to RCW (Table 1; Appendix 17). Specimens include nine specimens from our assemblage and seven specimens from the published literature (see Appendix 17 for more details). Loadings in bold represent dominant loadings for each principal component.

\begin{tabular}{lcccc}
\hline & PC1 & PC2 & PC3 & PC4 \\
\hline $\begin{array}{l}\text { Loadings } \\
\text { reIRCL }\end{array}$ & $\mathbf{0 . 6 5 2}$ & & & \\
relUCL & $\mathbf{0 . 6 1 0}$ & & -0.182 & $\mathbf{0 . 6 7 2}$ \\
reINCW & 0.285 & $\mathbf{0 . 8 4 3}$ & -0.446 & 0.095 \\
relUCW & 0.348 & 0.331 & $\mathbf{0 . 8 7 1}$ & 0.106 \\
Variance & & & & \\
Percent Variance & 0.435 & 0.238 & 0.224 & 0.103 \\
Cumulative Variance & 0.435 & 0.673 & 0.897 & 1.000 \\
\hline
\end{tabular}




\section{APPENDIX 19.}

The results of One-Way ANOVAs of difference for all therians measurements across all morphotypes. Significance indicated by the following: * for $p<0.05$; ${ }^{* *}$ for $p<0.01$; ${ }^{* * *}$ for $p<0.001$; ${ }^{* * * *}$ for $p<0.0001$. Both biozone (b) and residuals ( $r$ ) values are given for Sum of Squares, df, and Mean Squares. See Table 1 for measurement details; see Table 3 for data.

\begin{tabular}{|c|c|c|c|c|}
\hline & 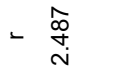 & $m \delta$ & $\begin{array}{c}\text { : } \\
\text { o. } \\
0\end{array}$ & $\stackrel{\sim}{\sim}$ \\
\hline U্口 & $\begin{array}{l}8 \\
0 \\
0 \\
0 \\
\\
\end{array}$ & + & م. & $\underline{0}$ \\
\hline Q & - & + & & $\stackrel{10}{\frac{10}{d}}$ \\
\hline 0 & 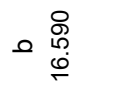 & L 10 & $\stackrel{\infty}{m}$ & $\stackrel{\leftrightarrow}{N}$ \\
\hline $\bar{c}$ & $-\underset{m}{0}$ & เ & & $\stackrel{\varnothing}{\infty}$ \\
\hline 0 & م $\begin{array}{c}\mathcal{N} \\
\text { N } \\
\tilde{N}\end{array}$ & $\omega$ & $\begin{array}{l}\infty \\
\infty \\
\infty \\
1 \\
0\end{array}$ & $\infty$ \\
\hline & $-\stackrel{\stackrel{W}{N}}{0}$ & $\infty$ & & శ్ \\
\hline ב & ـ $\frac{\text { ¿ }}{\dot{8}}$ & $r$ & م & $\underset{\sigma}{0}$ \\
\hline 3 & $-\frac{8}{8}$ & $\infty$ & & $\frac{\nabla}{6}$ \\
\hline u & $\begin{array}{ll} & \infty \\
\circ & 0 \\
0 & 0 \\
0\end{array}$ & 10 & $\begin{array}{l}\frac{0}{0} \\
\stackrel{6}{6}\end{array}$ & 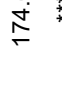 \\
\hline 3 & $-\frac{\bar{\sigma}}{0}$ & $\omega$ & $\begin{array}{l}\tilde{N} \\
\text { Oे. } \\
0\end{array}$ & 응 \\
\hline & $0 \frac{\hat{n}}{\stackrel{n}{n}}$ & $\sim$ & $\stackrel{\infty}{\circ}$ & ஜூ \\
\hline 3 & $-\underset{\tilde{N}}{0}$ & $N$ & $\stackrel{\infty}{\leftarrow}$ & $\widehat{\emptyset}$ \\
\hline & 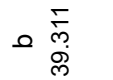 & $m$ & $\frac{\square}{\stackrel{0}{\sigma}}$ & $\stackrel{\circ}{ }$ \\
\hline & $-\stackrel{\hat{\sigma}}{\stackrel{f}{r}}$ & เo & 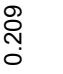 & 우 \\
\hline | & م & เ & 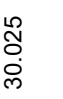 & 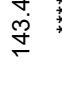 \\
\hline & - $\begin{array}{r}\mathbb{Z} \\
\infty \\
0\end{array}$ & o & $\frac{8}{\circ}$ & ం \\
\hline & م & 10 & 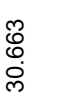 & $\stackrel{-}{\infty}$ \\
\hline & 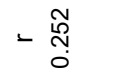 & - & $\begin{array}{l}\text { N̦ } \\
\text { O }\end{array}$ & 은 \\
\hline & ـ ْ̋ & - & ণั & 0 \\
\hline & 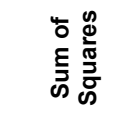 & \pm & 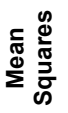 & น \\
\hline
\end{tabular}


APPENDIX 20.

Probabilities from Tukey honest significant difference (HSD) post hoc test of therian measurements by morphotype. Measurements subjected to the Tukey HSD test are those with significant ANOVA results (i.e., all measurements except TDW); see Table 1 for measurements and Table 3 for data. Significance indicated by the following: * for $p<0.05$; ${ }^{* *}$ for $p<0.01$; ${ }^{* *}$ for $p<0.001$; ${ }^{* * * *}$ for $p<0.0001$. NA indicates the morphotype did not include that particular measurement and therefore could not be subjected to ANOVA or Tukey tests.

\begin{tabular}{|c|c|c|c|c|c|c|c|c|c|}
\hline & & EuA & EuB & EuC & EuD & EuE & EuF & EuG & ThA \\
\hline \multirow[t]{8}{*}{ AW } & EuA & - & 0.643 & 0.155 & 0.094 & $* * *$ & $* * * *$ & NA & NA \\
\hline & EuB & 0.643 & - & 0.681 & 0.655 & $* * *$ & $* * * *$ & NA & NA \\
\hline & EuC & 0.155 & 0.681 & - & 0.998 & $* *$ & $* \star \star * *$ & NA & NA \\
\hline & EuD & 0.094 & 0.655 & 0.998 & - & $* * *$ & $* * * *$ & NA & NA \\
\hline & EuE & $* * *$ & $* * *$ & $* *$ & $* * *$ & - & $* * *$ & NA & NA \\
\hline & EuF & $* * \star \star$ & $* * * *$ & $* * * *$ & $\star \star \star \star *$ & $\star * *$ & - & NA & NA \\
\hline & EuG & NA & NA & NA & NA & NA & NA & - & NA \\
\hline & ThA & NA & NA & NA & NA & NA & NA & NA & - \\
\hline \multirow[t]{8}{*}{ TLW } & EuA & - & 0.463 & 0.182 & 0.073 & $* * *$ & $* * * *$ & NA & NA \\
\hline & EuB & 0.463 & - & 0.916 & 0.769 & $\star *$ & $* \star * *$ & NA & NA \\
\hline & EuC & 0.182 & 0.916 & - & 1.000 & $* *$ & $* * *$ & NA & NA \\
\hline & EuD & 0.073 & 0.769 & 1.000 & - & $* \star *$ & $* \star * *$ & NA & NA \\
\hline & EuE & $* * *$ & $* *$ & $* *$ & $* * *$ & - & $* * *$ & NA & NA \\
\hline & EuF & $* * * *$ & $* * * *$ & $* * * *$ & $* * * *$ & $* * *$ & - & NA & NA \\
\hline & EuG & NA & NA & NA & NA & NA & NA & - & NA \\
\hline & ThA & NA & NA & NA & NA & NA & NA & NA & - \\
\hline \multirow[t]{8}{*}{ NCW } & EuA & - & NA & NA & NA & NA & NA & NA & NA \\
\hline & EuB & NA & - & NA & NA & NA & NA & NA & NA \\
\hline & EuC & NA & NA & - & 0.999 & NA & NA & * & 0.162 \\
\hline & EuD & NA & NA & 0.999 & - & NA & NA & * & 0.169 \\
\hline & EuE & NA & NA & NA & NA & - & NA & NA & NA \\
\hline & EuF & NA & NA & NA & NA & NA & - & NA & NA \\
\hline & EuG & NA & NA & * & * & NA & NA & - & ** \\
\hline & ThA & NA & NA & 0.162 & 0.169 & NA & NA & ** & - \\
\hline \multirow[t]{8}{*}{ TW } & EuA & - & 0.794 & 0.852 & 0.219 & * & $* * *$ & $* * *$ & 0.999 \\
\hline & EuB & 0.794 & - & 1.000 & 0.929 & * & $* * *$ & $\star * *$ & 0.574 \\
\hline & EuC & 0.852 & 1.000 & - & 0.872 & * & $* * *$ & $* * * *$ & 0.638 \\
\hline & EuD & 0.219 & 0.929 & 0.872 & - & * & $* * *$ & $* * *$ & 0.126 \\
\hline & EuE & * & * & * & * & - & $* * *$ & ** & ** \\
\hline & EuF & $* * *$ & $* * *$ & $* * *$ & $* * *$ & $* * *$ & - & 0.776 & $* * *$ \\
\hline & EuG & $* * *$ & $* \star \star *$ & $\star \star \star *$ & $* * *$ & ** & 0.776 & - & $\star \star * *$ \\
\hline & ThA & 0.999 & 0.574 & 0.638 & 0.123 & $* *$ & $* * *$ & $* \star \star$ & - \\
\hline \multirow[t]{2}{*}{ CW } & EuA & - & 0.847 & 0.093 & 0.121 & $* * *$ & $* * * *$ & NA & NA \\
\hline & EuB & 0.847 & - & 0.289 & 0.511 & $* * *$ & $* * * *$ & NA & NA \\
\hline
\end{tabular}




\begin{tabular}{|c|c|c|c|c|c|c|c|c|c|}
\hline & & EuA & EuB & EuC & EuD & EuE & EuF & EuG & ThA \\
\hline & EuC & 0.093 & 0.289 & - & 0.771 & $* *$ & $* \star *$ & NA & NA \\
\hline & EuD & 0.121 & 0.511 & 0.771 & - & $* * *$ & $* * * *$ & NA & NA \\
\hline & EuE & $* * *$ & $* * *$ & $* *$ & $* * *$ & - & $* * *$ & NA & NA \\
\hline & EuF & $* \star * *$ & **** & $* * *$ & $* * \star *$ & $* * *$ & - & NA & NA \\
\hline & EuG & NA & NA & NA & NA & NA & NA & - & NA \\
\hline & ThA & NA & NA & NA & NA & NA & NA & NA & - \\
\hline \multirow[t]{8}{*}{ TL } & EuA & - & 0.932 & 0.139 & 0.972 & $* *$ & $* * *$ & $* * *$ & 0.962 \\
\hline & EuB & 0.932 & - & 0.391 & 0.999 & $* *$ & $* * *$ & $* * *$ & 0.524 \\
\hline & EuC & 0.139 & 0.391 & - & 0.125 & * & $* \star *$ & $* * *$ & 0.059 \\
\hline & EuD & 0.972 & 0.999 & 0.125 & - & $* * *$ & $* * * *$ & $* * * *$ & 0.487 \\
\hline & EuE & $* *$ & $* *$ & * & $* * *$ & - & $* *$ & $* * *$ & $* * *$ \\
\hline & EuF & $* * *$ & $* * *$ & $* * *$ & $* * * *$ & $* *$ & - & 0.724 & $* * *$ \\
\hline & EuG & $* * *$ & $* * *$ & $* * *$ & $\star \star \star \star *$ & $* * *$ & 0.724 & - & $* * * *$ \\
\hline & ThA & 0.962 & 0.524 & 0.059 & 0.487 & $* * *$ & $* * *$ & $\star * * *$ & - \\
\hline \multirow[t]{8}{*}{ CL } & EuA & - & 0.901 & 0.261 & 0.592 & $* *$ & $* * *$ & NA & NA \\
\hline & EuB & 0.901 & - & 0.653 & 0.998 & $* *$ & $* * *$ & NA & NA \\
\hline & EuC & 0.261 & 0.653 & - & 0.623 & $* *$ & $* * *$ & NA & NA \\
\hline & EuD & 0.592 & 0.998 & 0.623 & - & $* * *$ & $* * *$ & NA & NA \\
\hline & EuE & $* *$ & $* *$ & $* *$ & $* * *$ & - & $* *$ & NA & NA \\
\hline & EuF & $* * *$ & $* * *$ & $* * *$ & $* * *$ & ** & - & NA & NA \\
\hline & EuG & NA & NA & NA & NA & NA & NA & - & NA \\
\hline & ThA & NA & NA & NA & NA & NA & NA & NA & - \\
\hline \multirow[t]{8}{*}{ TD } & EuA & - & 0.128 & ** & 0.096 & $* * *$ & NA & NA & 0.393 \\
\hline & EuB & 0.128 & - & * & 0.989 & $* * *$ & NA & NA & * \\
\hline & EuC & ** & * & - & $* *$ & $* * *$ & NA & NA & $* *$ \\
\hline & EuD & 0.096 & 0.989 & $* *$ & - & $* * *$ & NA & NA & * \\
\hline & EuE & $* * *$ & $* * *$ & $* * *$ & $* \star * *$ & - & NA & NA & $* * *$ \\
\hline & EuF & NA & NA & NA & NA & NA & - & NA & NA \\
\hline & EuG & NA & NA & NA & NA & NA & NA & - & NA \\
\hline & ThA & 0.393 & * & ** & * & $\star \star * *$ & NA & NA & - \\
\hline \multirow[t]{7}{*}{$C D$} & EuA & - & NA & 0.810 & 0.970 & 0.101 & * & NA & NA \\
\hline & EuB & NA & - & NA & NA & NA & NA & NA & NA \\
\hline & EuC & 0.810 & NA & - & 0.932 & 0.235 & 0.060 & NA & NA \\
\hline & EuD & 0.970 & NA & 0.932 & - & 0.069 & * & NA & NA \\
\hline & EuE & 0.101 & NA & 0.235 & 0.069 & - & 0.215 & NA & NA \\
\hline & EuF & * & NA & 0.060 & * & 0.215 & - & NA & NA \\
\hline & EuG & NA & NA & NA & NA & NA & NA & - & NA \\
\hline
\end{tabular}




\section{APPENDIX 21.}

Boxplots for all therian measurement with significant ANOVA results according to morphotype (i.e., all measurement except TDW). Boxplots include minimum, quartiles, median, and maximum values. See Table 1 for measurements, Table 3 for data, and Appendices 19-20 for ANOVA and Tukey HSD results, respectively. The specimen attributed to morphotype MeA was not included in ANOVA and Tukey tests because it lacked any morphologies preserving our measurements.
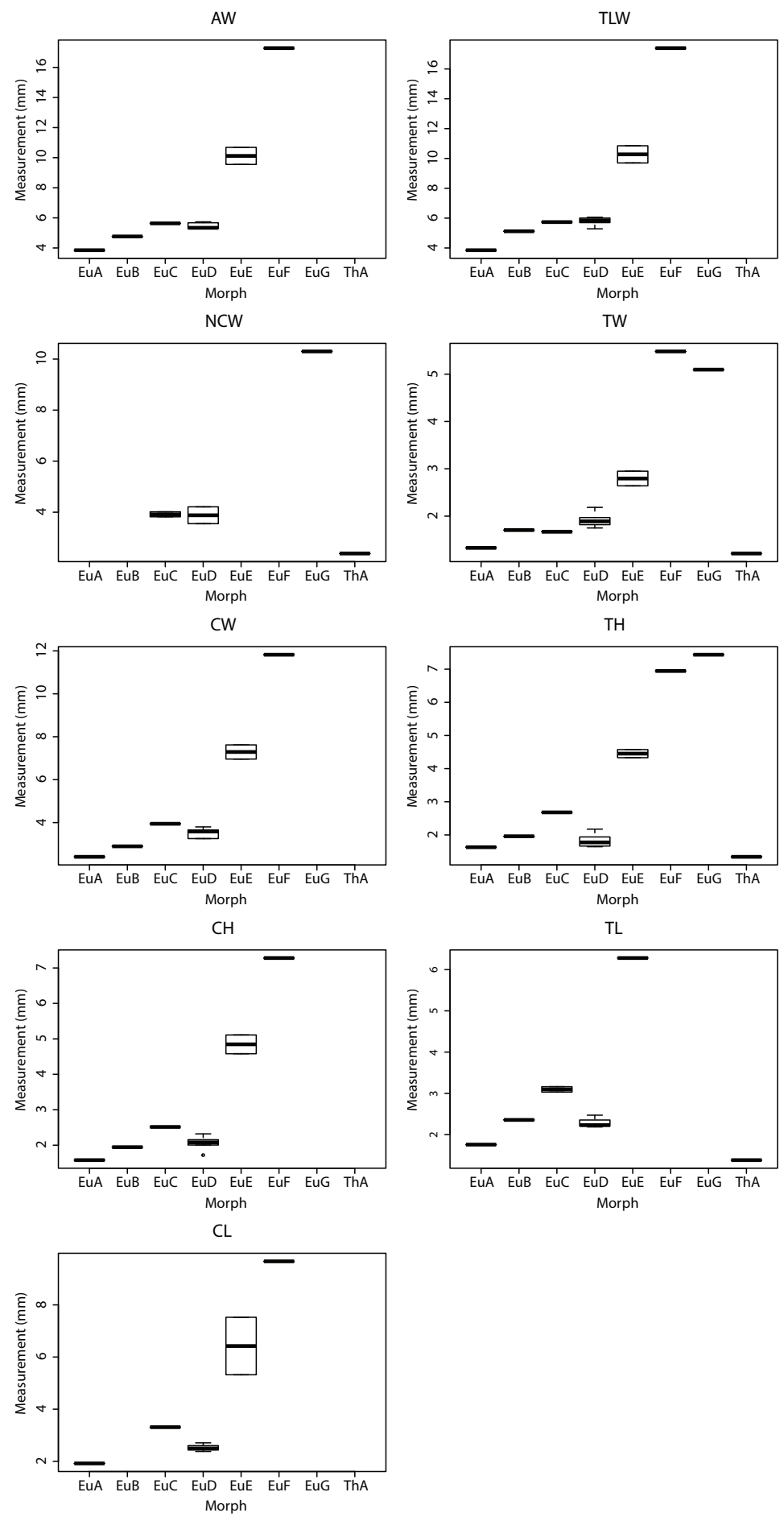


\section{APPENDIX 22.}

Variances for therian measurements with significant ANOVA results according to morphotype (i.e., all measurements except TDW) and preserving at least two specimens (i.e., only EuC, EuD, and EuE; see Appendix 8). See Appendix 21 for means, maxima, minima, and quartiles. See Table 1 for measurements, Table 3 for data, and Appendices 19-20 for ANOVA and Tukey HSD results, respectively.

AW
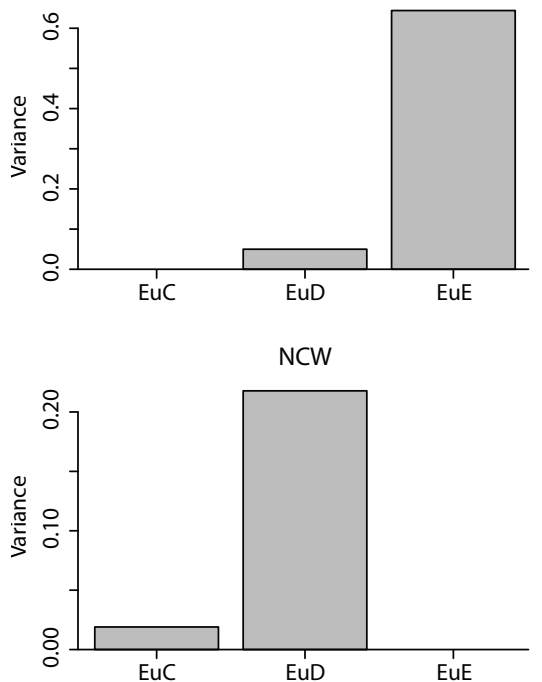

$\mathrm{CW}$

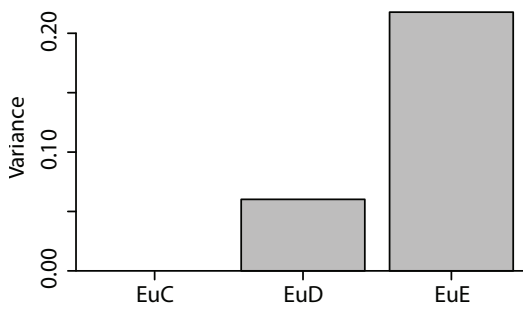

$\mathrm{CH}$

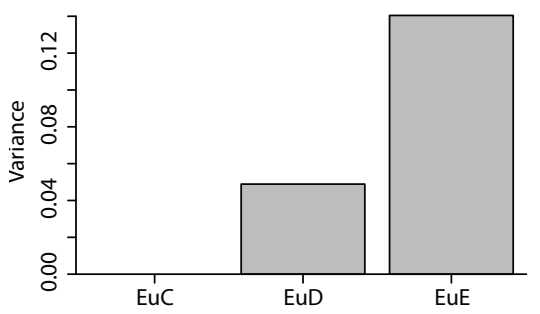

$\mathrm{CL}$

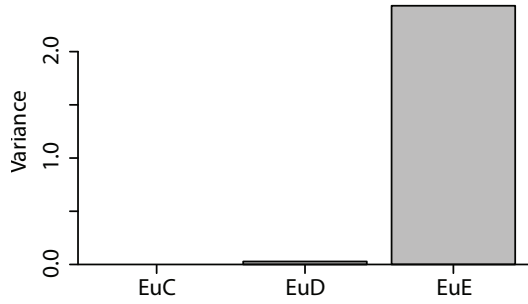

TLW

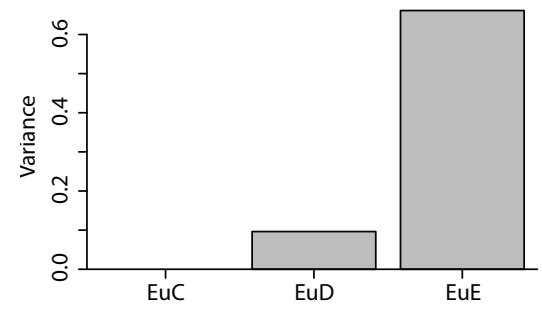

TW

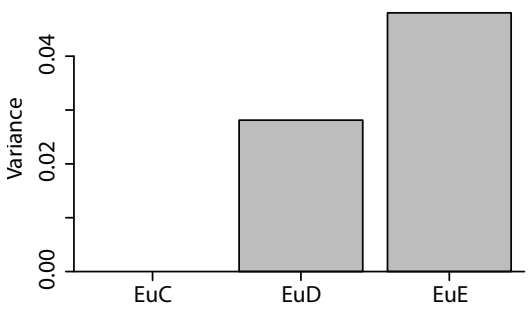

TH

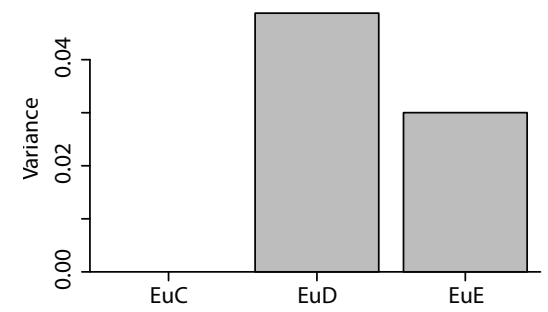

TL

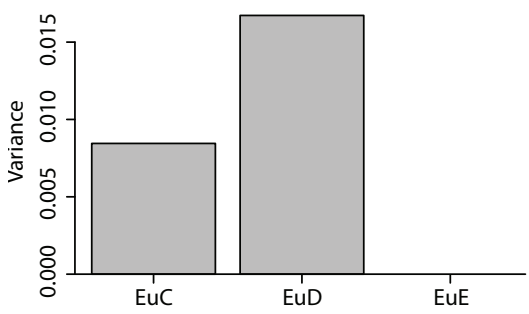




\section{APPENDIX 23.}

Means and standard deviations for multituberculate measurements for entire dataset and by biozone. For measurement descriptions see Table 1; for data see Table 2. NA indicates no specimens preserved the measurement (i.e., NA for mean) or only one specimen preserved the measurement (i.e., NA for SD). Bold values indicate specimen percent preservation (i.e., the number of specimens that preserve that measurement divided by the total number of specimens) greater than or equal to $80 \%$. Abbreviations: BCA, Bug Creek Anthills specimens of mixed age (see text for details); n, number of specimens; Pu1, early Puercan 1 biozone; Pu3, late Puercan biozone; SD, standard deviation.

\begin{tabular}{lcccccccccc}
\hline & TDW & AW & TLW & NCW & UCW & RCW & UCL & RCL & UCD & RCD \\
\hline Full Dataset (n= 30) & & & & & & & & & & \\
Mean & 6.859 & 3.551 & 4.089 & 2.049 & 1.639 & 2.219 & 2.576 & 2.482 & 2.826 & 2.801 \\
SD & 3.864 & 1.954 & 2.334 & 1.022 & 0.903 & 1.302 & 1.472 & 1.555 & 1.607 & 1.440 \\
\% Preservation & 36.67 & 53.33 & 53.33 & 50.00 & $\mathbf{8 6 . 6 7}$ & 70.00 & $\mathbf{8 6 . 6 7}$ & 73.33 & $\mathbf{9 0 . 0 0}$ & 63.33 \\
Lancian (n=11) & & & & & & & & & & \\
Mean & 10.475 & 5.232 & 6.199 & 3.066 & 2.243 & 3.151 & 3.627 & 3.587 & 4.145 & 3.650 \\
SD & 5.874 & 2.709 & 3.891 & 1.390 & 1.194 & 1.474 & 1.950 & 1.687 & 2.018 & 1.806 \\
\% Preservation & 27.27 & 45.45 & 36.36 & 36.36 & $\mathbf{8 1 . 8 2}$ & $\mathbf{8 1 . 8 2}$ & $\mathbf{8 1 . 8 2}$ & $\mathbf{9 0 . 9 1}$ & $\mathbf{8 1 . 8 2}$ & 72.73 \\
BCA (n=12) & & & & & & & & & & \\
Mean & 5.366 & 2.686 & 3.194 & 1.723 & 1.220 & 1.530 & 1.844 & 1.438 & 2.009 & 2.135 \\
SD & 2.054 & 1.006 & 1.177 & 0.637 & 0.485 & 0.621 & 0.732 & 0.586 & 0.828 & 0.800 \\
\% Preservation & 58.33 & 66.67 & 75.00 & 66.67 & $\mathbf{1 0 0 . 0 0}$ & 66.67 & $\mathbf{9 1 . 6 7}$ & 66.67 & $\mathbf{9 1 . 6 7}$ & 66.67 \\
Pu1 (n=4) & & & & & & & & & & \\
Mean & & & & & & & & & \\
SD & 6.460 & 3.090 & 4.250 & 1.960 & 1.965 & 1.470 & 2.653 & 1.858 & 2.595 & 2.335 \\
\% Preservation & NA & NA & NA & NA & 0.559 & 0.325 & 0.764 & 0.039 & 0.970 & NA \\
Pu3 (n=3) & 25.00 & 25.00 & 25.00 & 25.00 & 50.00 & 50.00 & 75.00 & 50.00 & $\mathbf{1 0 0 . 0 0}$ & 25.00 \\
Mean & & & & & & & & & & \\
SD & NA & 3.038 & 3.818 & 1.360 & 1.285 & 1.530 & 2.033 & 1.760 & 2.177 & 2.300 \\
\% Preservation & NA & 0.004 & 0.004 & 0.170 & 0.213 & 0.156 & 0.511 & 0.007 & 0.447 & 0.007 \\
\hline & 0.00 & 66.67 & 66.67 & 66.67 & $\mathbf{1 0 0 . 0 0}$ & 66.67 & $\mathbf{1 0 0 . 0 0}$ & 66.67 & $\mathbf{1 0 0 . 0 0}$ & 66.67 \\
\hline
\end{tabular}




\section{APPENDIX 24.}

Means and standard deviations for therian measurements by biozone. We include all specimens except for the specimen in morphotype MeA, which lacked any measureable features. For measurement descriptions see Table 1; for data see Table 3 (data excludes minimum values). NA indicates no specimens preserved the measurement (i.e., NA for means) or only one specimen preserved the measurement (i.e., NA for SD). Bold values indicate specimen percent preservation (i.e., the number of specimens that preserve that measurement divided by the total number of specimens) greater than or equal to $80 \%$. Abbreviations: BCA, Bug Creek Anthills specimens of mixed age (see text for details); n, number of specimens; Pu1, early Puercan 1 biozone; Pu3, late Puercan biozone; SD, standard deviation.

\begin{tabular}{|c|c|c|c|c|c|c|c|c|c|c|}
\hline & TDW & AW & TLW & NCW & TW & CW & TL & $\mathrm{CL}$ & TD & CD \\
\hline \multicolumn{11}{|c|}{ Full Dataset $(n=14)$} \\
\hline Mean & 9.560 & 7.189 & 7.414 & 4.713 & 2.438 & 4.836 & 3.084 & 3.026 & 2.708 & 4.416 \\
\hline SD & 0.357 & 3.926 & 3.888 & 2.812 & 1.351 & 2.838 & 2.084 & 1.824 & 1.360 & 2.836 \\
\hline$\%$ Preservation & 21.43 & 78.57 & 78.57 & 42.86 & 92.86 & 78.57 & 92.86 & 78.57 & 71.43 & 57.14 \\
\hline \multicolumn{11}{|l|}{ Lancian $(n=2)$} \\
\hline Mean & NA & 4.765 & 5.120 & 2.380 & 1.458 & 2.895 & 1.650 & 1.945 & 1.868 & NA \\
\hline SD & NA & NA & NA & NA & 0.350 & NA & 0.438 & NA & 0.689 & NA \\
\hline$\%$ Preservation & 0.00 & 50.00 & 50.00 & 50.00 & 100.00 & 50.00 & 100.00 & 50.00 & 100.00 & 0.00 \\
\hline \multicolumn{11}{|l|}{$\operatorname{BCA}(n=6)$} \\
\hline Mean & 9.560 & 5.492 & 5.773 & 3.860 & 1.881 & 3.583 & 1.980 & 2.133 & 2.429 & 2.724 \\
\hline SD & 0.357 & 0.212 & 0.278 & 0.332 & 0.182 & 0.282 & 0.396 & 0.272 & 0.354 & 0.414 \\
\hline$\%$ Preservation & 50.00 & 100.00 & 100.00 & 50.00 & 100.00 & 100.00 & 100.00 & 100.00 & 83.33 & 66.67 \\
\hline \multicolumn{11}{|l|}{ Pu1 (n= 2) } \\
\hline Mean & NA & 10.685 & 10.850 & 4.015 & 2.950 & 7.620 & 4.575 & 5.110 & 4.720 & 7.525 \\
\hline SD & NA & NA & NA & NA & NA & NA & NA & NA & 2.206 & NA \\
\hline$\%$ Preservation & 0.00 & 50.00 & 50.00 & 50.00 & 50.00 & 50.00 & 50.00 & 50.00 & 100.00 & 50.00 \\
\hline \multicolumn{11}{|l|}{$\operatorname{Pu} 3(n=4)$} \\
\hline Mean & NA & 10.227 & 10.315 & 10.300 & 3.636 & 7.062 & 5.085 & 4.480 & 1.756 & 5.637 \\
\hline SD & NA & 6.741 & 6.793 & NA & 1.987 & 4.708 & 2.676 & 2.852 & NA & 3.885 \\
\hline$\%$ Preservation & 0.00 & 75.00 & 75.00 & 25.00 & 100.00 & 75.00 & 100.00 & 75.00 & 25.00 & 75.00 \\
\hline
\end{tabular}




\section{APPENDIX 25}

The results of One-Way ANOVAs of difference for all multituberculate measurements across all biozones. Asterisk indicates significant $p$-values $(<0.05)$. Both biozone (b) and residuals $(r)$ values are given for Sum of Squares, df, and Mean Squares. See Table 1 for measurement details; see Table 2 for data and Appendix 26 for Tukey HSD results.

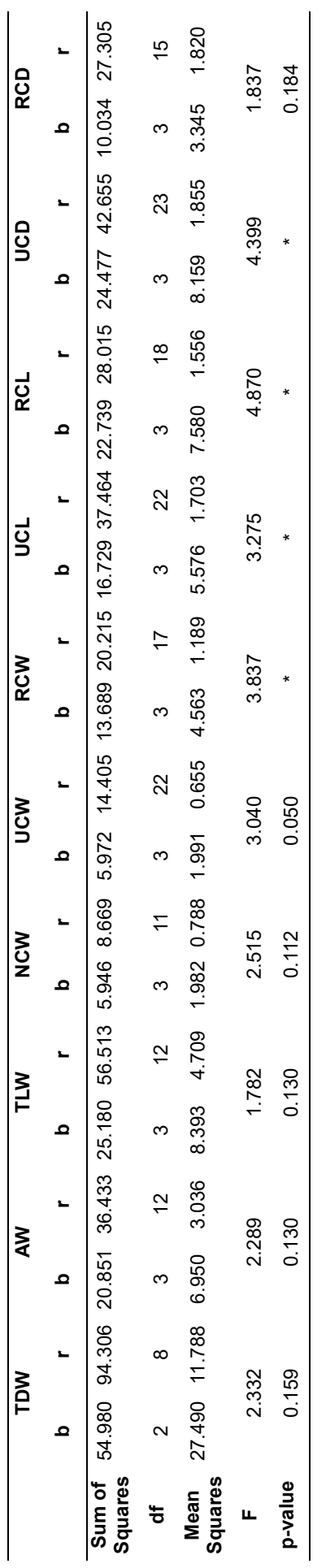




\section{APPENDIX 26.}

Probabilities from Tukey honest significant difference (HSD) post hoc test of multituberculate measurements by biozones. Measurements subjected to the Tukey HSD test are those with significant ANOVA results: radial condyle width (RCW), ulnar condyle length $(U C L)$, radial condyle length (RCL), and ulnar condyle depth (UCD). Significance indicated by the following: ${ }^{*}$ for $p<$ $0.05 ;{ }^{* *}$ for $p<0.01$.

\begin{tabular}{|c|c|c|c|c|c|}
\hline Measurement & & Lancian & BCA & Pu1 & Pu3 \\
\hline \multirow[t]{4}{*}{ RCW } & Lancian & - & * & 0.237 & 0.264 \\
\hline & BCA & * & - & 1.000 & 1.000 \\
\hline & Pu1 & 0.237 & 1.000 & - & 1.000 \\
\hline & Pu3 & 0.264 & 1.000 & 1.000 & - \\
\hline \multirow[t]{4}{*}{ UCL } & Lancian & - & * & 0.682 & 0.286 \\
\hline & BCA & * & _ & 0.777 & 0.996 \\
\hline & Pu1 & 0.682 & 0.777 & - & 0.936 \\
\hline & Pu3 & 0.286 & 0.996 & 0.936 & - \\
\hline \multirow[t]{4}{*}{ RCL } & Lancian & - & $* *$ & 0.310 & 0.267 \\
\hline & BCA & $* *$ & - & 0.973 & 0.988 \\
\hline & Pu1 & 0.310 & 0.973 & - & 1.000 \\
\hline & Pu3 & 0.267 & 0.988 & 1.000 & - \\
\hline \multirow[t]{4}{*}{ UCD } & Lancian & - & * & 0.258 & 0.162 \\
\hline & BCA & * & - & 0.881 & 0.998 \\
\hline & Pu1 & 0.258 & 0.881 & - & 0.977 \\
\hline & Pu3 & 0.162 & 0.998 & 0.977 & - \\
\hline
\end{tabular}




\section{APPENDIX 27.}

Boxplots (above) and variances (below) for each multituberculate measurement with significant ANOVA results according to biozone. Boxplots include minimum, quartiles, median, and maximum values. See Table 1 for measurements, Table 2 for data, Appendix 7 for means, and Appendices 25-26 for ANOVA and Tukey HSD results, respectively. Asterisks indicate pairs of significantly different values in Tukey tests (i.e., Lancian specimens are significantly larger than BCA specimens for all measurements).
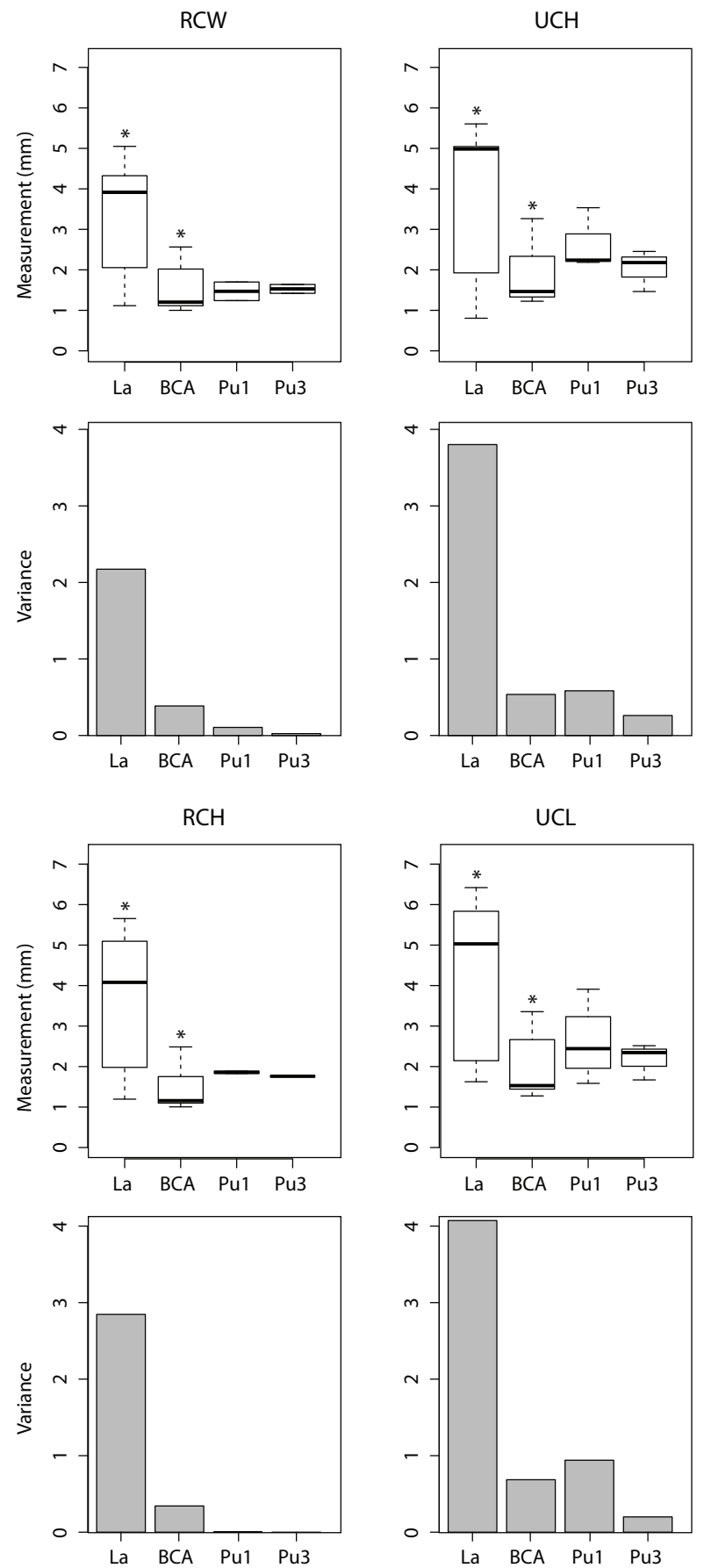


\section{APPENDIX 28.}

The results of One-Way ANOVAs of difference for all therians measurements across all biozones (for all measurements with specimens in at least three biozones, i.e., excluding TDW). Significance is as follows: * for $p<0.05$; ${ }^{* *}$ for $p<0.01$. Both biozone (b) and residuals ( $r$ ) values are given for Sum of Squares, df, and Mean Squares. See Table 1 for measurement details and Table 3 for data.

\begin{tabular}{|c|c|c|c|c|c|c|c|c|c|c|c|c|c|c|c|c|c|c|}
\hline & \multicolumn{2}{|c|}{ AW } & \multicolumn{2}{|c|}{ TLW } & \multicolumn{2}{|c|}{ NCW } & \multicolumn{2}{|c|}{ TW } & \multicolumn{2}{|c|}{ CW } & \multicolumn{2}{|c|}{ TL } & \multicolumn{2}{|c|}{ CL } & \multicolumn{2}{|c|}{ TD } & \multicolumn{2}{|c|}{ CD } \\
\hline & b & $r$ & b & $r$ & b & $r$ & b & $r$ & b & $r$ & b & $r$ & b & $r$ & b & $r$ & b & $r$ \\
\hline $\begin{array}{l}\text { Sum of } \\
\text { Squares }\end{array}$ & 63.066 & 91.093 & 58.483 & 92.688 & 39.327 & 0.220 & 9.791 & 12.127 & 35.811 & 44.726 & 29.665 & 22.464 & 16.641 & 16.637 & 10.805 & 5.844 & 25.591 & 30.696 \\
\hline df & 3 & 7 & 3 & 7 & 3 & 2 & 3 & 9 & 3 & 7 & 3 & 9 & 3 & 7 & 3 & 6 & 2 & 5 \\
\hline $\begin{array}{l}\text { Mean } \\
\text { Squares }\end{array}$ & 21.022 & 13.013 & 19.494 & 13.241 & 13.109 & 0.110 & 3.264 & 1.347 & 11.937 & 6.389 & 9.888 & 2.496 & 5.547 & 2.377 & 3.602 & 0.974 & 12.795 & 6.139 \\
\hline $\mathbf{F}$ & 1.6 & 615 & 1.4 & 472 & 119 & 066 & 2.4 & 422 & 1.8 & 868 & & 962 & 2.3 & 334 & 3.6 & & 2.0 & 084 \\
\hline p-value & 0.2 & 270 & 0.3 & 302 & * & * & 0.1 & 133 & 0.2 & 223 & & * & 0.1 & 160 & 0.0 & 81 & 0.2 & 220 \\
\hline
\end{tabular}




\section{APPENDIX 29.}

Probabilities from Tukey honest significant difference (HSD) post hoc test of therian measurements by biozones. Measurements subjected to the Tukey HSD test are those with significant ANOVA results, only entepicondyle condyle width (NCW) and trochlea depth (TL). Significance is as follows: ${ }^{*}$ for $p<0.05 ;{ }^{* *}$ for $p<0.01$.

\begin{tabular}{cccccc}
\hline Measurement & & Lancian & BCA & Pu1 & Pu3 \\
\hline NCW & Lancian & - & 0.147 & 0.176 & $* *$ \\
& BCA & 0.147 & - & 0.973 & $* *$ \\
& Pu1 & 0.176 & 0.973 & - & $*$ \\
& Pu3 & $* *$ & $* *$ & $*$ & - \\
TL & Lancian & - & 0.994 & 0.470 & 0.125 \\
& BCA & 0.994 & - & 0.465 & 0.056 \\
& Pu1 & 0.470 & 0.465 & - & 0.991 \\
& Pu3 & 0.125 & 0.056 & 0.991 & - \\
\hline
\end{tabular}




\section{APPENDIX 30.}

Boxplot (left) and variance (right) for eutherian NCW measurement, which had significant ANOVA results according to biozone. Boxplot includes minimum, quartiles, median, and maximum values; variance shown for biozones with $n>1$. See Table 1 for measurements, Table 3 for data, Appendix 8 for means, and Appendices 28-29 for ANOVA and Tukey HSD results, respectively. Asterisks indicate pairs of significantly different values in Tukey tests (i.e., Pu3 specimens are significantly larger than Lancian and BCA specimens).
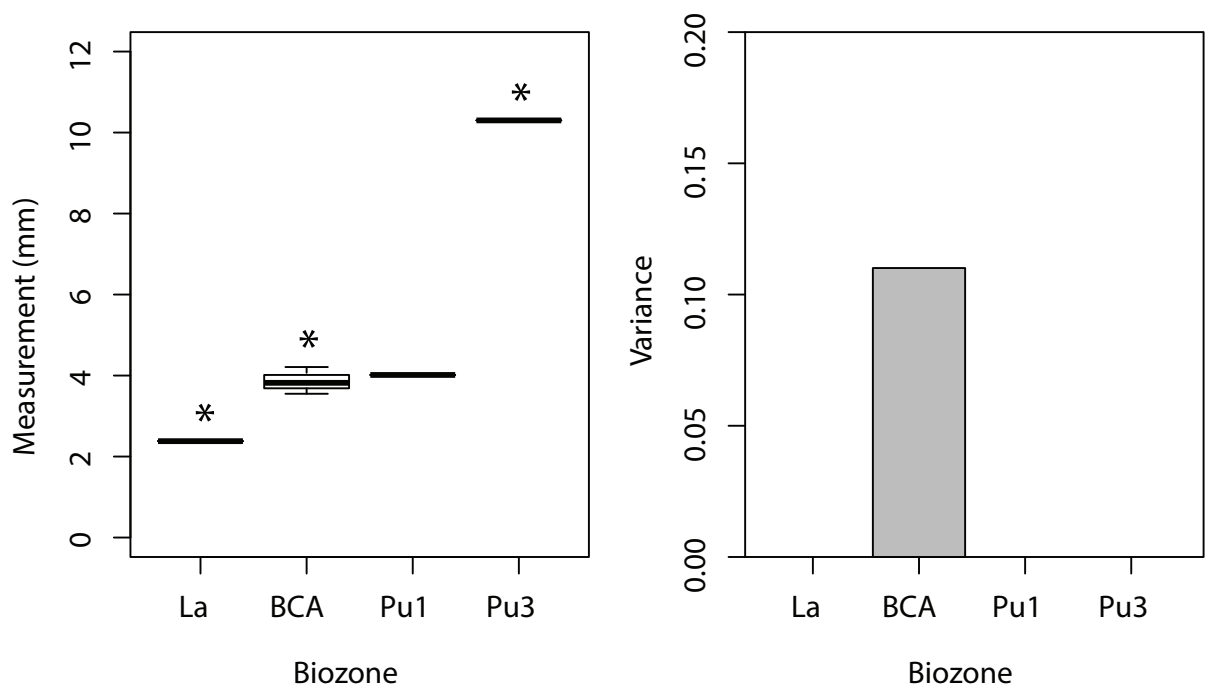


\section{APPENDIX 31.}

Eigenvalues, proportion of variance, and cumulative variance explained from PCAs. We conducted PCAs on two separate datasets: one "full dataset" that included all modern taxa (Table 4), and one "reduced dataset" of eutherians that excluded carnivorans and lagomorphs (see text for more details). Of the 40 total principal components in each PCA, we report only PCs that explained at least $1 \%$ of the variance.

\begin{tabular}{cccc}
\hline Eull Dataset & Eigenvalues & $\begin{array}{c}\text { Proportion of } \\
\text { Variance }\end{array}$ & $\begin{array}{c}\text { Cumulative } \\
\text { Variance }\end{array}$ \\
\hline PC1 & 0.0067938 & $46 \%$ & $46 \%$ \\
PC2 & 0.0018609 & $13 \%$ & $59 \%$ \\
PC3 & 0.0016220 & $11 \%$ & $70 \%$ \\
PC4 & 0.0011623 & $8 \%$ & $78 \%$ \\
PC5 & 0.0007075 & $5 \%$ & $83 \%$ \\
PC6 & 0.0004502 & $3 \%$ & $86 \%$ \\
PC7 & 0.0003615 & $2 \%$ & $88 \%$ \\
PC8 & 0.0003264 & $2 \%$ & $91 \%$ \\
PC9 & 0.0003162 & $2 \%$ & $93 \%$ \\
PC10 & 0.0002115 & $1 \%$ & $94 \%$ \\
PC11 & 0.0001540 & $1 \%$ & $95 \%$ \\
Reduced Dataset & & & \\
PC1 & 0.0042641 & $37 \%$ & $37 \%$ \\
PC2 & 0.0021872 & $19 \%$ & $56 \%$ \\
PC3 & 0.0015529 & $13 \%$ & $69 \%$ \\
PC4 & 0.0007259 & $6 \%$ & $75 \%$ \\
PC5 & 0.0007226 & $6 \%$ & $82 \%$ \\
PC6 & 0.0004394 & $4 \%$ & $85 \%$ \\
PC7 & 0.0003591 & $3 \%$ & $89 \%$ \\
PC8 & 0.0003120 & $3 \%$ & $91 \%$ \\
PC9 & 0.0002451 & $2 \%$ & $93 \%$ \\
PC10 & 0.0001782 & $2 \%$ & $95 \%$ \\
PC11 & 0.0001404 & $1 \%$ & $96 \%$ \\
\hline & & &
\end{tabular}




\section{APPENDIX 32.}

Principal Component Analysis (PCA) of all modern taxa with specimens labeled. PC1 and PC2 explain $46 \%$ and $13 \%$ of the total variance, respectively (Appendix 31 ). Partial warp shapes indicate the minimum and maximum of PC1 on a right humerus in distal view. Black circles are metatherians, gray circles are eutherians. See Table 4 for specimen information. We note the orientation of the maximum and minimum of PC1 is reversed here compared to Figures 3, 20-21); this is a function of the arbitrary assignment of maximum and minimum in PC space, and it does not affect the shape interpretation.

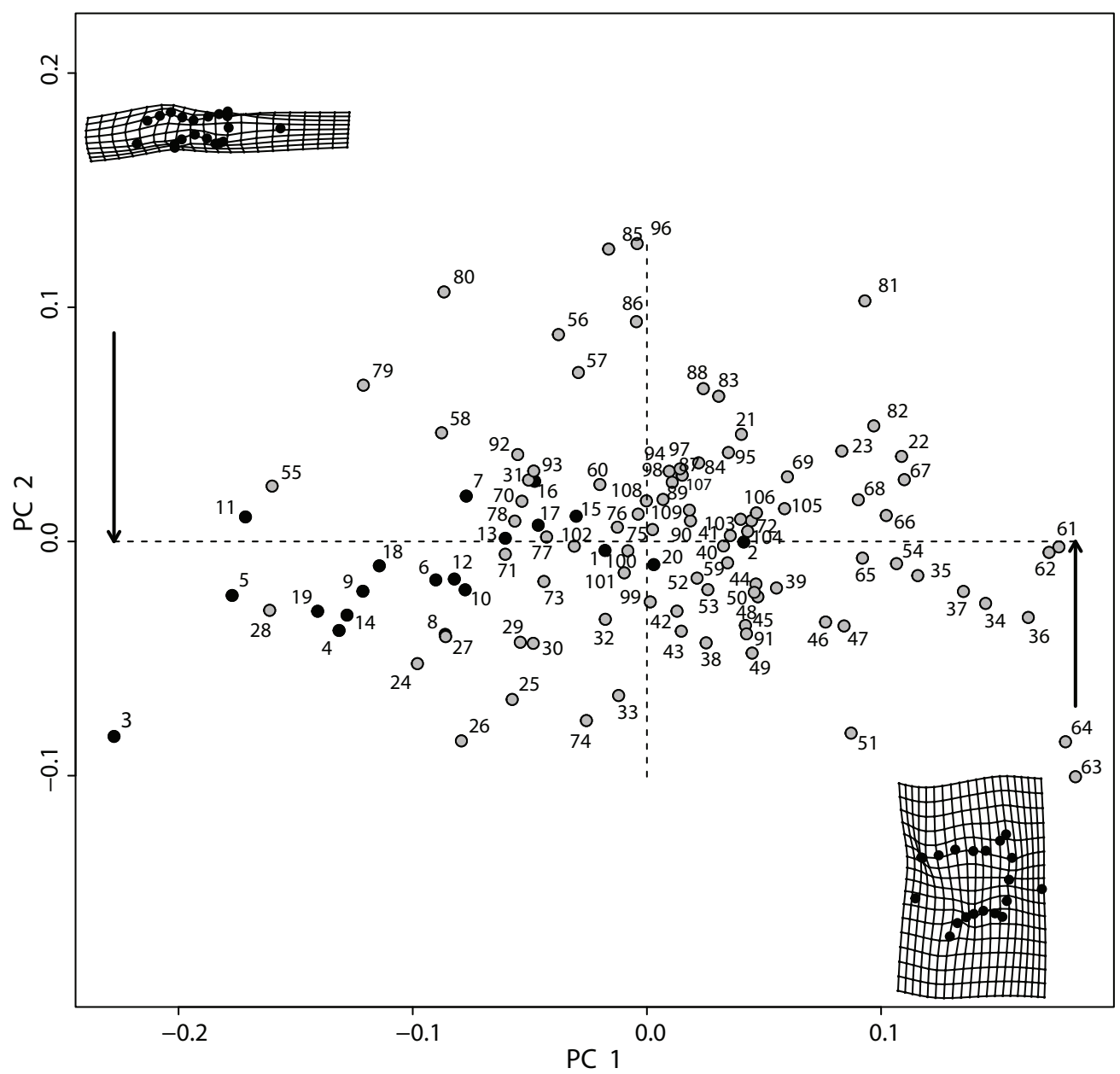


APPENDIX 33.

Principal Component Analysis (PCA) of all modern taxa with specimens labeled. PC2 and PC3 explain $13 \%$ and $11 \%$ of the total variance, respectively (Appendix 31). Partial warp shapes indicate the minimum and maximum of PC2. Black circles are metatherians, gray circles are eutherians. See Table 4 for specimen information.

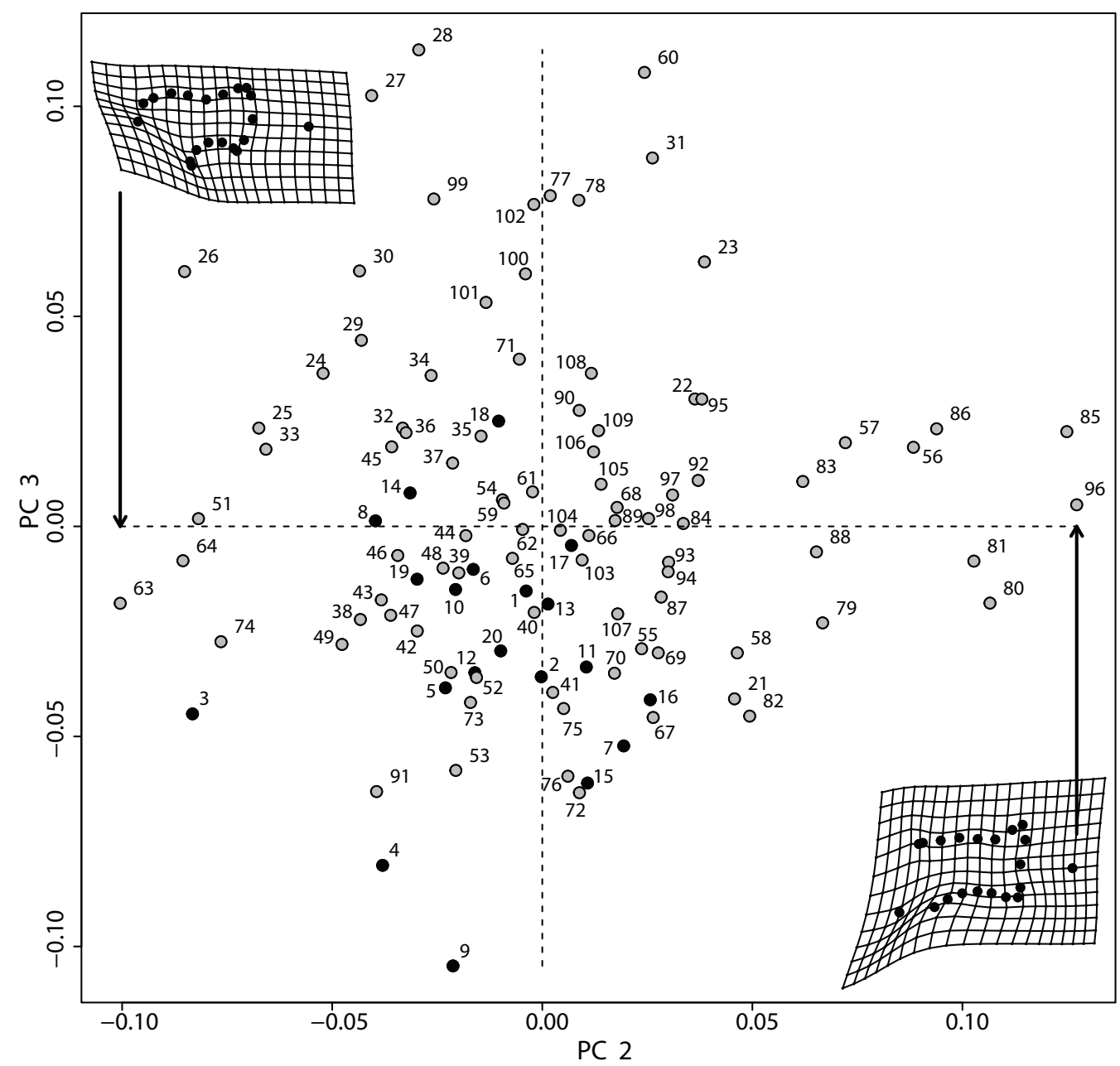




\section{APPENDIX 34.}

LDA results for the reduced dataset of extant mammals with known locomotion. LDA analyses used all significant principal components (i.e., those which represented at least $1 \%$ of the variation).

\begin{tabular}{|c|c|c|c|c|c|c|c|c|}
\hline \multicolumn{9}{|c|}{ Locomotor Group Means } \\
\hline & A & $\mathbf{F}$ & G & $s$ & Sa & Sc & Sf & $T$ \\
\hline PC1 & 0.01276 & -0.00884 & 0.06054 & 0.05556 & -0.01318 & -0.03556 & -0.01427 & 0.02452 \\
\hline PC2 & 0.02255 & -0.02874 & 0.03102 & -0.01765 & -0.07145 & 0.05872 & 0.00177 & 0.01686 \\
\hline PC3 & 0.01071 & -0.00397 & -0.00655 & -0.00441 & 0.00296 & 0.04311 & -0.01621 & 0.00011 \\
\hline PC4 & -0.00049 & -0.01497 & 0.00582 & 0.00888 & 0.01229 & 0.00693 & 0.00257 & 0.02051 \\
\hline PC5 & 0.00474 & -0.00238 & -0.03417 & 0.00849 & -0.00719 & -0.00493 & 0.00250 & 0.00677 \\
\hline PC6 & 0.01928 & -0.00531 & 0.00733 & -0.02232 & -0.00779 & -0.01032 & -0.00525 & -0.01245 \\
\hline $\mathrm{PC} 7$ & -0.00652 & -0.00415 & 0.01422 & -0.00893 & 0.01796 & 0.02135 & -0.01010 & 0.01034 \\
\hline PC8 & -0.00155 & 0.00139 & 0.01861 & 0.00473 & 0.00458 & -0.00357 & 0.00581 & -0.00768 \\
\hline PC9 & 0.00265 & 0.00418 & 0.00749 & -0.00980 & 0.00657 & -0.01905 & -0.00713 & 0.00275 \\
\hline $\mathrm{PC} 10$ & 0.00117 & -0.00358 & -0.00796 & 0.00495 & 0.00051 & -0.00717 & 0.00358 & -0.00140 \\
\hline PC11 & 0.00427 & 0.00338 & 0.00415 & 0.00051 & -0.00679 & 0.00198 & -0.00687 & -0.00108 \\
\hline
\end{tabular}

\begin{tabular}{ccccccc}
\hline \multicolumn{7}{c}{ Coefficients of Linear Discriminants } \\
& LD1 & LD2 & LD3 & LD4 & LD5 & LD6 \\
\hline PC1 & 2.94717 & 2.27578 & 2.17796 & 9.41316 & -6.31096 & -4.86250 \\
PC2 & 26.91399 & 13.17848 & -4.77661 & 4.56211 & 2.92216 & 0.42556 \\
PC3 & 7.31164 & 6.68984 & 1.18431 & -11.66506 & 2.81487 & -1.24342 \\
PC4 & -5.70621 & 22.80368 & -3.22197 & 4.88143 & -18.81627 & 11.10793 \\
PC5 & 2.06893 & -3.58513 & -21.96368 & -10.27321 & -13.82449 & -4.63802 \\
PC6 & 48.82373 & -21.34994 & 19.54012 & -11.13995 & -10.35859 & 23.00979 \\
PC7 & -20.15756 & 43.27913 & 29.14487 & -15.39684 & 0.14397 & 3.82854 \\
PC8 & -6.88752 & -9.20087 & 17.93410 & 29.18532 & 19.67257 & 17.61627 \\
PC9 & -3.79714 & -16.85835 & 37.88225 & -4.34904 & -33.12376 & -12.11852 \\
PC10 & -4.01667 & -13.76100 & -24.49836 & 5.73548 & -20.80180 & 21.90751 \\
PC11 & 44.60443 & -8.70142 & 17.22111 & -4.55220 & 6.04990 & -51.18676 \\
Proportions of & & & & & & \\
Trace & $\mathbf{5 0 . 4 2 \%}$ & $\mathbf{2 1 . 2 5 \%}$ & $\mathbf{1 3 . 2 9 \%}$ & $\mathbf{5 . 6 4 \%}$ & $\mathbf{4 . 9 5 \%}$ & $\mathbf{3 . 1 8 \%}$ \\
\hline
\end{tabular}


APPENDIX 35.

LDA predictions for locomotor mode for modern specimens in this study. LDA correctly predicts locomotor mode of modern specimens with an accuracy of $74.19 \%$. Published locomotor mode (LM) is indicated, as well as predicted locomotor mode; asterisks indicate specimens whose locomotor mode was incorrectly predicted. See Table 4 for additional specimen information.

\begin{tabular}{|c|c|c|c|c|c|c|c|}
\hline Specimen & Genus & species & Family & Order & Code & LM & $\begin{array}{c}\text { LM } \\
\text { Prediction }\end{array}$ \\
\hline S2008 & Potamogale & velox & Potamogalidae & Afrosoricida & 21 & $\mathrm{Sa}$ & $T^{*}$ \\
\hline 39039 & Dendrohyrax & arboreus & Procaviidae & Afrosoricida & 22 & $A$ & A \\
\hline 39038 & Dendrohyrax & arboreus & Procaviidae & Afrosoricida & 23 & $A$ & $S f^{*}$ \\
\hline S2008 & Limnogale & mergulus & Tenrecidae & Afrosoricida & 24 & $\mathrm{Sa}$ & $\mathrm{F}^{*}$ \\
\hline 34168 & Echinops & telfairi & Tenrecidae & Afrosoricida & 25 & $\mathrm{Sc}$ & $\mathrm{Sc}$ \\
\hline S2008 & Echinops & telfairi & Tenrecidae & Afrosoricida & 26 & $\mathrm{Sc}$ & $T^{*}$ \\
\hline S2008 & Hemicentetes & semispinosus & Tenrecidae & Afrosoricida & 27 & $\mathrm{Sf}$ & $T^{*}$ \\
\hline S2008 & Oryzorictes & $\mathrm{sp}$. & Tenrecidae & Afrosoricida & 28 & $\mathrm{Sf}$ & $\mathrm{Sf}$ \\
\hline S2008 & Setifer & setosus & Tenrecidae & Afrosoricida & 29 & $\mathrm{~T}$ & $\mathrm{~T}$ \\
\hline S2008 & Tenrec & ecaudatus & Tenrecidae & Afrosoricida & 30 & $\mathrm{~T}$ & $\mathrm{~T}$ \\
\hline S2008 & Microgale & cowani & Tenrecidae & Afrosoricida & 31 & $\mathrm{~T}$ & $\mathrm{~T}$ \\
\hline S2008 & Microgale & dobsoni & Tenrecidae & Afrosoricida & 32 & $T$ & $\mathrm{~T}$ \\
\hline S2008 & Microgale & talazaci & Tenrecidae & Afrosoricida & 33 & $\mathrm{~T}$ & $\mathrm{Sc}^{*}$ \\
\hline 34167 & Cabassous & centralis & Dasypodidae & Cingulata & 55 & $\mathrm{~F}$ & $\mathrm{Sa}^{*}$ \\
\hline 20735 & Dasypus & novemcinctus & Dasypodidae & Cingulata & 56 & $\mathrm{~F}$ & $\mathrm{~F}$ \\
\hline 22458 & Dasypus & novemcinctus & Dasypodidae & Cingulata & 57 & $\mathrm{~F}$ & $\mathrm{~F}$ \\
\hline 35468 & Euphractus & sexcinctus & Dasypodidae & Cingulata & 58 & $\mathrm{~F}$ & $\mathrm{~F}$ \\
\hline S2008 & Echinosorex & gymnurus & Erinaceidae & Erinaceomorpha & 59 & $\mathrm{~T}$ & $\mathrm{~T}$ \\
\hline S2008 & Solenodon & paradoxus & Solenodontidae & Soricomorpha & 60 & $\mathrm{Sf}$ & $\mathrm{Sf}$ \\
\hline S2008 & Petrodromus & tetradactylus & Macroscelididae & Macroscelidea & 67 & S & $T^{*}$ \\
\hline 35475 & Elephantulus & rufescens & Macroscelididae & Macroscelidea & 68 & $\mathrm{~T}$ & $\mathrm{~T}$ \\
\hline 34189 & Elephantulus & rufescens & Macroscelididae & Macroscelidea & 69 & $\mathrm{~T}$ & $\mathrm{~T}$ \\
\hline 39003 & Callithrix & pygmaea & Cebidae & Primates & 70 & $A$ & A \\
\hline 39005 & Callithrix & pygmaea & Cebidae & Primates & 71 & $A$ & $A$ \\
\hline 75541 & Leontopithecus & chrysomela & Cebidae & Primates & 72 & $A$ & $A$ \\
\hline 35406 & Saguinus & oedipus & Cebidae & Primates & 73 & $A$ & A \\
\hline 35405 & Saguinus & oedipus & Cebidae & Primates & 74 & $A$ & $A$ \\
\hline 82302 & Saimiri & sciureus & Cebidae & Primates & 75 & $A$ & $A$ \\
\hline 39014 & Saimiri & sciureus & Cebidae & Primates & 76 & $A$ & A \\
\hline 34071 & Aplodontia & rufa & Aplodontiidae & Rodentia & 77 & $\mathrm{~F}$ & $S f^{*}$ \\
\hline 34058 & Aplodontia & rufa & Aplodontiidae & Rodentia & 78 & $\mathrm{~F}$ & $S f^{*}$ \\
\hline 34116 & Castor & canadensis & Castoridae & Rodentia & 79 & $\mathrm{Sa}$ & $\mathrm{Sa}$ \\
\hline 34588 & Castor & canadensis & Castoridae & Rodentia & 80 & $\mathrm{Sa}$ & $\mathrm{Sa}$ \\
\hline 72830 & Cavia & porcellus & Caviidae & Rodentia & 81 & $\mathrm{~T}$ & $\mathrm{~T}$ \\
\hline 72831 & Cavia & porcellus & Caviidae & Rodentia & 82 & $\mathrm{~T}$ & $\mathrm{~T}$ \\
\hline 76622 & Microtus & pennsylvanicus & Cricetidae & Rodentia & 83 & $\mathrm{~F}$ & $\mathrm{~F}$ \\
\hline 34326 & Microtus & pennsylvanicus & Cricetidae & Rodentia & 84 & $\mathrm{~F}$ & $\mathrm{~F}$ \\
\hline 34324 & Ondatra & zibethicus & Cricetidae & Rodentia & 85 & $\mathrm{Sa}$ & $\mathrm{Sa}$ \\
\hline 72879 & Ondatra & zibethicus & Cricetidae & Rodentia & 86 & $\mathrm{Sa}$ & $\mathrm{Sa}$ \\
\hline
\end{tabular}




\begin{tabular}{|c|c|c|c|c|c|c|c|}
\hline Specimen & Genus & species & Family & Order & Code & LM & $\begin{array}{c}\text { LM } \\
\text { Prediction }\end{array}$ \\
\hline 66559 & Synaptomys & borealis & Cricetidae & Rodentia & 87 & $\mathrm{Sf}$ & $\mathrm{F}^{*}$ \\
\hline 66561 & Synaptomys & borealis & Cricetidae & Rodentia & 88 & $\mathrm{Sf}$ & Sf \\
\hline 76721 & Zapus & princeps & Dipodidae & Rodentia & 89 & $S$ & $\mathrm{Sf}^{\star}$ \\
\hline 75136 & Zapus & princeps & Dipodidae & Rodentia & 90 & $\mathrm{~s}$ & $s$ \\
\hline 34176 & Coendou & prehensilis & Erethizontidae & Rodentia & 91 & $\mathrm{Sc}$ & Sc \\
\hline 44624 & Thomomys & bottae & Geomyidae & Rodentia & 92 & $\mathrm{~F}$ & $\mathrm{~F}$ \\
\hline 38261 & Thomomys & bottae & Geomyidae & Rodentia & 93 & $\mathrm{~F}$ & $\mathrm{~F}$ \\
\hline 47378 & Chaetodipus & fallax & Heteromyidae & Rodentia & 94 & $\mathrm{~F}$ & $\mathrm{~S}^{*}$ \\
\hline 47379 & Chaetodipus & fallax & Heteromyidae & Rodentia & 95 & $\mathrm{~F}$ & $A^{*}$ \\
\hline 78740 & Dipodomys & deserti & Heteromyidae & Rodentia & 96 & $\mathrm{~s}$ & $F^{*}$ \\
\hline 48984 & Octodon & degus & Octodontidae & Rodentia & 97 & $\mathrm{Sf}$ & $A^{*}$ \\
\hline 39501 & Octodon & degus & Octodontidae & Rodentia & 98 & $\mathrm{Sf}$ & Sf \\
\hline 35278 & Sciurus & aberti & Sciuridae & Rodentia & 99 & A & A \\
\hline 82349 & Sciurus & aberti & Sciuridae & Rodentia & 100 & A & A \\
\hline 20646 & Sciurus & carolinensis & Sciuridae & Rodentia & 101 & A & A \\
\hline 30010 & Sciurus & carolinensis & Sciuridae & Rodentia & 102 & A & A \\
\hline 36334 & Glaucomys & sabrinus & Sciuridae & Rodentia & 103 & G & G \\
\hline 35129 & Glaucomys & sabrinus & Sciuridae & Rodentia & 104 & G & G \\
\hline 43897 & Glaucomys & volans & Sciuridae & Rodentia & 105 & G & G \\
\hline 32254 & Glaucomys & volans & Sciuridae & Rodentia & 106 & G & G \\
\hline 75774 & Cynomys & ludovicianus & Sciuridae & Rodentia & 107 & $\mathrm{Sf}$ & Sf \\
\hline 34227 & Tupaia & glis & Tupaiidae & Scandentia & 108 & A & A \\
\hline 34225 & Tupaia & glis & Tupaiidae & Scandentia & 109 & A & A \\
\hline
\end{tabular}




\section{APPENDIX 36.}

LDA results and predicted locomotor mode for fossil specimens in this study. Prediction probabilities that are in bold are the top ranked locomotor mode (i.e., rank of 1); all ranks are shown for predictions probabilities, but percentages are shown only for $>0.00 \%$. Abbreviations: Spec. Number, specimen number; Loc. locality; M. morphotype; Bioz., biozone.

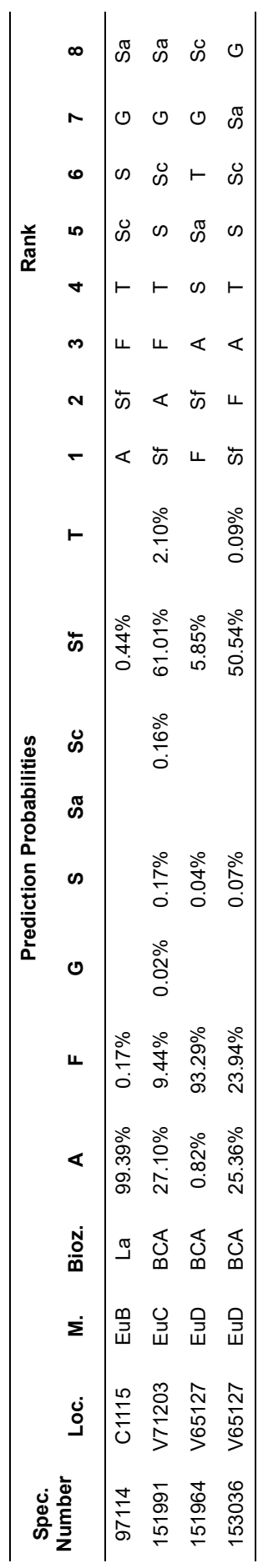

